\title{
○高
}
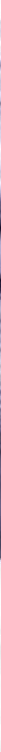

Engagement

Martyn Barrett Dimitra Pachi

A D OLESCENCE AND SOCIETY SERIES 


\section{YOUTH CIVIC AND POLITICAL ENGAGEMENT}

What exactly is civic and political participation? What factors influence young people's participation? How can we encourage youth to participate actively in their own democracies? Youth Civic and Political Engagement takes a multidisciplinary approach to answering these key questions, incorporating research in the fields of psychology, sociology, political science and education to explore the issues affecting youth civic and political engagement.

Drawing on evidence that has been obtained in many different national contexts, and through multinational studies, this book provides a theoretical synthesis of this large and diverse body of research, using an integrative multi-level ecological model of youth engagement to do so. It identifies unresolved issues in the field and offers numerous suggestions for future research.

Youth Civic and Political Engagement is an invaluable resource for researchers, teachers, youth workers, civil society activists, policymakers and politicians who wish to acquire an up-to-date understanding of the factors and processes that influence young people's civic and political engagement and how to promote youth engagement.

Martyn Barrett is Emeritus Professor of Psychology at the University of Surrey, UK, a Fellow of the British Psychological Society and a Fellow of the Academy of Social Sciences. He works as an expert for the Council of Europe and the OECD on the development of intercultural, democratic and global competence.

Dimitra Pachi is Senior Lecturer in Psychology at University of Winchester, UK, a BPS Chartered Psychologist and a Senior Fellow of the Higher Education Academy (SFHEA). She has led numerous national and international research projects on processes of youth social and political development. 


\title{
ADOLESCENCE AND SOCIETY
}

\author{
Series Editor: John C. Coleman \\ Department of Education, University of Oxford \\ https://www.routledge.com/Adolescence-and-Society/book-series/SE0238
}

In the 20 years since it began, this series has published some of the key texts in the field of adolescent studies. The series has covered a very wide range of subjects, almost all of them being of central concern to students, researchers and practitioners. A mark of its success is that a number of books have gone to second and third editions, illustrating its popularity and reputation.

The primary aim of the series is to make accessible to the widest possible readership important and topical evidence relating to adolescent development. Much of this material is published in relatively inaccessible professional journals, and the objective of the books has been to summarise, review and place in context current work in the field, so as to interest and engage both an undergraduate and a professional audience.

The intention of the authors is to raise the profile of adolescent studies among professionals and in institutions of higher education. By publishing relatively short, readable books on topics of current interest to do with youth and society, the series makes people more aware of the relevance of the subject of adolescence to a wide range of social concerns.

The books do not put forward any one theoretical viewpoint. The authors outline the most prominent theories in the field and include a balanced and critical assessment of each of these. Whilst some of the books may have a clinical or applied slant, the majority concentrate on normal development.

The readership rests primarily in two major areas: the undergraduate market, particularly in the fields of psychology, sociology and education; and the professional training market, with particular emphasis on social work, clinical and educational psychology, counselling, youth work, nursing and teacher training.

\section{Also in this series: \\ Teenage Pregnancy and Young Parenthood \\ Alison Hadley}

\section{Youth Civic and Political Engagement}

Martyn Barrett and Dimitra Pachi 


\section{YOUTH CIVIC AND POLITICAL ENGAGEMENT}

Martyn Barrett and Dimitra Pachi 
First published 2019

by Routledge

2 Park Square, Milton Park, Abingdon, Oxon OX14 4RN

and by Routledge

52 Vanderbilt Avenue, New York, NY 10017

Routledge is an imprint of the Taylor E Francis Group, an informa business

(C) 2019 Martyn Barrett and Dimitra Pachi

The right of Martyn Barrett and Dimitra Pachi to be identified as authors of this work has been asserted by them in accordance with sections 77 and 78 of the Copyright, Designs and Patents Act 1988.

With the exception of Chapters 1-4, no part of this book may be reprinted or reproduced or utilised in any form or by any electronic, mechanical, or other means, now known or hereafter invented, including photocopying and recording, or in any information storage or retrieval system, without permission in writing from the publishers."

Chapters 1-4 of this book is available for free in PDF format as Open Access from the individual product page at www.routledge.com. It has been made available under a Creative Commons Attribution-Non Commercial-No Derivatives 4.0 license.

Trademark notice: Product or corporate names may be trademarks or registered trademarks, and are used only for identification and explanation without intent to infringe.

British Library Cataloguing-in-Publication Data

A catalogue record for this book is available from the British Library

Library of Congress Cataloging-in-Publication Data

A catalog record has been requested for this book

ISBN: 978-1-84872-161-6 (hbk)

ISBN: 978-1-84872-162-3 (pbk)

ISBN: 978-0-429-02557-0 (ebk)

Typeset in Bembo

by Deanta Global Publishing Services, Chennai, India 
This book is dedicated to our parents, Maria and Konstantinos Pachi

and Miriam and William Barrett,

for their love and support 


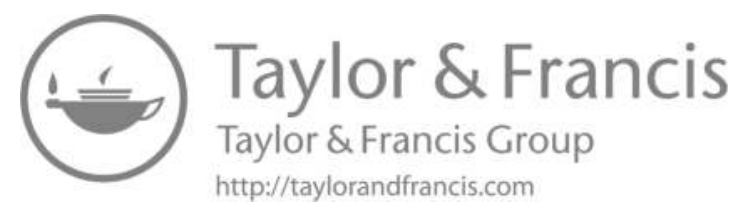




\section{CONTENTS}

List of illustrations

viii

List of abbreviations

1 Civic and political engagement among youth: Concepts, forms and factors

2 Psychological factors linked to youth civic and political engagement

3 Social and demographic factors linked to youth civic and political engagement

4 Macro contextual factors linked to youth civic and political engagement

5 Theoretical integration and actions for promoting youth engagement

References

Author index

Subject index 


\section{ILLUSTRATIONS}

\section{Figures}

1.1 The inter-relationships between macro, demographic, social and psychological factors, and their relationship to civic and political participation

5.1 The inter-relationships between macro, demographic, social and psychological factors, and their relationship to civic and political participation

\section{Tables}

1.1 Some of the different forms taken by conventional political participation, non-conventional political participation, civic participation and psychological engagement

1.2 The countries in which data were collected in CIVED, ICCS 2009, ICCS 2016 and PIDOP; the PIDOP listing also includes the national and ethnic groups within each country from which data were collected

5.1 A summary of the principal factors associated with youth civic and political participation

5.2 The 20 competences required to function as an interculturally competent democratic citizen within a culturally diverse democratic society, as proposed by the Reference Framework of Competences for Democratic Culture

5.3 Examples of scaled key descriptors in the Reference Framework of Competences for Democratic Culture 


\title{
ABBREVIATIONS
}

\author{
CIVED IEA Civic Education Study \\ ESS European Social Survey \\ ICCS 20092009 IEA International Civic and Citizenship Education Study \\ ICCS 20162016 IEA International Civic and Citizenship Education Study \\ NGO Non-governmental organisation \\ PIDOP Processes Influencing Democratic Ownership and Participation \\ study \\ RFCDC Reference Framework of Competences for Democratic Culture \\ SES Socio-economic status
}




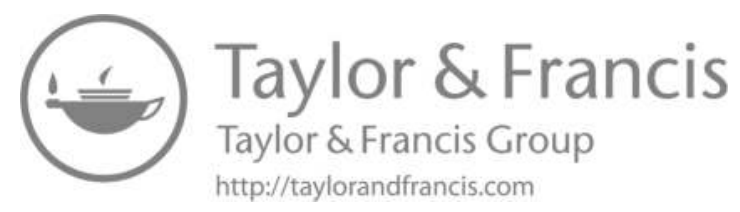




\section{1}

\section{CIVIC AND POLITICAL ENGAGEMENT AMONG YOUTH}

\section{Concepts, forms and factors}

This book provides an introduction to youth civic and political engagement. It describes the forms that such engagement takes, how it develops, the factors that facilitate or inhibit its development and the actions that can be taken to promote and encourage the civic and political engagement of youth and empower them as active democratic citizens.

The book is distinctive in a number of respects. It draws on findings that have been obtained across a range of academic disciplines, including psychology, sociology, political science and education, and it explores the many different psychological, social, demographic and macro factors that are related to youth engagement. It also examines the inter-relationships between these various factors, reviewing findings that have been obtained in different national contexts and through multinational studies. The final chapter provides a theoretical synthesis of this large and diverse body of research, using an integrative multi-level ecological model of youth engagement in order to do so. Along the way, the book offers suggestions for future research that needs to be pursued in order to address a number of unresolved issues. We therefore hope that the book will prove useful to those who wish to obtain a comprehensive overview of the research that has been conducted in this field, those who wish to obtain a theoretical integration of what can sometimes feel like a plethora of disconnected findings and those who wish to pursue further research in the field.

In this opening chapter, we provide a guide to many of the concepts that will be used throughout the book. We define some of the key terms that will be used, outline the various forms that youth civic and political engagement can take and take note of the findings of recent studies into patterns of youth engagement. We also introduce the numerous factors that are related to youth engagement these include psychological, social, demographic and macro factors. We outline 
the inter-relationships between these four sets of factors and explain how different forms of participation are influenced by different subsets of factors. In addition, this chapter maps the various topics onto the remaining chapters in the book, to aid the reader's navigation of the subsequent chapters. This opening chapter therefore serves as an introduction to the book.

\section{Some definitions}

As a first step, it will be useful to clarify the meanings of some of the key terms that are used throughout the book. To start with, the term youth itself, which appears in the title of the book, is ambiguous. For example, the United Nations defines 'youth' as the period between 15 and 24 years when (it is claimed) individuals make the transition from the dependence of childhood to the independence of adulthood. UNICEF defines 'young people' as the period of life that falls between 10 and 24 years, while the African Youth Charter defines 'youth' as the period that falls between 15 and 35 years (United Nations, 2014). An alternative view, advocated by the Council of Europe (2006), is based on the observation that the transition from childhood to early adulthood is actually a highly variable, non-linear, fragmented and sometimes extended process, with the transition to independent living in some contexts not taking place until 30 or even 35 years of age. For this reason, it is argued that it is preferable to leave the age-based definition of youth open. This book follows the latter approach and is similarly liberal in its use of the term, using it to denote the period of life that starts with early adolescence and extends through into early adulthood. The book will therefore draw broadly on evidence that has been collected about the civic and political engagement of young people across this entire period of life. Importantly, however, wherever possible, we will indicate the specific ages from which the evidence that is being discussed has been derived, so that appropriate conclusions can be drawn about young people's patterns of engagement at different ages.

The term citizen, which is used in the opening paragraph of this chapter, is another potentially ambiguous term. Following Barrett and Zani (2015a), we use this term to denote all individuals who are affected by political and civic decision-making and who can engage with political and civic processes through one means or another. This definition means that even those who are not legal citizens of the country in which they are living (e.g., first generation migrant youth who have not been naturalised and who therefore do not hold the passport of that country) are nevertheless citizens because they are affected by political and civic decision-making, and they are able to participate in political and civic processes through a number of means, including youth organisations, ethnic community organisations, pressure groups (e.g., anti-racist, human rights or environmental organisations) and Internet-based activism. This book therefore uses the term citizen with this broader meaning in mind. 
The term political engagement is used throughout the book to refer to the engagement of an individual with political institutions, processes and decisionmaking. By contrast, the term civic engagement is used to refer to the engagement of an individual with the concerns, interests and common good of a community. Here, community denotes either the people living within a particular geographical area (e.g., a neighbourhood, a city, a country or a transnational area such as Europe or Africa, or the world in the case of the 'global community'), a more geographically diffused cultural or social group (e.g., an ethnic group, a religious group, a recreational group, an occupational group or a sexual orientation group) or any other kind of cultural or social group which is salient to an individual and which therefore provides a site for that individual's civic action.

Engagement usually involves some kind of participatory behaviour that is directed towards political institutions, political processes and public authorities (in the case of political engagement) or towards the fellow members of a community (in the case of civic engagement). However, not all engagement is exhibited through participatory behaviour. It is entirely possible to have an interest in and to have knowledge, opinions or feelings about political or civic matters without undertaking any action. In other words, individuals can be cognitively or affectively engaged without being behaviourally engaged. As we shall see, it has been found that some youths are indeed psychologically but not behaviourally engaged in precisely this way. In other words, lack of overt political or civic action cannot necessarily be interpreted as a sign of political and civic disengagement.

Very often, however, political and civic engagement does involve not only interest, opinions and feelings about political or civic matters but also active participatory behaviours. The term political participation is used in this book to denote those behaviours that are intended to influence political institutions, processes and decision-making at either the local, regional, national or supranational level; these behaviours may be aimed either at influencing the selection of the people who make public policies and decisions, or at influencing the content of those policies and decisions (this definition is adapted from Verba, Schlozman \& Brady, 1995).

Political participation can take many different forms. Some forms involve electoral processes and are called conventional forms of political participation. These include voting, election campaigning, donating money to a political party, standing for election, etc. Some forms of conventional political participation (such as voting) are institutionally denied to youth below a particular age (usually 18 years, although other ages between 16 and 21 years apply in a few countries around the world), sometimes with consequences for their feelings of exclusion from political decision-making.

However, there are many other forms of political participation that do not involve electoral processes and that can be undertaken by individuals of any age. These so-called non-conventional forms of political participation 
include participating in political demonstrations, protests and marches, signing petitions, writing political articles or blogs, writing political graffiti on buildings, etc. Both conventional and non-conventional political participation can be undertaken either alone (e.g., voting, spraying political graffiti) or collectively in cooperation with other people (e.g., election campaigning, participating in a protest march about a particular issue). And some forms of political participation are legal (e.g., electoral campaigning, signing petitions) while others are illegal (e.g., spraying graffiti, throwing stones at a demonstration).

The term civic participation is used in this book to refer to activities that are focused on helping other people within a community, solving a community problem, working on behalf of a community or participating in the life of a community more generally (this definition is adapted from Zukin, Keeter, Andolina, Jenkins \& Delli Carpini, 2006). Once again, such activity can include work which is undertaken either alone (e.g., doing shopping for an ill neighbour, boycotting a product for environmental reasons) or in cooperation with others (e.g., attending a community meeting about an issue of concern, helping to renovate a facility such as a communal park in the neighbourhood).

Table 1.1 lists some of the numerous forms that political and civic engagement and participation can take.

In addition to engagement, however, young people can also be disengaged from both political and civic processes and may fail to display any of the characteristics that are shown in Table 1.1. As in the case of engagement, there are different forms of disengagement (Ekman \& Amnå, 2012). For example, some young people may simply not have any interest in political matters, may regard all such matters as boring and may have no wish to participate in any forms of political action because such action is viewed as either irrelevant to their lives or a waste of time that can be much better devoted to more enjoyable, stimulating or rewarding activities instead. These young people may be characterised as apolitical.

However, other youth may be strongly antipolitical and vehemently refuse to engage with political matters, being resolutely opposed to any form of political action. For example, some youth may adopt this stance because they view politicians as corrupt, dishonest or self-serving, or because they believe that politicians have no interest in the views and lives of young people.

A parallel conceptual distinction can be drawn between young people who are acivic and young people who are anticivic, that is, between those who are simply not interested in participating in any activities with or on behalf of other people in the communities to which they belong, and those who are actively opposed to engaging with other people in their communities, perhaps because they are antisocial and mistrustful of other people.

Having outlined some of the terminology and conceptual distinctions that we will be using in this book, we now turn to some of the claims that have been made about the nature of youth civic and political engagement. 
TABLE 1.1 Some of the different forms taken by conventional political participation, non-conventional political participation, civic participation and psychological engagement (reproduced from Barrett \& Zani, 2015a, pages 5-6).

Forms of conventional political participation

- Voting

- Membership of a political party

- Running for political election

- Working on political election campaigns for candidates or parties

- Donating money to political parties

- Trying to persuade others to vote

Forms of non-conventional political participation

- Protests, demonstrations, marches

- Signing petitions

- Writing letters/emails to politicians or public officials

- Writing letters/emails/phone calls with a political content to the media (both old and new media)

- Writing articles/blogs with a political content for the media (both old and new media)

- Using social networking sites on the Internet to join or like groups which have a political focus

- Using social networking sites on the Internet to distribute or share links which have a political content to friends and contacts

- Wearing or displaying a symbol or sign representing support for a political cause

- Distributing leaflets which express support for a political cause

- Participating in fundraising events for a political cause

- Writing or spraying graffiti on walls which expresses support for a political cause

- Participating in other illegal actions (e.g., burning a national flag, throwing stones, rioting) in support of a political cause

- Membership of political lobbying and campaigning organisations/attending meetings of these organisations/expressing one's point of view at these meetings/participating in the activities of these organisations/holding an office in these organisations

Forms of civic participation

- Informally assisting the well-being of others in the community

- Community problem-solving through community organisations/membership of community organisations/attending meetings of these organisations/expressing one's point of view at these meetings/participating in the activities of these organisations/ holding an office in these organisations

- Membership of other non-political organisations (e.g., religious institutions, sports clubs)/attending meetings of these organisations/expressing one's point of view at these meetings/participating in the activities of these organisations/holding an office in these organisations

- School-based community service

- Undertaking organised voluntary work

- Translation and form-filling assistance for non-native speakers

- Sending remittances to others living elsewhere

- Donations to charities

- Fundraising activities for good causes

- Consumer activism: boycotting and buycotting (preferential buying) 
TABLE 1.1 (Continued)

Forms of psychological engagement

- Paying attention to or following political or civic events

- Having political or civic knowledge or beliefs

- Holding opinions about political or civic matters

- Having feelings about political or civic matters

- Having political or civic skills

- Understanding political or civic institutions

- Understanding or holding political or civic values

\section{Is there a crisis of youth civic and political engagement?}

Many researchers and commentators have noted that youth who are eligible to vote in national elections do so less frequently than older generations (e.g., International IDEA, 2004; Macedo, 2005; Putnam, 2000). Youth are also less likely to be registered to vote than older generations. Furthermore, the percentage of youth who vote in national elections across the Western developed democracies has been in steady decline since the 1970s. These patterns have given rise to the claim that the future of democracy in these countries is in jeopardy. This is a consequence of the fact, so the claim goes, that political engagement in later life is rooted in the habits that are developed in youth, and the youth of today will eventually become the older generation of tomorrow. An accompanying worry is that, because youth fail to vote in sufficient numbers, those who are elected to positions of power do not represent youth and will inevitably undervalue or overlook the views of youth in their decision-making processes.

However, as we have seen, voting is only one form of political and civic engagement. And it has been argued by other commentators that while young people's commitment to conventional political participation is indeed currently in decline, young people nevertheless still remain committed to non-conventional and civic forms of participation. Indeed, many authors have suggested that to construe voting as the principal form of political engagement is to fundamentally misunderstand the way in which young people today conceptualise the political domain and the role of alternative forms of engagement. These authors argue that politicians and political institutions are often perceived by young people as having little interest in their views and concerns, with the result that many youth feel marginalised by and excluded from the conventional political arena. For this reason, they seek out and use alternative forms of civic and political engagement instead (Dalton, 2008; Forbrig, 2005; O’Toole, Lister, Marsh, Jones \& McDonagh, 2003; Zukin et al., 2006).

Hence, this counter-argument continues, declining levels of voting among youth need to be balanced against other evidence which suggests that non-conventional political and civic participation are still used by many young people today. Whereas in the past, issues of concern might have mobilised them into voting for particular candidates in elections or writing to their elected 
representatives, nowadays these issues might instead be tackled through consumer activism, protests and demonstrations, activity on the Internet, charitable fundraising and voluntary work in the community. Therefore, even though in many countries youth are less likely than they were in the past to vote, to be a member of a political party or to campaign on behalf of political parties during an election, these phenomena are not indicative of civic and political disengagement or apathy. Instead, they are a consequence of young people's sense that politicians and political institutions are not interested in their concerns and interests and do not address their needs. For this reason, they employ a different pattern of activism to support the causes that are of relevance and matter to them.

A great deal of evidence has now been collected which supports this view. For example, Marsh, O’Toole and Jones (2007) conducted interviews with British youth aged 16 to 25 years old. The interviews revealed that, although the majority would not consider voting in an election, these youth felt passionately about many issues, including education, employment, housing and the lack of facilities for young people in their local communities. However, they felt that no one was interested in finding out what they thought about these various matters or encouraged them to express their views, and the denial of voting to 16- and 17-year-olds was viewed as simply confirming the lack of interest that politicians had in finding out about and addressing the views and needs of young people.

Similar findings have been obtained in the USA. For example, in a study of 18- to 25-year-old American college students, Kiesa et al. (2007) found that most students said that voting was not an effective way to achieve change and expressed distrust of and dissatisfaction with the political system which they viewed as being inefficient, corrupt, self-serving, unresponsive to citizens' needs and counter to the genuine welfare of citizens. However, despite this dissatisfaction with the political system, many students still wanted to engage with public policy and did not dismiss politics from their lives. The problem was that they perceived the political system as being inaccessible to them, largely because their elected representatives did not consider their views to be important and therefore did not listen to them. At the same time, the students reported that they undertook voluntary work in a large variety of areas, including education, healthcare, poverty/welfare, the environment and human rights, with most of them viewing this kind of activity as one of their responsibilities so that they could help others and make things better in society. While some students did list national or international issues as being of concern to them, many more undertook volunteering action in their local areas instead. The students did not eschew politics as such but saw no clear way to access the system and felt that they could not have any influence through that route, and they therefore sought out volunteering instead as a way to have an impact, to effect change and to improve the lives of other people.

A further striking example of the disconnection in young people's lives between conventional political participation on the one hand and non-conventional political and civic engagement on the other hand comes from the region 
of Galicia in Spain (Blanch, 2005). Youth in Galicia typically display low levels of interest in politics, with more than three-quarters of youth aged 15 to 29 years old declaring that politics has little or no importance in their lives. Political disaffection takes the form of frustration and distrust over voting, being listened to by politicians and political parties, and being able to affect government policies. However, in 2002, the oil tanker MV Prestige sank off the coast of Galicia with 50,000 tonnes of oil being spilt, leading to a major environmental disaster in which hundreds of kilometres of coastline on the Spanish, French and Portuguese coasts were polluted. The contamination threatened to destroy the environment, fishing industry and tourism in Galicia. Major demonstrations over the oil spills took place in the Galician cities of Santiago and Vigo (involving 200,000 protestors in the former city and 130,000 in the latter), with the large majority of those participating in the demonstrations being youth and college students, and 325,000 people volunteered to take part in the environmental clean-up operation. Despite these enormous levels of non-conventional political and civic engagement, patterns of voting in subsequent elections did not show any indication of having been affected. This was despite extensive calls for the ruling party to be removed from power due to their poor performance during the crisis.

A fourth example is provided by the work of Weller (2007), who studied younger adolescents, British 13- to 16-year-olds. She found that over one-third of these teenagers had already engaged in civic activities, for example, by participating in local campaigns, planning local events (such as painting murals), maintaining local music events and involvement in bidding for money to improve the local environment. Although much of the engagement of these teenagers took place at the local level, many of them also considered the global dimensions of engagement and the possibility of connections with other youth elsewhere in the world, especially through the Internet and text messaging. Some respondents also firmly challenged the notion of teenage apathy and provided suggestions on how teenagers' contributions to their communities could be increased. However, $81 \%$ of them said that they had never been asked for their opinion on a local issue and had not had any opportunities to contribute to decision-making by the local council, despite the fact that they were extremely keen to express their opinions on those issues that were relevant to their lives. Furthermore, when the minority of youths who had participated in local consultations were questioned, it was found that these consultations were viewed as ineffective and tokenistic because they had rarely resulted in any real action. The frustration and resentment experienced by these teenagers rendered their active participation and involvement in the community problematic, and they largely construed political participation as an activity that only concerned adults.

In other words, there is ample research evidence which suggests that: (i) youth are far from apathetic when it comes to political and civic engagement; (ii) they experience the conventional political arena as one that marginalises and excludes them and perceive politicians as having very little interest in the views or needs 
of young people; (iii) they regard voting as one of the least effective ways of achieving change; and (iv) they view civic and non-conventional political forms of engagement as being much more effective for having an impact in the world.

\section{The shift towards issue-based activism}

A further interesting characteristic of youth engagement at the present time concerns the specific topics upon which youth activism tends to be focused. In the past, in Western democracies, political activism was very much focused on party politics, especially voting and sometimes party membership and campaigning for a specific party during elections, and such activism was primarily aimed at influencing the composition of government and public policymaking. However, many youth today simply sidestep any engagement with mainstream political parties as a consequence of their frustration with and cynicism about politicians and conventional political processes. Instead, they tend to focus their energies on single issues or causes about which they have strong feelings. Specific issues that commonly attract the attention of youth in this way include global warming, pollution, global poverty, the use of low-wage labour in third world countries, the greed of multinational corporations, human rights (at the global level); income inequalities, political corruption, youth unemployment, gender equality, gay rights, health care (at the national level); and graffiti, litter, unsafe streets, transport facilities, recycling facilities and youth amenities (at the local level) (Inglehart, 1997; Inglehart \& Norris, 2003; Kiesa et al., 2007; Marsh et al., 2007; Norris, 2002, 2003; Torney-Purta, 2009; Weller, 2007).

Young people's interest in and enthusiasm for such issues typically occurs on a case-by-case basis and is not usually organised through any formal political institution. However, their activism may be channelled and focused through special interest groups such as Oxfam, Amnesty International or Friends of the Earth. Initial engagement typically takes place through the Internet and social media, which are used for obtaining information, before the organisations concerned are approached offline. Importantly, the issues that are selected as the focus for action are usually experienced as having considerable personal meaning for those who engage with them, and they tend to be selected and shaped by young people's own lifestyles, identities and values as well as by the social networks through which they commonly interact and participate. And the particular forms of participation that are undertaken are often the ones that have the most relevance and meaning from the perspective of their own everyday lives, experiences and practices.

\section{Voting remains important}

In short, there is abundant evidence that a shift has taken place in youth political and civic engagement in recent times. This shift has involved a decline in levels of conventional political participation, an increase in levels of non-conventional 
political and civic participation and greater attention being paid to single-issue causes. That said, it would be misleading to overemphasise this shift. This is because quantitative studies have revealed that, while levels of voting among young people are currently at a historic low in Western democracies and are significantly lower than those exhibited by older generations, voting nevertheless remains a commonly used form of participation by young people.

This finding emerges clearly from a study by Sloam (2016), who looked at five different types of participation - voting in the previous national parliamentary election, displaying a badge or sticker, signing a petition, joining a boycott and participating in a demonstration. Analysing data collected from 15- to 24-yearolds in 15 European countries, Sloam found that voting tends to be the single most common form of participation among young Europeans in this age range. This finding held up in every country, including those that have exceptionally low proportions of young people turning out to vote in national elections (i.e., Luxembourg, Ireland and the UK - in all three countries, only about $37 \%$ of individuals in this age range vote). Indeed, on average across all 15 countries, $58.9 \%$ of youth voted in the previous election, whereas the frequencies of the other forms of participation were $24.7 \%$ for signing a petition, $14.2 \%$ for participating in a demonstration, $14 \%$ for joining a boycott and $11.1 \%$ for displaying a badge or sticker. Hence, despite the shift that has taken place in youth political and civic engagement in recent times, voting nevertheless still remains a commonly used form of participation by young people within Europe.

That said, voting is a relatively low-effort and low-cost form of participation. Once a person is registered to vote, the act of voting in a national election usually only involves contributing a few minutes of one's time in order to visit a polling station once every few years (or, in the case of a postal vote, ticking a box on a form and returning it through the post). As such, the effort involved can perhaps be compared to signing a petition, which is also a very simple and undemanding action to take. By contrast, participating in a demonstration is much more demanding and requires greater time, effort and commitment. Thus, in interpreting these figures, it is important to factor in the relative ease of engaging in the various forms of action.

\section{The concept of the standby citizen}

Amnå and Ekman $(2014,2015)$ have recently put forward a different perspective on the current characteristics of youth civic and political engagement. They argue that many young people can be classified as standby citizens. The concept of a standby citizen is based on the idea that a person may have an interest in political issues, follow political news in newspapers or on TV or the Internet, have political knowledge and hold informed opinions on many political matters but not engage in any forms of political action. Amnå and Ekman suggest that it is wrong to characterise such people as politically passive or politically uninvolved, and these individuals are certainly not politically apathetic. They are instead 
monitoring political events in a critical manner. Or, to use the terminology that was introduced earlier in this chapter, these individuals are psychologically but not behaviourally engaged.

Amnå and Ekman suggest that one reason why some individuals may adopt this orientation is because they have a high level of trust in the political system and in their political representatives who have been elected to make decisions on public policies. Their low level of participation therefore reflects rational decision-making: why spend time engaging with the system when that system is trusted to make decisions that are in the best interests of the people being governed? It is only when there is a reason to intervene (e.g., because it is thought that poor decisions are being made) that such citizens will become active and take up conventional and non-conventional forms of political participation.

While this characterisation of the standby citizen sounds far removed from the patterns of attitudes and behaviours reviewed in the preceding sections, Amnå and Ekman (2014) present evidence to support their argument. In a study of Swedish 16-year-olds, they found that these individuals fell into four distinct groups in terms of their citizenship orientations: (i) active youths, who were high on measures of both political interest and political participation; (ii) standby youths, who were high on interest but were significantly lower on participation; (iii) disengaged youths, who were very low on both interest and participation; and (iv) disillusioned youths, who were the lowest of all the four groups on political interest and also low on participation. In other words, Amnå and Ekman found that young people who do not participate politically can be differentiated empirically into three separate categories, with 'standby' youths being those who stay alert, keep themselves informed about politics and are willing and able to participate if needed.

Interestingly, in this Swedish sample, the standby category formed the single largest group, representing nearly $50 \%$ of the 16 -year-olds who were studied. It remains to be seen whether a similar proportion of youths living in other political contexts show this particular profile - it may be that the well-functioning Scandinavian democracies form a special case. Amnå and Ekman note that, in recent times, political parties in Sweden have become increasingly 'professional' and no longer require members for their organisation or funding due to the provision of state grants. For this reason, members of political parties have effectively been made redundant, with ordinary citizens being assigned the role of audience rather than participant in the political system. Thus, Swedish political parties have been implicitly transmitting the message that while they want people to turn out and vote for them in elections, they do not want them to be involved any further in the everyday business of politics. For this reason, the pattern found by Amnå and Ekman may be specific to political systems with these kinds of characteristics and may not generalise to other countries which have other kinds of political systems (and, indeed, the pattern may also be specific to a particular period in Scandinavian history which is currently drawing to a close). We will return to this issue of possible differences in patterns of youth civic and political engagement from one country to another later on. 


\section{The factors that are related to patterns of youth civic and political engagement}

There has been much research over the past 50 years into the factors that are related to young people's patterns of civic and political engagement. This body of research has shown that these factors can be classified into four main types: psychological, social, demographic and macro.

Psychological factors include, for example, having political knowledge and paying attention to political issues, both of which tend to be (contra Amnå and Ekman) consistent predictors of both political and civic participation (Delli Carpini \& Keeter, 1996; Zukin et al., 2006). A further very important psychological factor is internal political efficacy (often called more simply 'internal efficacy'). This is the self-belief that one can understand and participate effectively in politics. Internal efficacy is strongly related to having an interest in political issues, and people who have high levels of internal efficacy and high levels of interest in politics tend to show high levels of all forms of participation (Barrett \& Brunton-Smith, 2014; Brunton-Smith, 2011). Other important psychological factors that have been linked to civic and political participation are trust (e.g., the belief that societal and political institutions will generally operate in ways that are beneficial rather than detrimental to people) and emotions (e.g., anger about a perceived social injustice, feeling a humanitarian obligation to help other people, enjoyment in helping others). All of these psychological factors, and more, are discussed at length in Chapter 2 of this book.

In addition to these psychological factors, there are many different social factors that are related to civic and political engagement. First, parental behaviour is linked in numerous ways to young people's patterns of civic and political engagement. For example, individuals whose parents engage in civic volunteering have higher levels of civic and political participation, are more attentive to news about government and politics and are more likely to engage in consumer activism, while individuals who have frequent political discussions with their parents are more likely to volunteer and to vote (Zukin et al., 2006). In addition, parents' levels of political knowledge predict their offspring's levels of political knowledge (Jennings, 1996), while individuals whose parents engage in protests are also more likely to participate in protests (Jennings, 2002).

Education is a further social factor that is related to civic and political engagement (Emler \& Frazer, 1999; Nie, Junn \& Stehlik-Barry, 1996). Students who attend schools that provide training in civic skills (e.g., in letter writing and debating) are more likely to be involved in organisations outside school, to sign petitions, to participate in boycotts, to follow political news, to engage in charitable fundraising and to attend community meetings (Zukin et al., 2006). In addition, if there is an open classroom climate at school which enables young people to raise and investigate ethical, social, civic and political issues and explore their opinions and those of their peers within the classroom, they acquire a higher level of political interest, trust and 
political knowledge (Hahn, 1998; Schulz, Ainley, Fraillon, Losito, Agrusti \& Friedman, 2017; Torney-Purta, Lehmann, Oswald \& Schulz, 2001). In addition, the emphasis that is placed on voting and elections in school classes is a further significant predictor of young people's future voting intentions (Torney-Purta et al., 2001).

Links have also been found between civic and political engagement and peer group relationships. For example, civic and political participation is related to having positive relationships with peers and to having friends who are involved in civic and political activities (Silva, Sanson, Smart \& Toumbourou, 2004; Rossi, Lenzi, Sharkey, Vieno \& Santinello, 2016; Wentzel \& McNamara, 1999), and when youth feel a sense of solidarity with peers at school, they are more likely to commit to civic and political goals and values (Flanagan, Bowes, Jonsson, Csapo \& Sheblanova, 1998).

Another social factor related to civic and political engagement is membership of youth, community and religious organisations. For example, involvement in youth or community organisations in which the young person is able to take on specific roles (such as helping to organise activities and leadership roles) is related to prosocial-oriented political and civic participation (Albanesi, Cicognani \& Zani, 2007; Quintelier, 2008). Belonging to religious organisations seems to be particularly important: youth with high levels of religious attendance and religious activity are more likely to be civically and politically active (Crystal \& DeBell, 2002; Youniss, McClellan, Su \& Yates, 1999).

In summary, many different social factors are related to the civic and political engagement of youth, including parental behaviour, educational practices in schools, peer group relationships, and membership of civic organisations. All of these social factors are reviewed in detail in Chapter 3 of this book.

Young people's patterns of civic and political engagement are also related to three main demographic factors: socio-economic status (SES), gender and ethnicity. Individuals with higher SES tend to have higher overall levels of both civic and political participation (Hart, Atkins \& Ford, 1998; Zukin et al., 2006). There are also sometimes gender differences in political knowledge and political interest, and in the specific forms of participation that are undertaken by male and female youth (Bennett \& Bennett, 1989; Vromen, 2003; Wolak \& McDevitt, 2011). In addition, ethnic minority and ethnic majority individuals participate in different kinds of volunteer activities, with the former participating more in activities relating to their own ethnic community and to other minorities (Stepick, Stepick \& Labissiere, 2008). Generational status of migrant and ethnic minority individuals is linked to patterns of participation as well: for example, the first generation is less likely to be registered to vote than later generations (Stepick et al., 2008) and is also less participative in terms of actual voting, volunteering and boycotting when compared with majority group individuals (Lopez \& Marcelo, 2008). By contrast, the second generation is sometimes more civically and politically active than individuals belonging to the majority ethnic group (Lopez \& Marcelo, 2008; Stepick \& Stepick, 2002). 
Chapter 3 reviews the relationship between youth civic and political engagement and SES, gender and ethnicity in detail.

Finally, young people's patterns of engagement are related to macro factors. Macro factors include the historical, cultural and economic characteristics of the country in which the young person is living, and the structure and design of the political institutions within that country. For example, young people's trust in political and legal institutions is higher in countries that have longstanding democratic traditions; however, the importance that young people attribute to voting and joining a political party is higher in countries in which democratic institutions have been strengthened in the previous 30 years (Torney-Purta et al., 2001). In addition, youth in countries that have a high level of economic development have more political knowledge than youth who live in countries that have a low level of economic development (Schulz, Ainley, Fraillon, Kerr \& Losito, 2010; Schulz et al., 2017). As far as institutional design is concerned, youth participation is higher in countries that have institutional structures in place to hold the government accountable for its actions and to ensure and protect the rule of law, human rights and civil liberties (Brunton-Smith, 2011; Brunton-Smith \& Barrett, 2015). The role of macro factors such as these are reviewed in detail in Chapter 4 of this book.

\section{Relationships between the factors that are linked to youth civic and political engagement}

The factors that are linked to youth civic and political engagement usually do not operate in isolation from one another - instead, they are frequently inter-related (see Figure 1.1).

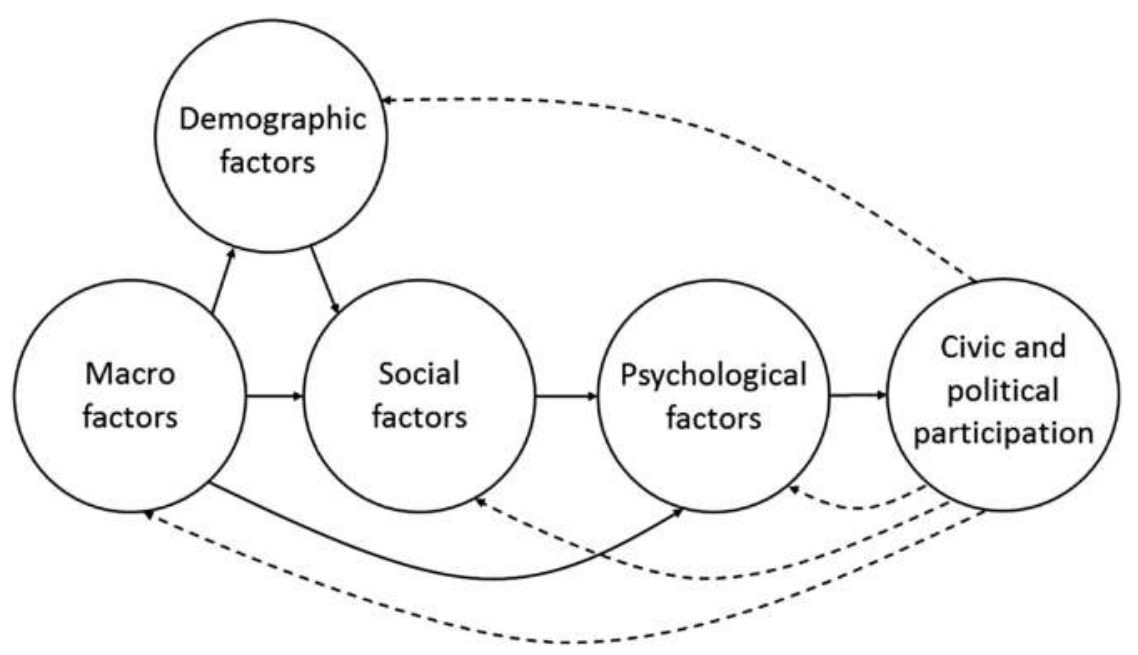

FIGURE 1.1 The inter-relationships between macro, demographic, social and psychological factors, and their relationship to civic and political participation 
For example, macro factors are often linked to both demographic and social factors. This applies most obviously in the case of the economic characteristics of a country. The level of economic development of a country (a macro factor) influences the economic positioning of the individuals who live within that country (a demographic factor) and thus the amount of time and money that they are able to devote to political activity (Brady, Verba \& Schlozman, 1995). In addition, a country's level of economic development is related to expenditure on education and the quality of educational provision within that country (IES, 2015), with the quality of educational provision affecting young people's experiences at school (a social factor). Macro factors are also sometimes linked to psychological factors. For example, in the case of a youth who is personally contacted by a political party during an election campaign, or a youth who participates in a country's youth parliament, the first-hand experience that is obtained through the direct contact with the political institution (a macro factor) may affect his or her attitudes to conventional political processes (a psychological factor), and this effect can be either positive or negative (Green \& Gerber, 2004; Turkie, 2010).

Demographic factors are also often linked to social factors. For example, SES (a demographic factor) is commonly related to the quality of the schooling that an individual receives (a social factor) and hence to the level of educational achievement by that individual (OECD, 2012). Educational achievement, in turn, is linked to subsequent employment (if indeed an individual manages to find employment, which is not always a given), and the type of employment that an individual undertakes (a further social factor) is related to the acquisition and maintenance of the knowledge and skills that are needed for civic and political participation (Wolfinger \& Rosenstone, 1980; Verba et al., 1995). In addition, education affects individuals' social networks and their ability to occupy positions of influence in civic life, which in turn are linked to individuals' patterns of civic and political participation (Nie et al., 1996). In other words, a demographic factor such as SES can have widespread ramifications on social factors and hence on outcomes.

Social factors are also related to psychological factors. For example, adolescents whose parents are interested in political and social issues have higher levels of interest in these issues themselves as well as higher levels of political knowledge (Schulz et al., 2010), and a family ethic of social responsibility predicts young people's levels of civic commitment (Flanagan et al., 1998).

Finally, psychological factors are related to patterns of civic and political participation. For example, interest in politics, political knowledge and internal efficacy are all usually related to levels of participation (Barrett \& Brunton-Smith, 2014; Brunton-Smith, 2011; Zukin et al., 2006).

However, it is important not to neglect the fact that participating in civic and political action itself can have effects on psychological, social, demographic and macro factors (the dashed arrows in Figure 1.1). For example, participating in collective protests is often perceived as an empowering experience which increases the sense of internal efficacy and reinforces a sense of identification with the group that has organised the protest (Drury \& Reicher, 2009). 
Participating in civic and political action can also have effects on other people within one's social environment. For example, young people may engage in civic or political activity about a particular issue which is of concern to them, perhaps as a result of a school project or a project run by a youth organisation, and they may then initiate political discussions at home with their parents about the issue, which prompts the parents to pay greater attention to news media, obtain new knowledge and construct new opinions (McDevitt \& Chaffee, 2002).

In addition, participating in civic and political action can have an effect on an individual's demographic situation. For example, people sometimes freely volunteer their time for community work for self-focused rather than other-focused reasons, such as enlarging their social networks, learning new skills, gaining experience or gaining qualifications in order to better compete in the employment market (Dean, 2015; Omoto \& Snyder, 2002); this in turn can then help them to enhance their own demographic situation.

Finally, participating in civic and political action can have effects on macro factors as well. Arguably the most dramatic example here is provided by the widespread demonstrations and protests in the Middle East which came to be known as the Arab Spring, which began in December 2010 and continued through 2011 into 2012. These acts of political protest by young people on the streets of numerous cities in the Middle East and North Africa brought about considerable changes in the macro political conditions of many countries, including Tunisia, Egypt, Libya, Yemen and Syria (Haseeb, 2012; Herrera \& Sakr, 2014).

Thus, the various factors at the psychological, social, demographic and macro levels do not operate independently of one another, and the causal routes through which these factors impact on young people's civic and political engagement can be complex. This complexity raises issues concerning the actions that may be taken to enhance young people's engagement with civic and political issues and boost their levels of active participation. We will return to these issues when we discuss possible interventions in Chapter 5.

\section{Intersectionality}

In considering the nature of youth civic and political engagement, it is also important not to oversimplify the nature of young people's lives and reduce them to a one-dimensional caricature based solely on their age. It is true that there are profound differences between the lives, perspectives and activities of a 16 -year-old who is still in full-time education and a 25 -year-old who has entered the world of work, but there can also be profound differences between the lives of males and females, and between the lives of ethnic majority and ethnic minority youths. However, much more subtly even than all of these broad distinctions, the lives - and hence the civic and political views and concerns - of young people are often specific to particular subgroups of youths who are defined in terms of the intersection between their country, ethnicity, gender and age. 
An illustration of this was found in a study by Pachi, Garbin and Barrett (2011), which was carried out as part of a large multinational study called PIDOP, which examined youth civic and political engagement in nine European countries (Barrett, 2012; Barrett \& Zani, 2015b). Pachi et al. conducted focus groups with British Bangladeshi, British Congolese and English youth aged 16 to 26 years who lived in London, discussing civic and political issues which were of concern to them and the forms of action which they would take. The topic of women's rights came up in these focus groups, where differences of opinion occurred not unexpectedly between female and male participants. However, gender differences in views about women's rights were far more pronounced among female Bangladeshis, many of whom deplored their parents' traditional cultural view that women should stay mainly in the domestic environment and not get involved socially or politically in the public sphere. In other words, an issue which was of the most profound importance to the female Bangladeshi participants was largely absent from the discourse of the male Bangladeshi participants and not especially pronounced in the discourse of the female and male Congolese and English participants. At the same time, however, there were differences between the younger and the older Bangladeshi girls in terms of the forms of political participation which they thought were acceptable: for example, younger Bangladeshi girls rejected illegal nonconventional forms of expression such as spraying graffiti on official buildings because of their illegality, whereas older Bangladeshi girls accepted these forms of action, especially for tackling local issues, as did both the younger and the older Bangladeshi boys. In other words, the views of these young people were specific to particular subgroups defined in terms of the three-way intersection between ethnicity, gender and age.

The importance of considering the specific concerns of individuals who occupy particular demographic niches as defined by the intersection of several demographic categories was confirmed by the subsequent quantitative research that was conducted by PIDOP, in which survey data about civic and political participation by 16 - to 26 -year-olds were collected from individuals belonging to the national majority group and two ethnic minority groups in nine countries (Barrett \& Zani, 2015b). There was very considerable variability in the data both between countries and between ethnic groups within individual countries. It was also clear that this variability could not be reduced to differences between the members of the majority national group and the members of the minority ethnic groups within individual countries, as there were significant differences between the two minority groups within each country, and also within each individual majority and minority group as a function of both age and gender. In other words, the participatory behaviours of young people (and indeed the factors that predicted those behaviours) were often specific to particular subgroups defined in terms of the intersection between country, age, gender and ethnicity (e.g., in Portugal, specific to younger females from an Angolan background, or to older males from a Brazilian background). 
In other words, it is important to be cautious in making generalisations about youth civic and political engagement. We need to be attentive to the specific groups of young people from which data have been gathered and especially attentive to possible differences in the experiences and concerns of groups that are defined in terms of intersections between demographic categories. This applies especially when it comes to efforts to identify actions that can be used to enhance levels of civic and political participation among youth. This is an important issue to which we will return in Chapter 5 of this book.

\section{Different subsets of factors are linked to the different forms of participation}

The findings from PIDOP also serve to underline a further point about the nature of youth civic and political engagement. The project revealed not only considerable cross-group variability in the patterns of political and civic participation that were displayed according to the intersection of country, ethnicity, gender and age - there was also a great deal of variability in the specific subsets of psychological and social factors that were linked to the different forms of participation. In other words, different constellations of factors were related to the different forms of participation.

This finding was obtained both in the nine-nation survey (Barrett \& Zani, $2015 b)$ and also in the secondary analysis of data from other existing large-scale datasets such as the European Social Survey (ESS) (Barrett \& Brunton-Smith, 2014; Brunton-Smith, 2011; Brunton-Smith \& Barrett, 2015). For example, the secondary analyses revealed that different subsets of factors are linked to voting, to forms of conventional political participation other than voting, to nonconventional political participation and to civic participation. Thus, a high level of attentiveness to political issues was linked to a higher tendency to vote and to participate civically, but was simultaneously linked to a lower tendency to engage in non-conventional political participation. It was also found that a high level of the belief that public and political officials and institutions are responsive to citizens' demands (i.e., a high level of what is called external political efficacy) was not systematically linked to voting behaviour, but was systematically related to forms of conventional political behaviour other than voting and to non-conventional political behaviour - people who had a high level of external efficacy exhibited high levels of conventional political activity other than voting as well as high levels of non-conventional political activity. In other words, depending on the specific type of participation being examined, different subsets of factors were operating. As we will see in Chapter 2, this same finding has been obtained in other studies as well.

Importantly, these findings indicate that boosting some psychological factors through, for example, educational interventions (e.g., to increase the political 
attentiveness of young people) might have a positive impact on some forms of participation (e.g., voting and civic participation) but might simultaneously have a negative impact on other forms (e.g., non-conventional political participation). Once again, this means that we need to exercise caution in developing interventions, especially if the goal is to develop robust interventions for enhancing levels of all forms of youth civic and political participation. The implications of these findings concerning the specificity of links between predictors and specific forms of participation are discussed further in Chapter 5.

\section{Civic and political engagement always takes place within specific contexts}

One final very important caution also needs to be flagged here. Young people's civic and political concerns are always formed within specific contexts that are situated within particular locations and at particular points in historical time, and their civic and political participatory behaviour is therefore also likely to be specific to those particular locations and times. For this reason, it is important to be careful about generalising from the results of any single study and assuming that the findings will necessarily apply to youth living in other contexts.

This caution gains additional force from the fact that the vast majority of studies that are available within the research literature in this field have been conducted in Western democracies. The lives, concerns and range of political and civic activities that young people undertake in Western democracies will be very different from those of youth living under other types of political regimes or in very different cultural conditions. We also cannot assume that findings that are obtained from youth living in one particular democracy will apply to youth living in another democracy, given that there are so many institutional, social and cultural factors that vary from one country to another. Hence, multinational studies, where data are collected from a number of different countries, are especially important sources of evidence in this field. Examples of such studies are CIVED (Torney-Purta et al., 2001), ICCS 2009 (Schulz et al., 2010), ICCS 2016 (Schulz et al., 2017) and PIDOP (Barrett, 2012; Barrett \& Zani, 2015b). All of these studies collected their data in multiple countries (see Table 1.2), and for this reason their findings are especially important and noteworthy.

Hence, throughout this book, whenever we discuss the findings from a particular study, we have tried to provide not only information about the specific ages of the youth who were involved in the study but also information about the countries where those youth were living. The aim here is twofold: to alert the reader to the possible specificity of the findings, and to encourage the reader to reflect on the extent to which the reported findings may or may not be applicable to youth living in other contexts. 
TABLE 1.2 The countries in which data were collected in CIVED, ICCS 2009, ICCS 2016 and PIDOP; the PIDOP listing also includes the national and ethnic groups within each country from which data were collected.

CIVED 1999 (Torney-Purta et al., 2001)

Australia, Belgium (French-speaking community), Bulgaria, Chile, Colombia, Cyprus, Czech Republic, Denmark, England, Estonia, Finland, Germany, Greece, Hong Kong SAR, Hungary, Italy, Latvia, Lithuania, Norway, Poland, Portugal, Romania, Russian Federation, Slovak Republic, Slovenia, Sweden, Switzerland, United States

ICCS 2009 (Schulz, Ainley, Fraillon, Kerr \& Losito, 2010)

Austria, Belgium (Flemish-speaking community), Bulgaria, Chile, Chinese Taipei, Colombia, Cyprus, Czech Republic, Denmark, Dominican Republic, England, Estonia, Finland, Greece, Guatemala, Hong Kong SAR, Indonesia, Ireland, Italy, Republic of Korea, Latvia, Liechtenstein, Lithuania, Luxembourg, Malta, Mexico, Netherlands, New Zealand, Norway, Paraguay, Poland, Russian Federation, Slovak Republic, Slovenia, Spain, Sweden, Switzerland, Thailand

ICCS 2016 (Schulz, Ainley, Fraillon, Losito, Agrusti \& Friedman, 2017)

Belgium (Flemish-speaking community), Bulgaria, Chile, Chinese Taipei, Colombia, Denmark, Dominican Republic, Estonia, Finland, Hong Kong, Italy, Republic of Korea, Latvia, Lithuania, Malta, Mexico, Netherlands, Norway, Russian Federation, Slovenia, Sweden (with additional data also collected in Croatia, North RhineWestphalia (Germany), Peru)

PIDOP (Barrett, 2012; Barrett \& Zani, 2015b)

Belgium (French-speaking community): Belgians, Turks, Moroccans

Czech Republic: Czechs, Roma, Ukrainians

England: English, Congolese, Bangladeshis

Germany: Germans, German resettlers from Russia, Turks

Italy: Italians, Albanians, Moroccans

Northern Ireland: Northern Irish Catholics, Northern Irish Protestants, Chinese, Polish

Portugal: Portuguese, Brazilians, Angolans

Sweden: Swedes, Kurds of Turkish background, Iraqis

Turkey: Turks, Roma, Turkish resettlers from Bulgaria

\section{Conclusions}

This chapter has provided an introduction to many of the themes and issues that are discussed at greater length throughout the remainder of this book. In particular, it has described the various forms that young people's civic and political participation can take, described recent changes in the forms of participation that are used by young people, outlined four groups of factors that are related to such participation (i.e., psychological, social, demographic and macro factors) and explained the inter-connections that can exist between these factors. This chapter has also sought to emphasise the complexity of youth civic and political engagement: young people's civic and political concerns are very much tied to their everyday lives and to their own specific social situation and context as defined by the intersection of their country, ethnicity, gender and age, and the 
different forms of participation which they adopt can be influenced by different constellations of factors.

Chapter 2, which follows, examines the role of psychological factors in greater detail. Chapter 3 focuses instead on social and demographic factors, while Chapter 4 explores the role of macro factors. Chapter 5 offers an integrated theoretical synthesis of the material that has been covered in Chapters 2, 3 and 4 . Chapter 5 also discusses the various actions that can be taken by different actors to enhance and promote youth engagement. In addition, this final chapter describes a major policy initiative that is currently under way in Europe that is aimed at enhancing young people's levels of democratic engagement and participation through the harnessing of state education systems. 


\section{2}

\section{PSYCHOLOGICAL FACTORS LINKED TO YOUTH CIVIC AND POLITICAL ENGAGEMENT}

As noted in the previous chapter, many psychological factors are related to young people's civic and political engagement. These psychological factors are often better predictors of different types of civic and political activity than either social or demographic factors (Barrett \& Zani, 2015b; Fife-Schaw \& Breakwell, 1990). They have also been found to mediate the relationship between macro, demographic and social factors and civic and political activity (Barrett, 2015; BruntonSmith, 2011; Brunton-Smith \& Barrett, 2014; Cohen, Vigoda \& Samorly, 2001; Nie, Verba \& Kim, 1974).

The present chapter reviews these psychological factors in detail. The specific factors that will be examined are the following: political knowledge; political attentiveness; political interest; political efficacy; the perceived effectiveness of participatory actions; personal, social and collective identities; trust; values; and emotions. We begin with political knowledge.

\section{Political knowledge}

There are several different types of political knowledge that can be distinguished. First, there is knowledge of the characteristics of political regimes and the processes related to their functioning. Western societies, where most of the research in this field has been conducted, are typically governed through democratic regimes, and for this reason most studies have examined young people's knowledge of democracy, elections, government, the role of the media, citizenship, rights and responsibilities, freedom, equality, rule of law, etc. Second, there is knowledge of current political incumbents, that is, of the individuals who hold particular political offices, who currently lead political parties or who are influential voices and operators within the political system. Third, there is knowledge of other current political facts, for example, knowing which political party or 
parties are in control of the government or the legislature, the main features of the ideologies or the policies that are advocated by the main political parties, knowledge of political biases in particular media sources, etc.

The importance of political knowledge for both actual and expected future electoral participation has been widely documented in the research literature (e.g., Delli Carpini \& Keeter, 1996; Zukin et al., 2006; Torney-Purta et al., 2001). For example, CIVED (Torney-Purta et al., 2001) examined 14-year-olds' knowledge of the characteristics of democratic systems. The data were collected in 28 countries (see Table 1.2, Chapter 1). A significant correlation was found between knowledge of democracy and expectations of future voting - those students who had the most knowledge were also the most likely to say that they would vote when they became adults, and this knowledge was the single most important predictor of the expectation of voting in the future. However, this link between political knowledge and participation has been most widely demonstrated in relationship to electoral participation, rather than in relationship to other forms of participation. In fact, a more complex pattern emerges when other forms of political and civic participation are taken into account.

For example, in ICCS 2016 (Schulz et al., 2017), data were collected from 14-year-olds in 21 countries (see Table 1.2, Chapter 1). Several measures of expected future political participation were used. First, the students were asked to estimate the likelihood that they would participate electorally in the future (i.e., vote in local elections, vote in national elections, get information about candidates before voting in an election, etc.). Second, they were asked to estimate the likelihood that they would engage in the future in legal forms of political participation in order to express their opinions (e.g., contact an elected representative, take part in a peaceful march or rally, participate in an online campaign). Third, they were asked to estimate the likelihood that they would engage in illegal forms of political participation in the future in order to express their opinions (e.g., spray-paint protest slogans on walls, stage a protest by blocking traffic). Fourth, they were asked to estimate how likely they were to engage at some future date in other forms of active political participation (e.g., join a political party, join a trade union, join an organization committed to a political or social cause). The data were analysed to identify the relationships between all of these forms of future expected participation and political knowledge.

In all countries, students who had higher levels of knowledge about the characteristics of democratic systems were more likely to say that they would participate in elections in the future, replicating the previous finding by TorneyPurta et al. (2001). However, there were few differences associated with levels of knowledge in the students' expectations of participating in legal activities in order to express their opinions: those who had low levels of knowledge were as likely to say that they would engage in such actions in the future as those who had high levels of knowledge. However, when it came to expected participation in illegal activities, in every country, students who had lower levels of political knowledge were more likely to say that they would participate in illegal protest 
activities. Also, and rather curiously, expected active political participation was higher in 12 of the 21 countries among students who had lower levels of political knowledge (there was no significant association between knowledge and expected active political participation in the other nine countries). Thus, when forms of participation other than electoral participation are used, a varied pattern emerges. The most counter-intuitive finding is the negative relationship between political knowledge and expected active political participation in the future. Schulz et al. (2017) speculate that more knowledgeable students may be more likely to consider their commitments carefully and to understand properly the constraints that they might experience in pursuing such engagement in the future.

Of course, having an expectation that one will engage politically in the future may not always translate into actual political action in the future. However, ICCS 2016 also examined the relationship between the students' political knowledge and their willingness to participate in current school activities, such as voting in a school election for a student representative, joining a group of students campaigning for an issue they believed in, participating in discussions in a student assembly and writing articles for a school newspaper or website. It was found that in 13 out of the 21 countries, political knowledge was related to willingness to participate in these school activities, with more knowledgeable students being more willing to participate in these various actions. In another seven countries, knowledge was not related to willingness to participate in school activities, while in one country (Colombia), political knowledge was actually related to being unwilling to participate in school activities (Schulz et al., 2017). The different patterns that arose in different countries are noteworthy, revealing the need to examine the role of psychological factors in conjunction with macro contextual factors.

Overall, it has been found that young people generally have low levels of all forms of political knowledge, including knowledge about system processes, incumbent political representatives, political facts and current issues (Delli Carpini \& Keeter, 1996; Putnam, 2001; Wattenberg, 2007). This lack of political knowledge may be a significant factor that inhibits young people from engaging in civic and political action. Indeed, Pachi, Garbin and Barrett (2011), in a focus group study of 16- to 26-year-old British Bangladeshi, Congolese and English youth that was conducted as part of PIDOP, found that these youth often felt that they did not know enough about political issues to be able to engage in effective action to influence political, civic and social change, and cited this as one of the main reasons why they were civically and politically disengaged.

As far as demographic variations in political knowledge are concerned, there is consistent evidence of a systematic relationship between young people's political knowledge and their SES (Torney-Purta et al., 2001; Schulz et al., 2010, 2017). For example, ICCS 2016 used parental occupation, parental education and the number of books in the family home to measure SES. It was found that, on all three measures, higher SES was consistently associated with higher 
political knowledge scores. This pattern occurred in every country that was studied (Schulz et al., 2017). We will revisit these findings in more detail in Chapter 3, where we discuss the role of SES at greater length.

There are also sometimes differences in political knowledge as a function of gender. For example, in the USA, it has been found that, at the age of 17-18 years, males typically have more knowledge than females, especially knowledge about political parties, elections and protest activities (Niemi \& Junn, 1998; Wolak \& McDevitt, 2011). However, the gender gap in knowledge tends to be relatively small, and there are also some studies that have failed to find a gender difference in political knowledge. For example, CIVED (Torney-Purta et al., 2001) found no statistically significant gender differences in knowledge in 27 of the 28 countries that were studied (although males did exhibit slightly higher levels of knowledge in 11 countries). By contrast, ICCS 2016 found that the females actually had higher levels of political knowledge than the males in 19 of the 21 countries studied (the USA did not participate in this study) (Schulz et al., 2017).

There also tend to be differences in levels of political knowledge as a function of the ethnicity of young people. For example, in the USA, African-American and Hispanic youth perform significantly worse on standardised tests and surveys of political knowledge than White and Asian youth; furthermore, this difference is already present by fourth grade and continues all the way through middle and high school (Levinson, 2010, 2012). Ethnic group differences were confirmed on a larger scale in ICCS 2016, where it was found that, in general, 14-year-olds from non-immigrant families had higher political knowledge scores than those from immigrant families, and students who spoke the language of school instruction at home tended to have higher scores than students who did not speak this language at home (Schulz et al., 2017).

Before leaving the topic of political knowledge, it should be noted that some studies have suggested that knowledge needs to be accompanied by, for example, institutional trust or perceptions of an injustice in order for participation to occur (Bennett, 2007; Hart \& Gullan, 2010; van Zomeren, Postmes \& Spears, 2008). That is to say, simply having knowledge about system processes, incumbent political representatives, political facts or current affairs may not be sufficient in and of itself to mobilise young people to participate - young people may also need to engage in cognitive, emotional or ethical appraisals of political processes, representatives or current affairs in order to be sufficiently motivated to participate, and they may also need to feel that they can be efficacious through the particular forms of action that they undertake (see the discussions below on emotions, values and political efficacy, respectively).

\section{Political attentiveness}

Political attentiveness refers to the extent to which an individual pays attention to sources of political information such as the news and current affairs, documentaries on political events on the radio, television or Internet, political 
debates and discussions, etc. It has been found that political attentiveness tends to be higher in early adulthood than in adolescence (Bennett \& Bennett, 1989; Fernandez-Jesus, Malafaia, Ribeiro \& Menezes, 2015).

Political attentiveness has been treated in the research literature primarily as an antecedent of civic and political participation, and higher levels of political attentiveness are indeed associated with higher levels of participation (Nie et al., 1996; Zukin et al., 2006). However, attentiveness may not influence political participation directly. This is because attentiveness is also related to internal efficacy (see below), which in turn is known to strongly predict levels of participation. In addition, it has been found that, in 14- to 18-year-old American youth, internal efficacy predicts political attentiveness, with attentiveness then predicting both political knowledge and intentions to vote in future elections (Pasek, Feldman, Romer \& Jamieson, 2008). In other words, the patterns of causality involving attentiveness are probably highly complex, involving reciprocal relationships with other psychological variables.

Political attentiveness was examined by ICCS 2016, which included questions asking the 14-year-olds how often they used television and newspapers to obtain information about political and social issues. Overall, 66\% of students watched television at least once a week in order to obtain information about news, whereas only $27 \%$ read newspapers at least once a week; however, these figures mask considerable variation across countries, with the range being $45 \%-80 \%$ for television and 16\%-60\% for newspapers, depending on the country concerned (Schulz et al., 2017). Compared with the findings of the survey conducted in the previous round of ICCS in 2009 (Schulz et al., 2010), in which data were collected from 14-year-olds in 38 countries (see Table 1.2, Chapter 1), these figures represent a decline in the frequency with which young people are attending to political and social issues through the use of traditional media.

It is possible, of course, that young people are turning to new media instead in order to access their news and information about political issues. For this reason, ICCS 2016 also included questions about whether students used the Internet at least once a week for obtaining information about political and social issues, for posting comments or images about a political or social issue and for sharing or commenting on other people's online posts about a political or social issue. It was found that, overall, $31 \%$ of students used the Internet at least once a week to find out information about such issues, only $9 \%$ posted a comment or image about such issues at least once a week and only $10 \%$ shared or commented on another person's online post about such issues at least once a week (but again, there were considerable variations from one country to another) (Schulz et al., 2017).

In other words, despite the declining use of television as a source of information, these 14-year-olds were nevertheless still more likely to use television than social media for obtaining information about political or social issues (66\% vs. $31 \%$ overall). In addition, there was little relationship between the use of social media for obtaining information about political and social issues and levels of political knowledge. That said, there is good evidence that the use of television 
and newspapers is associated with levels of political knowledge in young people (this evidence will be reviewed in Chapter 3, where we discuss the effects of the mass media in more detail). Thus, the idea that social media are now serving as a significant source of information and news for young people does not receive support from the findings of ICCS 2016.

Finally, it is important to note that political attentiveness sometimes has opposite relationships to participation depending on the specific form of participation that is involved. For example, as part of PIDOP, Brunton-Smith (2011) analysed data from the European Social Survey (ESS), which had been collected in 20 countries from youth aged 15-24 years old and from adults aged 25 years and older. He found that, in both age groups, higher attentiveness to political issues was associated with a higher tendency to vote and to participate civically but with a lower tendency to engage in non-conventional political participation. The fact that a single psychological variable such as attentiveness is related in opposite directions to different kinds of participatory behaviour implies that interventions aimed at boosting participation rates by increasing political attentiveness need to consider precisely which behaviours are being targeted, and also need to be mindful that other behaviours may be negatively affected as a consequence of the intervention.

\section{Political interest}

Political interest refers to the interest that an individual has in politics and political issues. Interest has sometimes been conceptualised as the converse of political apathy (Bynner \& Ashford, 1994). There are scales that have been designed to measure political apathy, for example the Political Apathy Scale (e.g., Bennett, 1986), as well as scales to measure political interest more directly (e.g., Barrett \& Zani, 2015b).

It has been consistently found that young people show lower levels of interest in conventional politics than adults, with many considering traditional politics to be 'boring', 'irrelevant' to their lives, ineffective and incomprehensible (Kiesa et al., 2007; Marsh et al., 2007; Zukin et al., 2006). Russo and Stattin (2017) conducted a longitudinal study into changes in levels of political interest among Swedish youth aged between 13 and 28 years old. They found that instability in levels of political interest was most pronounced between 13 to 15 years of age, but that interest became more stable with increasing age, especially from the early twenties onwards.

Political interest tends to be conceptualised as a psychological predisposition, which alongside political knowledge and political attentiveness leads to civic and political participation. And indeed, it has been found that, in both youth and adult populations, the more interest a person shows in political issues, the more likely they are to participate in civic and political activities (see, e.g., Brady et al., 1995; Brunton-Smith, 2011; Schulz, 2005; Schulz et al., 2017). Thus, Emler (2011), for example, proposes that political interest functions as the initial factor 
that leads to political participation. He suggests that interest stimulates political attentiveness, which in turn leads to political knowledge, with knowledge leading to opinionation and to political participation.

However, the causality between interest and participation may sometimes actually run not from interest to participation but in the opposite direction, from participation to interest. Evidence on this issue is reported by Šerek, Machackova and Macek (2017), who conducted a longitudinal analysis of the relationship between young people's interest in politics and their political participation. The data were collected from Czech youth aged 14 to 17 years old. The analyses revealed an effect of participating in protests on political interest (but no effects of volunteering or of engaging with elections or elected representatives on interest). There were also no significant effects in the opposite direction, from political interest to participation.

The links between political interest and both political knowledge and political attentiveness are very close and are probably also bi-directional. Young people who learn about political issues and processes have been found to be more interested in political issues, and similarly young people who are interested in political issues show a preference for resources that allow them to learn more about political issues. Furthermore, it is difficult to isolate factors that promote or hinder one of these three variables without affecting the others simultaneously (Delli Carpini \& Keeter, 1996).

Education is an important factor that has been found to be related to interest in many studies. For example, Emler and Frazer (1999) report that, in the case of British 16- to 19-year-olds, both the level of educational attainment and the amount of post-16 education are related to political interest. Likewise, Cicognani, Zani, Fournier, Gavray and Born (2012) report that, in Italy, 18-yearold students who are on an academic educational track rather than a technical or vocational track have higher levels of political interest. It also seems likely that engaging in political discussions further contributes to young people's political interest. ICCS 2016 found that political interest was strongly and consistently related to the extent to which 14-year-old students discussed political and social issues outside school with parents and with friends; this finding arose in every country that was studied (Schulz et al., 2017). Once again, the causality here is probably bi-directional, with interest leading to discussions and discussions further strengthening interest.

It has also been reported that SES is linked to political interest in at least some populations of youth. For example, Bynner and Ashford (1994) studied British 16to 19-year-old youth. They found that lack of political interest and intention not to vote were associated with low SES, poor educational performance and cynicism about politics. That said, ICCS 2009 only found associations between SES and students' political interest in some rather than all countries, and even in those countries where the association was present, it was relatively small (Schulz et al., 2010).

In the USA, a gender gap in levels of political interest has been reported by Bennett and Bennett (1989), with females typically having less interest in 
politics than males. Dassonneville, Quintelier, Hooghe and Claes (2012) also found a gender gap in favour of males in a study of 16- and 18-year-old Belgian youth. However, other studies have reported the opposite pattern in levels of interest between males and females. For example, Haste and Hogan (2006), in a study of British youth aged between 11 and 21 years old, found high levels of interest towards both social and political issues among females, with the females displaying a higher level of interest in social and environmental issues than males. Similarly, Pachi and Barrett (2012a; Pachi, Garbin \& Barrett, 2011), in their focus group study of British Bangladeshi, Congolese and English 16- to 26-year-olds, found that the females tended to have just as much political interest as the males.

\section{Political efficacy}

Another important construct that has been linked to civic and political participation is political efficacy (Craig, Niemi \& Silver, 1990; Delli Carpini \& Keeter, 1996; Klandermans, 2002a; Schulz, 2005; van Zomeren, Postmes \& Spears, 2008). Three distinct forms of efficacy have been distinguished in the research literature: internal, external and collective efficacy. Each of these forms has different antecedents and different consequences for civic and political participation. Internal political efficacy is the belief that one understands political issues and is able to participate effectively in political situations; external political efficacy is the belief that politicians and political institutions are responsive to citizens' demands; while collective political efficacy is the belief that a collective group to which one belongs is able to have an effect on political situations.

There is a strong and consistent relationship in both adults and youth between political participation and internal efficacy: the higher the level of internal efficacy, the higher the level of both actual participation and future intended participation (Blais, 2010; Brunton-Smith, 2011; Schulz et al., 2010; Schulz et al., 2017; Verba, Schlozman \& Brady, 1995). For example, ICCS 2016 found that, at 14 years of age, internal efficacy was significantly related to both expected electoral participation and expected active political participation (e.g., working on a political campaign or running for office) in all 21 countries that were studied (Schulz et al., 2017).

Similarly, the higher the level of external efficacy, the more likely the individual is to participate in the political processes that are controlled by the actors who are perceived to be responsive to the demands of citizens (Abramson \& Aldrich, 1982; Craig et al., 1990; O’Toole et al., 2003; Pachi and Barrett, 2011a; Rosenstone \& Hanser, 1993). When people do not believe that politicians or policymakers will take people's demands and needs into consideration, then they are less motivated to participate (Soss, 1999). Interestingly, O'Toole (2004), in a study of British youth aged 16 to 25 years, found that these youth differentiated between national and local scale politics. They felt that mainstream national politicians were unresponsive to their needs and that they could not have any 
impact on decision-making at the national level. In contrast, they felt much more efficacious with respect to local political issues, issues which are treated on a smaller scale and which they perceived as having a direct effect on their own lives and their peers' and families' lives.

Collective efficacy in youth has been less extensively studied than either internal or external efficacy. However, collective efficacy has been identified as one of the main predictors of participation in collective action (i.e., organised social or political action carried out by a group of people to try to achieve a shared collective goal - marches, protests and demonstrations are typical examples). In a meta-analysis of 53 studies of collective action, several of which included youth as participants, van Zomeren et al. (2008) found clear evidence that collective efficacy predicts participation in such action. However, collective efficacy may affect participation in collective action indirectly rather than directly. For example, Jugert et al. (2016) found that collective efficacy is related to participation in pro-environmental behaviour among German 18- to 30-year-olds, but this effect is indirect; the perception that the collective group is capable of reaching its collective goals leads to an increased sense of internal efficacy, which in turn then motivates individuals to act on behalf of the group. One context within which the sense of collective efficacy among young individuals has been studied is the school: CIVED (Torney-Purta et al., 2001) examined the extent to which the 14-year-old students felt that, by working together, they could help to solve school problems. It was found that the majority of students had a moderately positive sense of collective efficacy in this context.

As far as the development of efficacy is concerned, Schulz (2005) explored this issue using CIVED data which had been collected not only from 14-year-olds but also from 17- to 18-year-olds (Amadeo, Torney-Purta, Lehmann, Husfeldt \& Nikolova, 2002). He examined differences in both internal and external efficacy between 14-year-olds and 17- to 18-year-olds from 10 countries, and found that levels of internal efficacy increased across this age range, while levels of external political efficacy decreased. In other words, self-confidence in dealing with political issues and taking political action increased, while beliefs about the responsiveness of the political system to citizens' demands decreased. In addition, Schulz found that internal efficacy had a consistently positive relationship to expectations of becoming more actively involved in politics in the future at both ages, whereas external efficacy only had a relatively weak relationship to future expected involvement.

In terms of its relationship to other factors, internal efficacy is strongly related to political interest. This finding was obtained by Schulz (2005) in the analyses of the CIVED data and also by Schulz et al. (2017) in their analyses of the data from ICCS 2016. Indeed, the latter revealed a clear relationship between students' internal efficacy and their interest in political and social issues in all 21 countries that were studied. Exactly the same finding was obtained by BruntonSmith (2011) in his analyses of ESS data in PIDOP. Indeed, he found that internal efficacy and political interest were so highly correlated with one another that 
they effectively formed a single factor that was positively related to levels of participation: among those who had high levels of both internal efficacy and political interest, there were consistently higher levels of all forms of participation (i.e., voting, other forms of conventional political participation, non-conventional participation and civic participation). Furthermore, these same relationships were found to be present in those who were aged between 16 and 24 years as well as in those who were aged 25 years and older.

In addition, the analyses of CIVED data by Schulz (2005) revealed that external efficacy, perhaps not unexpectedly, is related to trust in institutions (government, local council, courts, police, parties and parliament). He also found that internal efficacy is related to political discussions with peers and parents and to the frequency of using media (newspapers, television and radio) for obtaining information about national and international issues.

Once again, there are demographic group differences in levels of efficacy. For example, a link between internal efficacy and SES has been found: youth whose families have a higher income and a higher educational level tend to have higher levels of internal efficacy (Schulz, 2005; Schulz et al., 2017). Youth from higher SES families are more likely to have access to resources such as time, money and opportunities for participation, all of which will enable them to acquire civic and political skills and attitudes such as internal efficacy and political interest that will enable them to participate civically and politically (cf. Brady et al., 1995). SES has also been found to be related to external efficacy, with those who have attained higher educational levels and higher incomes believing more in politicians' and government's responsiveness to people's needs (Flanagan et al., 2003; Soss, 1999; Wu, 2003). In addition, it has been reported that women and girls sometimes feel less efficacious than men and boys (Easton \& Dennis, 1967; Goel \& Milbrath, 1977; Lyons \& Menezes, 2012), although there are also other studies that have not found any gender differences (e.g., Vecchione \& Caprara, 2009; Wu, 2003). We discuss demographic differences in greater detail in Chapter 3.

While it is tempting to conclude that internal and external efficacy are causal factors that impact on participation, the causality that is involved here is almost certainly bi-directional. Quintelier and van Deth (2014) conducted a three-wave longitudinal study in which data were collected from Belgian adolescents when they were aged 16, 18 and 21 years old. They found that there was a reciprocal causal effect between political participation and internal efficacy, but the effects of political participation on internal efficacy were much stronger than the effects of efficacy on participation. These findings are consistent with those of Šerek et al. (2017), whose longitudinal study, which was conducted with Czech youth aged 14 to 17 years old, revealed that participation in protests strengthened both internal and external efficacy (as well as political interest), and that participation in volunteering activities strengthened external efficacy. It therefore seems highly likely that there is a reciprocal causal relationship between internal efficacy and participation. 


\section{Perceived effectiveness of participatory actions}

A further construct that is closely related to external political efficacy is the perceived effectiveness of different participatory actions. Despite the significance of this construct, it has not received much attention to date, apart from a few studies that have been conducted with adult populations (e.g., Klandermans, 1984; Simon et al., 1998). In these studies, perceived effectiveness has been linked to people's cost-benefit calculations when they make decisions about which forms of action to take.

Notice that the perceived effectiveness of particular actions is distinct from external efficacy (i.e., the extent to which one believes that politicians and political institutions are responsive to citizens' demands). For example, one can feel that government is generally not responsive to citizens' demands (i.e., have a low sense of external efficacy), but in attempting to persuade a government about one's case, the judgement might still be made that, say, participating in a militant action (e.g., a mass protest on the streets) is more likely to be effective than participating in a moderate action (e.g., signing an e-petition).

Young people's perceptions of the effectiveness of different forms of conventional, non-conventional and civic participation were examined by Pachi and Barrett (2012a) as part of PIDOP. The data were collected from 16- to 26-year-old British Bangladeshi, Congolese and English youth living in London using focus groups. The findings revealed differences in judgements about the effectiveness of action across ethnic groups, genders and ages. As far as ethnic group differences were concerned, English majority young people believed more in the effectiveness of conventional forms of participation (such as voting) than ethnic minority young people. However, gender differences were also apparent; for example, the effectiveness of actions based on membership of a religious organisation was more salient among the female participants. In addition, age differences were present: older participants, in contrast to younger participants, gave greater emphasis to the effectiveness of participation through charities, which was seen as effective for ensuring the distribution of benefits to those who are most in need and for helping disadvantaged groups in society, as well as being important for personal development and enrichment. Differences based on the intersection between ethnicity, gender and age were also apparent. For example, as far as non-conventional forms of participation, such as spraying graffiti and joining demonstrations were concerned, these were largely rejected by the females who were below voting age and by the ethnic minority males who were above voting age, who argued that these actions were ineffective due to the fact that they involved breaking the law; thus, the perceived legality or illegality of actions was a particularly salient consideration for these particular subgroups of participants. More generally, personal experience of different forms of participatory action, perceptions of the effectiveness of different organisations, the personal need for expression and perceptions of discrimination were all widespread justifications that were given by these young people for their evaluations of the effectiveness or ineffectiveness of the various forms of action that were discussed. 


\section{Identities}

Youth is a critical period in human development for exploring and developing identities and for thinking about one's own position and possible future roles within society (Erikson, 1963, 1968; Kroger, 2004, 2007). A central aspect of identity development during this period is reflecting on and considering one's role as a citizen within the wider social, civic and political communities in which one lives. The identity commitments that are made (or not made) can have important implications for civic and political behaviour.

There are many different types of identities that may be explored during youth. Some are based on personal attributes (e.g. studious, fun-loving), some on interpersonal relationships and roles (e.g. daughter, friend, student) and some on autobiographical narratives (e.g., born in London to middle class parents, educated at a state school) (Stryker, 1980; Deaux, 1992, 1996). Other identities may be based on membership of social groups (such as a nation, an ethnic group, a religious group, a gender group, a neighbourhood, or a school). When membership of a particular social group forms a salient part of one's self-concept, so that emotional significance and value is attributed to that group membership, then the person is said to have acquired a social identity (Tajfel, 1978). Furthermore, in cases where a number of people share the same social identity, feel solidarity with one another and take action together to pursue the goals of the group, they may be said to have acquired a collective identity (Klandermans, 1997). These multiple identifications with different attributes, relationships, roles, narratives and social groups help individuals to define, position and orientate themselves relative to other people, and can have significant consequences for individuals' civic and political behaviour.

Numerous researchers have built on Erikson's (1963, 1968) account of identity development during adolescence, with the most well-known body of work being that conducted by Marcia (1966; Marcia, Waterman, Matteson, Archer \& Orlofsky, 1993). However, a more recent account, namely the three-factor identity model, has been used explicitly to explore the relationship between identity development and civic and political participation. The three-factor model proposes that identity development during adolescence involves an interplay between three key processes: identity commitment (which refers to the firm identity choices that have been made), identity exploration (which refers to the extent to which current identity commitments have been reflected upon and examined by searching for information and speaking to others about those identities) and reconsideration of commitment (which refers to the comparison of present identity commitments with alternative possible commitments when existing commitments are judged to be unsatisfactory) (Crocetti, Rubini \& Meeus, 2008; Meeus, 1996; Meeus, Iedema, Helsen \& Vollebergh, 1999; and Meeus, van de Schoot, Keijsers, Schwartz \& Branje, 2010).

From the interplay between these processes, specific identity statuses emerge. Specifically, youth who have an achievement status are those who have strong 
identity commitments that have been explored deeply and are not being reconsidered. Youth who have an early closure status have moderate identity commitments that have been neither explored nor reconsidered properly. Youth who have a moratorium status have low commitments to identities and are reconsidering these commitments in search of more satisfying alternatives that have a better fit to their needs and aspirations. Finally, youth who have a diffusion status have low commitments, have engaged in little identity exploration and are not reconsidering their commitments (Crocetti, Schwartz, Fermani, Klimstra \& Meeus, 2012; Meeus et al., 2010).

Interestingly, links have been found between these various identity statuses and patterns of civic engagement. Crocetti, Jahromi and Meeus (2012) conducted a study with Italian high school students aged between 14 and 20 years old. It was found that those youth who had an achieved identity status were more involved in volunteer activities, reported higher levels of efficacy and had stronger aspirations to contribute to their communities than those who had a diffused status. In addition, a link was found between identity processes (i.e., commitment and exploration) and past and future volunteer activities, with the relationship between identity and future volunteering and future political participation being mediated by these young people's sense of civic duty.

Different identity styles have also been found to have consequences for patterns of participation. A distinction may be drawn between youth who have an information-oriented style (who actively seek out and evaluate identity-relevant information), those who have a normative style (who readily adopt the prescriptions and expectations of others) and those who have a diffuse-avoidant style (who delay the identity formation task for as long as possible) (Berzonsky, 2011). Crocetti, Erentaitè and Žukauskienè (2014) used these distinctions in a study of 14- to 19-year-old youth in Lithuania and found that youth who had an information-oriented style were more likely to participate in volunteering activities than those who had a normative or diffuse-avoidant style. Collecting a second set of data from the same youth one year later, Crocetti, Garckija, Gabrialaviciute, Vosylis and Žukauskienè (2014) further found that identity style was relatively stable over time, with the effects of identity style on civic behaviour being stronger than the effects of civic behaviour on identity style. That said, higher levels of participation in civic activities at the earlier point in time did reduce the tendency of those adolescents who originally had a diffuse-avoidant style to persist in the avoidance of identity issues.

Collective identities are particularly important in relationship to civic and political participation, because they can act as strong motivators to undertake collective action on behalf of the group. They help young people to articulate common grievances and common goals, which can politicise them and lead them to act together to change the prevailing situation (Klandermans, 2014, 2015; Simon, 2011; Simon \& Klandermans, 2001; van Zomeren et al., 2008). Martínez, Peńaloza and Valenzuela (2012) provide a good example in a study of Chilean youth who were aged 16 to 24 years old. These youth identified 
with social and political causes and integrated them into their own identities. Their sustained social action was related to their identification with the goals of the collective group organisations to which they belonged, and their accounts conveyed a collective sense of 'we' that was developed through working toward shared goals with the other members of these organisations.

Ethnic identity, in particular, can function as a powerful collective identity for young people who belong to ethnic minority groups and can motivate their civic and political participation. For example, in the USA, Jensen (2008) interviewed second generation immigrant youth aged between 14 and 18 years old, nearly all of whom regarded political and civic engagement as important. Some were highly active participants, especially at the community level. One-third were engaged in community activities that specifically had a cultural focus or occurred through cultural organisations, and their motivations were based on their ethnic or immigrant identities. In another study, Lyons, Chrysanthaki, Verkuyten, Selivanov and Pavlenko (2008) collected data from 15- to 18-year-old ethnic minority youth in England, the Netherlands, Greece, Spain, Russia, Azerbaijan, Ukraine and Georgia, focusing in particular on their use of the Internet in support of minority rights. It was found that there was a strong positive relationship between levels of ethnic identification and the likelihood of using the Internet in support of these rights. Likewise, van Bergen, Feddes, Doosje and Pels (2015), in a study of 14- to 18-year-old Muslim Dutch youth, found that their connectedness to their ethnic group (defined as their emotional attachment to and understanding of the culture of that group) predicted their willingness to use violence to defend their ethnic group. All of these findings are consistent with the notion that a minority ethnic identity, if transformed into a politicised collective identity, can be a powerful motivator of civic and political action for minority youth (Pachi, Chrysanthaki \& Barrett, 2014).

However, as we have noted already, young people are in the process of developing not just a single but multiple identities during adolescence. Much of the research literature in this field addresses single identities and ignores their intersections. In real life, people's beliefs, emotions and behaviours are usually the product of a complex system of multiple identities, which sometimes interact in a complementary way and sometimes in a conflicting way. For example, Chryssochoou and Lyons (2011) found that a perceived incompatibility between national and ethnic/religious identities was negatively related to levels of political participation among 15- to 18-year-old Muslim youth in Spain and the Netherlands.

Another collective identity that can be important for young people is their identification with their school. The school is a space of common experiences for students, and this can reinforce their identification both with the group's space and with its members. It has been found with American 11- to 17-year-olds that the sense of solidarity with classmates predicts the motivation to act on behalf of the common good by protecting both the school space and other school members (Flanagan, Stoppa, Syvertsen \& Stout, 2010). Thus, when young people are 
given the opportunity to identify with a collective community, they can develop a sense of emotional belonging, trust and solidarity with that community, which in turn can lead them into active engagement (Kassimir \& Flanagan, 2010).

Finally, it should be noted that most research examining the relationship between identities and civic and political participation has tended to regard identification as an antecedent of participation. The study by Crocetti et al. (2014), which was discussed above, is an exception in this regard. There is, in fact, very good evidence that, in adults, collective action itself can strengthen collective identities in particular (Klandermans, 1997, 2002; Reicher \& Drury, 2010). It seems highly likely that the same phenomenon occurs in youth as well, with the causal relationship between collective identification and participation in collective action being reciprocal.

\section{Trust}

Trust has been conceptualised at an interpersonal, social, political and institutional level (Citrin \& Muste, 1999; Newton, 2001, 2013; Weatherford, 1987). To trust someone or something is to believe that they are honest, well-intentioned, will not knowingly or willingly do you harm and at best will act in your interests. Interpersonal trust is the belief that another specific individual is trustworthy; social trust is more generalised, and is the belief that most other people in broader society are trustworthy; political trust is the belief that political actors and institutions ranging from politicians to the incumbent government to the political regime of a country are trustworthy; and institutional trust is the belief that societal institutions such as the police, courts, media, educational institutions, banks, companies, etc., are trustworthy.

CIVED (Torney-Purta et al., 2001) measured 14-year-olds' trust in national government, national parliament, political parties, local government, courts, the police, news on television, news on the radio, news in newspapers, the United Nations, school and the people who live within the respondent's own country. ICCS 2009 (Schulz et al., 2010) used a similar set of items to those used in CIVED, while ICCS 2016 measured trust using the same set of items as ICCS 2009 , together with an additional item that measured trust in social media (Schulz et al., 2017). These three studies between them revealed that, in general, 14-year-olds tend to express the lowest levels of trust in political parties and the highest levels of trust in courts of justice. However, in countries which have high scores on indices of corruption and low scores on indices of government efficiency, more politically knowledgeable students tend to have less trust in institutions; by contrast, in countries which have low scores on indices of corruption, more politically knowledgeable students tend to have higher levels of trust in institutions (Lauglo, 2013; Schulz et al., 2017). ICCS 2016 also revealed changes in students' levels of trust between 2009 and 2016: in many countries, the ICCS 2016 students had higher levels of trust than their 2009 counterparts in government, parliament and courts of justice; however, they expressed lower 
levels of trust in media and people in general. As far as trust in social media is concerned, ICCS 2016 found that social media were trusted less than traditional media (television, newspapers and radio). This could be the reason why students are more likely to use television rather than social media for obtaining information about political and social issues (cf. the discussion above in the section on political attentiveness).

Torney-Purta, Barber and Richardson (2004) also used the CIVED data to examine the relationship between trust in institutions and civic and political participation in six of the countries in which data had been collected from 14-yearolds. They found a relationship between institutional trust and expected future voting, volunteering, joining a political party and writing letters to a newspaper about social or political concerns. In addition, they found that institutional trust itself is sometimes predicted by reading articles in newspapers about current affairs (an index of political attentiveness). However, the relationship between trust and participation was fairly modest in magnitude, and other psychological factors (e.g., political knowledge) were much more powerful predictors of expected future civic and political participation.

However, the relationship between institutional trust and different forms of participation might not only be modest in strength. This relationship might actually vary in its direction depending on the particular form of participation involved. Evidence suggesting that this is the case is reported by Brunton-Smith (2011) in his analyses of data from the ESS, which were collected in 20 countries from youth aged 15-24 years old and from adults aged 25 years and older. He found that, in both age groups, institutional trust did indeed have different relationships with different forms of participation. For example, individuals with higher levels of institutional trust were more likely to vote, but they were less likely to participate in non-conventional political activities such as participating in public demonstrations and signing petitions. This finding does make intuitive sense, insofar as people who have high levels of institutional trust might not feel the need to take any action outside conventional channels because of their high level of trust in their elected representatives (cf. Amnå \& Ekman's, 2014, 2015, concept of the standby citizen discussed in Chapter 1).

Finally, as far as social trust is concerned, Kelly (2009) explored the link between social trust and participation in American youth aged between 15 and 25 years old. She found that both ethnic majority and ethnic minority youths who had high levels of social trust were more likely to have performed voluntary service in the community within the 12 months prior to the study and were more likely to value the practice of voting than those who had low levels of social trust. In addition, ethnic minority youths who had high levels of social trust were more likely to say that they would engage in political volunteering; this relationship was not present in the majority youth. However, the causality here is ambiguous. It could be the case that high levels of social trust motivate individuals into voluntary service and valuing voting. Alternatively, it could be the case that when young people engage in strengthening their communities through 
voluntary service and through voting, social trust is enhanced. Longitudinal data are really required to determine the direction of the causality that operates between trust (of all kinds) and participation. Unfortunately, such data from youth do not currently exist on this issue.

\section{Values}

Values are another set of psychological factors that can motivate civic and political participation. Values are general beliefs that individuals hold about the desirable goals that should be striven for in life (Schwartz, 2006, 2013). They motivate people's actions and serve as broad guiding principles for deciding how to act. They also provide standards or criteria for evaluating actions, people and events. Values transcend specific situations, and as such they are much broader than attitudes (which instead are usually focused on specific actions, objects or events). In addition, and importantly, values have a normative-prescriptive quality about what ought to be done or thought across many different contexts. They therefore differ from attitudes in this respect as well, because attitudes do not carry the same kind of prescriptive quality.

In an audit of the literature on the psychological factors related to young people's democratic competence, Barrett (2016) examined 101 conceptual schemes that purport to describe these factors. Examining the values contained in these schemes, he found that they commonly contained the valuing of justice, fairness, equality, democracy and the rule of law as components of democratic competence.

In fact, research indicates that valuing justice can be a particularly powerful value for motivating civic and political participation. This is because a social justice orientation can readily generate a deep sense of injustice when violations of just and fair principles are perceived, which in turn can lead to anger. This set of psychological conditions has been identified in many different national contexts as one of the primary motivations behind collective action among both adults and youth (van Zomeren et al., 2004, 2008). We return to the role of anger below, when we discuss emotions.

However, it is not only collective action that may be motivated by justice considerations. Neufeind, Jiranek and Wehner (2014) studied the role of justice considerations in volunteering, conventional political participation and participating in collective protests among a group of Swiss youth who had a mean age of 23 years. They found that these young people's beliefs about justice predicted the extent of their volunteering as well as their political participation. Likewise, Luengo Kanacri, Rosa and Di Giunta (2012) studied the role of benevolence (i.e., valuing the welfare of those with whom one is in frequent personal contact) and universalism (i.e., valuing the appreciation, tolerance and protection of the welfare of all people) among 19- to 29-year-old Italian youth. It was found that these two values were related to one another and that benevolence (but not universalism) directly predicted membership of civic associations (e.g., associations 
for the protection of human rights, trade unions, volunteer social service associations). By contrast, valuing power (i.e., valuing social status and control or dominance over other people and resources) predicted membership of political associations.

Flanagan, Gallay, Gill, Gallay and Nti (2005) examined the values held by 12- to 19-year-old American youth. They explored these youths' definitions of democracy, the values they endorsed and whether the aspects of democracy that they found personally meaningful were concordant with their families' values. It was found that those who were older, came from better educated families, discussed current events at home and participated in extracurricular activities in school or in the community were more likely to define democracy correctly. The meanings that these young people ascribed to democracy were freedom, individual rights, civic equality, popular sovereignty and representative government. Social vigilance (i.e., wariness of other people who might take advantage and get an upper hand) and materialism were more prominent values for those youth whose families' views of democracy emphasised individual rights. By contrast, responsibility for the environment and for people in need were the values reported by youth whose families emphasised equality. Youth from more educated families were more likely to endorse social and environmental responsibility and were less likely to endorse materialist values and social vigilance.

In a study of British youth aged between 11 and 21 years, Haste and Hogan (2006) examined the issues that were of concern to them and the values that they held. It was found that there were three different sets of issues that concerned these young people: quality of life and social order (e.g., facilities for young people, health care, opportunities for women and controlling crime); perceived threats to national or cultural sovereignty (e.g., the effects of other countries on British politics and immigration control); and environmental issues and animal experimentation. Haste and Hogan report that these patterns were linked to three different moral orientations: an ethic of care, community and responsibility; an ethic of protecting the state and formal institutional action; and an ethic based on single issues and social activism. The first and third value orientations were more likely to be adopted by females, while the second orientation was more likely to be adopted by males.

Additional evidence about the role of values in young people's political and civic participation comes from a study of American 17- to 18-year-old students conducted by Malin, Ballard and Damon (2015). They found that, among those who were politically or civically engaged, concern about civic and political issues was usually accompanied by strongly held values, including concerns about injustice, the need to help others and the importance of the family. Distinguishing between traditional political activity (e.g., discussing political issues, attending demonstrations), expressive activity (e.g., expressing political opinions, contacting elected representatives) and community service (e.g., volunteering in the community, fundraising), Malin et al. found that community service had the most purposeful and involved participants, with these particular individuals 
having the most sustained and strongest intentions to contribute to the world beyond the self.

An alternative perspective on the role of values is provided by young people's conceptions of what is meant by 'good' citizenship. Dalton (2008), in a study of American youth and adults, found that two broad dimensions characterised their views of what constitutes good citizenship. One dimension valued citizen duty: voting in elections, never evading taxes, serving in the military, obeying the law, reporting crime and serving on a jury. The other dimension instead valued citizen engagement: helping those who are worse off than oneself, both in one's own country and in the world, choosing products for political, ethical or environmental reasons, understanding others, being active in voluntary groups and associations, being active in politics and forming one's own opinions. The former is focused on allegiance to the state and the existing political order, whereas the latter is focused more on the moral and empathetic aspects of citizenship.

Breaking the results down by generation, Dalton found that adherence to citizen duty values was highest amongst the elderly and lowest amongst youth, whereas adherence to citizen engagement values showed the opposite pattern, being highest amongst youth and lowest amongst the elderly. Dalton further found that these two different value orientations predicted individuals' tolerance for others, support for civil liberties, support for minority rights and priorities for government spending. The orientations also predicted the forms of political and civic activity that were undertaken by individuals: those who adhered to citizen duty values were more likely to vote, whereas those who adhered to citizen engagement values were more likely to participate in demonstrations and consumer activism. Note that these findings echo those discussed in Chapter 1 on the shift among young people away from conventional political participation towards non-conventional political participation and civic participation - Dalton's findings imply that this shift is a consequence of a difference in the values that are held by young people vs. older individuals.

Dalton's conclusions, which were drawn from American data, were examined more broadly by Hooghe, Oser and Marien (2016) using the ICCS 2009 data that had been collected from 14-year-olds in 38 countries. Hooghe et al. found that they could also identify groups of individuals who adhered either to engaged citizenship values or to duty-based values. Those who adhered to engaged citizenship values (about 25\% of the sample) attributed importance to protecting the environment, protecting human rights and helping others in the local community, and downplayed the importance of voting and joining a political party; those who adhered to duty-based values (about $20 \%$ of the sample) displayed the converse pattern. However, together, these two groups only accounted for $45 \%$ of the 14 -year-olds, with the other $55 \%$ not fitting into Dalton's binary typology. These individuals instead showed one of three further profiles. A small group (about 6\%) did not attribute importance to any of the citizenship behaviours examined and simply regarded themselves as subjects who should obey government and authorities rather than actively participate. A larger group (about 18\%) 
was characterised by attributing importance to many citizen behaviours but not to discussing politics or to joining a political party. The largest group (about $32 \%)$ viewed all citizen behaviours as being important. The differences between Dalton's and Hooghe et al.'s findings may well be due to the fact that the former were derived from older individuals, with the patterns displayed by the 14-yearolds being more characteristic of younger individuals whose citizenship values are still in the process of developing.

\section{Emotions}

Interest in the role of emotions in civic and political engagement has grown in recent years. A wide range of emotions has now been studied in adults, either as motivators of political and civic action, as factors that emerge during the course of action, or as consequences of action (Capelos, 2013; Capelos \& Exadaktylos, 2015, 2017; Goodwin, Jasper \& Polletta, 2004). For example, Omoto and Snyder (1995) found that the duration of voluntary service in the health field is predicted by emotions such as feeling a humanitarian obligation to help others, enjoyment in helping others, a feeling of community concern, and also by the personal satisfaction that is derived from engaging in voluntary service. Likewise, Jasper (1998) argues that emotions play an important role in collective protest. He notes that individuals can initially experience emotions that motivate them to join protest groups, and that other emotions are then formed or reinforced during the course of collective action itself. These emotions may be transitory context-specific emotions, usually reactions to information and events, or they may be more stable affective bonds and loyalties between members of the protest group. Negative emotions such as anger have also been found to play a significant role in motivating collective action (Leach, Iyer \& Pedersen, 2006; Smith, Cronin \& Kessler, 2008; van Zomeren et al., 2004). However, other emotions such as fear may co-exist with action-motivating emotions and suppress the role of those emotions and inhibit action-taking (Miller, Cronin, Garcia \& Branscombe, 2009).

Most of the roles that emotions can play in the civic and political participation of adults have not yet been extensively studied in youth. However, it is known that 10-year-olds in both Canada and Taiwan are more likely to engage in environmental actions if they feel fear, anger and concern about current environmental issues (Huang \& Yore, 2005). Youth volunteering has also been found to be linked to emotions: Bringle (2015) found that, in American college students, empathic anger (i.e., feeling angry about injustice or inequity to other people who are not family or friends) is associated both with a social justice orientation to community involvement and with levels of charitable activity (i.e., helping those in need) and advocacy (i.e., working to change public policy for the benefit of other people). Finally, van Zomeren et al. (2004) found that group-based anger is a strong predictor of the willingness to participate in collective protests about an injustice, a result that was obtained in three separate studies conducted with 20-year-old Dutch university students. 
In general, females tend to score higher than males on altruism, empathy and social responsibility (Wilson, 2000). Young females, in particular, appear to understand that they are usually viewed as being more compassionate than men (Gordon \& Taft, 2011); however, they themselves do not always accept this attribute. Taft (2010) found that they tend not to hold these gender stereotyped attributes in great esteem, partly because compassion has been associated with other attributes such as being 'dreamy' and 'hopeful' as part of a superficial female identity. Anger, on the other hand, is more commonly associated with males and is often regarded as being a socially unacceptable emotion for females (Brown, 1999).

Further feelings that have been examined in relationship to patterns of civic and political engagement are those that young people have towards their own nation. CIVED (Amadeo et al., 2002; Torney-Purta et al., 2001) found that most youth have positive feelings towards their nation at both 14 years of age and 17-18 years of age. A more fine-grained analysis of the data from the 14-year-olds from five Western European and five Eastern European countries by Torney-Purta (2009) revealed that these students could be grouped into five distinct clusters based on their feelings and attitudes across a range of issues: a conventional-political cluster of individuals who had positive feelings towards their nation, believed that governments had social responsibilities and believed that adults should be active in both conventional politics and civic activities; a social justice cluster who believed in rights for everyone but did not feel obliged to do anything about them beyond voting; an indifferent cluster who did not think much about being active in politics at all; a disaffected cluster who were similar to the indifferent cluster but felt more negatively about the rights of others and about being involved in the community; and an alienated cluster who did not believe in norms of citizen participation, were alienated from politics and did not believe in the rights of others. It was noticeable that positive feelings towards the nation were associated with valuing conventional politics and civic activities in both Western and Eastern European countries.

Finally, a wide range of negative emotions and their links to civic and political participation were examined by Pachi and Barrett (2012b) in their analysis of survey data collected from 16- to 26-year-old British Bangladeshi, Congolese and English youth as part of PIDOP. They looked in particular at negative emotions (e.g., anger, frustration, worry, shame) that were based on beliefs about specific issues (e.g., discrimination, environmental issues). They found differences in these emotions according to the demographic characteristics of the individuals, as well as differences in the relationships between these emotions and various forms of participation. Females appeared to have more pronounced negative emotions about both environmental issues and discrimination than males, while the older youth had more pronounced negative emotions than the younger youth about discrimination. However, negative emotions about environmental issues predicted volunteering only among the Bangladeshi youth, while negative emotions predicted expected future illegal non-conventional participation (e.g., 
spraying graffiti) and lower levels of voting only among the Congolese youth. In the case of the English youth, their negative emotions were linked to a lower likelihood of using the Internet for political and civic purposes. In other words, different patterns of relationships between emotions and participation emerged in the three ethnic groups.

The implication is that it is important to examine emotions in relationship to specific issues in specific ethnic groups. We are therefore reminded once again that the psychological factors related to civic and political participation are often specific to specific subgroups of youth living within specific sociocultural and societal contexts. Young people's civic and political concerns and interests, and the ways in which they respond to these, clearly vary considerably across both demographic groupings and settings. Findings of studies therefore need to be interpreted cautiously, without overgeneralising conclusions beyond the evidence base that is actually available.

\section{Conclusions}

This chapter has reviewed a large number of psychological factors that are related to young people's civic and political engagement. These factors include: political knowledge; political attentiveness; political interest; internal, external and collective efficacy; the perceived effectiveness of participatory actions; personal, social and collective identities; social, political and institutional trust; values; beliefs about good citizenship; and emotions. As we have seen, in some cases there is evidence that these factors influence young people's patterns of civic and political engagement. However, as we have also seen, civic or political participation itself can also sometimes have a causal effect on these psychological factors, strengthening or weakening them depending on the factor and the form of participation involved.

This review of psychological factors has revealed a number of unresolved issues that will need to be addressed by future research. First, we have seen that the relationship between psychological factors and participation can vary from one country to another (e.g., the ICCS 2016 finding that, within different countries, political knowledge relates differently to participation in civic activities within the school and to future expected political participation). It is unclear why different relationships between psychological factors and participation should arise in different countries. For example, this might be due to different parental or teacher attitudes to youth participation in different countries, different political and policy discourses concerning youth participation in different countries, different meanings that are attributed by youth to the various forms of participation in different countries, etc. The sources of this cross-national variability clearly require further research.

Likewise, we still do not properly understand the variability in psychological factors that is associated with demographic characteristics such as SES, gender, ethnicity and age. It is one thing to identify the existence of these demographic 
differences and it is another to explain them. It may well be the case that the variability stems from the different experiences that individuals belonging to different demographic subgroups have encountered in the family, in the peer group or in the school. We need to understand why these differences occur (and in some cases, why they occur in some countries but not in others). Future research will also need to be sensitive to the possibility that differences occur between different subgroups that are defined not in terms of a single demographic characteristic (such as SES or gender) on its own, but in terms of the intersection between nation, ethnicity, gender, age, SES and locale. We will return to some of these issues concerning demographic factors in the following chapter.

There has also been very little research to date into young people's understanding of legality and the rule of law in the context of civic and political engagement. As we have seen, the distinction between legal and illegal forms of action can have consequences for some young people's willingness to engage in certain kinds of actions, but precisely how their understanding of the law relates to their participatory behaviours is poorly understood at the present time.

Other under-investigated issues include how young people perceive the power relationships that exist between the various actors who operate at different levels of the political hierarchy, and how they perceive their own relationships to these actors. Their perceptions of adult norms concerning active citizenship, and their views regarding obedience to these norms, have also not yet been widely investigated. Further research is also required into the way in which young people's multiple identities interact with each other to drive their civic and political behaviours.

Finally, a large cluster of unresolved issues arises in connection with the causality that operates in this domain. As we have seen, there are sometimes reciprocal relationships between civic and political participation on the one hand and psychological factors such as internal efficacy, political interest and identity style on the other. This raises the broader question of the causality that operates between all of the psychological factors and civic and political participation. Further research is required to unpack the complex patterns of causal relationships that no doubt exist between the various psychological factors themselves and between the psychological factors and participatory behaviours. Furthermore, this research will once again need to be sensitive to the possibility that these causal relationships differ in different demographic subgroups as defined through the intersection between nation, ethnicity, gender, age, SES and locale. Such research will need to use longitudinal designs to follow the development of not only psychological factors but also civic and political behaviours through adolescence and early adulthood, as it is only longitudinal research that can produce a proper understanding of the causality that operates in this domain.

In the next chapter, we will add further complexity to this analysis by reviewing what is known about the relationship between young people's civic and political engagement and social and demographic factors. 


\section{SOCIAL AND DEMOGRAPHIC FACTORS LINKED TO YOUTH CIVIC AND POLITICAL ENGAGEMENT}

This chapter focuses on the social and demographic factors that are linked to young people's civic and political engagement. The chapter begins by discussing the social factors that are the closest to the developing individual, including both the family and the peer group, then moves outwards towards intermediate level social factors such as the neighbourhood, the school and youth organisations, before discussing the most distal social factors such as popular music and the mass media. The chapter concludes by discussing the demographic factors of SES, gender and ethnic status.

\section{Social factors}

\section{The family}

The context that is provided by family life is linked in numerous ways to young people's civic and political engagement. Parental political interest, political knowledge, partisanship and civic and political practices, as well as family values and climate, have all been found to be related to young people's civic and political engagement and participation.

Starting with the links to parental political interest, the findings are consistent. For example, ICCS 2009 (Schulz et al., 2010; see Table 1.2 for a list of the 38 countries studied) found that 14 -year-olds whose parents were interested in political and social issues had higher levels of political knowledge, as well as higher levels of political interest, in every country that was studied, compared to youth whose parents were not interested in such issues.

In addition, both parental political knowledge and parental political practices have been found to be important. For example, Jennings $(1996,2002)$ conducted a longitudinal three-wave national survey of American youth who were aged 
17-18 years old at the first point of data collection in 1965, when data were also collected from the youths' parents; subsequent waves of data collection from both the youth and their parents took place in 1973 and 1982. The study revealed that parents' political knowledge predicted their offspring's political knowledge, even into the latter's midlife (Jennings, 1996); parents' engagement in protests predicted their offspring's engagement in protests (Jennings, 2002); and the best predictor of young people's political partisanship was the political partisanship of their parents (Jennings \& Niemi, 1968; Niemi \& Jennings, 1991).

General family values are also related to the development of civic and political attitudes. Flanagan, Bowes, Jonsson, Csapo and Sheblanova (1998) collected data from 12- to 18-year-old youth in seven countries (Australia, Bulgaria, Czech Republic, Hungary, Russia, Sweden and the USA) and found that there was a consistent relationship between a family ethic of social responsibility (i.e., an ethic emphasising the need to be attentive to others, especially to less fortunate members of society) and the youths' civic and political commitment in all seven countries: those youths from families in which this ethic was maintained were the most likely to view helping their country and doing something to improve society as important life goals for themselves.

In terms of parental practices, ICCS 2009 (Schulz et al., 2010) found that students whose parents frequently discussed political and social issues with them had higher levels of political interest in political and social issues as well as higher levels of political knowledge. The link with youth interest in political and social issues was found in all 38 countries that were studied (see Table 1.2, Chapter 1), while the link with youth political knowledge was found in all but two countries (the Dominican Republic and Guatemala being the exceptions).

Parental practices were also examined in a study of 15- to 25-year-old American youth conducted by Andolina, Jenkins, Zukin and Keeter (2003; Zukin et al., 2006). They found that among youth who are eligible to vote, those who have grown up in families in which there are regular political discussions are more likely to vote compared to those who have grown up in families in which there are no political discussions. Andolina et al. also found that: youth who often hear family political discussions when growing up are more likely to volunteer compared to those who have not heard such discussions; those who grow up in families in which one or both parents volunteer are more likely to volunteer themselves, to join community groups and associations and to wear political buttons or display political bumper stickers; and those who have engaged role models in their families have higher levels of political attentiveness and are more likely to participate in consumer activism.

An alternative perspective on the role of parents is provided by adolescent political alienation. Political alienation involves feelings of political meaninglessness and political powerlessness and the perception that political decisions are unpredictable and cannot be influenced by citizens. In a study of German youth aged 12 to 16 years old, Gniewosz, Noack and Buhl (2009) found that the more politically alienated these youths' parents were, the more alienated the youths 
themselves were. They also discovered that the use of an authoritarian parenting style (i.e., a controlling, demanding and threatening style based on the assertion of parental power, with little expression of praise or pleasure in the young person's achievements) was also associated with young people's political alienation.

Family climate has also been linked to young people's development of political knowledge, interest and internal efficacy. Family climate can be operationalised as the degree of cohesion and expressivity between family members, the level of organisation and control of family activities, and the cultural or intellectual orientation that is adopted towards family activities. Using this concept, Azevedo and Menezes (2007) collected data from 14- to 23-year-old youth in Portugal. Their findings revealed the importance of gender, rule-following and family activities and routines. Among girls, an emphasis on rules and structured family routines was related to low levels of political knowledge and to poor ability to interpret political messages. However, having common family activities with an intellectual or cultural orientation (e.g., visiting museums, having discussions about political and social issues) was related to high levels of political knowledge and good abilities to interpret political messages among girls. By contrast, in boys, a high level of family cohesion and expressivity was related to political knowledge and the ability to interpret political messages. Finally, in both girls and boys, a high level of family cohesion and expressivity and having family activities with an intellectual or cultural orientation were both positively related to political interest and internal efficacy.

There is, therefore, clear evidence that numerous aspects of family life and parenting are related to various aspects of youth civic and political engagement. However, it is important not to oversimplify or overgeneralise in interpreting these findings. One of the factors that was measured in the PIDOP survey was parental norms for civic and political participation, that is, whether or not the youths' parents approved of their offspring engaging in political action, and whether parents themselves engaged in political action (Barrett \& Zani, 2015b). The findings revealed that parental norms operated differently in different ethnic groups, even within the same country. For example, in the Czech Republic, Czech youth and Roma youth aged 16-26 years old whose parents held strong participatory norms were more likely to participate both offline and online; however, similarly aged Ukrainian youth who participated both offline and online were more likely to have parents who held weak participatory norms (Šerek, Petrovičová \& Macek, 2015). Likewise, in Germany, where data were collected from both German and Turkish youth aged 16-26 years old, parental norms only predicted offline participation in Turkish youth, not in German youth, while parental norms did not predict online participation in either group (Noack \& Jugert, 2015). In other words, the link to family factors varied from one country to another and from one ethnic group to another within individual countries.

Furthermore, it should not be assumed that causal influences within families necessarily flow only from parents to offspring. This is because offspring themselves are often able to transform patterns of family communication in ways that 
benefit not only themselves but also their parents. This has been demonstrated by McDevitt and Chaffee (2002), who studied 11- to 18-year-old American students and their parents. They found that youth-initiated discussions in the family - which had been stimulated by a civics curriculum at school - prompted parents to increase their own civic competence through increased use of news media in order to acquire more knowledge so that they could develop their own opinions on the issues that their offspring were studying. These parental behaviours were a consequence of parents' desire to maintain their leadership role within the family. In other words, it is not only parents who can influence their offspring; offspring can also influence parents and affect the interpersonal dynamics of the family.

\section{The peer group}

There are also links between young people's experiences within their peer group and aspects of their civic and political engagement. Having positive peer group relationships, having friends who are politically engaged and having friends who provide social support all tend to be associated with higher levels of engagement.

For example, among 11- to 14-year-old American youth, having positive relationships with peers is related to levels of helping others in need (Wentzel \& McNamara, 1999); American high school alumni who engage in voluntary service are more likely to have friends who also engage in voluntary service than those who do not volunteer (Yates \& Youniss, 1998); and American youth whose peers offer social support for discussing personal issues and problems are more likely to engage in civic activism and to volunteer for community service in later adolescence (Zaff, Malanchuk \& Eccles, 2008).

Similar findings have been obtained in other countries. For example, Silva, Sanson, Smart and Toumbourou (2004) collected data from Australian 15- to 17-year-olds, assessing various aspects of these youths' peer relationships as well as their levels of political activity and community civic activity. It was found that friendship quality, peer encouragement to participate in political or volunteering activities, and peer participation in these activities all predicted higher levels of political activity and community civic activity. Similar findings were obtained with Italian 11- to 15-year-olds by Rossi, Lenzi, Sharkey, Vieno and Santinello (2016), who likewise found that having friends who are involved in civic activities and are sensitive to civic issues predicts both civic responsibility and civic behaviours in these youth. Finally, in a study conducted in Belgium, Quintelier, Stolle and Harell (2012) found that having peer social networks that contain a diversity of political opinions and convictions at age 16 is linked to higher levels of political participation at age 18. Quintelier et al. argue that having contact with a range of diverse views generates heightened levels of political discussion and interest, which in turn lead to heightened levels of political action. Interestingly, this study also discovered that political participation at age 16 was associated with having more diverse social networks at the age of 18 . This presumably occurs because many 
political activities are social in character and therefore have the effect of bringing young people into contact with other people who have different beliefs from themselves. Hence, political participation and political diversity in social networks appear to mutually strengthen each other, creating a virtuous circle.

In short, relationships between peer group experiences and youth civic and political engagement have now been documented in a number of countries. However, these relationships may not be present to the same extent in all countries. Evidence suggesting that it may not be possible to generalise from one country to another comes from the multinational study by Flanagan et al. (1998) in which data were collected from 12- to 18-year-old youth in seven countries (Australia, Bulgaria, Czech Republic, Hungary, Russia, Sweden and the USA). They found that having a sense of peer solidarity at school was positively related to these individuals' political and civic commitments in several of the countries that were studied, but not in all countries. Furthermore, different findings were obtained for girls and for boys. Among the girls, the relationship between peer solidarity and political and civic commitments was present in Australia, Hungary, Sweden, Russia and the USA but not in Bulgaria or the Czech Republic, whereas among the boys, the relationship between peer solidarity and commitments was found in Australia, Bulgaria, Hungary and Russia, but not in the Czech Republic, Sweden or the USA.

Likewise, PIDOP found cross-national differences as well as ethnic group differences in the relationship between peer group norms (i.e., the extent to which peers approve of political action and the extent to which they engage in political action) and levels of online and offline political participation in 16to 26-year-olds. For example, in the Czech Republic, peer group norms supporting political participation predicted both online and offline participation among Czech youth, but only predicted online participation among Roma and Ukrainian youth (Šerek et al., 2015). By contrast, in Germany, peer group norms only predicted the offline participation of Turkish youth, not of German youth, and these norms did not predict online participation among either Turkish or German youth (Noack \& Jugert, 2015). Thus, one needs to be cautious about generalising about the effects of peer groups from one country to another and from one ethnic group to another.

Furthermore, it should not be assumed that peer group effects, where they occur, are always positive. For example, CIVED found that the amount of time that was spent in the evenings outside the home with friends was inversely related to political knowledge in those particular countries where peer group culture devalues education (Torney-Purta et al., 2001). Once again, this finding indicates the need for caution in thinking about peer group influences.

\section{The neighbourhood}

Various characteristics of the neighbourhood in which youth live have also been found to be related to their civic and political engagement. One such characteristic 
is whether the neighbourhood is urban, suburban or rural. Different features are associated with these three types of neighbourhood, and the consequence is that each offers different kinds of opportunities for the development of civic participation. Atkins and Hart (2003), in a study of American 11- to 18-yearolds, found that youth living in urban neighbourhoods were less likely than their suburban and rural peers to participate in community service. In addition, youth in poor neighbourhoods had lower levels of political knowledge than youth in affluent neighbourhoods.

The reasons for such outcomes are almost certainly numerous and complex. Poor communities tend to have fewer resources to invest in neighbourhood institutions, organisations and activities. This means that there are fewer opportunities for youth in poor communities to engage civically and politically and to acquire the skills that are needed to participate. Social trust is also lower in such communities (Hart \& Atkins, 2002), which may weaken the sense of civic responsibility in youth still further. Furthermore, adults living in these communities may be less likely to possess the kinds of civic skills that are required for organising and participating in community meetings and activities (Brady, Verba \& Schlozman, 1995), once again resulting in fewer opportunities for youth in such communities, as well as fewer adult role models being available for these youth.

The level of connectedness between youth and adults within the neighbourhood also appears to be important. In a study with Italian 11- to 15-year-olds, Lenzi, Vieno, Pastore and Santinello (2013) examined intergenerational social connectedness between young people and adults in the local community (i.e., the extent to which there are adults in the neighbourhood that young people look up to, and the extent to which parents in the neighbourhood know their offspring's friends), and explored whether there was a link between such connectedness and the sense of civic responsibility. They found that in neighbourhoods in which there was strong intergenerational connectedness, youth had a higher sense of civic responsibility toward their local community (i.e., they thought it was important to work for improving the neighbourhood and would work to improve it if there were opportunities to do so). A high sense of civic responsibility was in turn related to actual civic behaviours (such as volunteering or participating in the organization of local parties). Furthermore, youth who had stronger social relationships with peers and adults in the local community tended to have a stronger emotional bond to their neighbourhood, and this emotional bond, in turn, was also positively associated with having a higher sense of civic responsibility towards the local community. These results highlight the importance of emotions towards specific peers and adults in the proximal social environment, which appear to generalise to the community as a whole.

\section{The school and education}

A major factor linked to young people's civic and political engagement in all populations is formal education (Delli Carpini \& Keeter, 1996; Emler \& Frazer, 1999; 
Nie, Junn \& Stehlik-Barry, 1996; Niemi \& Junn, 1998; Verba et al., 1995; Zukin et al., 2006). Irrespective of whether formal education is measured in terms of level of attainment or years of education, the higher the level of education, the more likely it is that a person will have high scores on measures of civic and political engagement. This conclusion has repeatedly emerged from many studies.

For example, analysing data collected from American adults, Verba et al. (1995) found that educational level was related to a wide range of civic and political measures, including political knowledge, political interest, civic skills and civic and political activity - in all cases, those who had completed an undergraduate degree or higher showed the highest scores, whereas those who did not have a high school diploma showed the lowest scores. In the case of British 16- to 19-year-olds, both the level of educational attainment and the amount of post-16 education are related to political interest, political attentiveness, a lack of cynicism about politics and future expected voting (Emler \& Frazer, 1999). Likewise, in Italy, 18-year-old students who are on an academic educational track rather than a technical or vocational track have higher levels of political interest, trust in institutions, intentions to vote in the future and both online and offline civic and political participation (Cicognani, Zani, Fournier, Gavray \& Born, 2012).

Some of the links here are likely to stem from the enhancement of the specific knowledge, skills or behaviours that are directly targeted by the school curriculum. For example, in a study with American youth aged between 12 and 17 years, Chapman, Nolin and Kline (1997) found that civic education courses that required students to pay attention to national issues, government and politics did indeed increase students' attentiveness to national political news and also increased their interest in national issues and politics. Likewise, analysing data from 17-year-old American youth, Niemi and Junn (1998) found that the civics curriculum to which these youth had been exposed at school was related to how much they knew about American government and politics: the variety of topics studied and the amount of course work were both directly linked to the amount of knowledge acquired. However, Niemi and Junn also found that the method of teaching was important: higher levels of knowledge were acquired if students were allowed to discuss and analyse politics and political issues in relationship to contemporary events, rather than having to learn historical facts or facts about government organisation and processes by rote memorisation

However, the relationship between education and civic and political engagement is much more wide-ranging than just the specific behaviours or knowledge that are targeted explicitly by the curriculum. Educational effects generalise to a wide range of participatory behaviours and aspects of engagement. For example, Zukin et al. (2006; Andolina et al., 2003), in their study of American 15- to 25 -year-old youth, found that students who attend schools that provide training in civic skills (e.g., letter writing and debating) are more likely to be involved in organisations outside school, to sign petitions, to participate in boycotts, to follow political news, to engage in charitable fundraising and to attend community meetings, and that students who participate in classroom discussions about 
volunteering are more likely to volunteer regularly, to work on community problems, to participate in charity fundraising and to try and influence other people's voting. These findings fit with those of Feldman, Pasek, Romer and Jamieson (2007) and Pasek, Feldman, Romer and Jamieson (2008), who found that a civic education intervention with American high school students increased not only their knowledge of politics and current affairs but also their political efficacy, interest in politics, attention to politics and subsequent voting.

In addition, CIVED, ICCS 2009 and ICCS 2016 have all consistently shown that having an open classroom climate at school is one of the most important factors that can enhance students' civic and political engagement. An open classroom climate is characterised by students having the freedom to raise controversial social and political issues that are of interest to them within the classroom; encouraging them to discuss these issues, to listen to a range of different perspectives and opinions, and to make up their own minds about those issues; and allowing them to express opinions in class even when their opinions differ from those of other students. CIVED, ICCS 2009 and ICCS 2016 all revealed that having an open classroom climate at school is a major predictor of young people's levels of political knowledge, political interest and intentions to vote in the future (Schulz et al., 2010; Schulz et al., 2017; Torney-Purta et al., 2001). For example, ICCS 2016 found that in all 21 countries that were studied (see Table 1.2, Chapter 1), an open classroom climate was positively associated with students' interest in political and civic issues, and in 19 of the 21 countries, an open classroom climate was also related to levels of political knowledge (the exceptions being Lithuania and the Netherlands).

An open classroom climate has also been linked to political trust and levels of efficacy. For example, Hahn (1998), in a study of 15- to 19-year-olds in five countries (Britain, Denmark, Germany, the Netherlands and the USA), found that the presence of an open classroom climate predicted levels of political interest, internal and external efficacy and trust in politicians and government officials. Ichilov (1991) also found, in a study of 14- to 18-year-old Israeli youth, that participation in class debates and discussions predicted internal and external efficacy and political involvement (a unitary measure that included media use, political interest, willingness to be actively involved and discussion of politics with others). Likewise, Azevedo and Menezes (2007), in their study of 14- to 23-year-old Portuguese youth, found that an open classroom climate predicted political knowledge, the interpretation of political messages, political interest, collective efficacy, political trust and dispositions for future political activity.

Flanagan, Cumsille, Gill and Gallay (2007) instead examined the effects of teachers practising a democratic ethos within the classroom - that is, whether teachers listen to students' ideas and opinions even when they are at odds with the teachers' ideas, insist that students respect one another, and actively intervene to stop acts of intolerance between students. Flanagan et al. (2007) examined the effects of teachers implementing a democratic ethos within the classroom amongst 11- to 18-year-old American students. It was found that the extent to 
which teachers practised a democratic ethos in the classroom predicted the students' levels of civic commitment. Interestingly, in a study with Italian 11- to 15-year-old youth, Lenzi et al. (2014) discovered that a democratic ethos within the classroom was associated with higher levels of civic responsibility in students, but this association was fully mediated by open classroom discussions about civic and political issues (i.e., an open classroom climate) and by the perceived fairness of teachers. In addition, the students' levels of civic responsibility predicted their intentions for future civic and political engagement.

Schools can implement a democratic ethos not only within the classroom but also at school level by establishing school councils or parliaments. These councils and parliaments are important ways in which students can obtain first-hand practical experience of the democratic process, representing others, and expressing views and perspectives to people in positions of authority. CIVED found that participation in a school council was a significant predictor of political knowledge and of intentions to vote in national elections in adulthood (Torney-Purta et al., 2001). ICCS 2016 also found that participation in civic activities at school was positively associated with political knowledge and with future voting intentions in 16 of the 21 countries that were studied (Schulz et al., 2017).

ICCS 2016 additionally looked at students' perceptions of the value of student-based participation in civic-related activities at school by asking questions about, for example, whether student participation in the running of schools makes schools better, whether organising groups of students to express their opinions can help to solve problems in schools and whether voting in student elections can make a difference to what happens at schools. It was found that the more positively students viewed student-based participation, the higher their levels of interest in political and social issues and the higher their levels of political knowledge. These links to political interest and political knowledge were found to be present in all 21 countries.

That said, once again, some caution is required in interpreting these findings. This is because the effects of an open classroom climate and of opportunities to participate can differ among youth attending the same schools and following the same educational system, depending on their ethnic background. This conclusion emerges from a study conducted as part of PIDOP by Jugert, Eckstein and Noack (2016) with 16- to 25-year-old German and Turkish minority youth in Germany. They examined the relationship between open classroom climate and opportunities to participate in school decision-making and these youths' political attentiveness, collective efficacy and political trust. They found that links to classroom climate and opportunities to participate differed between the German majority and Turkish minority youth. Open classroom climate was only related to political attentiveness and political trust among Turkish, not German, youth, while opportunities to participate in school decision-making was only related to collective efficacy and political trust in German, not Turkish, youth. In other words, classroom climate had more impact among the minority Turkish youth, whereas opportunities to participate had more impact among the majority 
German youth. Thus, findings do not always generalise across ethnic groups, and it cannot be assumed that actions that are effective in promoting engagement in one ethnic group will necessarily be effective for other ethnic groups.

Another action that schools can take to promote the civic and political engagement of youth is to provide institutionally organised opportunities for volunteer work and service learning. While some countries and institutions provide such opportunities for youth on a widespread basis, others do not do so. The benefits of these activities have been very well documented (Billig, 2000; Hatcher, Bringle \& Hahn, 2017). For example, Astin, Sax and Avalos (1999) collected longitudinal data from American college students four years after college entry and nine years after college entry. They found that the amount of time the students had spent doing volunteer work in their final year at college predicted how much they helped others in difficulty, participated in community action programmes, participated in environmental clean-up programmes and promoted racial understanding, nine years after college entry. Likewise, Smith (1999) found that American students who participated in volunteer and community service activities in their final year of high school had higher levels of both voting and volunteering for a political organisation two years later, compared to peers who had not participated in service activities. In addition, Hart, Donnelly, Youniss and Atkins (2007) found that voluntary and school-required community service in the final year of American high school were both strong predictors of adult voting and volunteering eight years later.

A distinction may be drawn between volunteering and service learning. Volunteering involves giving time freely without financial reward to causes or to help other people, and it includes philanthropic or charitable activity (Cnaan, Handy \& Wadsworth, 1996; Wilson, 2000). Service learning, by contrast, emphasises learning and reflection. It is an institutionally required, course-based, credit-bearing educational experience in which students participate in service activities that benefit the community beyond the school, college or university; afterwards, students are required to reflect on their service activity to develop their academic learning and to gain further understanding of course content (Bringle, 2017; Hatcher, 2017; Rauschert \& Byram, 2017). Service learning differs from volunteering in that it is a formal component of academic study, it is initiated by the educational institution and it explicitly requires learning in pursuit of educational goals.

As such, service learning is an experience that can be made mandatory by educational institutions as a method of promoting the civic and political engagement of students. A study by Haski-Leventhal et al. (2010), which was conducted in 14 countries (Australia, Belgium, Canada, China, Croatia, England, Finland, India, Israel, Japan, Korea, The Netherlands, New Zealand and the USA), examined both volunteering and service learning in 20- to 26-year-old university students. Rates of volunteering and service learning varied considerably across countries. However, it was found that, across the sample as a whole, participation in service learning programmes at high school was positively related to present 
volunteering, especially so when service learning had been compulsory at high school. It was also found that service learning in university had an even greater impact on volunteering. That said, the strength of these relationships varied considerably from one country to another, and there appeared to be strong cultural differences within these findings. These can potentially be explained by the different macro factors and processes that operate within different countries. We will discuss macro factors in detail in Chapter 4.

In another study of American university undergraduates, Levesque-Bristol, Knapp and Fisher (2010) employed a broader range of outcomes. They found maximal effects occurred when service learning courses were well-designed and enhanced the positivity of the learning environment. Courses needed to support students in developing their autonomy, help them to build their confidence in achieving the course objectives, provide them with opportunities for in-class discussion and provide them with opportunities for reflection. Courses with these characteristics led to higher levels of future intended civic action, more positive attitudes to cultural diversity and greater confidence in solving problems. However, service learning courses which did not have these characteristics did not produce these beneficial changes.

Morgan and Streb (2001) likewise found that service learning programmes had much greater effects on the civic and political outcomes achieved by American 14to 18 -year-old students if the service learning was made authentic and significant for the students. When students had real responsibilities, challenging tasks, helped to plan their own service learning, and made important decisions, involvement in service learning projects had significant and substantive impacts on students' political interest and attentiveness and commitment to undertake social action. It also led to more positive attitudes towards the elderly and people with disabilities.

Service learning therefore represents a further action that can be taken by schools, colleges and universities to promote the civic and political engagement of young people. However, in order to achieve this goal, service learning activities need to be well-designed. They need to support the development of autonomy, responsibility and confidence in young people, and offer ample opportunities for in-class discussion and reflection.

The implications of these numerous studies into the effects of education on young people's civic and political engagement are clear. Engagement is promoted when teachers and educational institutions:

- provide citizenship education courses that require students to discuss and analyse politics and political issues in relationship to contemporary events

- $\quad$ provide training in civic skills such as letter writing and debating

- ensure that teachers treat all students in a fair and just manner

- allow students to raise controversial issues that are of interest to them in the classroom

- encourage students to discuss social and political issues

- enable students to hear a wide range of views about these issues 
- allow students to express their own opinions even when their opinions differ from those of other students and from those of the teacher

- ensure that students respect one another and are not intolerant towards one another

- $\quad$ support students in formulating their own views about social and political issues after considering a diversity of perspectives and opinions on those issues

- operate school councils or parliaments that enable students to acquire firsthand practical experience of democratic processes and to feel that participation in these councils or parliaments is a valuable and worthwhile activity

- provide high-quality service learning opportunities for students, that is, service learning that supports the development of autonomy, responsibility, confidence, decision-making and planning skills in young people, and provides plentiful opportunities for in-class discussion and reflection

\section{Youth, community and religious organisations and associations}

The organisations and associations to which young people have access are a further important factor that can influence their civic and political engagement. Many different types of organisations may be available to youth, including youth clubs, sports clubs, hobby clubs, music clubs, debating groups, charities, religious or ethnic associations, advocacy groups, youth political organisations and so on. Albanesi, Cicognani and Zani (2007) examined the sense of community that is generated by membership of and participation in such organisations, focusing on Italian youth aged 14-19 years old. They defined sense of community as the extent to which the community provides youth with a sense of belonging, a feeling of support and emotional connection with peers, a feeling of support and emotional connection with the community more generally and satisfies their needs, and provides opportunities for involvement and influence. They found that belonging to formal organisations was associated with an increased sense of community, and that sense of community itself was linked to levels of both prosocial-oriented civic engagement (e.g., charity purchasing and participating in cultural events and festivals) and protest-oriented civic engagement (e.g., occupation of schools, signing petitions and participating in strikes).

In another study involving Belgian youth, Quintelier (2008) differentiated between six kinds of organisations, according to their goals:

- $\quad$ Sports and hobby groups

- Youth clubs and youth groups such as the Scouts and Girl Guides

- Cultural groups that focus on music, dance or theatre

- Organisations that have the goal of helping disadvantaged people or places, such as anti-racist, human rights, peace and environmental organisations

- Deliberative organisations that provide a forum for debating current issues

- Religious-ethnic organisations based on a particular faith or ethnic community 
In order to examine the relationship between the young people's membership of these organisations and their civic and political participation, Quintelier drew on data from the Belgian Youth Survey 2006. This was a large-scale survey of over 6,000 16-year-olds in both French-speaking and Flemish-speaking schools in Belgium. Her analyses differentiated between three forms of participation: political participation (e.g., wearing a badge, illegal protesting, forwarding political emails, drawing political messages, contacting politicians, being a member of a political party); civic participation (e.g., donating/collecting money, signing petitions, protesting, attending a show with political content); and political consumerism (e.g., boycotting and preferentially buying particular products). The findings revealed that the number of memberships was more strongly associated with participation than the difference between membership and non-membership, with those who were involved in multiple organisations being more likely to participate in political and civic activities. It was also found that both political and civic participation, but not political consumerism, were related to whether individuals had played a leadership role within organisations and had helped to organise activities; however, participation was not linked to involvement in decision-making within organisations. Political participation was most strongly related to membership of deliberative, cultural and helping organisations, whereas civic participation was most strongly related to membership of helping and religious-ethnic organisations. Political consumerism, by contrast, was not strongly related to the characteristics of the organisations to which individuals belonged.

These findings are echoed in other studies conducted with other populations. For example, McFarland and Thomas (2006) analysed longitudinal data that had been collected from large samples of American youth aged between 14 and 26 years old. They found that involvement in what they termed 'politically salient' youth organisations had significant positive returns on political participation seven to 12 years later - 'politically salient' organisations were defined as organisations that entail activities of public speaking, debate, community service, communal representation and communal rituals, all of which help to develop the kinds of relations, skills, knowledge, identities and interest in political systems that are relevant to political participation. The politically salient organisations were: helping organisations; student councils; drama clubs; musical groups; and religious organisations. Membership of other kinds of organisations, such as sports and hobby groups, did not have any positive relationship to long-term political involvement (with cheerleading actually having a negative relationship).

The findings of Quintelier (2008) and McFarland and Thomas (2006) suggest that it is not organisational membership or participation through organisational channels per se that is critical for young people's future civic and political engagement, but rather the type and quality of the participation experiences that young people obtain through organisations and the opportunities for developing participatory skills that this experience affords. Indeed, Ferreira, Azevedo and Menezes (2012) have suggested that poor quality participation experience 
may sometimes even have detrimental effects, such that youth who do not have any participation experiences at all may develop more positive political attitudes than those who have low-quality experiences. Studying a group of Portuguese youth aged 15 years and older, they measured the quality of their most important organisation-based participatory action by asking them about the extent of their involvement in the action, how frequently they had searched for information about the issues, whether they had participated in organising the activities, whether they had been involved in group decision-making, whether a variety of points of view had been discussed, and whether they had encountered new ways of perceiving the issues in question. It was found that only participatory actions that provided high-quality participatory experience on these various dimensions predicted the youths' dispositions to undertake political action in the future.

In a follow-up study conducted as part of PIDOP, Fernandes-Jesus, Malafaia, Ferreira, Cicognani and Menezes (2012) collected similar data from Portuguese, Angolan origin and Brazilian origin youth aged 15 to 29 years old who were growing up in Portugal. The Portuguese and Brazilian youth exhibited a similar pattern, with low-quality participation experiences being equivalent to having no experiences at all in terms of impact on dispositions to undertake political action in the future - only high-quality experiences had a beneficial effect. However, in the case of the Angolan youth, even low-quality participation experiences had a positive impact on their dispositions towards future action. Fernandes-Jesus et al. speculate that this may have been the case because these youth experience racism and discrimination more frequently and are less engaged in all forms of participation than members of the other two groups. Because of this lower baseline, participation in any form of activity may have a positive effect. Whatever the explanation, the similarities between the Brazilian and Portuguese youth, and the differences between the Angolan and Brazilian youth, show that one needs to be cautious about assuming that effects that are found with some subgroups of youth will generalise to all youth irrespective of their specific cultural positioning. The study also confirms that the quality of participation experiences does need to be ensured because participation itself does not always have a beneficial effect.

Other studies into the role of youth organisations in fostering youth engagement have revealed that young people who have high levels of religious commitment, attendance and activity through religious organisations are more likely to become civically and politically engaged (Crystal \& DeBell, 2002; Youniss, McClellan, Su \& Yates, 1999; Zaff et al., 2008; Zukin et al., 2006). This effect of membership of religious organisations has been examined in both youth and adults. Djupe and Grant (2001) found that, in the case of American adults attending Christian churches, the churches generated political participation through a number of routes: through co-religionists recruiting other church members into political activities, through holding political meetings in the church, and through members following the perceived political norms and expectations of their church. Brady, Verba and Schlozman (1995) also found that, in the USA, 
religious institutions assist their members in developing the civic skills that are needed to participate in political activities.

In the case of youth, Kerestes, Youniss and Metz (2004) conducted a longitudinal study of the relationship between religious commitments and political and civic activity in American students who were aged 14-18 years old. They found that participation in political activities (e.g., working on a political campaign, demonstrating for a cause) and intentions to perform community service in the future were highest among those who started the study at the age of 14 with a strong religious commitment and maintained that strong commitment through to the age of 18. In addition, those who had a weak religious commitment at the age of 14 but then strengthened their commitment over the course of the study showed the highest increases over time in intentions to perform community service in the future. Kerestes et al. suggest that attending religious education programmes and participating in community outreach groups organised by the church which integrate youth into the community are the most likely factors responsible for these effects.

Affiliation with religious institutions may be of particular importance in the case of ethnic minority and immigrant youth. Involvement with a church or a mosque is an act of civic engagement for such youth and is, in many instances, the only context in which they engage civically (Pachi \& Barrett, 2011a; Stepick \& Stepick, 2002). Involvement with a religious institution can be for religious (spiritual) reasons, but it can also be for community, family or humanitarian reasons. In their research with 16- to 26-year-old British Congolese youth in London that was conducted as part of PIDOP, Pachi and Barrett (2011b) found that church attendance was an integral part of these young people's lives, and the church constituted the main provider of direction and opportunities for civic and political participation. Religious sermons did not only involve messages about religious texts and doctrines but also offered advice about social and political endeavours. The Congolese youth who were more religious exhibited a more conservative view of how society and the political system should function, as well as higher levels of civic and political participation. These young people tended to follow the encouragement of their religious leaders to engage in civic and political activities both in relationship to Britain and in relationship to the Congo, with a range of different forms of participation being undertaken, including voting in national/local elections, participating in demonstrations for religious or other reasons related to the Congo, and participating in voluntary and other organisations for humanitarian reasons.

In short, membership of youth, community and religious organisations and associations can promote young people's civic and political engagement. That said, these organisations and associations vary considerably in terms of how much encouragement and opportunity they actually offer to young people to develop and exercise civic skills and to participate civically and politically. The research suggests that organisations that allow youth to acquire high-quality participation experience and to practise their participatory skills are the most effective 
for boosting their civic and political engagement (Fernandes-Jesus et al., 2012; Ferreira et al., 2012; McFarland \& Thomas, 2006; Quintelier, 2008). In practice, this means that the organisations that are most effective in promoting young people's engagement are those that enable or encourage youth to:

- $\quad$ search for information about the issues involved

- $\quad$ participate in group decision-making

- explore a variety of points of view about the issues

- encounter new ways of perceiving the issues in question

- develop communication, public speaking and debating skills

- take on leadership, organisational and representative roles

- $\quad$ engage in community service

\section{Youth sections of political parties}

Youth sections of political parties provide a further specialised organisational channel that can be used to promote the political engagement of youth. Youth sections are typically run by the youth members themselves but sometimes with funding provided by the political party and with administrative support from the party as well. In some cases, if an individual who joins a political party is at an age that falls within the age range stipulated for membership of the party's youth section, they automatically become a member of that section.

One of the primary functions of youth sections is to attract younger members into a political party: Hooghe, Stolle and Stouthuysen (2004) report that over $40 \%$ of councillors in Belgium began their political careers in the youth section of a political party. That said, the members of youth sections often want to be autonomous of the parent political party. For example, in one study of youth sections within five countries (Russia, Finland, Denmark, Spain and Slovakia), it was found that the members wanted to be independent and free in making their own decisions, developing policy and organising their own activities (HashemWangler, Busse, Tholen \& Wolnik, 2015).

It has been argued that youth sections are typically viewed by older party members as being marginal to the party, with some parties being reluctant to allow youth sections to have too great an input to party policies because of the worry that policy proposals that are too radical might alienate older voters (Mycock \& Tonge, 2012). However, Bennie and Russell (2012), in a study into youth sections within UK political parties, found that these parties made significant efforts to include their youth sections in the development of party policies. The youth members who were studied were not especially radical in the policies they advocated, and the parties made efforts to give them a vocal role in the internal and external running of the party organisations. It was also found that the youth members were generally supportive of the party structures and leaders. Bennie and Russell argue that youth members are a vital resource for the future life of political parties: they tend to be active and enthusiastic party members, 
they hold moderate policy positions and they are generally supportive of party structures and leaders.

It is, however, notable that the membership of youth sections is very small compared with the size of the general youth population. In order to investigate why some youth choose to join political parties, Bruter and Harrison (2009) conducted a survey of young members (aged between 18 and 25 years old) of 15 political parties in six European countries (France, Germany, Hungary, Norway, Spain and the UK). They found that these individuals had joined the political party for one of three reasons: moral (i.e., for altruistic or ideological reasons), social (i.e., for the social aspects and for the enjoyment which they derived from being a member) and professional (i.e., to build their own knowledge and skills in order to advance their future careers in politics). These three groups were characterised by different attitudes, activities, hopes and expectations about their own future. Most young people joined because of a sense of moral duty. These youth were the most radical activists, and they were the most likely to engage in non-conventional forms of participation such as demonstrations. They did not consider politics to be a profession, and they saw their future as activists, not as politicians. The socially-minded members instead joined to fulfil their social needs, to meet like-minded people and to engage in interesting discussions. They were the least active members and the least likely to devote time to the political cause of the party. They were also the most critical towards the party, which made them doubt their own long-term commitment to the party. Finally, the professionally-minded party members joined in order to pursue a future career in politics. They wanted to become politicians, run for election and access positions of responsibility. They cared about their party's ability to win votes and were highly involved in the electoral activities of the party, but they avoided more radical forms of participation.

In the case of professionally-minded youth, becoming a member of the youth section of a political party clearly provides a unique opportunity to enter the world of politics, and several studies have now revealed that an important function of youth sections is indeed the political socialisation and training of their members in readiness for future political activities (e.g., Hashem-Wangler et al., 2015; Hooghe et al., 2004). This is achieved by equipping them with knowledge about public and political affairs and by training them in the strategies that can be used to achieve political goals and the skills that are needed for a political career (e.g., public-speaking, debating and group leadership skills). In a study of the youth section of a Portuguese political party, Malafaia, Menezes and Neves (2018) found that the section did indeed provide high-quality political participation experiences for its members who, through their activities in the section, had acquired high levels of internal efficacy and critical thinking. Hashem-Wangler et al. (2015) and Rainsford (2017) (the latter of whom studied the youth sections of UK political parties) likewise found that the members of youth sections generally display high levels of internal efficacy and feel politically empowered, although Rainsford additionally found that these youth can have 
a lower sense of the organisational efficacy of the youth section to which they belong. Furthermore, the participants in Hashem-Wangler et al.'s study drew a distinction between the impact that their activities had on political life in general, which they estimated to be low, and the impact that their activities had on their local communities, which they estimated to be much higher.

The available research therefore reveals that youth sections of political parties can play an important role both in recruiting party members for the future and in socialising and training young people for political activity in the future. If political parties are genuinely concerned to promote young people's levels of engagement with conventional politics, they should support their youth sections by providing them with adequate financial and administrative resources, and they should try to broaden the appeal of these sections to much wider swathes of the youth population.

\section{The mass media}

A further significant influence on youth civic and political engagement is the mass media. As we saw in Chapter 2, ICCS 2016 revealed that, on average, 66\% of 14-year-olds watch television at least once a week to obtain information about political and social issues, $31 \%$ use the Internet at least once a week to obtain information about such issues, while $27 \%$ read newspapers at least once a week (Schulz et al., 2017). In other words, despite the widespread use of social media by 14 -year-olds, they are twice as likely to use television rather than social media for obtaining information about political or social issues.

These findings are important because there are links between the extent to which individuals attend to news on television and political knowledge, political interest and intentions for future political participation. For example, CIVED found that, among 14-year-old youth, the frequency of watching television news was associated with political knowledge in about half of the 28 countries that were studied and also with future intentions to vote in all but two of the countries (Torney-Purta et al., 2001). Likewise, ICCS 2009 found that students who used television to inform themselves about national and international news on a weekly basis, or who read newspapers to inform themselves about national and international news on a weekly basis, had higher levels of political knowledge than those who did not use these sources of information so frequently (Schulz et al., 2010).

Linnenbrink and Anderman (1995) also found that 13- to 18-year-old American adolescents who frequently watched news on television and frequently read newspapers had the highest levels of knowledge about current events. In addition, they discovered that those students who took the time to read newspapers tended to think about the news the most deeply and the most critically. Likewise, Hahn (1998), in her study of 15- to 19-year-olds in five countries (Britain, Denmark, Germany, the Netherlands and the USA), found that students in all countries reported that they had obtained much of their political 
information from the mass media. In this case, however, the students also reported that they had gained their negative views about politics and politicians from precisely these same sources as well. The most cynical students in Hahn's study said that they obtained their information from tabloid rather than from serious newspapers because they found them more interesting and because they were not so full of 'the boring stuff'.

Hahn's findings suggest that exposure to information about politics in the mass media may sometimes actually lead to disaffection with politics among young people and reduce rather than enhance their levels of political engagement. The term 'media malaise' has been coined to denote this phenomenon, in which the mass media generate political cynicism, distrust, disillusionment, disaffection and alienation from politics among citizens as a consequence of their superficial focus on political conflict, scandal, corruption and failure (Capella \& Jamieson, 1997; De Vreese \& Semetko, 2002). The suggestion is that this type of negative news content produces cynicism among citizens about politicians' competence and morals. Political advertising may further exacerbate this trend because it involves relentlessly attacking opponents in a negative way (Ansolabehere \& Iyengar, 1995). In addition, both entertainment media and commercial advertising may reinforce the effect, the former by inducing passivity, the latter by generating a self-centred and individualistic consumerist materialism that is opposed to civic and social responsibility and interest in the common good (Putnam, 2000).

An alternative view that is sometimes pitted against the concept of media malaise draws on the idea that political engagement and media usage form a virtuous circle: those who are more politically engaged are more likely to watch or read political news, which means that they acquire more knowledge about politics, which in turn enhances their political engagement and trust still further (Norris, 2000).

A third approach emphasises that different types of content in mass media news produce the different effects: sustained exposure to news outlets that have high levels of political content (such as public service television news and broadsheet newspapers) contribute to knowledge gains and engagement, while sustained exposure to mass media that have a lower proportion of political content and a higher proportion of entertainment content (such as commercial television and tabloid newspapers) has negative effects on engagement and trust (Aarts \& Semetko, 2003). In other words, in-depth and serious news coverage on television and newspapers may inform and engage citizens, whereas superficial and sensationalist coverage may induce cynicism.

The evidence that is available from adults tends to support the third approach, namely that there are mixed effects depending on the specific type of content that is viewed or read (Curran, Coen, Soroka, Aalberg, Hayashi et al., 2014; Newton, 1999). However, a recent longitudinal study of Swedish youth provides some support for the notion of a virtuous circle rather than for media malaise in the case of young people (Kruikemeier \& Shehata, 2017). The youth 
in this study were aged between 13 and 17 years old at the first wave of data collection, with subsequent waves of data being collected from the same youth one and two years later. It was found that there were no negative effects of reading newspapers, watching television news, listening to radio news or reading news on the Internet on either future political interest or future intended political participation. Instead, the frequency of using all four media for accessing news predicted future levels of intended political participation, and the frequency of reading newspapers predicted future levels of political interest. In addition, levels of political interest and levels of intended political participation independently predicted levels of accessing news through all four media. In other words, the more politically engaged and interested these youth were, the more they accessed the mass media for news; and the more they accessed the mass media for news, the more likely they were to participate politically in the future. Hence, the evidence was consistent with the notion of a virtuous circle rather than media malaise.

Unfortunately, Kruikemeier and Shehata did not measure media use more generally; the focus of their study was only on the use of media for obtaining news. It remains for future studies to explore whether similar results are obtained from youth when the measures of media use are broader than this and also include their consumption of entertainment and advertising. That said, it is clear from the body of existing research that the mass media are a significant factor that can impact on levels of political knowledge, political interest and future intended political participation in youth. Additional findings on how the Internet and social media are related to youth civic and political engagement are reviewed later on in this book, in Chapter 4.

\section{Popular music}

Another source of social influence is artistic communications, especially those that emanate from popular music (Pachi, 2018), which may serve either to mobilise or to discourage youth from engaging with and participating in civic and political life. Popular music plays an extremely important role in the lives of young people: they spend a significant amount of time on a daily basis listening to music, sharing information about music and artists with their friends, and following their favourite artists through social media (Bennett, 2000; Brown \& Bobkowski, 2011; Miranda, 2013; Pachi, 2018; Roberts, Henriksen \& Foehr, 2009; Tarrant, North \& Hargreaves, 2000). In addition, many artists share information about their professional and personal life on a daily basis with their fans and maintain an open channel of communication, which creates a virtual relationship between fans and their 'favourite' artists.

Young people use their musical preferences for a variety of purposes, including managing their own identities; for self-presentational purposes; to differentiate themselves from their parents and from younger children; to evaluate the similarities between others and the self; to make judgements about the personalities, 
characteristics and values of other people; and to establish ingroups and outgroups among their peers (Bakagiannis \& Tarrant, 2006; Rentfrow \& Gosling, 2006; Rentfrow, McDonald \& Oldmeadow, 2009).

In addition, Street (2003, 2012; Street, Hague \& Savigny, 2008) has argued that popular music often embodies political values and experiences, and that it can help to structure and organise young people's responses to societal issues. As such, music can contribute to young people's civic and political development and it can also serve as a medium for their own civic and political expression and participation. Furthermore, Street notes that, because of music's aesthetic properties, it has considerable power to evoke communal or collective values and to provoke political responses. This power of music to move people emotionally and to make them believe and feel differently about civic or political issues means that music does not only give formal expression to existing political beliefs and feelings; it can also create or contribute to the formation of new beliefs and feelings. For this reason, music can be used for propaganda purposes to promote and advance specific causes and interests and also to enact opposition, resistance and defiance to existing norms and values. This means that music often plays a central role in social movements. Street supports his argument through detailed analyses of how music was used in the civil rights movement in the USA, in Rock Against Racism (an anti-racist movement in the UK) and in the Jubilee 2000 movement and Live 8 event which aimed to persuade the leaders of the world's richest countries to change their policies on debt relief for developing countries.

Another example of the power of music to influence young people's engagement is reported by Pachi and Barrett (2011b, 2015; Pachi, Garbin \& Barrett, 2011), who conducted focus groups with 16- to 26-year-old British Bangladeshi, Congolese and English youth in London. They found that some of these youth had been influenced in their thinking about civic and political issues by political messages and conspiracy theories that had been communicated to them by popular musicians. Conspiracy theories about the Freemasons and the Illuminati were prevalent in both Islamic and Christian fundamentalism at the time that the study was conducted and were found to be particularly prevalent among the Bangladeshi and Congolese youth. These theories encouraged them to distrust and disengage from official political and social actors, and created a feeling of powerlessness in the face of the existing political and social order. The youth had been introduced to these theories through the lyrics of international hip-hop artists, which intrigued them and stimulated them into searching for further information about the Freemasons and the Illuminati.

Because hip-hop was the most important music genre for these youth, Pachi and Barrett (2015) analysed the lyrics of a number of songs by Jay-Z and Tupac. These two artists were chosen because they had been cited by the youth in the focus groups as being especially influential on their thinking. It was found that there were neither implicit nor explicit expressions of expectations of political or civic action in the lyrics, although both artists referred to religion as a way of enduring the cruelty of society (discrimination, social injustice, poverty, etc.). 
The most prevalent expectation expressed by both artists in response to a discriminatory and unjust social and political system was individual empowerment through accruing personal wealth. In their lyrics, they described both their own earlier experiences of socio-economic difficulties and their more recent experiences of economic affluence, which they displayed as an example for other people to follow through their own individual agency (rather than through, for example, collective action or political-representative channels). Jay- $Z$ also called on young people to follow him in his new discovery, which was Masonry; this was portrayed as a form of religion with the God of Peace as a central figure.

It was particularly notable that neither artist held high expectations of youth in regard to either political or civic participation. The lyrics conveyed a bleak and negative image of a society in which it is difficult to effect any change through action. The evidence from the accompanying focus groups suggested that messages from these hip-hop artists about social deprivation, unemployment and unfair treatment by the police were indeed taken up by some of the youth as a justification for their own political and civic disengagement and non-participation. Thus, these artists, instead of mobilising youth, appeared to be encouraging and reinforcing a passive stance towards society, the state and its institutions.

\section{Social factors: Conclusions}

It is clear from this review that there are many social factors that can influence young people's civic and political engagement. These include: the family; the peer group; the neighbourhood; education; youth, community and religious organisations and associations; youth sections of political parties; the mass media; and popular music. All of these sources of social influence can help to either promote or hinder youth engagement. However, caution is required in interpreting the direction of the causality that operates between these factors and the engagement of the developing individual, insofar as youth themselves, through their own discourse and behaviour, can have reciprocal effects on some of these sources of influence. In addition, care needs to be taken in generalising from the results of studies that are conducted in particular countries with particular groups of youth. Findings from CIVED, ICCS 2009, ICCS 2016 and PIDOP show that patterns of social influence can vary significantly from one country to another and from one demographic group to another within a country. We now turn to further consideration of the role that demographic factors play in this domain.

\section{Demographic factors}

\section{Socio-economic status}

The links between SES and civic and political engagement in adults have been extensively researched. Most often, a positive relationship has been found, with those who have a higher SES displaying higher levels of engagement 
(Brady et al., 1995; Henn, Weinstein \& Forrest, 2005; Nie et al., 1996; Verba et al., 1995). However, occasionally a negative relationship has been found (Simon \& Grabow, 2010), and there is also evidence that SES is related differently to different types of civic and political participation. For example, Pattie, Seyd and Whiteley (2003) found that, among British adults, social class is positively linked to both individualistic activism and contacting officials but not to collective activism.

The SES of adults has traditionally been measured in terms of their employment, income and education. Of these, education is usually the most powerful predictor of many forms of political and civic participation, including voting, interest in politics, membership of civic associations and volunteering (Putnam, 2000). Brady et al. (1995) argue that formal education is so crucial because it helps to equip people with the skills that are needed to participate civically and politically. These include the abilities to speak and write well and to organise and take part in meetings.

In the case of youth, SES is usually measured in terms of parental employment, parental income or parental educational achievement. There is considerable evidence from studies conducted in the USA that youth who come from families with higher SES have more civic and political knowledge (Delli Carpini \& Keeter, 1996; Niemi \& Junn, 1998) as well as higher levels of participation (Hart, Atkins \& Ford, 1998; Zukin et al., 2006). That said, Hart and Gullan (2010) found that education and social class were more strongly related to political activism in the USA in 1974 than in 1994. They also report that family income was related to political participation in 1974 but not in 1994. American society was very different at these two points in time in terms of its racial heterogeneity, poverty levels and political climate regarding activism, and these findings provide an important reminder of the possible historical specificity of the relationships between variables in this domain.

Additional, and more geographically extensive, evidence about the relationship between SES and civic and political engagement in youth was collected in CIVED, ICCS 2009 and ICCS 2016, all of which collected their data from 14-yearold school students in a large number of countries (see Table 1.2, Chapter 1). All three studies used the number of books in the family home as reported by students in order to index their SES. This index has been found to correlate well with educational achievement (Beaton et al., 1996), and it is commonly interpreted as a proxy for the emphasis which a family places on education, the resources to which the young person has access for acquiring and supporting literacy, and the academic support which the family offers to the young person. (Note however that, with the increasing use of information technology instead of books as an educational resource, this measure may now be losing its usefulness as an index of SES.)

CIVED found that home literacy resources were correlated with political knowledge scores in all but one of the 28 countries that were studied (with Hong Kong being the exception) - the more books the 14-year-olds reported in their 
homes, the better they performed on the test of political knowledge (TorneyPurta et al., 2001). ICCS 2009 and ICCS 2016 also used this same measure of home literacy resources to index SES but in addition used two further measures of SES, namely parental occupational status and parental educational attainment. Both studies likewise found broad and consistent evidence of a strong relationship between students' political knowledge and SES (with Indonesia and the Dominican Republic being the only exceptions where no relationship was found in ICCS 2009 - no exceptions were found in ICCS 2016) (Schulz et al., 2010, 2017).

These studies also looked at whether SES was related to future expected voting. All three studies found that there was cross-country variability: in some countries, there was a positive (but often a relatively weak) relationship, while in other countries there was no relationship at all. The ICCS studies also examined the relationship between SES and future expected active political participation more broadly (e.g., working on a political campaign or running for office). Here, and perhaps somewhat surprisingly, a negative (but again, a relatively weak) relationship was found in some countries, while in other countries there was no relationship. As a general rule, the psychological factors (such as internal efficacy and political interest) had a far larger association with future expected activity than SES. In other words, the findings from these three studies suggest that, in 14-year-old youth, SES is fairly consistently related to political knowledge but is only sometimes (and weakly and inconsistently) related to future expected political participation.

Finally, it should be recalled from Chapter 2 that SES has also been found to be linked in at least some populations of youth to political interest (Bynner \& Ashford, 1994), internal efficacy (Schulz, 2005; Schulz et al., 2017) and external efficacy (Flanagan et al., 2003; Soss, 1999; Wu, 2003). The links to interest and internal efficacy are especially noteworthy, given the important role that these two factors play as direct predictors of all forms of civic and political participation (Brunton-Smith, 2011).

\section{Gender}

Research into political participation among adults has revealed gender differences in both political interest and political engagement, with women tending to be less interested and less engaged than men (Burns, Schlozman \& Verba, 2001; Karp \& Banducci, 2008). These differences probably arise because women are constrained by psychological, familial and societal restraints (cf. Verba, Nie \& Kim, 1978). Psychological restraints stem from women's internalisation of traditional gender roles which commonly restrict them to the domestic sphere, while familial restraints stem from the power dynamics and division of labour in the household which can hinder women from accessing opportunities for participation in the public sphere. Societal restraints stem from countries' policies on women's rights and gender equality and from structural gender inequalities 
in pay, workforce participation, managerial and boardroom positions and the amount of unpaid care work undertaken by women (European Commission, 2016; OECD, 2014, 2015, 2016, 2018), all of which can limit women's opportunities for developing the civic and political dispositions and skills that are required to participate civically and politically.

In the case of youth, as we saw in Chapter 2, gender differences exist in political knowledge, but these differences are variable in their direction. Males have higher levels of knowledge than females in the USA, especially knowledge about political parties, elections and protest activities (Niemi \& Junn, 1998; Wolak \& McDevitt, 2011). However, in other countries, females sometimes have higher levels of knowledge than males (Schulz et al., 2017). Wolak and McDevitt (2011) explored the various sources of knowledge and the characteristics of the environments which facilitate political knowledge for male vs. female youth in the USA. They found that while males tend to be motivated to learn more in a context of debate and conflict, females tend to be motivated to learn in more peaceful, less competitive (less partisan) environments, trends which are consistent with established gender roles in American society.

As we also saw in Chapter 2, there are inconsistent gender differences in levels of political interest as well, which sometimes show a male advantage (Bennett \& Bennett, 1989; Dassonneville et al., 2012) and sometimes a female advantage (Haste \& Hogan, 2006). In the case of internal efficacy, females sometimes have lower levels than males (Lyons \& Menezes, 2012), although some studies have failed to find a gender difference (e.g., Vecchione \& Caprara, 2009; Wu, 2003). It is possible that we are at the beginning of a change in the political socialisation of females and males in some countries, which has not yet generalised to other countries or cohorts. It remains to be seen whether these differences will lead to different participation levels during adulthood in the future.

There are also gender differences in the specific forms of participation that are undertaken by female and male youth. For example, in Australia, Vromen (2003) found that, among 18- to 34-year-olds, women are more likely to engage with 'activist' and 'communitarian' activities than men, while in the USA, Hooghe and Stolle (2004) found that, among 14-year-olds, girls are drawn towards social movement activities more than boys, while boys are drawn towards confrontational and radical activities more than girls.

PIDOP likewise found gender differences in the forms of participation used by males and females. The same measures of participation were used in all nine participating countries (for details of these countries, see Table 1.2, Chapter 1). These revealed that gendered patterns of participation varied across countries. For example, in Belgium, where data were collected from 16- to 26-year-old Belgian, Moroccan and Turkish youth, males engaged in non-conventional political actions (e.g., demonstrating) more frequently than females. However, females were just as politically interested as the males but, because they were confined to the domestic sphere more than the males, the females used the Internet for accessing news about the world more frequently than the males. They were also more likely to wear 
protest bracelets and to engage in consumer activism than the males (Gavray, Born \& Fournier, 2015). In England, where data were collected from 16- to 26-year-old English, Bangladeshi and Congolese youth, it was found that females exhibited higher levels of volunteering and non-conventional forms of participation (e.g., demonstrating and consumer activism), while younger males in particular exhibited higher levels of illegal forms of participation (e.g., throwing stones) than girls (Pachi \& Barrett, 2012a). In Portugal, where Fernandes-Jesus et al. (2015) studied 15- to 29-year-old Portuguese, Angolan and Brazilian youth, the Angolan and Brazilian females were found to have higher levels of volunteering, consumer activism and donating money to social or political causes than the Angolan and Brazilian males, whereas this pattern was reversed among the Portuguese youth where males had higher levels of these three forms of activity than females. Thus, there were varying patterns of gender differences across the countries that were studied. These varying patterns presumably arose because the specific meanings that are attached to gender, and expectations of women's vs. men's rights, duties and behaviour, as well as policies to promote female participation, vary from one country to another, and sometimes from one ethnic group to another (Stockard \& Johnson, 1992; Dion \& Dion, 2001).

A gender-based finding that sometimes emerges is that females tend to have higher levels of civic than political participation, especially involvement through volunteering (Pachi \& Barrett, 2011b; Stepick \& Stepick, 2002). This is likely to be a consequence of the roles, values and duties that are traditionally ascribed to women. Cooperative and nurturing roles linked to care and responsibility for the well-being of others are often associated with females from an early age, based on societal gender stereotypes in which women are viewed as being warmer, more supportive, kinder and gentler than men (Beutel \& Marini, 1995; Diekman \& Eagly, 2000).

\section{Ethnic minority status and migrant generational status}

Research has also revealed widespread differences between ethnic majority and minority groups in patterns of civic and political engagement in most continents and countries (Stepick \& Stepick, 2002; Torney-Purta, Barber \& Wilkenfeld, 2007; Barrett \& Zani, 2015b). For example, minority youth in America are less likely than majority youth to express their political opinions (e.g., by contacting officials, expressing opinions to the media and taking part in protests and petitions) (Zukin et al., 2006), and are also more likely to have lower levels of political knowledge (Hart \& Atkins, 2002; Levinson, 2010, 2012; cf. the discussion of political knowledge in Chapter 2). In addition, American ethnic minority and majority youth participate in different kinds of volunteer activities, with the former participating more in activities relating to their own ethnic community and to other minorities (Stepick, Stepick \& Labissiere, 2008).

PIDOP also found numerous differences between ethnic groups within all nine countries that were studied, not just in the patterns of civic and political participation 
that were displayed by the youth, but also in the psychological and social factors that predicted the different forms of participation. It was also clear that this variability could not be reduced to broad majority vs. minority group differences within individual countries, as there were also significant differences between the two minority groups within each country (Barrett, 2012; Barrett \& Zani, 2015b). Turkey provides a clear example. The data were collected from Turkish and Roma youth and from immigrant Turks who had resettled in Turkey from Bulgaria (to which earlier generations of Turks had migrated during the period of the Ottoman Empire). The youth were aged 16-26 years old. Significant differences in levels of civic and political participation were found between the three groups, with the resettler youth from Bulgaria showing the highest levels of participation, the Roma youth showing intermediate levels, and the native Turkish youth showing the lowest levels. In addition, levels of participation were predicted by different factors in the three groups: by institutional trust in the resettler youth, by the strength of negative emotions (such as anger about social problems) in the Roma youth, and by external efficacy in the Turkish youth such that the less responsive the government was perceived as being towards the views of citizens, the higher the levels of participation (Şener, 2015). At the same time, however, the quality of previous participation experiences significantly predicted levels of participation in all three groups (consistent with the arguments of Ferreira et al., 2012).

Levels of participation have also been found to vary according to migrant generational status. For example, first generation migrants in the USA (who were born and educated in another country prior to migrating) are less likely to be registered to vote than members of later generations (Stepick et al., 2008), and are also less participative in terms of actual voting, volunteering and boycotting products when compared with majority group individuals (Lopez \& Marcelo, 2008). By contrast, second generation individuals (who were born and educated within the USA) tend to be more civically and politically participative than the first generation (Lopez \& Marcelo, 2008; Stepick \& Stepick, 2002).

A distinct generational grouping consists of youth who were born in another country but arrived in their country of residence at an early age, and so have grown up and received most or all of their education within that country. These individuals are sometimes referred to as the 1.5 generation. In cases where they lack formal citizenship of their country of residence because they entered the country with their parents illegally, these individuals can show a distinct pattern of engagement. This is because they do not have legal citizenship in that country and so have a distinctive orientation towards that country; however, they are educated to the same level as their native peers and they also have native proficiency in the national language (unlike the first generation). These youth often have a good understanding of the society in which they live and of its institutional structures. It has been found that, in the USA, due to their knowledge and skills, 1.5 generation youth tend to act on behalf of other, less well-positioned, minority and migrant individuals, and undertake voluntary and community service and engage in political leadership (Seif, 2010). 
Because ethnic minority individuals frequently have lower SES than members of the ethnic majority group within a country, it is arguable that at least some of the differences in levels of engagement between minority and majority youth stem from the reduced opportunities for participating and for acquiring civic skills that are associated with lower SES and lower educational attainment (Diemer \& Li, 2011; Hart \& Atkins, 2002; Levinson, 2012). Lower levels of participation among minority youth may also be due to institutional and social discrimination based on their ethnicity, which generates feelings of exclusion from the society in which they have been born and lived; minority youth may also internalise the negative stereotypes and prejudice against their ethnic group with the consequence that they feel they do not have the right or the ability to engage with official societal forms of participation (Pachi, 2015; Pachi et al., 2011). However, sometimes experiences of discrimination by members of the majority society and of economic disadvantage and deprivation may actually play a galvanising role - such experiences can stimulate minority youth into civic or political activity (Bedolla, 2000; Portes \& Rumbaut, 2001, 2006; Rumbaut, 2008; Stepick et al., 2008; Wray-Lake et al., 2008).

The relationships between ethnicity and civic and political engagement are therefore complex and are the product of a large set of factors. In addition, the patterns of engagement that are displayed by any given individual are often linked not only to their ethnicity or gender, but to the intersection between their ethnicity and gender within a particular locale and country. For example, Bogard and Sherrod (2008) studied 13- to 20-year-old youth who attended high school in the USA. The sample included European American, African American, Hispanic, Asian and other or mixed ethnicity youth. Examining these youths' patterns of civic and political engagement, they found that these patterns were linked to complex multiple interactions between the specific ethnicity of the individual, their gender and their levels of community and school participation.

Similar findings concerning interactions between ethnicity and gender that are distinctive to particular locales and countries (and sometimes to particular age groups as well) also emerged from the quantitative research conducted by PIDOP (Fernandes-Jesus et al., 2015; Gavray et al., 2015; Pachi \& Barrett, 2012b, 2012c). The accompanying qualitative focus groups helped to throw light on these interactions. For example, the focus groups conducted with the English, Bangladeshi and Congolese youth in England (Pachi et al., 2011) revealed that gender differences in views about women's rights were much more pronounced among the female Bangladeshi participants than any other subgroup (see the discussion in Chapter 1). These young women deplored their parents' traditional cultural view that women should restrict themselves to the domestic sphere and not get involved with issues outside the home either civically or politically. However, only the Bangladeshi females expressed this point of view. The focus groups further revealed broader frustrations and tensions arising from the incongruence between the values of the home ethnic and religious culture and the values of wider British society; this broader issue was voiced by both 
the Bangladeshi and Congolese females, but in different ways (Pachi \& Barrett, 2014). In the case of the Bangladeshi females, they noted that female confinement to the home actually stood in contrast to the Muslim discourse of female empowerment, and to the putative equality of women and men privately, socially and politically espoused by Islam. By contrast, the Congolese young women also talked about the incongruence of female roles in Congolese and British cultures but did so in cultural rather than religious terms. They saw Congolese cultural prescriptions on gender roles as being inhibitory for any type of civic or political engagement. These findings align with the literature on ethnic minority women and the pressures and challenges they face (e.g., Dion \& Dion, 2001; Maira, 2002; Stockard \& Johnson, 1992) and underline the need for culturally specific research which allows for a deeper exploration and understanding of precisely how ethnicity and gender (and age) intersect in generating the concerns, interests and patterns of engagement of specific subgroups of minority youth in particular countries and locales.

\section{Demographic factors: Conclusions}

This review of demographic factors reveals that there are widespread differences in young people's civic and political engagement as a function of their SES, gender and ethnicity. However, the differences that have been found are by no means either universal or consistent. Furthermore, the differences that are linked to demographic categories are complex, with patterns of engagement sometimes being specific to particular subgroups defined in terms of the intersection between two or more demographic categories (e.g., specific to girls of a particular age with particular ethnic affiliations who are living in a particular locale in a particular country). The picture that emerges from this body of research is that the lives of young people show enormous heterogeneity as a function of SES, gender, ethnicity, locale and national context, and their civic and political interests and concerns inevitably vary accordingly. It is perhaps not surprising, therefore, that their patterns of civic and political engagement and participation vary as well and are often specific to the particular demographic niches which they occupy.

\section{Conclusions}

In this chapter, we have reviewed the research literature on the social and demographic factors that are related to young people's civic and political engagement. As we have seen, there are many social factors linked to youth engagement and participation, as well as considerable demographic variation in patterns of youth engagement and participation. While the research that has been conducted to date has undoubtedly been extremely informative about both social and demographic factors, there are several issues that would benefit from further research.

For example, although there has been a great deal of research into the role of the family, the school and youth organisations, there has been far less research 
into the role of the mass media. For example, little attention has been paid to the effects of young people's consumption of news and current affairs from different types of mass media outlets (e.g., broadsheet newspapers and public service television news vs. tabloid newspapers and commercial television news) or the effects of their consumption of entertainment, commercial advertising and political advertising on their civic and political engagement. The phenomenon of media malaise and the concept of a virtuous circle, as well as the possibility that different effects might arise from different types of media content, need much more extensive investigation in relationship to young people than has been undertaken to date.

Additional research is also required into the role of popular music. While the work of Street $(2003,2012)$ and Pachi and Barrett (2015) has made a useful start here, many more music genres need to be explored for the messages that they communicate either explicitly or implicitly to young people in relationship to the civic and political worlds. Young people's perception, reception and appropriation of these messages also need to be properly explored. Given the ubiquitous role that popular music plays in the lives of most young people today, this line of research would seem to be particularly important to pursue.

More generally, much greater attention also needs to be paid to the social and psychological processes that facilitate young people's adoption of the civic and political interests, values and practices that are modelled by their parents, teachers and peers. In addition to exploring how and why some young people adopt the orientations and practices of other people in their environments, this research also needs to explore how and why some young people fail to adopt, or even actively resist, the messages that are communicated to them by other people. And, in pursuing this line of research, caution will need to be exercised in interpreting the causality that operates between the sources of influence and the engagement of developing youth, insofar as young people themselves, through their own discourse and behaviour, can have reciprocal effects on other people. This means that the social and psychological processes underlying patterns of social influence will need to be explored using appropriate research methods that are able to identify the direction of causality (e.g., longitudinal panel designs).

Another phenomenon that still needs to be investigated is the process through which citizenship behaviours that are practised within small, intimate groups subsequently come to be extended to larger frames of reference such as the neighbourhood community, the wider locale in which they live and indeed the polity (if they are extended that far). Research needs to explore how this generalisation takes place and the role of emotional bonds, motivations and the available political opportunity structures in the process.

There has also been very little research into how young people in general perceive and feel about the youth sections of political parties. While some attention has been paid to the perceptions and feelings of those individuals who join these sections, little attention has been paid to the views of those who do not join them. Such research could be of considerable benefit to political parties seeking 
to expand the membership of their youth sections, particularly if it uncovers negative perceptions of these youth sections and identifies the particular features of youth sections that are held in negative regard.

As far as demographic factors are concerned, the research has consistently identified SES as one of the most important factors that is related to variability in youth civic and political engagement, although this relationship has been found to vary depending on whether current engagement or future expected engagement is involved. The relationship may also vary depending on whether individual or collective activism is involved. There is clearly much more work that needs to be conducted to unpack why links between SES and engagement might differ according to time frame and type of activism.

Finally, it is worth reiterating here once again that the research into social and demographic factors that has been reviewed in this chapter leads to the same conclusion as the research on psychological factors that was reviewed in the previous chapter: namely, that patterns of youth engagement and participation, and the factors that predict these patterns, sometimes vary according to the intersections between multiple demographic factors, with these patterns sometimes being specific to particular subgroups that are defined through the intersection of nation, ethnicity, gender, age, SES and locale. Thus, future research, if it is to cast meaningful light on how youth civic and political engagement is generated, will need to pay much greater attention to the social processes that occur within highly specific subgroups in the youth population, rather than assuming that social processes that are found in one particular subgroup of youth will necessarily occur in other subgroups.

It will also be important for future research to bear in mind that the social and demographic niches that youth inhabit are themselves always situated within much broader macro contexts that are characterised by particular cultural, economic, political and institutional features. Importantly, youth civic and political engagement is related not only to social and demographic factors but also to the broader macro contexts within which young people live. In the next chapter, we turn to this body of research that has been conducted on the links between young people's civic and political engagement and their macro societal contexts. 


\section{4}

\section{MACRO CONTEXTUAL FACTORS LINKED TO YOUTH CIVIC AND POLITICAL ENGAGEMENT}

The previous two chapters have explored the psychological, social and demographic factors that are linked to youth civic and political engagement. By contrast, the present chapter focuses on macro factors. By macro factors, we mean the large-scale factors that together define the broader societal and institutional context within which an individual lives. These factors include historical, cultural, economic, political, legal, policy and technological factors.

This chapter examines a wide range of macro factors including: the broad patterns of political and civic engagement that occur among adults within a country; the historical, cultural, economic, institutional and legal characteristics of a country; public policies on young people's active citizenship; the legally specified minimum age for voting; the provision of youth organisations; the availability of a youth parliament within a country; the education policies and regulations that determine the quality of the formal education that young people receive within a country; the role that digital technology, the Internet and social media play in youth civic and political engagement; and youth mobilisation by politicians and political parties.

\section{The relevance of adults' civic and political engagement to young people's civic and political engagement}

Adults' patterns of civic and political engagement within a country are important for understanding patterns of youth engagement because the patterns of engagement that are displayed by adults are typically mirrored in the patterns displayed by young people living within the same country. This finding emerged clearly from a study by Sloam (2016). Analysing the patterns of political participation exhibited by 15 - to 24-year-olds in 15 European countries, he found widespread differences in these patterns from one country to another. Interestingly, 
however, the rate of participation among youth was proportional to the rate of participation among adults living within the same country. Thus, the three countries with the highest rate of voting among adults (Belgium, Denmark and Sweden) were also the three countries that had the highest rates of youth voting, while those countries with the lowest rates of voting among adults also had the lowest rates of youth voting (Luxembourg, Ireland and the UK). Exactly the same applied to the other forms of participation that were examined (displaying a badge or sticker, signing petitions, joining boycotts and participating in a demonstration) - the extent to which youth engaged in each individual practice was proportional to the extent to which adults living in the same country engaged in that practice. In short, youth political and civic engagement was directly proportional to the broader political-civic participatory culture among adults in the country where they lived. This finding is not surprising, given that adult behaviour often functions as a powerful role model for young people, particularly in relationship to their prosocial and civic behaviour (Eisenberg, Spinrad \& Knafo-Noam, 2015).

It is also noteworthy that the political-civic participatory culture of adults within a country is itself systematically related to a wide range of macro factors. Thus, the participatory culture of adults may well mediate the effects of macro factors on youth civic and political engagement. There are numerous macro factors that have been found to be systematically linked to adults' patterns of participation, including characteristics of the electoral, political and legal institutions that are used to govern the country, the level of economic development of the country and the recent political history of the country.

For example, the likelihood of adults turning out to vote in elections is related to various characteristics of the electoral system (Geys, 2006). More adults are likely to vote when:

- A proportional representation system is used rather than a first-past-the-post system

- Voter registration processes are simple rather than cumbersome

- When voting takes place on a rest day rather than a working day

- Voting is compulsory rather than optional

Voter turnout in elections is also related to certain broad characteristics of a country's population. Turnout is higher when the electorate is small, the population is stable (in terms of the length of time that individuals have resided in specific locations) and the ethnic minority share of the total population is small (Geys, 2006).

In addition, the structure of political institutions within a country shapes the particular forms of non-electoral political participation that are used by adults. For example, in countries where political institutions provide many opportunities for citizens and civil society organisations to influence policy (e.g., Switzerland), there are high levels of moderate forms of action such as signing 
petitions and participating in campaigns. By contrast, in countries where there are relatively few such opportunities (e.g., France), there are high levels of more extreme forms of action such as demonstrations and strikes (Kriesi, Koopmans, Duyvendak \& Giugni, 1995). Likewise, it has been found that adults are more likely to engage in non-conventional political and civic participation in countries that have decentralised political, administrative and fiscal systems (Vráblíková, 2014; Vráblíková \& Císař, 2015).

That said, PIDOP found that all forms of participation (apart from voting) are higher among adults in countries in which there is a high level of government accountability. In other words, participation is higher in countries where the government is held to account for its actions by a free press and at periodic elections, financial contributions to political parties are openly disclosed, freedom of the press is guaranteed and corruption is controlled (Brunton-Smith, 2011; Brunton-Smith \& Barrett, 2015).

PIDOP also discovered that the forms of participation used by adults are related to the human rights and legal institutions of the country in which they are living. Three features are especially important here: rule of law (i.e., the presence of an independent judiciary, impartial courts and legal protection for minorities), human rights record (i.e., women's rights, minority rights and legal prohibitions on the use of torture) and civil liberties (i.e., freedom of expression and protest, freedom to form professional organisations and trade unions, and religious tolerance). Adults are more likely to participate using civic and conventional political means in countries that are high on the rule of law and on their human rights record; however, they are more likely to participate using nonconventional means in countries that are high on civil liberties (Brunton-Smith, 2011; Brunton-Smith \& Barrett, 2015).

In addition, PIDOP confirmed that the economy of a country is a further relevant macro factor: all forms of participation other than voting are higher in countries that have a well-performing economy. In other words, participation is higher in countries where GDP growth and GDP per capita are high, gross domestic savings as a proportion of GDP are high, foreign direct investment is high, unemployment is low and effective tax collection takes place (BruntonSmith, 2011; Brunton-Smith \& Barrett, 2015).

Adults' patterns of political and civic participation are also linked to the recent history of the country in which they live. For example, in the 1990s, adults living in the former communist countries of Eastern Europe had lower levels of participation than those living in Western European countries that had a longstanding history of democracy. This gap widened further between 1990 and 1999, with the proportion of people who took part in non-conventional forms of participation in Western Europe rising by 7\% while the proportion in Eastern Europe fell by $9 \%$. However, participation levels remained high during this period in those particular Eastern European countries where collective popular action had contributed to bringing down the communist regime (Czechoslovakia, East Germany and Poland); participation only declined in those countries where the transition from 
communism had been driven by political elites (Bulgaria, Estonia, Hungary, Latvia, Lithuania, Romania and Slovenia) (Bernhagen \& Marsh, 2007).

Finally, the cultural characteristics of countries are also linked to adults' patterns of political and civic participation. For example, in countries that have predominantly Catholic traditions, women have lower levels of political interest, political knowledge and political participation compared to women in countries that have predominantly Protestant traditions (Galligan, 2012; Inglehart \& Norris, 2003). The availability of associations, organisations and social networks within a country is also related to higher levels of participation among adults (Putnam, 2000). Associations and organisations are important because they provide contexts in which individuals acquire the skills that are needed for political participation and provide individuals with opportunities to engage in political discussions and to become civically and politically active.

In short, adults' patterns of civic and political participation are systematically related to a wide range of macro factors, including: characteristics of the electoral system; the structure of political institutions; government accountability; the country's record on rule of law, human rights and civil liberties; the country's level of economic development; the recent political history of the country; and the cultural characteristics of the country. Insofar as adults' patterns of participation are mirrored in patterns of youth participation (Sloam, 2016), the latter are similarly related to these various macro factors.

\section{Direct evidence of the relationship between macro factors and youth engagement}

Additional, more direct, evidence on the relationship between macro factors and youth engagement was obtained in CIVED (Torney-Purta et al., 2001), ICCS 2009 (Schulz et al., 2010) and ICCS 2016 (Schulz et al., 2017). All of these studies also found significant cross-national differences in 14-year-olds' political and civic knowledge, attitudes and engagement. These differences were not random but were systematically related to particular characteristics of the countries in which these teenagers were living.

For example, CIVED found differences in levels of trust in political and legal institutions among the 14-year-olds according to whether their country had more or less than 40 years of continuous democracy: higher levels of trust were found among those who lived in countries with longstanding democratic traditions. However, the importance which they attributed to conventional citizenship practices such as voting and joining a political party tended to be lower in countries in which there were longstanding democratic traditions, and higher in countries in which conventional political institutions and forms of participation had been strengthened in the previous 30 years (Torney-Purta et al., 2001).

CIVED also uncovered significant differences in levels of political knowledge across countries. Youngsters living in ten countries (including Finland, Hong Kong and the United States) had scores that were significantly higher than the 
international average, while those living in eight countries (including Romania, Chile and Colombia) had scores that were significantly lower than the international average. The levels of political knowledge among the 14-year-olds were significantly correlated with the levels of economic development (indexed in terms of gross national product per capita) of the country in which they lived (Torney-Purta et al., 2001).

Likewise, both ICCS 2009 and ICCS 2016 found differences in 14-year-olds' political knowledge across countries. In both cases, these differences were significantly associated with their country's score on the United Nations Human Development Index (HDI). The HDI is a composite index that captures the extent to which the people living within a given country have long and healthy lives, are knowledgeable and have a decent standard of living - in other words, the HDI reflects the level of health, educational and economic development of a country. Both ICCS studies found a strong positive association between the level of political knowledge among 14-year-olds and the HDI of the country in which they lived (Schulz et al., 2010; Schulz et al., 2017).

Further evidence concerning the relationship between macro factors and patterns of civic and political engagement among youth comes from PIDOP (Brunton-Smith, 2011; Brunton-Smith \& Barrett, 2015). As noted already, these analyses revealed that, among adults, all forms of participation other than voting are higher in countries that score well on economic performance, government accountability, rule of law and human rights. Exactly the same relationships between levels of participation and these four macro factors were also found among 15- to 24-year-old youth. In other words, these relationships were present irrespective of age - not only adults but also youth displayed these relationships, consistent with the findings of Sloam (2016).

\section{Explaining the influence of macro factors on youth engagement}

The causal relationships through which many of these macro factors impact on youth engagement are almost certainly indirect and mediated by demographic and social factors (see Figure 1.1 in Chapter 1). For example, the economic characteristics of a country are most likely to impact on youth engagement in two main ways. First, they are likely to influence the socio-economic situation of youth and hence their ability to acquire the material resources and the civic skills that are required for political activity (Brady et al., 1995). Second, they are likely to impact on national expenditure on educational provision (IES, 2015), with the quality of that provision being the more immediate proximal social factor that affects young people's experiences at school (education being a significant source of influence on young people's civic and political engagement - see Chapter 3).

Social mediators are presumably also responsible for the effects of historical, cultural and political macro factors on youth engagement. Indeed, it seems highly 
likely that it is adults in youths' social environments, especially their parents and teachers, who are the critical mediators between macro factors and youth civic and political engagement. This is because macro factors provide the background against which parents and teachers position themselves ideologically, politically and socially. Their positioning will influence their beliefs, attitudes, values, discourses and practices. Youth are then exposed to the discourses and practices of these individuals (rather than to the macro factors per se), with it being these more proximal discourses and practices in their immediate social environment that actually influence their patterns of engagement and participation. In short, it is likely that very few macro factors operate independently of social and demographic factors. Instead, it is much more likely that macro, demographic and social factors are intertwined in complex causal pathways. These pathways have not been investigated in any great depth to date. This is a task which research in the future will need to tackle.

\section{National policies on migrant integration and naturalisation}

In the case of youth who migrate to another country either on their own or with their families, a major constraint on, or facilitator of, their political participation is the set of legal, institutional and educational arrangements for migrants that are in place in the country to which they have migrated. These arrangements vary considerably from one country to another. They can also vary within individual countries according to migrants' national or ethnic origins (e.g., depending on whether there are former colonial links to their country of origin). Some countries also allow naturalisation based on the individual having lived within the country of residence for a certain number of years, being descended from a citizen of the country, or being married to a citizen of the country. The extent to which a country facilitates or impedes migrants' access to naturalisation, grants or denies voting rights to migrants, ensures or blocks the representation of migrants' interests in the political system, and establishes or fails to establish formal consultative bodies through which migrant communities can communicate their views to local and national government can all have a significant impact on migrants' political engagement (Ireland, 1994; Martiniello, 2005; Penninx, Martiniello \& Vertovec, 2004). The legal rules for naturalisation are especially important insofar as acquiring the citizenship of the country bestows full voting rights on those who are above the legal minimum voting age.

Of course, whether or not immigrants and their offspring actually take up the opportunities for participation that are provided by the institutional framework depends on a wide range of factors. These include, for example, their own political values, interest and attitudes; their knowledge of the country's political system; their levels of previous political engagement in their country of origin; whether or not they perceive their presence in their country of residence as being permanent; their sense of belonging to the country of residence; and the availability of migrant associations and organisations within the country of residence 
(Martiniello, 2005). Importantly, there are many opportunities for participation available to migrant youth beyond electoral participation. For example, migrant youth who are not naturalised can nevertheless still participate legally in both civic and political actions - they can participate through community organisations, trade unions and pressure groups such as anti-racist, human rights or environmental organisations. They can also engage in a wide variety of civic and non-conventional political actions, including consumer activism, fund-raising and charitable activity, writing letters to politicians and public officials, signing petitions and participating in political demonstrations.

Further macro factors that can facilitate or hinder the civic and political engagement of migrant youth stem from the education system into which these youth are enrolled in their new country of residence. Various structural features of the education system may lead to low educational achievement by migrant students, which, as we saw in Chapter 3, can have significant consequences for their civic and political engagement. For example, educational systems that sort students into different ability tracks at an early age often lead to lower educational achievement by migrant students; achievement among migrants tends to be higher in comprehensive education systems which operate a late selection of students into different ability tracks (NESSE, 2008). In addition, migrant students benefit if their schools offer support for their language needs when their mother tongue is not the official language of instruction. The amount of time that schools devote to teaching immigrant pupils the language of instruction varies substantially across countries. For example, in one European survey, it was found that the figure ranged from two to 14 hours per week depending on the country (Eurydice, 2009). Hence, in countries where late selection and extensive linguistic tuition is available, the level of educational achievement by migrant students tends to be higher, and as a consequence the civic and political engagement of those students is also likely to be higher.

However, it is not only young migrants attending school who can benefit from receiving instruction in the language of the host country. Migrants who are beyond school leaving age can also benefit from such instruction. Indeed, there are a large number of measures that can be taken to aid the integration of migrants into the country of residence and boost their civic and political participation (Council of Europe, 2016a). These include:

- Giving migrants who have limited proficiency in the language of their country of residence access to language instruction

- Providing integration programmes that focus on opening doors to the local community, so that migrants meet local organisations, services and mentors who are open to diversity and interested to support their integration

- Requiring that staff who deliver migrant integration and language programmes work with volunteers from the local community and promote intercultural activities such as conversation tandems where migrants and non-migrants can learn about each other's culture and way of life 
- Creating grants to support migrant-run associations and support the setting up of mainstream civic and political organisations to mentor migrants

- Recruiting residents of migrant background to local consultative bodies of all types

- Granting the right to vote and stand in local and regional elections to migrants after a minimum period of legal residence (e.g., five years)

- Granting an entitlement to citizenship for first-generation migrants after a minimum period of legal residence (e.g., ten years)

- Granting an entitlement to citizenship for migrants' children who have been educated or born in the country

In short, many different policies and institutional arrangements on migrant integration, naturalisation and the education of migrant youth can have significant effects on the civic and political activity of migrant youth. Depending on their configuration, these legal and institutional arrangements can either facilitate or hinder these youths' civic and political engagement.

\section{Youth policies}

Youth policies also form an important part of the institutional macro context within which youth civic and political engagement occurs. These policies may be developed at different levels of governance, for example at local, regional or national level (and, in the case of European countries, at European level as well). Youth policies are important because they contribute to framing public debates and discussions about youth engagement. Policies that are formulated by national governments are especially important in this respect because they not only help to frame public discussion and debate but also delineate official expectations of young people's civic and political engagement and help to shape government spending priorities and the allocation of resources to support youth engagement, for example, through the provision of funding for youth organisations.

For this reason, PIDOP examined national governments' policies on active citizenship and participation among youth in seven European countries: Belgium, Czech Republic, Germany, Italy, Portugal, Turkey and the UK (Bee \& Guerrina, 2014; Guerrina \& Bee, 2012). Official government policy documents published between 2004 and 2009 were analysed to identify the government discourses that were used about youth engagement in these countries.

It was discovered that these documents contained several common emphases across countries. For example, most national governments emphasised the importance of encouraging the active participation of young people and of strengthening tolerance, respect for diversity, democracy, justice and human rights. In addition, in the Czech Republic, Germany, Italy and Turkey, there was an emphasis on the need to enhance and promote intercultural dialogue among young people. 
However, some notable differences across countries were also found. For example, the Portuguese policy documents drew attention to the need to empower youth organisations by encouraging and supporting their activities, to ensure the representation of youth organisations at the municipal level, and to promote the discussion of issues related to the aspirations and needs of young people. The need for youth councils and organisations to be accepted and included as equal partners in dialogue was also emphasised in Germany, while in the Czech Republic the need to contribute to the development of organisations that support the activities of young people was also identified as a key objective. However, a very different orientation was present in the UK policies, which instead focused on youth justice and social justice, the objective being to enhance the government's understanding of the needs of young people who commit offences, so that these needs can be properly addressed, and to ensure that the voices of children and young people are able to shape and influence safeguarding policies and practices. Consistent with other UK government policies at that time, the UK documents also stressed the need for policies to support youth activities that help to enhance community cohesion and foster a sense of social solidarity at the local level. In Turkey, by contrast, the official documents that were analysed emphasised the role of social services as a tool for remedying social problems and enhancing life standards, the importance of improving protective and preventive measures in social services and the need to provide social services for those who are in need regardless of class, language, religion and region.

In a subsequent analysis, Bozkurt, Çok and Şener (2015) examined a more recent Turkish government document which contained the first comprehensive statement of policy strategies related to youth in Turkey - the National Youth and Sports Policy Document. This document was published by the Turkish Ministry of Youth and Sports in 2013. Bozkurt et al. found that, despite the existence of government discourse promoting youth participation in the document, there were also signs that the government viewed youth as a segment of the population that needed to be shaped, controlled and protected, rather than as active citizens who should be involved in the decision-making processes that affect themselves and society more generally. For example, there were references in this policy document to the vulnerability of youth, the need to protect youth from bad habits and the need to prevent youths' alienation from national and moral values. Commenting on another document published in 2012 by the conservative ruling party, the Justice and Development Party (AKP), Bozkurt et al. note that the main mission ascribed to youth by the party in this document is to be virtuous and exemplary. Bozkurt et al. argue that there is a tension within the Turkish government's view between, on the one hand, the engagement of youth in civic and political life (which encourages civic activism among youth) and, on the other hand, the AKP's avowal of conservative values (which discourages such activism). They argue that this tension erupted during the Gezi Park protests in Istanbul in 2013, when youth willingly took on the role of civic activists but in doing so were brutally attacked by the police under the control of the government. 
In another study of youth policies within an individual country, Villano and Bertocchi (2014) examined 32 Italian national and regional documents in order to identify their underlying assumptions. The Italian Ministry for Youth, which was established in 2008, is mandated to deal with, among other issues, the rights of young people to freedom of speech and forms of association, their needs and interests and their right to take part in public life. However, the delivery of this agenda is delegated to the regions of Italy. Examining the documents from the region of Emilia Romagna, Villano and Bertocchi note that the region places high value on the participation of youth in civil and social life, on the promotion of active citizenship and on intergenerational, intercultural and inter-religious dialogue to support the cohesion and the growth of the community. This is coupled to practical support and funding for various forms of youth association aimed at youth activities as well as support for the involvement of young people in decision-making processes by means of the practices of e-democracy. In short, at the official level, there are attempts to promote the civic and political participation of young people by supporting the creation and development of youth associations and organisations.

However, in addition to examining these policy documents, Villano and Bertocchi conducted interviews with politicians and representatives of nongovernmental organisations (NGOs) that promote projects for young people. The interviews revealed that, in practice, attention to the active participation of young people has not been very widespread to date, with there being many gaps in the implementation of the official policy agenda. It was noted that there were missed opportunities offered by the European Union to promote young people's participation and also a widespread failure to take advantage of available funding opportunities. This has been accompanied by cuts to public funding for training and a failure to invest sufficiently in research, universities and schools, which has further exacerbated the problems in the implementation of the youth policies. In addition, the interviewees reported that many young people are much more orientated towards non-conventional and indirect forms of participation rather than the traditional forms of conventional participation such as voting, which makes the encouragement of the latter much harder to achieve. In other words, what emerges from this study is a gap between what may be very well-intentioned policies and their actual implementation on the ground.

There can, of course, also be a further gap between the measures that are implemented and the perceptions of those measures and of government intentions by those who are the intended recipients and beneficiaries of the policies. Unfortunately, there is a paucity of concrete research into these sorts of issues in this area. Future research will need to elucidate not only the causal links that exist between government policies and youth engagement but also the mediating role that young people's perceptions of government policies are likely to play in the process. This is because, as we saw in Chapter 2, trust in government institutions, perceived institutional effectiveness and the emotions that are linked to the perceived fairness of those institutions are important psychological factors that are related to youth engagement and participation. 


\section{Voting age}

One macro factor that obviously affects youth political participation is the legally specified minimum age of voting within the country in which young people live. The most common voting age around the world is 18 years, although some countries allow those aged 16 years and above to vote in national elections (e.g., Argentina, Austria and Brazil), while a few countries do not allow youth to vote in such elections until they are 21 years of age (e.g., Malaysia and Singapore). Even though the minimum age of voting in national elections may be 18 years, youth are sometimes allowed to vote from the age of 16 in certain types of elections (e.g., local or regional elections or referenda) in some countries. The extent to which young people actually vote once they have attained the minimum age for voting additionally depends on whether voting within the country is compulsory or optional - voting rates are higher when it is compulsory (Geys, 2006).

In recent years, there have been efforts in a number of countries to reduce the voting age from 18 to 16 years. The most common argument made against making such a change is that 16- and 17-year-olds lack sufficient political maturity in terms of their ability to consider the effects of their voting decisions on society, their country and themselves. This argument does not rule out the possibility that there may be some 16- and 17-year-olds who do possess the necessary level of political maturity; instead, it simply assumes that the likelihood of someone aged 18 years or older possessing political maturity is higher than the likelihood of someone aged 16 years possessing it, and that age 18 is a pragmatic cut-off point above which a sufficient proportion of citizens are likely to have the necessary political maturity to be able to vote in a meaningful manner.

Chan and Clayton (2006) have usefully evaluated the evidence on the political maturity of 16- and 17-year-olds. They define political maturity in terms of having an interest in politics, having knowledge of the political system, understanding the nature and significance of the issues that are the subject of public and political debate, possessing political convictions that are logically coherent and are not subject to whimsical revision, and appreciating the expected consequences of the political choices that one makes. Reviewing a wide range of evidence collected in British surveys, they show that 16- and 17-year-olds are indeed less mature politically than older people: they are less interested in politics, less knowledgeable about political facts, their attitudes are less coherent and their attitudes are less stable over time. For this reason, Chan and Clayton recommend that the voting age should not be lowered from 18 to 16 .

However, a problem with Chan and Clayton's argument is that the data on 16- and 17-year-olds which they analyse are drawn from individuals who, as we saw in Chapter 1, often have considerable interest in a wide range of both local and global issues but feel excluded from the political process because they do not have the vote and think that politicians do not have any serious interest in their point of view. They therefore reject the conventional political arena and turn instead to single issue causes and use non-conventional political and civic 
forms of participation instead. In other words, it may be precisely because they feel excluded from the conventional political arena that they disengage from it and exhibit lower levels of political maturity in relationship to that arena. It is possible that granting voting rights to 16 - and 17 -year-olds may provide just the incentive that is required to encourage them to learn about conventional politics and to become more politically mature.

One way to test this argument is to examine data from countries in which the voting age has been reduced to 16 in order to see how this change has affected 16- and 17-year-olds' political interest and knowledge, and whether under these circumstances 16- and 17-year-olds' electoral behaviour differs from that of older youth and adults. Such data have been collected in Austria, where the voting age was lowered from 18 to 16 for participation in national elections in 2007. Analyses of Austrian data by Zeglovits and Zandonella (2013) reveal that political interest among 16- and 17-year-olds increased substantially between 2004 and 2008, as did following political news; importantly, political interest in 2008 was highest among those youth who talked to their teachers about politics and who engaged in citizenship activities at school, suggesting that citizenship education in schools can play a significant role in developing the political maturity of new young voters.

Wagner, Johann and Kritzinger (2012) also analysed Austrian data which were collected in 2009. They found that interest in politics was equally high among 16- and 17-year-olds as among 22- to 25-year-olds, and that those aged under 18 were equally motivated to take part in political life as older age groups. Furthermore, these youngest voters' trust in political institutions, and their satisfaction with national and European democracy, were both high, and these youth did not differ from those aged 18 and over in the extent to which they recognised that the national parliament had an important impact on them personally. Finally, Wagner et al. conducted a number of analyses to investigate whether the precise voting choices that were made by 16 - and 17-year-olds and the quality of their decision-making were in any way less good than the decision-making of those aged over 18. They found very few differences between these younger voters and older voters. They conclude that 16 - and 17-year-olds are both able and willing to participate effectively in politics, and that their voting choices are of no lesser quality than those of individuals aged 18 or older.

It is therefore plausible that, in countries where the voting age remains at 18 , many 16- and 17-year-olds lack political maturity primarily because they are not permitted to vote and because they believe that politicians lack serious interest in their views. In addition, it is noteworthy that, given that many 16- and 17-year-olds are still in full-time education, if these youth were to be allowed to vote, they would be able to receive educational support for their political decision-making (e.g., by being encouraged to conduct research into political issues; to explore those issues from a range of different perspectives; to compare and contrast different perspectives; to engage in critical evaluations of perspectives, information and the sources from which information has been derived; 
to think logically and coherently about political issues; and to draw reasoned conclusions). The available evidence is consistent with the view that, under such conditions, high levels of political interest would be generated, which could then have substantial benefits for the future political participation of the individuals concerned insofar as voting is known to be habit-forming, with individuals who have voted in the past being more likely to continue voting in the future (Geys, 2006). Allowing 16- and 17-year-olds to vote has the additional benefit of enabling them to seek political representation on matters that can deeply affect their lives. This will not only reinforce their levels of political internal efficacy but will also have an effect on the candidates who are elected, their political priorities and the extent to which the policies that they put forward take into account the concerns and views of youth.

\section{The provision of youth organisations}

As we saw in Chapter 3, another route that can be used to promote youth civic and political engagement is through the provision of youth organisations. Youth organisations can offer young people a wide range of opportunities to develop their civic and political skills and to become involved with civic and political issues. They help young people to encounter and explore new ways of perceiving social and political issues, to develop communication, public speaking and debating skills, to participate in group decision-making and to take on leadership, organisational and representative roles. The availability of youth organisations in a particular locale is therefore an important factor that can impact on youth engagement and participation within that locale.

A survey of youth organisations in Europe by the European Youth Forum (2016) revealed that these organisations are often founded on a common vision of building a just and fair society. Their missions frequently focus on the empowerment of youth, the mobilisation of youth to contribute to the building of more just and inclusive societies, the encouragement of youth to become autonomous active citizens and the enhancement of young people's participation in decisionmaking processes and democratic structures. It was found that a common general aim is to make young people agents of change in their own communities - key words that often appear in the strategic plans of youth organisations are 'participation', 'engagement', 'empowerment' and 'change'.

Many youth organisations therefore aim explicitly to function as incubators for active citizenship. In pursuing this goal, they provide not only the space for raising awareness of civic and political issues and for discussing these issues, but also the structures and opportunities that may be needed to translate young people's views and ideas into practice. Furthermore, because many youth organisations are youth-led, they often have their own internal participatory and decision-making processes, which means that democracy and participation can be intrinsic to their culture (European Youth Forum, 2016). In other words, by participating in these organisations, young people engage in 
activities and actions that enable them to experience the principles and practice of democracy first hand.

Of course, youth organisations provide a very wide range of different programmes, projects and activities, the nature of which are determined by each organisation's own particular mandate, the context within which it operates, and the particular membership group to which it is dedicated. They also vary in terms of how effective they are in boosting youth civic and political engagement (see Chapter 3 for a review). However, an advantage of youth organisations over schools and universities as incubators of citizenship is that they can reach out to all youth, including disadvantaged youth and those alienated from school, early school leavers and educational dropouts, as well as young people who are not in employment, education or training.

Unfortunately, however, youth organisations are not always available to young people. Their presence within a locale is often crucially dependent on local, regional or national government funding to support their operation (which in turn links back to public youth policies). If public funding is not available, these organisations can operate only through the good will of dedicated volunteers, through religious or other private associations or through private donations. In locations where there is a paucity of youth facilities and organisations, young people can experience a sense of frustration, feel a lack of power in their own communities and express antipathy towards local authorities. It is noteworthy that, when Weller (2007) asked a group of alienated 13- to 16-year-old English teenagers what they would like to change about where they lived, most called for more facilities such as youth clubs and for 'more say over what happens'. If public authorities genuinely wish to equip young people with a sense of civic purpose and community involvement, then one of the most effective actions they can take to bring about these outcomes is to support the provision of suitable youth organisations through targeted funding.

\section{Youth parliaments}

Another action that public authorities can take to support and encourage young people's engagement with politics is to operate a youth parliament. A survey of 128 countries conducted by the Inter-Parliamentary Union in 2016 revealed that youth parliaments exist in about half of the countries that were surveyed. The structure and mode of operation of these parliaments vary considerably from one country to another. Some but not all youth parliaments have a formal relationship to the national parliament, and in some cases the national parliament building is also used for meetings, with parliamentarians and parliamentary staff being involved in their operation. The majority of youth parliaments involve teenagers, although a few involve children aged 7 or 8 years upwards, while others involve youth from the voting age of 16 or 18 years up to the age of 30 or 35 years. Youth parliaments vary in terms of how their participants are selected. Sometimes school-based elections take place; in other cases, there is an application process; 
occasionally, there are open public elections or public-speaking competitions. The frequency with which youth parliaments meet also varies across countries. Some meet only once per year, following a period in which the participants are prepared for the meeting either by their schools or by youth organisations; others meet more frequently, sometimes every two months. Meetings may be either plenary-based or committee-based. Length of tenure in office lasts anywhere between one day and two years (Shephard \& Patrikos, 2013).

Youth parliaments usually have several objectives (Inter-Parliamentary Union, 2016). First, they typically aim to give young people the chance to express their views to those in power and to contribute to the youth agenda in the development of public policies. Allied to this, some youth parliaments try to create ongoing links between youth and government and parliamentary officials. Second, youth parliaments aim to empower young people politically by arousing their interest in public affairs, equipping them with debating and leadership skills and providing them with personal experience of participatory democracy. Third, youth parliaments commonly seek to raise awareness of political and parliamentary processes among youth by giving them an understanding of how, for example, bills are drafted, laws are passed through parliament, and the various ways in which members of parliament conduct constituency work and liaise and interact with the media.

While all of these aims are eminently praiseworthy, youth parliaments have been criticised on a number of counts. First, there is the common criticism that there is little direct evidence of any meaningful impact of youth parliaments on government policy (although a few notable exceptions do exist, such as the Scottish Youth Parliament). At best, it has been suggested, most youth parliaments have a more general indirect effect of keeping particular issues or points of view in the political arena (Shephard \& Patrikos, 2013). For this reason, it has been argued that, as a minimum requirement, governments should be formally obliged to issue responses explaining why they support or oppose proposals that have been made by the youth parliament so that youth can feel that their views are being taken seriously and are being considered by those in power (Kyranakis \& Nurvala, 2013).

Second, it is often officially maintained that involvement in youth parliaments enhances young people's public speaking, debating, collaborative, leadership and organisational skills, and increases their levels of political engagement. However, there is a notable lack of research into the effects of youth parliaments on young people and therefore very little research evidence to support these claims. Indeed, it actually seems much more plausible that it is youth who already possess these kinds of skills, and who are already politically engaged, who are the most likely to become members of youth parliaments in the first place. That said, the skills and knowledge of these individuals are likely to be further enhanced as a consequence of the experience that they acquire through the youth parliament. Indeed, in a rare study into the effects of participation in a youth parliament (in Brazil), Fuks and Avila Casalecchi (2012) found that the participants, who were 
high school students, showed a substantial increase in trust and confidence in the State Assembly as a consequence of their participation in the youth parliament, and that this increase was associated with the acquisition of knowledge about the Assembly. More research into the effects of youth parliaments on their participants is needed.

Third, it has been argued that youth parliaments favour select groups of youth, in particular those who are from more affluent backgrounds, those who happen to attend particular schools or youth organisations, and those who have a particular interest in politics (Wall \& Dar, 2011). And indeed, young people from vulnerable or marginalised groups, such as ethnic minority youth, disabled youth, youth in care and homeless youth, tend not to be involved in youth parliaments (Turkie, 2010). Barriers to participation in a youth parliament include: the informal requirement for youth to be highly motivated, articulate and ambitious in order to become a member of a youth parliament; the cost in terms of time, effort and financial resources to reach out to marginalised youth in order to draw them into a youth parliament; and the perception that quotas that could be used in principle to ensure the involvement of marginalised youth are usually unworkable, tokenistic or patronising in practice (Turkie, 2010).

Despite these reservations, it is nevertheless the case that the availability of a youth parliament within a country does at least provide a further additional channel through which youth can be engaged with political and policy processes. That said, if such an institution is to command broad respect among youth in general, rather than only among a relatively small number of advantaged youth, then the processes used to recruit youth to the parliament need to be sufficiently robust so that it is not exclusive to those who are socio-economically and educationally privileged. In addition, the formal link between the youth parliament and the national parliament and policymakers needs to be sufficiently strong to ensure that the youth parliament is not perceived by young people as being politically powerless and irrelevant.

\section{Education policies and regulations on citizenship education}

As we saw in Chapter 3, both the citizenship education courses which young people receive at school and the educational practices that are used by teachers in schools can have a significant impact on their civic and political engagement. In particular, engagement is enhanced when schools provide citizenship education courses that require students to pay attention to national issues, government and politics, and to think about political issues in relationship to contemporary events, and when schools provide training in civic skills. Further enhancement of their engagement occurs when schools have an open classroom climate, operate student councils or parliaments and provide high-quality service learning for students.

A critical issue here is the particular type of citizen that citizenship education should aim to foster. Should it produce citizens who are knowledgeable 
about current political institutions and processes, who use official political processes and who feel an obligation to participate through these means? Or should it produce citizens who engage in critical reflection, direct participation and community-based action and who utilise interactive information technology to learn and to exchange views about civic and political issues? The former has been called dutiful or duty-based citizenship, while the latter has been called engaged or actualising citizenship (Bennett, 2007; Dalton, 2008). The key question is whether citizenship education should aim to promote just one of these two types of citizen, or whether both forms should be promoted, which is arguably the ideal.

Whether or not optimal curricula, pedagogies and school practices are in place to foster this ideal form of citizenship depends to a large extent on the education policies, regulations and recommendations that are provided by the relevant educational authorities (whether these be at the national, regional or local level) and on the provision of suitable levels of funding and resources for implementing those policies, regulations and recommendations. Two aspects of the education system are particularly important in this respect: policies and regulations to ensure that an appropriate and effective citizenship education curriculum is provided by schools, and the provision of suitable teacher education and training to ensure that teachers are competent in the practices and pedagogies that need to be applied for delivering high-quality citizenship education.

In order to examine these issues, Eurydice (2017) conducted a review of national policies on citizenship education across Europe. The review covered 37 countries in total, including the 28 members of the European Union as well as Bosnia and Herzegovina, the Former Yugoslav Republic of Macedonia, Iceland, Liechtenstein, Montenegro, Norway, Serbia, Switzerland and Turkey. Because some countries have more than a single education system (e.g., Belgium and the $\mathrm{UK}$ ), the review focused its attention on the formal requirements for citizenship education as it is delivered in public sector schools in 42 education systems.

The review revealed that all 42 systems had curricula in place which were aimed at developing the abilities of students to interact effectively and constructively with others, to act in a socially responsible manner, to act democratically and to think critically. Students' interpersonal interactions were usually targeted at primary school level, critical thinking at lower secondary level, and learning how to act democratically at upper secondary level. Three main approaches were used for implementing citizenship education in the curriculum: as a separate school subject, integrated into a broader learning area such as the social sciences, or as a cross-curricular theme for delivery by all teachers. Most systems used either the integrated or cross-curricular approach (and both were frequently used together), meaning that a substantial proportion of teachers were expected to be involved in citizenship education. Citizenship education was less often implemented as a compulsory separate subject; in those systems where this approach was adopted, it tended to be used at secondary rather than primary school level. 
Almost all education systems had recommendations in place for schools to operate student councils at secondary level. However, there were significantly fewer recommendations on organising participation through student councils at primary level. Very few education systems provided recommendations on encouraging students to interact with political authorities. Twenty-nine education systems provided recommendations on the provision of extra-curricular opportunities to support citizenship education, but these recommendations were made most frequently in relationship to lower and upper secondary education rather than primary education. The most common recommendations on extracurricular activities that were made were for environmental activities, followed closely by activities to raise awareness of political life, while recommendations on providing opportunities for voluntary work were the least common (particularly at primary and at lower secondary levels).

Regulations and recommendations on assessment in citizenship education were a further problem identified by the Eurydice review. While many education systems provided teachers with official guidelines on classroom assessment in citizenship education for the purposes of teaching and learning, national tests aimed at summarising students' achievements at the end of a period of learning (for the purpose of either awarding certificates or making decisions about student progression) were only available in 17 out of the 42 education systems. Furthermore, only eight used summative assessment for evaluating the effectiveness of schools and of the education system in achieving the intended learning outcomes. Given the fact that teachers commonly 'teach to the test', that is, focus their teaching on what is going to be assessed at the end of a course of study (Black, 1998; Spratt, 2005; Stobart, 2008), the general lack of summative assessment means that citizenship education may well receive low priority from both teachers and students, especially when the curriculum is overloaded.

Teacher education and training was a further problem identified by the Eurydice review. Only six education systems allowed new teachers to specialise during their initial teacher training in citizenship education. In addition, a further seven trained prospective teachers to become semi-specialists in citizenship education (i.e., to specialise in citizenship education and up to three other subjects). In all of these cases, the main content of initial teacher training was knowledge of what needs to be taught, the capacity to plan relevant learning activities, and the social skills required for engaging with students, parents, peers and the local community. Few education systems provided training in the competences that teachers need to evaluate and improve their own teaching practices. In addition, it is noteworthy that out of the 36 education systems where all teachers had a formal responsibility for delivering citizenship education because it was delivered using a cross-curricular approach, only 13 specified the competences that secondary school teachers need to acquire for teaching citizenship education. Finally, in the case of continuing professional development for practising teachers, about two-thirds of education systems provided programmes in citizenship 
education for teachers, although similar programmes for school principals were only available in 14 systems.

In short, the Eurydice review implies that citizenship education in Europe is less than optimal. Although all countries do have curricula in citizenship education, it is clear that several improvements need to be made at the macro level in order to boost the effectiveness of citizenship education for promoting young people's civic and political engagement. In particular:

- Citizenship education should be fully incorporated not just into the secondary school curriculum but also the primary school curriculum, with the contents of the curriculum being adapted to the educational level of the students

- Student councils at both primary and secondary school levels should be made mandatory

- Opportunities for service learning, voluntary work and extra-curricular activities in the community should be expanded considerably, for example, in collaboration with community-based organisations, youth organisations and other NGOs, and service learning should be made mandatory

- Summative assessments in citizenship education should be made mandatory

- Initial teacher training in citizenship education should be made mandatory for all prospective teachers

- Initial teacher training should focus much more directly on the specific pedagogies that are known to be effective in promoting youth engagement, and on the specific competences that teachers require for reflecting on, evaluating and improving their own teaching practices

- Where they are not yet available, continuing professional development courses for school principals should be introduced on how to implement citizenship education within their schools

\section{The role of the Internet and social media}

Another important factor that is highly relevant to youth engagement is, of course, digital technology. In one sense, we could have reviewed the research that has been conducted into the influence of the Internet and social media on youth engagement in Chapter 3, alongside our review of the influence of traditional mass media. However, because the Internet and social media involve technologies that have only been developed very recently, they provide a fascinating opportunity through which to explore how technological developments at the macro level impact on patterns of youth engagement. For this reason, we have chosen to review the role that is played by digital technology in the current chapter on macro factors instead.

Indeed, over the past 20 years, there has been an extraordinary expansion both of the range of devices for accessing the Internet and of social media platforms for communicating and interacting with other people. Furthermore, the 
scale of use by young people today is staggering: one recent UK report estimates that 12- to 15-year-olds now spend over 20 hours per week online and send over 140 text-based messages per week (Ofcom, 2016). Some have argued that young people nowadays are digital natives who, because they have grown up immersed in digital technology, relate to this technology in a qualitatively different way from those in older generations who only started to use this technology during the course of their adulthood (e.g., Palfrey \& Gasser, 2008; Prensky, 2001); others have argued that the concept of digital natives overstates these inter-generational differences (e.g., Kennedy, Judd \& Dalgarno, 2010; Jones, Ramanau, Cross \& Healing, 2010). Whatever the case, the reality is that by the time they start school, many children in the developed world have encountered a range of technologies, including mobile phones, games consoles, DVD players, MP3 players, desktops, laptops and tablets (Plowman, 2011). As a consequence, children and young people often have far higher levels of digital expertise than older generations, with the Internet being seamlessly integrated into their everyday lives (Mesch \& Talmud, 2010; Thomas, 2011). Digital technology will clearly continue to feature within young people's lives on a significant scale in the future, and it is entirely possible that, with the emergence of new devices (e.g., Internet-connected watches and glasses), the impact of this technology on young people will continue to grow, especially as its cost continues to fall and its utilisation increases still further.

The potential of digital technology to transform civic and political engagement was enthusiastically championed in the early days of the Internet (Barlow, 1996; Hague \& Loader, 1999; Loader, 1997). It was argued that the Internet, as a globally networked communications system, would allow everyone across the world to share information, to communicate with one another, to deliberate on political issues and to sidestep the control and authority of the state. It was further suggested that youth, who were the most enthusiastic to adopt the new technology and use it creatively, would have hugely expanded opportunities for undertaking civic and political action through the Internet.

However, research into the uptake and use of the Internet by young people during the early part of the new millennium suggested that youth were far more interested in using it for interacting and communicating with their friends, managing their social relations, organising their social activities, being entertained and staying in touch with current trends in popular culture and celebrity news, rather than for enhancing their civic and political understanding or participation (Livingstone, Couldry \& Markham, 2007; Mesch \& Coleman, 2007; Dahlgren \& Olsson, 2007). These same studies did reveal, however, that in the case of young people who were already civically and politically engaged, the Internet did provide a useful additional tool which they were using to supplement their existing participatory activities. And there were also some indications that 18 - to 25 -year olds were more likely to use the Internet to access political information and news than those who were aged 26 and older (Mesch \& Coleman, 2007). However, during this period, the Internet did not appear to induce or entice 
other individuals who were not already actively engaged into civic or political activity (Livingstone et al., 2007). In addition, offline socio-economic, educational and gender differences in participation were found to be largely replicated online, with digital technology reinforcing rather than overcoming existing inequalities (McLeod, Shah, Hess \& Lee, 2010; Mesch \& Coleman, 2007).

This rather pessimistic picture of the role of digital technology in enhancing youth engagement was dramatically challenged by the events of the Arab Spring. These events began in December 2010 and continued through 2011 into 2012, and involved political protests on the streets of numerous cities in the Middle East and North Africa, including cities in Tunisia, Libya, Egypt, Yemen, Syria, Iraq and Bahrain (Haseeb, 2012). These protests, which involved large numbers of young people, deployed social media on a widespread scale and eventually led to significant political changes taking place in some of these countries (Herrera \& Sakr, 2014). Facebook and Twitter, in particular, were used for organising protests, mobilising protestors, communicating the claims and demands being made by the protestors and reporting on the progress that was being made. In all of these countries, the Internet was used to create virtual spaces where the protestors could meet and communicate with one another without supervision or interference by the government, police or security forces. Furthermore, as the protestors established ways in which they could circumvent the official media and operate outside the existing political system, they started to devise and develop their own methods and spaces for acting as citizen journalists, for documenting and sharing news, for exchanging opinions and for crystallising their own views about the political situation. Interestingly, these online exchanges sometimes led to offline meetings in parks or coffee shops where serious and heated discussions would take place which nevertheless helped to build trust between the protestors, which contributed further to their mobilisation; this was an example of online activism leading directly to yet further offline activism in the streets (Herrera \& Sakr, 2014; Sakr, 2014).

These findings have been replicated in studies of other mass protests such as the Indignados protests in Spain and Greece in 2011, the global Occupy protests from 2011 onwards and the Gezi Park protests in Turkey in 2013 (Bennett \& Segerberg, 2012; Chrona \& Bee, 2017; Gerbaudo, 2012; Juris, 2012; Sotiropoulos, 2017). In all of these cases, platforms such as Facebook and Twitter have been used to communicate information about the protests, to invite other people to participate in the protests, to express solidarity with the protestors and to disseminate pictures and videos of the protests. These postings spread the messages well beyond the sites of the protests, creating global audiences and generating global solidarity. In other words, social media, in the hands of young people, have become an extremely powerful tool for mass protest organisation, information dissemination, communication and mobilisation.

There is, however, a complementary side to the role of social media in events such as these. The very nature of social media means that governments are able to develop methods to monitor, surveil and infiltrate the online spaces that are used by protestors and activists (Bajoghli, 2014; Tarkowski, Fathy \& Melyantsou, 2011). 
As a consequence, digital technologies and the Internet may not always lead to such significant changes to political institutions as they did during the Arab Spring. Indeed, traditional power relations may actually be consolidated through digital technology, as governments learn how to control and manipulate the virtual spaces that are used by protestors and activists for communication.

The Internet and social media can, of course, be used not only for organising mass protests on the streets and in city squares and parks but also for a variety of other political purposes. As has been noted already, young people below the age of 25 tend to use the Internet to access political information and news more frequently than older individuals (McLeod et al., 2010; Mesch \& Coleman, 2007). They are also more likely than older people to use online platforms such as YouTube for watching political video clips such as speeches and interviews (Bennett, Freelon \& Wells, 2010; Smith \& Rainie, 2008). In addition, some young people themselves produce online political satires and parodies and upload them to YouTube or other platforms - if these become viral, they reduce the ability of political campaigns to manage their own messages (Gueorguieva, 2008). Other political uses of social media include joining political groups, receiving information about election candidates, and organising political events and meetings - in one study, nearly a third of American 18- to 29-year-olds were found to use social media for these kinds of political purposes (Smith \& Rainie, 2008). Because the Internet and social media are so powerful and effective, both democratic and repressive regimes across the world that wish to minimise information dissemination and mass mobilisation during critical political times have banned or blocked their use within their countries, as has occurred, for example, in Egypt, Turkey and China (Howard, Agarwal \& Hussain, 2011; King, Pan \& Roberts, 2013; Roberts, 2016).

Another phenomenon based on digital technology that has been examined is that of game playing. Lenhart et al. (2008) found that 97\% of American 12- to 17 -year-olds play computer, web, portable or console games. They also found that for most of these teenagers, gaming was a social activity, with three-quarters of the respondents playing games with others rather than on their own, at least for some of the time. Lenhart et al. analysed the games that were played according to whether they provided 'civic gaming experiences', that is, experiences that involved simulations of civic actions, helping or guiding other players, participating in guilds or other groups associated with the game, learning about social issues or grappling with ethical issues. It was found that those youth that had encountered more of these civic experiences during gaming were also more engaged civically and politically. In particular, they were more likely to go online to get information about politics and current events, to give or raise money for charity, to stay informed about political issues or current events, to volunteer, to try to persuade others how to vote in an election, and to participate in a protest march or demonstration. In other words, it appeared that digital game playing that involved simulations of civic actions had helped to equip these teenagers with a wide range of civic and political skills and aptitudes that were being applied not just in the online world but in the offline world as well. 
As noted already, in the mid-2000s, the patterns of use of social media for political purposes tended to reflect socio-economic, educational and gender differences in offline participation (McLeod et al., 2010; Mesch \& Coleman, 2007). However, more recent research suggests that digital media may now be helping to reduce these inequalities. Indeed, fundamental changes may currently be occurring in political practices as youth take greater advantage of social media for political purposes. This conclusion emerges particularly clearly from a largescale study conducted in the USA by Cohen, Kahne, Bowyer, Middaugh and Rogowski (2012; see also Bowyer \& Kahne, 2016, and Luttig \& Cohen, 2016). In 2011, they collected data from nearly 3,000 American youth aged between 15 and 25 years old, sampling not just white American youth but also black, Latino and Asian-American youth. Data were subsequently collected from subsets of the same respondents in 2013 and 2015.

Cohen et al. found that, in 2011, contrary to the traditional picture of a digital divide (i.e., a sharp divide between those who have ready access to digital technology and those who do not), $97 \%$ of the youth in their study had access to the Internet, while $78 \%$ used social media to send messages, share status updates or chat online at least once per week. The study also examined these youths' engagement in 'participatory politics'. This was defined as interactive, peerbased acts through which individuals or groups seek to exert both voice and influence on issues of public concern. Examples of such acts include blogging, circulating political news, starting a new political group, creating petitions and mobilising one's social network on behalf of a cause. These acts need not occur online, although digital media do provide expanded opportunities for them. It was found that, in 2011, 41\% of the youth had engaged in at least one act of participatory politics. Furthermore, participatory politics occurred in addition to more conventional forms of political engagement rather than replacing them: among young people who engaged in participatory politics, 90\% had either voted or engaged in some other form of institutionalised politics.

Participatory politics was equitably distributed across the different ethnic groups in the study. In addition, it was found that young people from socio-economically disadvantaged backgrounds were more likely to get their news from online media sources, while those from advantaged backgrounds were more likely to use traditional news sources instead. Those who obtained their news from more traditional sources were more likely to vote; by contrast, those who obtained their news through online media were more likely to protest business practices. This latter trend was most pronounced among the black, Latino and Asian-American youth who visited websites created by and for ethnic minority individuals. The data collected in 2015 further revealed that the young people who had increased their engagement in participatory politics the most between 2013 and 2015 were the ones who used social media for political purposes the most, and these were the minority groups and those who had the fewest socio-economic resources (Luttig \& Cohen, 2016). In short, social media appeared to be mobilising young people for specific types of political activity, especially the most disadvantaged young people. 
The same study also provided some clues about how social media were exerting this effect. In the survey, Cohen et al. asked their respondents about two distinct forms of online activity: friendship-driven activity and interest-driven activity. In the former, an individual uses social media for interacting with friends and family members (e.g., by posting status updates or tagging photos); in the latter, individuals engage online with their interests (e.g., by visiting websites about music, sports, fashion, etc. and communicating online with others who share those same interests). The survey found that $50 \%$ of young people engaged in friendship-driven activity every day, while 25\% engaged in interest-driven activity every day. Bowyer and Kahne (2016) then examined how these two types of activity related to voting, offline political action and online political action. They found that friendship-driven activity in 2013 led to more online political activity in 2015. By contrast, interest-driven activity in 2013 led to more offline political activity in 2015 - those who participated in interest-driven activity in 2013 were more likely to have had someone online ask them to participate in politics, and those who had been asked to participate were then more likely to vote in the US elections that took place in 2014.

Despite these encouraging findings, there is still a debate about the value of digital acts of civic and political participation. Some authors (e.g., Gladwell, 2010; Morozov, 2011) have argued that online participation only fosters lowcost, low-risk and low-impact activism - so-called 'slacktivism' or 'clicktivism' - which requires very little effort or cost, has little effect in the real world and lacks serious motivation but makes the person feel that they have engaged and made a contribution. Examples of such action include 'liking' or sharing political content on Facebook, signing online petitions, joining online organisations but without making any significant contribution to their activities, and using a slogan or avatar as a profile picture. The criticism is that such activities are not only ineffective in bringing about meaningful change but actually make individuals less likely to engage in other forms of civic and political activism that would be more effective. As we have seen, this last contention is probably incorrect. Bowyer and Kahne's (2016) findings contradict it, as do the findings of a study by Ogilvy PR and Georgetown University's Center for Social Impact Communication (2011): the latter found that those who support causes most often through social media (e.g., by joining a group dedicated to a cause on Facebook, blogging about a cause, or posting an icon on a social profile) in fact participate in more than twice as many civic and political activities (both online and offline) compared to people who do not use social media in this way.

Other criticisms that have been made of activism through social media are that:

- It encourages the oversimplification of complex issues

- It can lead to the uncritical acceptance of fake news and the insufficient vetting of information 
- It encourages the ghettoization of discourse and the creation of 'echo chambers' or 'filter bubbles', with people only receiving information online that is consistent with their pre-existing beliefs

- The anonymity that can be used online makes it easy to insult, offend and even threaten other people

In the case of mass protests organised through social media, several additional criticisms have been made (see Tarkowski et al., 2011; Passini, 2012; and Kahne, Middaugh \& Allen, 2014, for useful discussions of these). For example, it has been argued that:

- Such actions may be poorly coordinated due to the lack of formal organisers and leaders

- The lack of a traditional organisational hierarchy may also mean that there is little control of the forms of protest that are used and few constraints to prevent the hijacking of the protest by other groups

- Communications through social media rarely facilitate dialogue and the expression of minority ideas that do not conform to group norms, which can generate a false consensus

- Communications through social media do not adequately support meaningful negotiation and deliberation

- Social media communications may generate participation by people who have low motivation or commitment to the cause and who only have weak social links to other protestors

On the other hand, it is becoming increasingly clear that using social media does have many positive benefits for civic and political engagement (Kahne et al., 2014; Passini, 2012). These include:

- The speed of information dissemination

- The low financial costs that are incurred in communicating with large numbers of people

- Flexibility in the practical coordination of events such as flash-mobs and protests

- The potential for pluralism of information about issues and concerns, especially information that public authorities might be withholding, and for challenging the information monopoly of repressive governments

- Overcoming geographical distance and national borders in the dissemination of information and eyewitness accounts of protests and building global solidarity

- Obtaining external financial support

Given the rapid evolution of digital devices and social media platforms, one conclusion is certain: the creative ways in which young people use digital technology 
will continue to develop in the future. And studies into young people's use of such technology in the pursuit of civic and political goals will no doubt continue to preoccupy social science researchers for many years to come.

\section{The role of politicians and political parties}

The final macro factor to be considered here is the role that politicians and political parties can play in mobilising youth. It has been known for many years that mobilisation by other people, especially politicians and political parties, is associated with people's levels of political activity. The same applies in the case of civic activity. Thus, being contacted and invited personally to vote or to participate in a political or civic process is a powerful predictor of subsequent participation (Green \& Gerber, 2004; Rosenstone \& Hansen, 1993; Zukin et al., 2006). However, all too often, youth feel ignored by politicians and believe that their concerns and interests are regarded as being irrelevant, unimportant and trivial by those in power or by those seeking power. Under such circumstances, it is perhaps not surprising that youth disengage from participating in conventional political activity.

This finding emerged especially clearly from focus groups that were conducted by PIDOP with both national majority and ethnic minority 16- to 26-year-olds in nine European countries (Barrett, 2012; Barrett \& Zani, 2015b; see Table 1.2 in Chapter 1 for a list of the ethnic groups and countries involved). It was clear from the discussions that took place in these focus groups that most youth in these countries felt that politicians were not interested in their issues and concerns. In addition, many young people said that they did not bother to participate in civic and political matters because they distrusted politicians, who they viewed as cynically pursuing their own goals and interests, rarely keeping their promises to the electorate. Some youth also believed that many politicians employed stereotypes when thinking about youth and regarded youth as being so politically disengaged and alienated that it was not worth the effort of trying to engage with them; in response, the politicians themselves were then disregarded and ignored by the youth.

It is notable that when politicians do make significant efforts to engage actively with youth, then youth respond. There have been two occasions in the past decade when this strategy has been employed to good effect by politicians: by Barack Obama in 2008 in the USA, and by Jeremy Corbyn in 2017 in the UK.

In 2008 , in addition to the traditional substantial advertising on television, the Obama campaign used social media to target youth on a significant scale, setting up blogging communities and Twitter feeds and distributing regular emails containing video clips that exhorted recipients to get involved by recruiting friends, organising campaign events and donating money (Bennett et al., 2010). Young voters were more likely to be contacted by the Obama campaign than by the opposing McCain campaign - 25\% of voters aged 18-29 years old reported being contacted either in person or by phone on behalf of the Obama campaign, 
whereas only 13\% reported being contacted by the opposing McCain campaign. The disparity was even larger in some of the key battleground states, where more than half of the voters under the age of 30 said that they had been contacted by the Obama campaign (54\% in Pennsylvania and 61\% in Nevada) (Keeter, Horowitz \& Tyson, 2008). Another notable feature of the campaign was the creative production of unofficial online videos by Obama supporters (rather than by his official campaign), some of which went viral and attracted many millions of views. The campaign was extraordinarily successful, with voting among $18-$ to 29 -year-olds up to $53 \%$, which was an increase of $4-5 \%$ on the 2004 election and $11 \%$ on the 2000 election. Furthermore, exit polls suggested that $70 \%$ of those aged under 30 had voted for Obama.

In the case of the 2017 general election in the UK, the Labour Party also deliberately targeted youth voters (Hobbs, 2017; Therrien, 2017). Social media were used to distribute advertisements with positive messages, which emphasised that the party was building a social movement for progressive change. In addition, Momentum - a Labour Party subgroup supporting Corbyn - created videos, many of which were parodies, as well as quirky entertaining posts, which were widely 'liked' and shared on social media, and some of which went viral. Momentum also mobilised young people into an army of canvassers, and set up a website that enabled activists to coordinate their canvassing activities in marginal seats. This led to young people who had no previous experience of canvassing to team up with more experienced canvassers. In addition, the Labour manifesto specifically targeted young people in its policy proposals (e.g., with a promise to abolish university tuition fees, reintroduce student maintenance grants, abolish zero-hours contracts and increase the minimum wage). Corbyn, with his emphasis on justice, fairness and human rights, was also endorsed by many anti-establishment celebrities and musicians, including from the world of grime (a UK music genre), which further bolstered Corbyn's youth credentials. He also undertook interviews with youth music magazines and with a YouTube football channel, again specifically targeting youth audiences. The strategy had significant effects: the result of the election, in which the Conservatives had been expected to win a large increased majority, was a hung parliament, with Labour gaining 31 seats and the Conservatives losing 12 seats. Labour's share of the youth vote increased significantly from the 2015 general election (Prosser, Fieldhouse, Green, Mellon \& Evans, 2018). Among first-time voters (i.e., those aged 18 and 19 years), Labour was 47\% ahead of the Conservatives, whereas among voters aged 70 or older, the Conservatives were ahead by $50 \%$ (YouGov, 2017). Perhaps most tellingly of all, the average age at which a voter was more likely to have voted Conservative rather than Labour was 47 years, an increase from 34 years at the start of the election campaign (YouGov, 2017). That said, there is also evidence that turnout among those aged 18-24 years did not increase on the scale that some newspapers and pundits claimed at the time, with the most significant increases in voter turnout actually being among those aged 25-44 years (Prosser et al., 2018). 
Both the Obama campaign and the Corbyn campaign indicate that, when politicians and political parties pay attention to young people's views on civic and political matters, propose policies that address their concerns and use methods to communicate which youth themselves use to communicate with each other, then young people are more likely to support those politicians and parties. In other words, if politicians and political parties wish to gain support from young people, then they need to engage more actively with youth through relevant media, they need to treat their views and concerns with greater respect, and they need to propose policies that address the needs of young people. This is perhaps not a surprising conclusion, but it is one which politicians and political institutions should heed if they wish to enhance levels of youth engagement with conventional political processes.

\section{Conclusions}

This chapter has reviewed a wide range of macro factors that can influence youth civic and political engagement. These factors include: the patterns of political and civic engagement that are exhibited by adults within a country; the recent history and longevity of democracy within a country; the level of economic, educational and health development of a country; the extent to which human rights, the rule of law and government accountability apply within a country; national policies on migrant integration and naturalisation; national, regional or local policies on youth engagement; voting age; the provision of youth organisations within a country; the availability of a youth parliament within a country; the extent to which education policies and regulations foster the provision of effective citizenship education; the availability of digital technology and social media; and the extent to which politicians and political parties attempt to engage with and mobilise youth.

This review of the existing research into macro factors suggests that rather less research has been conducted into the relationship of macro factors to youth engagement than has been conducted into psychological, social and demographic factors, and much more research is required to enable us to properly understand how macro factors affect young people's engagement. Such research would benefit considerably from interdisciplinary collaboration involving political scientists, sociologists, policy analysts, educationalists and psychologists. As we noted earlier in this chapter, it is unlikely that many macro factors operate independently of social and demographic factors - it is instead much more likely that macro, demographic, social and psychological factors are intertwined in complex causal pathways, pathways that have not yet been properly investigated in any great depth to date. For this reason, interdisciplinary teams of social scientists would be ideal for undertaking investigations of these causal pathways involving multiple levels of factors.

In addition, a great deal of further research is required into the impact of the policy environment on youth civic and political engagement. As we have seen 
in the case of policies on migrant integration, these can have significant effects on the civic and political activity of migrant youth by either facilitating or hindering their school education, and their participation in local communities and in conventional politics. In the case of educational policies, these too can either encourage and support youth in becoming active citizens (by providing them with suitable educational experiences to promote their civic and political knowledge and skills) or limit their capacities to engage civically and politically (by denying them these experiences). Likewise, youth policies can also either support youth engagement (by specifying high expectations of youth as active citizens and providing plentiful resources for youth organisations so that they can help to equip young people with the relevant skills and experience needed for meeting those expectations) or hinder their engagement (by having limited expectations of youth and withholding the necessary resources from youth organisations). However, even when very well-intentioned policies are in place, there can still be a significant gap between those policies and their actual implementation on the ground, as well as a further gap between the measures that are implemented and the perceptions of those measures by young people themselves. There is currently very little research into these various issues, and further investigations are required to understand the causal links that can exist between policies and youth engagement, the mediating role that young people's perceptions of policies can play in the process and the policy implementation gaps that can arise.

In addition, much more research is needed into the effects of youth parliaments, both on the youth who participate in them and on the youth who are excluded from them. There is a notable lack of research into (as opposed to official rhetoric about) the extent to which youth parliaments serve to enhance the civic and political skills of those who participate in youth parliaments, and into the attitudes and subsequent behaviours of those who are excluded from these parliaments. There is also a need to identify ways in which these parliaments can be made much more inclusive, rather than being populated by youth who are socio-economically and educationally advantaged, and ways to ensure that youth do not view these parliaments as being politically ineffective and irrelevant.

The role of the Internet and social media in youth civic and political engagement is another area that is in need of further investigation. Studies are required to monitor the changes that occur to youth engagement as digital technology continues to develop. Digital devices and social media platforms are rapidly evolving, and youth engagement will almost certainly continue to change in conjunction with this evolution. Studies using longitudinal and cohort sequential designs could be invaluable for understanding how digital technology impacts on the civic and political engagement of young people.

Finally, our review of the literature raises a crucial question about responsibility for the civic and political education of young people: whether this responsibility should lie with the state or with civil society or whether it should be a private or family matter. Because the research reveals that the state, civil society and the family can all be influential agents for fostering the civic and political 
engagement of young people, there is a question about whether all three should share this responsibility equally or whether one or two of these agents should take the primary responsibility. The answer to this question will presumably vary depending on the cultural and ideological orientation of the person providing the answer. There are important political-normative issues here which would benefit from the attention of political theorists.

This chapter concludes our survey of the different levels of factors that are related to youth civic and political engagement. We have now seen that many different psychological, social, demographic and macro factors are linked to youth engagement. In the next chapter, we will integrate some of the main conclusions that have emerged from our survey and provide a more theoretical perspective. We will also summarise some of the actions that may be taken to promote youth civic and political engagement, drawing together the various lines of evidence that have been reviewed. In addition, we will describe a major policy initiative that is currently under way in Europe which is aimed at enhancing young people's levels of democratic engagement and participation through the harnessing of state education systems. 


\section{5}

\section{THEORETICAL INTEGRATION AND ACTIONS FOR PROMOTING YOUTH ENGAGEMENT}

Over the course of the four preceding chapters, we have examined many issues concerning young people's civic and political engagement. In this chapter, we will try to draw these issues together to provide a more integrated theoretical synthesis. We will also draw together our recommendations on the various actions that can be taken to enhance and promote youth engagement. Next, this chapter will describe a major policy initiative that is currently under way in Europe, which aims to promote young people's levels of democratic engagement and participation by harnessing state education systems for this purpose. We will conclude by drawing together our reflections on outstanding issues that still require proper investigation within this field.

\section{Integrating the findings}

As we have emphasised throughout this book, young people's civic and political engagement always occurs within specific contexts that are characterised by particular constellations of macro and social factors. For this reason, their civic and political participatory behaviour is often specific to the particular societal, demographic and social niches which they occupy. At the same time, however, their participatory behaviour is driven by a wide range of psychological factors which, as we saw in Chapter 2, sometimes operate differently in different macro contexts and in youth belonging to different demographic subgroups. Indeed, it is for this reason that we have cautioned throughout this book about making unwarranted generalisations about youth engagement based on data collected from limited samples within specific national contexts. This is also the reason why, throughout this book, we have tended to emphasise findings from multinational studies, where these are available, so that the possible generality or specificity of the findings may be assessed. 
Table 5.1 lists, in a summary format, the various factors that have been found to be associated, in one context or another, and in one population or another, with youth civic and political participation. These are the factors that have been reviewed in detail in the previous three chapters. The table classifies these factors into the four main categories of macro, demographic, social and psychological factors.

In order to understand how these four groups of factors relate to one another, and how they relate to participatory behaviours, it is helpful to return to Figure 1.1 in Chapter 1, which is reproduced for convenience here as Figure 5.1. This diagram provides an outline sketch of the causal links that exist between the four groups of factors and between the factors and civic and political participation. As we noted in Chapter 1 (and indicate by means of solid arrows in Figure 5.1), macro factors can have effects on demographic, social and psychological factors, demographic factors can have effects on social factors, while social factors can have effects on psychological factors. These psychological factors underlie the production of civic and political participatory behaviours (an important point to which we will return in more detail below). Furthermore, participatory behaviours themselves can in turn sometimes impact on macro, demographic, social and psychological factors (as depicted by the dashed arrows in Figure 5.1). Examples illustrating all of these causal relationships were provided in Chapter 1.

Obviously, however, not all of the factors listed in Table 5.1 have the same magnitude of influence on youth engagement and behaviour, and in many cases the effects of some of the factors are likely to be swamped out by the effects of other factors. In addition, as we have seen in previous chapters, different forms of participation are influenced by different subsets of these factors. Furthermore,

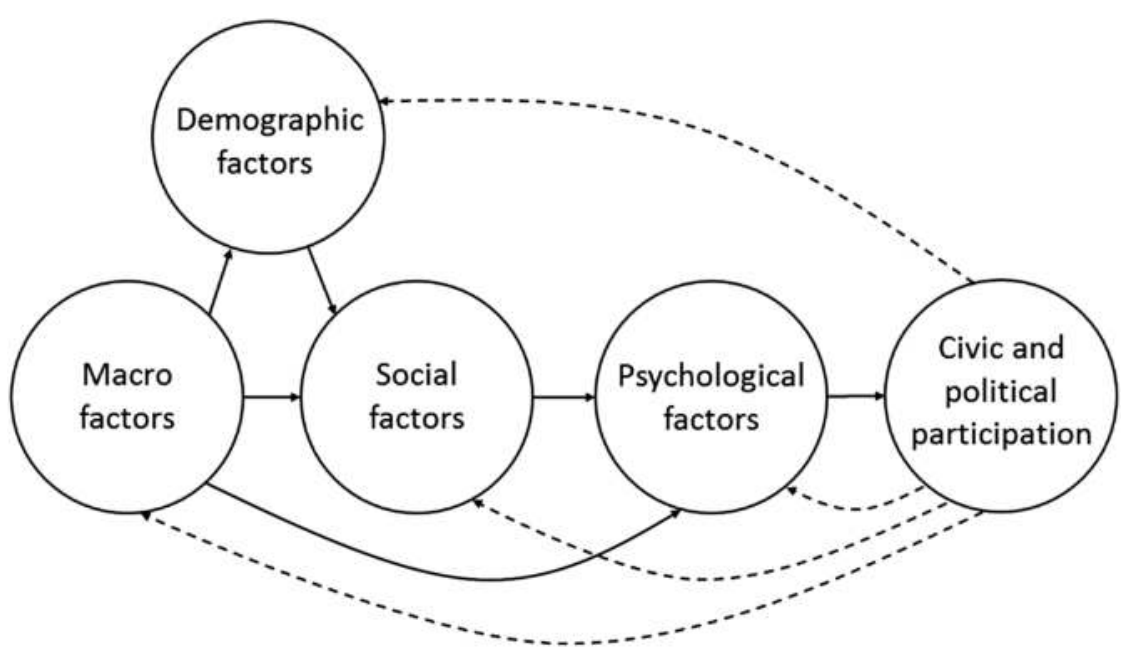

FIGURE 5.1 The inter-relationships between macro, demographic, social and psychological factors, and their relationship to civic and political participation 
108 Theoretical integration and actions

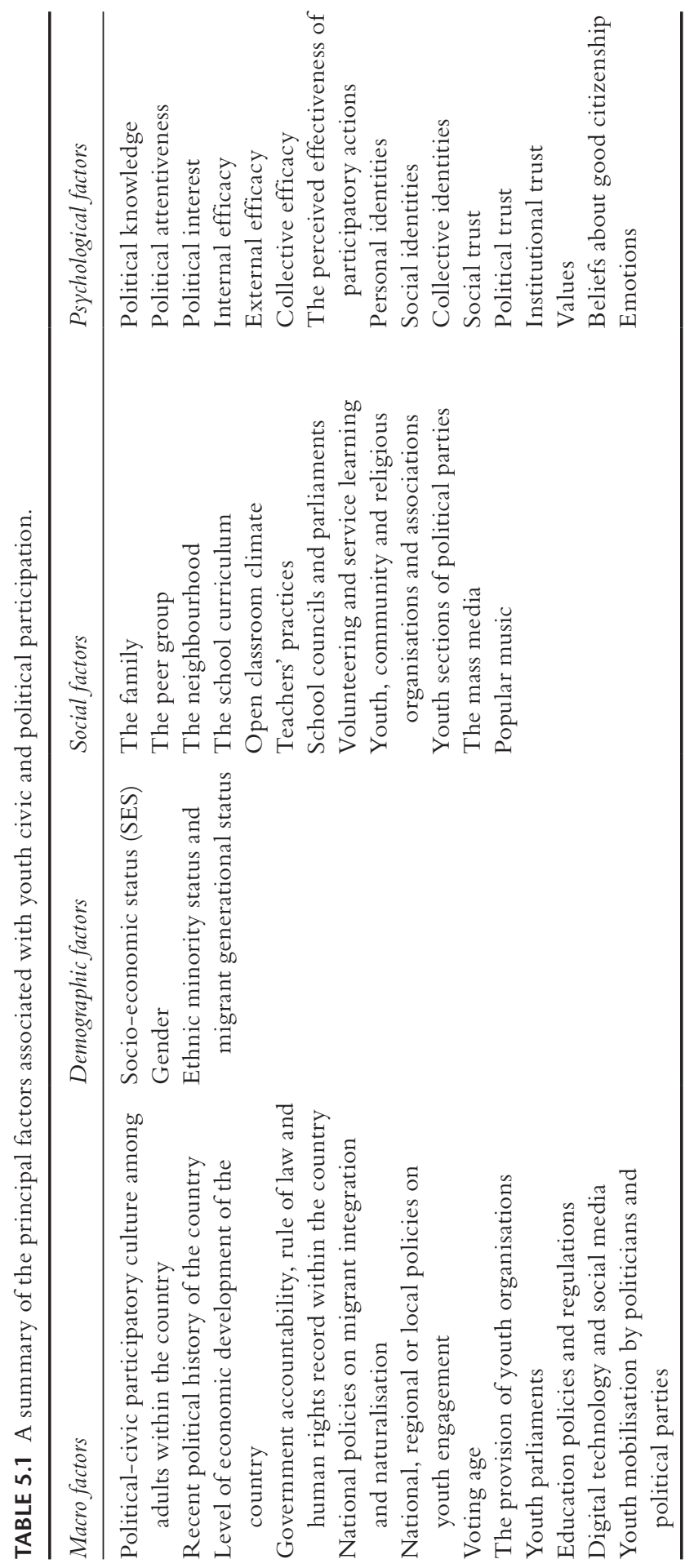


some of the factors may simply not be relevant to some subgroups of youth or to youth who are living in certain contexts.

As can be seen from Figure 5.1, the social factors that are situated in the centre of the diagram play a core role in mediating the effects of macro and demographic factors on the developing individual. The family is one of the most important social factors for two reasons. First, the family can exert direct effects on young people through the discourses and practices that operate and circulate within the family and home context; hence, for example, parental modelling of participatory behaviours and parental political partisanship are often linked directly to youth patterns of participation and partisanship. Second, the family also exerts indirect effects, through the schools that parents choose for their offspring (which in turn can influence the curricula, classroom climate, teacher practices and pedagogies to which their offspring are exposed) and via the purchase and use within the family home of televisions, newspapers and digital technology (all of which in turn influence the amount and type of civic and political information to which young people are exposed).

Family discourses and practices themselves are heavily influenced by both SES and ethnicity, and parents may use different discourses and practices in relationship to male and female offspring. For these reasons, there are demographic variations in young people's civic and political engagement as a consequence of the different parenting practices to which they have been exposed. In addition, family discourses and practices are influenced by macro factors, because parents position themselves ideologically, politically and civically in relationship to the politics of the country in which they are living, and their discourses and practices vary according to their own personal ideological, political and civic positioning.

That said, other macro factors can also exert effects independently of the family. For example, education policies and regulations may influence educational provision in the form of a prescribed or recommended curriculum; in addition, regulations and guidance on the particular pedagogical and assessment practices that should be used within schools may affect the educational experiences of youth. Likewise, national policies on youth engagement may lead to the provision of government funding for youth organisations; if such funding is provided, the widespread availability of such organisations and the quality of the services they provide may enable young people to obtain high-quality participation experiences that foster the development of their civic skills. In addition, some macro factors might impact directly on psychological factors. For example, in the case of a youth who is a member of a national youth parliament, it is possible that frustration about the lack of influence of the youth parliament on government policies affects his or her attitudes towards conventional political processes.

The fact that some factors are specific to particular subgroups of youth is illustrated by national policies on migrant integration and naturalisation. These policies are, of course, primarily relevant to migrant youth. The impact of these policies is likely to be moderated by the specific ethnicity of the migrant youth concerned, their generational status, parenting practices within their family, 
and the availability of ethnic community associations and organisations in their neighbourhood.

Table 5.1 and Figure 5.1 together therefore imply that, in principle, a wide range of macro, demographic and social factors can potentially impact on young people's civic and political engagement, either directly or indirectly. However, it is important to note that the factors listed in Table 5.1 are only potential sources of influence. This is because the influences that actually exert effects on any given individual are also, at least partially, determined by a wide range of further intraindividual psychological factors. These psychological factors include not only those that are listed in the fourth column of Figure 5.1 but also other attentional, perceptual, cognitive, affective and motivational factors.

Attentional, perceptual and motivational factors are often overlooked by theorising within this field. However, it is well-established that young people's learning is affected by a wide range of intra-individual factors, including their attentional, retentional, representational and motivational processes (Bandura, 1986, 1989a). Learning - whether of information, ways of thinking, or ways of behaving - never consists simply of passively absorbing, assimilating or appropriating influences from exogenous sources. Young people are highly active rather than passive processors of environmental information and influences: they actively select the information in the environment to which they attend, and their selections depend on their current state of perceptual readiness, their cognitive concerns and their interests; they also scour their social environments for information that is relevant to their own current motivations, affective preferences and cognitive goals, and they often disregard, ignore or resist information that does not fit in with their motivational needs and cognitive goals; and they also often draw their own inferences from the information that they have assimilated from their environments, sometimes going well beyond the information that is given and generating mistaken beliefs as a result (Bandura, 1989a; Barrett, 2007; Durkin, 2005).

However, there is not only a selective and sometimes biased uptake of information from the environment. The way in which young people then construct their own civic and political attitudes and beliefs on the basis of the information that they have acquired from the social environment is also affected by their motivational states and needs. It is probable that a wide range of motivations underpins the development of attitudes and beliefs in the civic and political domain. Indeed, social-psychological research with adults has revealed that there are many different motivations that are linked to the construction of social and political attitudes, including the needs for a sense of belonging, distinctiveness, purpose, meaning, self-efficacy, power, personal enhancement, threat reduction, cognitive closure, cognitive consistency, confirmation, and desire to bring about social change (Baumeister \& Leary, 1995; Brewer, 1993; Deaux, 2000; Hinton, 2016; Hogg \& Abrams, 1993; Jost \& Amodio, 2012; Pachi \& Barrett, 2012b; Schwartz, Luyckx \& Vignoles, 2013). The motivational underpinning of young people's attitudes and beliefs in relationship to civic and political issues still 
requires thorough investigation to uncover precisely which of these numerous motivations are involved in the construction of their civic and political attitudes. Such research is likely to reveal a plethora of relevant motivations.

The fundamental argument being made here therefore is that young people should not be construed as passive recipients of environmental influences. They are instead highly active agents who actively select the information to which they attend in their environments and actively construct their own civic and political attitudes and beliefs, with a range of psychological processes influencing both of these activities.

A third point that also needs to be made about the psychological processes underpinning the civic and political behaviour of youth is that the behavioural choices that individuals make are also affected by a range of further psychological factors. For example, these choices are influenced by: beliefs about whether significant others want the individual to perform or to desist from those behaviours; motivations to comply with or to violate other people's expectations or desires; positive or negative beliefs or attitudes towards the specific behaviours that are involved; beliefs about whether it is easy or difficult to perform those behaviours; judgments about whether the behaviours are likely to lead to the desired outcomes; and beliefs about whether the expected outcomes will be relevant, valuable and meaningful for the individual him- or herself (Ajzen, 1985, 1991; Ajzen \& Fishbein, 1980; Bandura, 1986, 1989b). Thus, efficacy is clearly involved (which explains the ubiquity of internal efficacy as a predictor of civic and political participatory behaviours), but in addition, perceptions of social norms, motivations, attitudes towards and judgements of behaviours and possible obstacles, and judgements about expected outcomes can all feed into the specific behavioural outcomes that are chosen.

Thus, theoretical models that posit that youth civic and political behaviours are a direct product of either structural (macro or demographic) or social circumstances underestimate the complexity of the psychological processes that underpin the production of human behaviour. Our argument is that psychological factors always mediate between structural and social factors on the one hand and civic and political behaviours on the other. Hence the positioning of psychological factors in Figure 5.1 as the only direct and unmediated set of causal factors driving the civic and political participatory behaviours of youth.

In summary, our argument is that macro, demographic, social and psychological factors all play a role in influencing young people's civic and political behaviour, but that the relationships between these factors are complex, and the effects of macro, demographic and social factors on behaviour are mediated by psychological processes. We would also maintain that any theory that neglects to include all four sets of factors within its scope will not be able to explain the full range of evidence that is now available concerning youth civic and political engagement.

A consequence of the view that macro, demographic, social and psychological factors can all play a role in young people's development in this domain is that the developing individual may be conceptualised as being situated within 
an ecological niche which itself constantly changes as the individual develops (cf. Barrett, 2007; Torney-Purta \& Barber, 2011). First, changes to the ecological niche occur due to the historical changes that are constantly taking place, for example, to the political circumstances of the country in which the individual lives. Second, the niche changes over time as a function of the different discourses, practices and representations to which individuals are exposed at different ages by agents of socialisation such as parents, teachers and the media. Hence, a 12-year-old, a 17-year-old and a 22-year-old will encounter very different discourses, practices and representations from these sources; as a result, changes in patterns of civic and political engagement across this age range may be, at least in part, a product of cultural norms concerning how young people at particular ages should be talked to and treated by parents and teachers, the types of curriculum to which they should be exposed, what they should be allowed to view via digital or mass media sources, and the political actions in which they should be allowed to participate. Third, the ecological niche also changes over time as a function of the individual's own cognitive, affective and motivational development. Young people's cognitive level and affective and motivational state at any given point in their development will determine the types of information that they will seek out in the environment and the types of information that they will be motivated to process and retain. In other words, the agents of socialisation can only exert their effects if the individual's cognitive, affective and motivational systems are sufficiently developed for them to be able to attend to and assimilate their influence. In this sense, then, the developing individual is also a partial determinant of the contents of his or her own 'environment of influence'. Fourth, as the individual expresses civic or political beliefs, attitudes or values, other individuals such as parents, teachers or peers may well respond to these expressions, either by reinforcing, supporting, challenging or questioning these expressions, and possibly, in the cases of educators and parents, by increasing the provision of civic or political information. In this sense, then, there may also be effects that are exerted on the ecological niche by the developing individual.

Thus, our argument is that young people's development in this domain takes place through an active, interactive and dynamic process through which the developing individual continually responds to a particular cultural, societal and social niche which itself is constantly changing over time and as that individual's cognitive, affective and motivational systems develop. An implication of this line of reasoning is that the unit of analysis which is required for understanding the civic and political development of the young person is not the young person per se, nor is it macro, demographic or social factors per se. Instead, the correct unit of analysis is the 'young-person-situatedwithin-an-ecological-niche', with this unit being construed as an integrated and holistic system that is continuously changing over time.

In addition, it seems likely that the balance of influence between different factors will vary from one societal setting to another, depending on the specific configurations of macro, demographic and social factors that are present. In other words, different factors are likely to be the primary drivers of political 
and civic engagement in different populations and in different settings. If this reasoning is correct, then the prediction is that there will be considerable variability both across and within populations in the macro, demographic and social factors that are operative, and that this variability will depend on the particular population involved and the specific societal setting within which they live. The review of findings in Chapters 2, 3 and 4 provides ample evidence in support of this prediction.

The approach to the development of youth civic and political engagement that we have just sketched fits well with the perspective of Bronfenbrenner's (1979, 1989) ecological systems theory of human development. Bronfenbrenner draws distinctions between five systems: microsystems, mesosystems, exosystems, macrosystems and chronosystems. Microsystems are the immediate settings within which the individual lives and which directly influence the experience of the developing individual. The family is a microsystem; the school (in the case of a young person) and workplace (in the case of a young working adult) are others; and peer groups are another. The mesosystem is the system of links between different microsystems through which experiences in one microsystem influence or impact on experiences in another microsystem. For example, experiences within the family may impact on social relationships at school (and vice versa). Exosystems are settings in which the individual concerned does not directly participate but which nevertheless affect the functioning of the microsystems. For example, a parent's experience in the workplace may impact on their family life and hence influence what is experienced by their offspring. The macrosystem is the wider set of institutions, ideologies, values, norms, etc. that characterise the society in which the individual lives and which therefore constrain and shape exosystems, mesosystems and microsystems. Finally, there is the chronosystem, which consists of the historical changes that occur across time to all of the other four systems. Bronfenbrenner referred to the chronosystem as an overarching system encompassing all of the other systems across the lifetime of an individual. These conceptual distinctions are useful, insofar as they help to delineate different levels of factors and some of the relationships that can exist between them.

In a subsequent formulation, Bronfenbrenner and Ceci (1994) extended the model into a bioecological model. This more recent model proposes that the development of the individual takes place through processes of progressively more complex reciprocal interactions between an active and developing biopsychological human individual and the persons, objects, symbols and information in his or her immediate environment. The processes that drive development vary systematically as a result of the interplay between the characteristics of the developing person (including their genetic characteristics), the environment in which the processes take place and the nature of the developmental outcomes that are involved. These outcomes include, amongst others, the acquisition of knowledge and skills, the construction of a social and symbolic environment for oneself, and the ability to direct and control one's own behaviour and to act as an autonomous agent. It is noteworthy that the theory predicts considerable 
variability in development according to the interplay between individual characteristics and the ecological context (which itself is layered from the micro to the macro level). This prediction fits well with the findings that have been reviewed in Chapters 2, 3 and 4.

In conclusion, we would argue that in order to explain the complex array of findings in this field in a coherent manner, it is necessary to adopt an integrative multi-level ecological model that incorporates: (a) a conception of the environment as being constituted by a wide array of macro, demographic and social factors (as listed in Table 5.1), which are constantly changing over time; (b) an understanding of the inter-relationships that exist between these macro, demographic and social factors (as depicted in Figure 5.1); (c) a conceptualisation of the young person as occupying an ecological niche that is characterised by an array of macro, demographic and social factors, but an ecological niche that itself is constantly changing and developing as the young person develops; (d) an emphasis on the agency of the developing individual and on the psychological factors and processes that mediate between the macro, demographic and social factors and the young person's civic and political behaviour; and (e) an emphasis on the variability that can occur in the development of young people's civic and political engagement as a function of their own personal characteristics and the characteristics of the particular ecological niches in which they are situated.

Readers who are interested to see how this kind of integrative multi-level ecological model may be developed further, down to the level of the causal interrelationships that exist between individual factors, especially between the various social factors and between the various psychological factors, should consult Barrett (2015). Additional evidence in support of this approach (based on secondary analyses of data from existing large-scale data-sets that were conducted as part of PIDOP) is reported in Barrett and Brunton-Smith (2014).

\section{Actions that may be used to promote youth civic and political engagement}

Over the course of this book, we have reviewed a large number of findings concerning youth civic and political engagement. Many of these findings imply that there are specific actions that can be taken - either by specific agents of socialisation or by politicians and policymakers - that would help to promote youth civic and political engagement. In this section, we provide a summary overview of the various actions that may be taken. Our discussion is divided into three sections: actions that are specifically aimed at enhancing psychological factors; further actions that can be taken by specific agents of socialisation; and further actions that can be taken by politicians and policymakers.

\section{Actions aimed at enhancing psychological factors}

We start by considering the key psychological factors that might be targeted in order to promote young people's levels of civic and political participation. The review of psychological factors in Chapter 2 suggests that there are three possible 
psychological factors that it might be useful to target: political knowledge, internal efficacy and political interest. It will be helpful to spell out the reasoning behind the choice of these three factors.

In the case of political knowledge, as we saw in Chapter 2, there is good evidence that such knowledge is important for youth engagement. For example, political knowledge is significantly correlated with expectations of future voting among young people in all countries that have been studied (Schulz et al., 2017; Torney-Purta et al., 2001), and youth often report that they feel they do not know enough about political issues to be able to engage in effective action to influence political, civic and social change (Barrett \& Zani, 2015b; Pachi et al., 2011). These findings are consistent in suggesting that enhancing young people's knowledge of civic and political issues, and of how to become involved in politics and other voluntary spheres of activity, may be beneficial for promoting their civic and political engagement.

However, one needs to be cautious in assuming that merely enhancing knowledge on its own will be sufficient to promote youth engagement. This is because Schulz et al. (2017) also found that political knowledge was not always associated with current levels of participation through the school (e.g., voting in a school election for a student representative, joining a group of students campaigning for an issue in which they believed, etc.): a relationship between political knowledge and current participation was only found in 13 out of the 21 countries that were studied. Political knowledge was also not clearly related to students' expectations of participating in legal activities in the future in order to express opinions (e.g., by contacting an elected representative, taking part in a peaceful march or rally), nor to their expectations of future political participation through means other than voting (e.g., joining a political party, joining an organisation committed to a political or social cause). Clearly, factors other than knowledge must be at play as well.

Arguably, a much more powerful psychological factor than political knowledge is internal efficacy. As we saw in Chapter 2, it has been found repeatedly that the higher the level of internal efficacy, the higher the level of both actual participation and future intended participation (Blais, 2010; Barrett \& Brunton-Smith, 2014; Brunton-Smith, 2011; Schulz et al., 2010; Schulz et al., 2017; Verba, Schlozman \& Brady, 1995).

However, once again, one needs to be cautious in drawing implications from these findings for promoting young people's levels of participation. This is because Quintelier and van Deth (2014) found that there is a reciprocal causal effect between political participation and internal efficacy, and that the effects of participation on efficacy are actually stronger than the effects of efficacy on participation. Even more problematically, there is at least one study in the research literature by Šerek et al. (2017) that failed to find any effect of internal efficacy on participation and instead only found an effect of participating in protests on internal efficacy. Thus, even boosting internal efficacy may not be a consistently successful way to promote participation. 
As far as political interest is concerned, it has been found in many studies that the more interest a person shows in political issues, the more likely they are to participate in civic and political activities (Brady et al., 1995; BruntonSmith, 2011; Schulz, 2005; Schulz et al., 2017). In addition, Brunton-Smith (2011) found that political interest was very highly correlated with internal efficacy, so much so that these two psychological factors effectively formed a single factor that was positively related to levels of all forms of participation. However, once again, Šerek et al. (2017) report that the causal relationship between political interest and participation may sometimes run from participation to interest rather than the other way around: in their study, they found an effect of participating in protests on political interest but failed to find an effect in the opposite direction, from political interest to participation.

That said, the implication of these various findings on political knowledge, internal efficacy and political interest is clear: interventions aiming to promote levels of youth participation should target political knowledge, internal efficacy, political interest and participatory action simultaneously as a single holistic cluster. Importantly, these interventions should not focus on the three psychological factors alone - instead, interventions should also include opportunities for undertaking participatory action in order to strengthen both internal efficacy and political interest still further. In other words, interventions that are aimed at enhancing psychological factors should optimally:

- Provide information about civic and political issues, processes, procedures and policies, enabling young people to construct well-informed understandings of civic and political matters and well-informed beliefs and attitudes

- Provide information about the opportunities that exist for becoming actively involved in the civic and political domains (e.g., information about the possible forms of participation, their relevance and suitability, means of access)

- Provide young people with concrete opportunities to obtain high-quality civic and political participation experience

- Support the development of the skills (e.g., writing and debating skills) that young people require in order to take up these opportunities and to participate effectively in the civic and political life of their community and country

- Ensure that all of this takes place in a manner that stimulates and nurtures the internal efficacy and the political interest of the young people involved (e.g., by using youth-relevant means of communication, involving individuals and activities that are of interest to them and focusing on issues in which young people have an existing interest)

While psychological factors other than knowledge, efficacy and interest may also be targeted for enhancement, it is important to bear in mind that doing so may increase some forms of participation but decrease others. As we saw in Chapter 2, Brunton-Smith (2011) found that those with high levels of attentiveness to political issues are more likely to vote and to participate civically but are less likely to engage in non-conventional political participation. Likewise, he found contrary 
effects of institutional trust: individuals with higher levels of institutional trust are more likely to vote but are less likely to participate in non-conventional political activities. Consequently, while interventions to enhance political attentiveness and institutional trust may increase the frequency of some participatory behaviours, they may simultaneously reduce the frequency of other behaviours. Hence, there is a need for caution and a careful consideration of the full range of possible outcomes if psychological factors other than political knowledge, internal efficacy and political interest are targeted for enhancement by interventions.

In addition, as we saw in Chapters 2 and 3, some psychological variables may have an effect on a particular form of participatory action in some demographic subgroups but not in others. This was a pervasive finding in PIDOP (Barrett, 2012; Barrett \& Zani, 2015b), which had a particular focus on demographic differences through its strategy of collecting data on youth from two ethnic minority groups in addition to the national majority group in each of nine countries (see Table 1.2 in Chapter 1). Numerous differences were found not only between countries but also between the three ethnic groups within all nine countries. Furthermore, these differences were not just exhibited in these youths' patterns of civic and political participation; they were also exhibited in many of the psychological and social factors that predicted the different forms of participation (see, for example, the discussion in Chapter 2 of the differences in the effects of negative emotions on participatory behaviours found by Pachi \& Barrett, 2012b). The same applied to the patterns of participation, and the predictors of these patterns, that were exhibited by younger vs. older participants and by females vs. males.

The implication is that, in developing interventions to promote levels of civic and political participation in youth, one needs to be mindful that different forms of intervention may be required for minority vs. majority individuals, younger vs. older individuals and females vs. males. Indeed, bearing in mind the possibility of intersectionality, it may actually be the case that different interventions are required for different demographic subgroups defined through the intersection of age, gender, ethnicity and nation (such as younger males from a particular ethnic group living in a particular country vs. older females from another ethnic group living in another country; cf. the discussions of intersectionality in Chapters 1 and 3).

\section{Further actions that can be taken by specific agents of socialisation}

Interventions aimed at promoting the political knowledge, internal efficacy, political interest and participatory behaviour of youth can be delivered by a range of social actors, including parents, schools and youth, community and religious organisations and associations.

Parents, of course, are highly suitable actors to implement an intervention for promoting their offspring's civic and political engagement. As we have just seen, this should ideally involve fostering their offspring's political knowledge, 
internal efficacy, political interest and engagement in participatory behaviours. In addition, the research reviewed in Chapter 3 indicates that this intervention will be most effective if, in addition, parents themselves:

- Are interested in political and social issues and have a high level of political knowledge

- Regularly discuss political and social issues with their offspring

- Regularly engage in participatory actions

- Operate a family ethic of social responsibility

- Operate a family climate of family cohesion and expressivity and avoid an authoritarian parenting style

- Regularly engage in family activities that have an intellectual or cultural orientation

Public authorities could actually play a significant role in supporting parents in this endeavour. For example, they could provide opportunities at a local or community level for adults and families who wish to learn about civic and political processes and about responsible democratic citizenship. These opportunities could be taken up either individually or by the entire family so that all members of the family participate together.

As far as schools are concerned, the review of research findings in Chapter 3 revealed that schools can take a number of additional actions to promote young people's civic and political engagement, over and above delivering the kind of intervention outlined in the previous section. These were listed in Chapter 3, but for convenience, we reproduce the list here; however, the reader should refer back to Chapter 3 for the evidence and rationale for these various actions. Students' civic and political engagement will be promoted if teachers and educational institutions:

- Provide citizenship education courses that require students to discuss and analyse politics and political issues in relationship to contemporary events

- Provide training in civic skills such as letter writing and debating

- Ensure that teachers treat all students in a fair and just manner

- Allow students to raise controversial issues that are of interest to them in the classroom

- Encourage students to discuss social and political issues

- Enable students to hear a wide range of views about these issues

- Allow students to express their own opinions even when their opinions differ from those of other students and from those of the teacher

- Ensure that students respect one another and are not intolerant towards one another

- Support students in formulating their own views about social and political issues after considering a diversity of perspectives and opinions on those issues 
- Operate school councils or parliaments that enable students to acquire firsthand practical experience of democratic processes and to feel that participation in these councils or parliaments is a valuable and worthwhile activity

- Provide high-quality service learning opportunities for students; that is, service learning that supports the development of autonomy, responsibility, confidence, decision-making and planning skills in young people, and provides plentiful opportunities for in-class discussion and reflection

Similarly, the review of research into the role of youth, community and religious organisations and associations in Chapter 3 revealed that these organisations and associations can also take a number of additional actions to promote young people's civic and political engagement, over and above delivering the kind of intervention outlined in the previous section. Once again, we reproduce the list that appeared in Chapter 3 here for convenience, but the reader should refer back to Chapter 3 for the evidence that supports the use of these various actions. Most importantly of all, youth, community and religious organisations and associations should enable and encourage young people to acquire high-quality participation experiences, that is, experiences that require them to:

- Search for information about civic and political issues

- Participate in group decision-making

- Explore a variety of points of view about civic and political issues

- Encounter new ways of perceiving the issues in question

- Develop communication, public speaking and debating skills

- Take on leadership, organisational and representative roles

- Engage in community service

While all of the recommendations contained in the three lists above emerge directly from findings that have been obtained in a variety of national contexts, two cautions should nevertheless be noted. First, not all of these actions will necessarily result in the enhancement of all aspects of youth engagement in all national contexts. For example, as we saw in Chapter 3, ICCS 2009 (Schulz et al., 2010) found that, although parental discussion of political and social issues with their offspring was associated with the latter's political interest in all of the countries that were studied, the association between parental discussions and youth political knowledge was not found in all countries.

Second, there is also evidence that some actions may have different effects in different demographic subgroups even within the same country (see Chapter 3). For example, parental norms (i.e., whether parents themselves engage in political action and whether they approve of their offspring engaging in political action) are associated with different youth outcomes in different ethnic groups within the same country. Thus, Šerek et al. (2015) found that in the Czech Republic, majority Czech youth and minority Roma youth whose parents held strong participatory norms were more likely to participate both offline and online, while minority 
Ukrainian youth who participated both offline and online were more likely to have parents who held weak participatory norms. In addition, Jugert et al. (2016) found that, in Germany, the effects of an open classroom climate (i.e., allowing students to raise controversial issues in the classroom, encouraging them to discuss social and political issues, and enabling them to hear a wide range of views about these issues) and opportunities to participate through school councils or parliaments differed between German majority and Turkish minority youth: an open classroom climate had more impact among the Turkish youth, whereas opportunities to participate had more impact among the German youth.

Despite these caveats, it may nevertheless be argued that the more of the actions listed above that are taken by parents, schools and youth organisations and associations, the more likely it is that the civic and political engagement of young people will be promoted. As the review of research about the effects of social factors in Chapter 3 revealed, the evidence in support of this broad conclusion has been collected from youth belonging to a wide variety of demographic subgroups living in a large number of different countries.

\section{Further actions that can be taken by politicians and policymakers}

Finally, from the review in Chapter 4, it is clear that politicians and policymakers in three policy areas can also make a significant contribution to the promotion of youth civic and political engagement. These three areas are youth policies, education policies and migrant integration policies. Politicians and political parties aiming to mobilise youth politically also have an important role to play.

In the case of youth policies, the evidence reviewed in Chapter 4 suggests that young people's civic and political engagement will be optimally promoted if politicians and policymakers:

- Introduce public policies on youth civic and political participation that clearly and consistently emphasise the importance of young people's engagement and active participation, and the need for the empowerment of youth as autonomous citizens who can act as agents of change within their communities

- Provide plentiful opportunities for youth to participate in political decisionmaking processes and democratic structures, and strongly encourage youth to take up these opportunities

- Provide targeted public funding for youth organisations that provide highquality participation experiences for young people (for the characteristics of high-quality participation experiences, see the third bullet list in the previous section) and ensure that youth organisations take full advantage of the available funding opportunities

- Lower the voting age to 16 years and require schools to provide educational support for the political decision-making of 16- and 17-year-olds (e.g., by encouraging them to conduct research into political issues, to explore 
those issues from a range of different perspectives, to compare and contrast different perspectives, to engage in critical evaluations of perspectives, information and the sources from which information has been derived, to think logically and coherently about political issues, and to draw reasoned conclusions)

As far as education policies are concerned, the actions that should be taken were listed in Chapter 4, but for convenience, we reproduce the list here. The actions that should be taken are the following:

- Citizenship education should be fully incorporated not just into the secondary school curriculum but also the primary school curriculum, with the contents of the curriculum being adapted to the educational level of the students

- Student councils at both primary and secondary school levels should be made mandatory

- Opportunities for service learning, voluntary work and extra-curricular activities in the community should be expanded considerably, for example, in collaboration with community-based organisations, youth organisations and other NGOs, and service learning should be made mandatory

- Summative assessments in citizenship education should be made mandatory

- Initial teacher training in citizenship education should be made mandatory for all prospective teachers

- Initial teacher training should focus much more directly on the specific pedagogies that are known to be effective in promoting youth engagement, and on the specific competences that teachers require for reflecting on, evaluating and improving their own teaching practices

- Where they are not yet available, continuing professional development courses for school principals should be introduced on how to implement citizenship education within their schools

In the case of migrant integration policies, the actions that should be taken were also listed in Chapter 4, and once again we reproduce that list here for convenience. Young migrants' civic and political engagement can be promoted by:

- Giving migrants who have limited proficiency in the language of their country of residence access to language instruction

- Providing integration programmes that focus on opening doors to the local community, so that migrants meet local organisations, services and mentors who are open to diversity and interested to support their integration

- Requiring that staff who deliver migrant integration and language programmes work with volunteers from the local community and promote intercultural activities such as conversation tandems where migrants and non-migrants can learn about each other's culture and way of life 
- Creating grants to support migrant-run associations and support the setting up of mainstream civic and political organisations to mentor migrants

- Recruiting residents of migrant background to local consultative bodies of all types

- Granting the right to vote and stand in local and regional elections to migrants after a minimum period of legal residence (e.g., five years)

- Granting an entitlement to citizenship for first-generation migrants after a minimum period of legal residence (e.g., ten years)

- Granting an entitlement to citizenship for migrants' children who have been educated or born in the country

Finally, in attempting to mobilise youth, the evidence reviewed in Chapter 4, and also some of the evidence that was reviewed in Chapter 1, suggests that politicians and political parties are more likely to be successful in achieving this goal if they:

- Pay much closer attention to young people's views and concerns on civic and political matters and treat these views and concerns with greater respect

- Treat non-conventional political participation and civic participation as being equally important as conventional political participation - for example, politicians should address and provide responses to issues that have been raised through alternative forms of action such as protests, petitions and voluntary action taken by significant numbers of youth on single-issue causes

- Engage in better and more effective communication with young people, so that young people can feel that politicians and political parties are interested in and concerned with their needs and perspectives on civic and political affairs

- Use methods to communicate with young people that youth themselves use to communicate with each other, especially social media

- Propose policies that directly address the most important and widely shared concerns and needs of young people

- Support the youth sections of their own political parties by providing them with adequate financial and administrative resources and by broadening the appeal of these youth sections to much wider swathes of the youth population

- Establish youth parliaments in countries where they do not currently exist, take steps to ensure that such parliaments are not exclusive to youth who are socio-economically and educationally privileged, establish formal links between the youth parliament and the national parliament, and oblige governments to issue formal responses explaining why they support or oppose proposals that have been made by the youth parliament so that the members of the youth parliament can see that their views are being taken seriously and are being considered by those in power

The evidence and rationales for all of the actions contained in the four lists above are provided mainly in Chapter 4 but also partially in Chapters 1 and 3 . 
However, once again, it is necessary to caution that it is highly likely that not all of the actions that are included in these lists will necessarily result in the promotion of the civic and political engagement of all subgroups of youth in all national contexts. Nevertheless, the evidence reviewed in Chapters 1, 3 and 4 strongly suggests that the more of these actions that are taken by politicians and policymakers, the more likely it is that the civic and political engagement of young people will be promoted.

\section{Conclusion}

From this summary, it is apparent that there are many different actions that can be taken by a wide range of social actors in order to promote youth civic and political engagement. Parents, teachers and schools, youth, community and religious organisations and associations, and politicians and policymakers all have a significant role to play. In the absence of such actions, it seems likely that youth will continue to avoid engaging with the conventional political arena, with significant consequences both for the perceived legitimacy of elected democratic governments and the policies they introduce, and for youth themselves who will lack political representation within the conventional political arena.

Of these various actors, it is arguably teachers and schools (backed up by politicians and policymakers with responsibilities for education) who are in a position to play the most decisive role. Not all parents are interested in promoting their offspring's civic and political engagement, and while youth organisations and associations are very well-positioned to reach out to all youth, including disadvantaged youth and those alienated from school and education, the reality is that not all youth become members of these organisations and participate in their activities. By contrast, every young person spends a very considerable proportion of their life attending school, and it is also well-established that schools can function as highly effective incubators of youth civic and political engagement. There is therefore very good reason to single out school education as being an especially important arena for promoting youth engagement. In the following section, we report on a new initiative that is currently under way across Europe that aims to promote young people's levels of democratic engagement and participation by harnessing state education systems for this purpose.

\section{Promoting students' competences for democratic culture through formal education}

In 2013, the Council of Europe launched a major initiative that was aimed at unlocking the potential of the formal educational system for promoting the democratic competences of young people. This initiative resulted in the production of a 'Reference Framework of Competences for Democratic Culture' (RFCDC) (Barrett, 2016; Barrett et al., 2018a, 2018b, 2018c). This Framework is currently being implemented in whole or in part in the national curricula of a number of European countries. 


\section{The background to the RFCDC}

The Council of Europe has always had an active interest in education for democratic citizenship as a direct consequence of the specific mandate of the organisation. The Council was established by 10 countries in 1949 in the aftermath of World War II, and the intention behind the founding of the organisation was to ensure that totalitarianism could never arise again in Europe. The aims of the organisation, which were laid down at that time, were to promote and protect human rights, democracy and the rule of law. Indeed, human rights, democracy and the rule of law are known as the 'three pillars' of the Council of Europe, and the Council is, at its very heart, a values-based organisation. Today, the Council has 47 member states, and its headquarters are located in Strasbourg in France. The best-known international agreement that has been established by the Council is the European Convention on Human Rights, while its best-known agency is the European Court of Human Rights, which is responsible for legal judgements concerning the application of the Convention. A common misperception is that the Council of Europe is a constituent part of the European Union. On the contrary, it is an entirely separate and independent intergovernmental political organisation (the European Union was only founded in 1993, for very different purposes).

In essence, the RFCDC aims to promote and strengthen democracy in Europe by harnessing member states' national education systems for this purpose. The Framework provides a range of proposals on how formal education - ranging all the way from pre-school through to university level - can be used to equip young people with the competences that are required for participating actively and effectively in democratic culture. The Framework specifies these competences in detail, and it also provides extensive guidance for ministries of education on how to develop suitable curricula, pedagogical methods and assessment tools for use in formal education that will help to equip young people with these competences.

The term 'democratic culture' rather than 'democracy' is used in the title of the Framework to emphasise the fact that, while democracy cannot exist without democratic institutions and laws, such institutions and laws cannot work in practice unless they are grounded in a culture of democracy, that is, in democratic values and attitudes. In other words, the RFCDC proposes that a functioning democracy requires citizens to have: a commitment to democratic processes; a willingness to express their own opinions; a willingness to listen to the opinions of others; a commitment to decisions being made by majorities; a commitment to the protection of minorities and their rights; and a conviction that conflicts must be resolved peacefully. If citizens do not hold these democratic values and attitudes and do not put them into practice (i.e., if a democratic culture does not prevail), then democratic institutions will be unable to function.

In addition, the RFCDC proposes that democratic culture within culturally diverse societies requires intercultural dialogue. A fundamental principle of 
democracy is that the people who are affected by political decisions should be able to express their views when those decisions are being made, and that decision-makers should pay attention to those views when making their decisions. Intercultural dialogue is the means through which citizens can express their opinions, concerns and aspirations to other people who have different cultural affiliations from themselves. In other words, in the case of culturally diverse societies, intercultural dialogue is vital for democratic discussion, debate and deliberation and for enabling all citizens to contribute to political decision-making on an equal footing, irrespective of their specific cultural affiliations. For this reason, citizens within culturally diverse democratic societies need to be not only democratically competent but also interculturally competent.

The RFCDC specifies in detail the nature of the democratic and intercultural competences that young people need to acquire through the educational process so that they can operate as effective and respectful democratic citizens. The Framework rests on a particular definition of the term 'competence': competence is defined as the ability to mobilise and deploy relevant values, attitudes, skills, knowledge and understanding in order to respond appropriately and effectively to the demands, difficulties and opportunities that are presented by democratic and intercultural situations. The Framework also uses the term 'competences' (in the plural) to refer to the specific values, attitudes, skills, knowledge and understanding that are mobilised and deployed. Thus, in this second sense of the term, competences are the components of democratic and intercultural competence. In other words, competence consists of the mobilisation and deployment of competences to meet the demands, difficulties and opportunities presented by democratic and intercultural situations.

\section{The three components of the RFCDC}

The RFCDC consists of three components. First, it contains a conceptual model of the competences that young people need to acquire in order to participate effectively in democratic culture and intercultural dialogue. Second, it contains validated and scaled descriptors for all of the competences that are contained in the conceptual model. Third, it contains guidance for ministries of education and education practitioners on how the conceptual model and the descriptors can be used to create more effective education systems for promoting the democratic and intercultural competences of young people. In the following, we expand on each of these three components in turn.

\section{The conceptual model of competences}

The contents of the competence model were developed through a lengthy process that began with an audit of existing conceptual schemes of both democratic competence and intercultural competence (for full details, see Barrett, 2016). In total, 101 competence schemes were audited. A set of principled criteria was 
used to identify the common competences that were contained across the 101 schemes. A conceptual model based on these common competences was then produced, and a document describing the model was written. This document was submitted to an international consultation involving academic experts, education practitioners and policymakers, including experts nominated by the education ministries of the Council of Europe's member states. The model received strong endorsement in this consultation. However, a great deal of useful feedback was also received concerning specific details of the model, and this feedback was used to fine-tune and finalise the model. The model that resulted from this process contains 20 competences which young people need to acquire in order to fulfil the role of an interculturally competent democratic citizen within a culturally diverse democratic society. These competences are listed in Table 5.2. As can

TABLE 5.2 The 20 competences required to function as an interculturally competent democratic citizen within a culturally diverse democratic society, as proposed by the Reference Framework of Competences for Democratic Culture (Barrett, 2016; Barrett et al., 2018a).

\section{Values}

- Valuing human dignity and human rights

- Valuing cultural diversity

- Valuing democracy, justice, fairness, equality and the rule of law

\section{Attitudes}

- Openness to cultural otherness and to other beliefs, world views and practices

- Respect

- Civic-mindedness

- Moral responsibility

- Self-efficacy

- Tolerance of ambiguity

\section{Skills}

- Autonomous learning skills

- Analytical and critical thinking skills

- Skills of listening and observing

- Empathy

- Flexibility and adaptability

- Linguistic, communicative and plurilingual skills

- Cooperation skills

- Conflict-resolution skills

\section{Knowledge and critical understanding}

- Knowledge and critical understanding of the self

- Knowledge and critical understanding of language and communication

- Knowledge and critical understanding of the world, including politics, law, human rights, culture, cultures, religions, history, media, economies, the environment and sustainability 
be seen from the table, the 20 competences fall into four broad categories: values, attitudes, skills, and knowledge and critical understanding.

Each of the 20 competences is described in detail by Barrett (2016; see also Barrett et al., 2018a). It is noteworthy that the model contains all of the most important psychological factors that were described in Chapter 2. It includes, for example, the valuing of democracy, justice, fairness, equality and the rule of law. In addition, it includes civic-mindedness, which is a very broad construct encompassing all of the following: a feeling of belonging to and identification with a community; mindfulness of other people in that community, of the interconnectedness between those people and of the effects of one's actions on those people; a sense of solidarity with other people in the community, including feelings of concern and care for their rights and welfare; an interest in, and attentiveness towards, the affairs and concerns of the community; and a sense of civic duty, a willingness to contribute actively to community life, and a willingness to participate in decisions concerning the affairs, concerns and common good of the community. In other words, civic-mindedness encompasses several of the psychological factors discussed in Chapter 2, including civic and political identifications, beliefs about good citizenship, sense of duty, political interest and political attentiveness.

Attitudes and skills that are postulated by the RFCDC to be directly relevant to civic and political engagement within culturally diverse democratic societies are: openness to cultural otherness and to other beliefs, world views and practices; respect (particularly for other people who are perceived to have different cultural affiliations or different beliefs, opinions or practices from one's own); responsibility (i.e., being reflective about one's actions, forming intentions about how to act in a morally appropriate way, conscientiously performing those actions, and holding oneself accountable for the outcomes of those actions); tolerance of ambiguity (i.e., a willingness to accept that objects, events and situations are sometimes open to multiple incompatible interpretations and points of view); analytical and critical thinking skills; empathy (i.e., the ability to take the perspective of other people); cooperation skills; and conflict-resolution skills. The RFCDC model also includes self-efficacy (i.e., internal efficacy), as well as knowledge and critical understanding of politics, law, media and economies.

It is clear from the list of competences that some of them (e.g., openness and empathy) can be targeted from a relatively early age at pre-school and primary school, whereas others are more suitable for targeting in upper secondary school or even in higher education (e.g., knowledge and critical understanding of politics, law and economies). As such, promoting the development of these competences is a task that applies across all levels of formal education, from pre-school through primary and secondary education to higher education.

The model postulates that, in real-life situations, these various competences are rarely mobilised and used individually. Instead, they are much more likely to be deployed in clusters. Depending on the situation and the specific demands, challenges and opportunities which that situation presents, as well as the specific needs of the individual within the situation, different subsets of competences will be activated 
and deployed. Furthermore, any given situation also changes over time. For this reason, an effective response requires the constant monitoring of the situation and the appropriate ongoing adjustment of the competences being deployed. In other words, a competent individual will mobilise and deploy competences in a fluid, dynamic and adaptive manner in order to meet the constantly shifting demands, challenges and opportunities that arise in democratic and intercultural situations.

In short, the RFCDC proposes that formal education should seek to promote all 20 competences in young people in order to foster their civic and political engagement. Formal education should also provide plentiful opportunities for young people to practise and consolidate their ability to deploy these competences in a dynamic and adaptive manner.

\section{The scaled descriptors}

In order to assist education systems to achieve this goal, the RFCDC also provides validated and scaled descriptors for each of the 20 competences. These descriptors are clear, explicit and concise statements or descriptions of the observable behaviours that a person will display if they have achieved a certain level of development in a given competence. The descriptors are formulated using the language of learning outcomes. In other words, each descriptor contains an action verb together with the object of that verb, and the behaviour that is described is observable and assessable. Using the language of learning outcomes means that the descriptors can be used not only for assessment purposes but also for curriculum development and pedagogical planning.

The process of developing the descriptors began with an audit of existing psychometric scales, research documents and policy documents that contained potentially suitable statements about behaviours and learning outcomes that could be matched to one of the 20 competences. In total, 98 source documents were audited. Scale items and statements found in these documents were extracted and rephrased to construct short statements that could potentially serve as descriptors. Initially, 2,085 descriptors were written. These descriptors were then evaluated using a series of rating tasks and validation tasks involving education professionals in 53 countries (with the bulk of the data coming from 15 countries) and a rating and scaling task in which data were collected from 16 countries. The data from these tasks revealed that 447 of the descriptors were valid and were also judged to be useful by teachers for educational purposes. These 447 descriptors were scaled to three levels of proficiency - basic, intermediate and advanced. Finally, a smaller set of 135 key descriptors representing the three levels of proficiency for all 20 competences was identified on the basis of an analysis of the scaling data and the contents of the descriptors. Table 5.3 provides some examples of scaled key descriptors for two of the 20 competences. The full bank of 447 validated and scaled descriptors, and the 135 key descriptors, are reported in Barrett et al. (2018b).

The key point about the descriptors is that they provide an operationalisation of the 20 competences in terms of the concrete observable behaviours that may 
TABLE 5.3 Examples of scaled key descriptors in the Reference Framework of Competences for Democratic Culture (Barrett et al., 2018b).

\section{Competence: Civic-mindedness}

Basic level of proficiency

- Expresses a willingness to cooperate and work with others

- Collaborates with other people for common interest causes

Intermediate level of proficiency

- Expresses commitment to not being a bystander when the dignity and rights of others are violated

- Discusses what can be done to help make the community a better place

Advanced level of proficiency

- Exercises the obligations and responsibilities of active citizenship at either the local, national or global level

- Takes action to stay informed about civic issues

\section{Competence: Skills of listening and observing}

Basic level of proficiency

- Listens attentively to other people

- Listens carefully to differing opinions

Intermediate level of proficiency

- Can listen effectively in order to decipher another person's meanings and intentions

- Watches speakers' gestures and general body language to help himself/herself to figure out the meaning of what they are saying

Advanced level of proficiency

- Pays attention to what other people imply but do not say

- Notices how people with other cultural affiliations react in different ways to the same situation

be displayed by students at different levels of proficiency. Furthermore, because the descriptors are expressed using the language of learning outcomes, they can be used to develop a curriculum for citizenship education that specifies not only the competences that should be targeted at particular educational levels but also the specific learning outcomes that should be achieved at each level. In addition, they can be used as an aid for designing and evaluating learning activities for enhancing young people's competences. The descriptors can also be used to support the assessment of students' level of proficiency, either to identify areas for further development (formative assessment) or to assess achieved proficiency after a period of learning (summative assessment).

\section{The guidance for ministries of education and for education practitioners}

The third component of the RFCDC is the guidance that it offers to ministries of education and education practitioners on how the conceptual model and the 
descriptors can be used in citizenship education (Barrett et al., 2018c). There are six areas of application that are covered:

- How the RFCDC can be used for the purposes of curriculum development - This guidance explains how the model of competences and the descriptors can be used for auditing and reviewing the current curriculum to identify where democratic and intercultural competences may be targeted as suitable learning outcomes, and explains how the Framework can be used to develop the curriculum in order to ensure that as many competences as possible are fostered in students. It also discusses the use of a cross-curricular approach in citizenship education.

- How the RFCDC can be used to select or develop appropriate pedagogical methods for the teaching and learning of the 20 competences - This guidance reviews the teaching and learning methods that are the most suitable for fostering the development of democratic competences in students. It identifies these as being teachers modelling democratic attitudes and behaviours within the classroom and ensuring an open classroom climate, cooperative learning, project-based learning and service learning.

- How the RFCDC can be used for assessing students - This guidance reviews the various assessment methods that are suitable for supporting the development of democratic competences in students. These include open-ended diaries, reflective journals and structured autobiographical reflections, observational assessment, dynamic assessment, project-based assessment and portfolio assessment.

- How the RFCDC can be applied through a whole-school approach in order to foster the development of the 20 competences - This guidance explains what a wholeschool approach is and how to implement it. The approach involves using democratic and interculturally respectful structures and procedures in all aspects of school life, including curriculum development, the teaching and learning methods and resources that are used, the assessment methods that are used, school leadership, governance and decision-making, staff-staff, staff-student and student-student relationships, extracurricular activities, and links with the community.

- How teacher education should be adapted in order to support the use of the RFCDC in national education systems - This guidance explains how such education needs to prepare teachers adequately for implementing the RFCDC and discusses the role of both pre-service and in-service teacher education.

- How the RFCDC can be used to combat radicalisation leading to violent extremism and terrorism - This guidance explains the nature of radicalisation, violent extremism and terrorism, describes the predisposing and enabling conditions that can lead to radicalisation and explains precisely why and how the Framework is relevant to building students' resilience to radicalisation.

Because the Framework is intended as a tool to help education policymakers and practitioners rethink their existing activities in the field of citizenship education, 
the guidance offered on each topic tends to be non-directive and open-ended - it identifies the various options that may be used to implement the RFCDC and outlines the pros and cons of each option. The user is then invited to consider the relevant issues and to make their own decisions in the light of those considerations. All decision-making is very deliberately left to local policymakers and practitioners who have the detailed understanding of their own national and local contexts in which they are operating.

That said, there is an underlying philosophy of the RFCDC concerning the optimal educational practices that ideally ought to be used to foster the democratic competences of students. First, both the competence model and the descriptors should be used for the purposes of reviewing and developing the existing curriculum, to ensure that all 20 competences are included within the curriculum. Second, the competences of students will be optimally nurtured if a cross-curricular approach is used, with the responsibility for fostering the democratic competences of students being distributed across and shared by all teachers, irrespective of the specific school subject that they teach (thus, even subjects such as mathematics and the natural sciences can make a contribution if they adopt, for example, pedagogies based on cooperative group work which require students to practise competences such as skills of listening and observing, empathy, respect, communication skills, cooperation skills and conflict-resolution skills). This implies that all teachers, irrespective of the subject that they teach, should be trained to deliver citizenship education to their students.

Third, the competences of students will also be optimally nurtured if educational activities take place within an institutional environment in which democratically and interculturally appropriate and respectful structures and procedures permeate all aspects of institutional life (i.e., if a whole-school approach is employed). Fourth, the competences of students will be optimally nurtured if education is based on experiential learning (rather than knowledge transmission through frontal teaching, for example). For this reason, there should be plenty of opportunities for authentic and high-quality democratic participatory experiences and actions that are relevant to the lives of students. Fifth, in order to identify students' learning needs, formative assessments should be used to obtain information about the specific areas that need to be targeted for further development. Sixth, summative assessments should also occur at the end of a period of learning, to identify which learning outcomes have been achieved. The results of summative assessments can then be used to identify further learning needs that should be targeted in the next cycle of learning. For these reasons, there always ought to be a close relationship between assessment and the teaching and learning of the 20 competences.

Thus, the RFCDC provides a comprehensive approach to citizenship education. It offers a systematic method for designing the curriculum, the teaching and learning and the assessment of democratic competences, and introducing them into education systems in ways that are coherent, comprehensive and transparent. 


\section{The political process behind the RFCDC}

The positive reception that the RFCDC has received from the education ministries of the Council of Europe's member states is due, in part, to the fact that the ministries were kept informed about the Framework at all stages of its development, and the ministries provided feedback on, and inputted their own ideas into, the Framework as it developed. This meant that the RFCDC evolved in direct response to the expressed needs of the ministries.

However, there is also another reason underlying the positive reception that has been accorded to the RFCDC. This is the urgent need of governments to respond to the phenomena of radicalisation, violent extremism and terrorism. Because of the regular occurrence of terrorist attacks in European countries over recent years, in 2015 the Council of Europe drew up an Action Plan on The Fight Against Violent Extremism and Radicalisation Leading to Terrorism (Council of Europe, 2015), in which the RFCDC was given a central role. This Action Plan led to a political expectation that the Framework can and will be used by national education systems to equip young people not only with the competences needed for participation in democratic culture but also with the competences needed to recognise and deal with, for example, online propaganda (e.g., analytical and critical thinking skills), to recognise misinformation, fake news and hate speech in the news media and online (e.g., knowledge and critical understanding of media) and to value human dignity, human rights and democratic processes. It is for this reason that the RFCDC contains guidance for national governments on how to use the Framework to combat radicalisation leading to violent extremism and terrorism. Subsequently, in 2016, the Council of Europe drew up a further Action Plan on Building Inclusive Societies (Council of Europe, 2016b), with the RFCDC being accorded a major role in this endeavour as well.

Because of this high level of political attention, the RFCDC was presented to the education ministers of the Council of Europe's member states at the Council's Standing Conference of Ministers of Education, which took place in Brussels in 2016. The final conference declaration, which was unanimously agreed by the education ministers, welcomed and endorsed the Framework and called on the Council of Europe to assist member states in examining and implementing it in their own national education systems (Council of Europe, 2016c).

Full or partial implementation of the RFCDC in a number of countries is currently under way. After it has been introduced, it will of course be necessary to conduct evaluations of its effectiveness for promoting the civic and political engagement of young people. At the time of writing, it seems highly likely that different countries will adopt different approaches to implementation, and evaluation studies will also need to ascertain the mode and manner of implementation that is the most effective for enhancing the democratic competences of youth. Nevertheless, the fact that there now appears to be a serious and significant political will to foster young people's democratic engagement in many countries leads 
to some hope that the widespread disengagement among young people from the conventional political arena that was described in Chapter 1 may eventually be reversed in at least some European countries.

\section{Issues in the study of youth civic and political engagement requiring further research}

At the end of each of the previous three chapters, we noted a number of outstanding issues that still require further investigation within this field. Thus, in Chapter 2, we noted that further research still needs to be conducted into: why the relationship between psychological factors and participation varies across countries; the processes through which demographic characteristics such as SES, gender and ethnicity are linked to psychological factors; young people's understanding of the law and the relationship between this understanding and their participatory behaviours; young people's perceptions of political power relationships; young people's perceptions of adult norms concerning active citizenship; the ways in which the multiple identities of young people interact with each other to drive their civic and political behaviours; and the direction of the causality that exists between psychological factors and civic and political participation.

In addition, at the end of Chapter 3, we noted that further research still needs to be conducted into: the effects of young people's consumption of different types of mass media content; the role of popular music as a driver of young people's civic and political engagement; the social and psychological processes that facilitate young people's adoption of the civic and political interests, values and practices that are modelled by their parents, teachers and peers; the processes through which citizenship behaviours that are practised within small, intimate groups come to be extended to larger frames of reference, such as the neighbourhood or the wider political community; young people's perceptions of the youth sections of political parties; why the links between SES and engagement differ depending upon the time frame and type of activism involved; and the variability in youth engagement and participation that occurs across highly specific subgroups within the youth population.

Finally, Chapter 4 noted that further research still needs to be conducted into: the causal interconnections between macro, demographic, social and psychological factors or levels; the impact of the policy environment on youth civic and political engagement; the effects of youth parliaments, both on the youth who participate in them and on the youth who are excluded from them; and the role of the Internet and social media in young people's civic and political engagement.

In addition, this current chapter has identified a host of further issues that also still need to be addressed by researchers in this field. For example, earlier in this chapter, we discussed the role of endogenous psychological processes. There are highly complex psychological processes (including attentional, perceptual, cognitive, affective and motivational processes) that underlie the selection and uptake of civic and political information from the social environment. There are 
also complex psychological processes that affect the construction of civic and political attitudes and beliefs by young people and that influence the civic and political behavioural choices that they make. However, there has been relatively little research into these underlying psychological processes. For this reason, the roles played by cognitive goals, affective preferences and motivational needs in this domain still need to be investigated properly.

Interventions for boosting young people's levels of civic or political engagement also need to be properly evaluated using appropriate methodology. Such evaluation studies require not only groups of youths who receive the intervention but also suitable control groups, to ensure that any changes that are observed to take place can be unambiguously attributed to the intervention. In addition, some interventions, such as the RFCDC, allow a great deal of latitude to education practitioners in exactly how to implement them, and it is highly likely that some modes of implementation will be more effective than others. Evaluation studies are required to identify the optimal modes of implementation of interventions such as the RFCDC within specific contexts.

An additional complication in using interventions to promote youth engagement is the potential for the effects of any given intervention to only apply to particular subgroups of youth. As we have reiterated throughout this book, young people's civic and political concerns and patterns of engagement are often specific to particular groups of individuals who occupy specific demographic niches as defined by the intersection of several demographic categories such as nationality, ethnicity, gender, age, SES and locale. For this reason, an intervention that raises the level of engagement in one subgroup may not do so in another subgroup, and a different form of intervention may be required to promote engagement in that other subgroup. There is a considerable research agenda here, to identify the interventions that are most suitable for promoting engagement among particular subgroups of youths who are living in specific contexts.

Another issue that has not yet been adequately addressed by existing research is the direction of the causality that operates in this domain. This issue was first raised in Chapter 2, and it has repeatedly resurfaced throughout the course of this book. A great deal of the research in this field has used cross-sectional and correlational designs; however, only longitudinal research designs can really uncover whether and how particular interventions or specific macro, social or psychological factors at one point in time affect young people's behaviour at a later point in time. Precisely because issues of causality can only be properly addressed using longitudinal data, there is a very real need for many more longitudinal investigations (or investigations using a cohort sequential design) to allow much firmer conclusions to be drawn about the causality that drives young people's civic and political engagement.

In addition, it should be noted that there are more imaginative ways in which mixed-methods designs could be used in this field of research. Qualitative research has its obvious strengths (e.g., identifying young people's perceptions, beliefs, thinking and reasoning), as does quantitative research (which can permit 
sophisticated statistical analyses to be conducted that help to draw out the relationships between variables). However, the best and most revealing research is often that which uses both qualitative and quantitative methods together in a mixed design. However, the way in which mixed designs are most commonly conducted is through the initial use of a qualitative method to identify and scope the key variables, followed by a subsequent phase in which those key variables are then measured. Researchers do not often use qualitative methods to follow up quantitative methods. This is unfortunate because this research strategy can help to elucidate the participants' own understandings and interpretations of the patterns that have been identified in the quantitative analyses, which could be very different from those constructed by the researcher.

Furthermore, the range of qualitative research methods used within this field is remarkably limited, with the thematic analysis of verbal responses that have been collected either through individual interviews or through focus group discussions being the method that is used most frequently. By contrast, studies using grounded theory, discourse analysis and conversation analysis are very rarely reported in the literature. This is a pity, because grounded theory is extremely useful for generating novel concepts and for building theories and models from qualitative data, while both discourse analysis and conversation analysis can help to provide unique insights into how power relations, and the positioning of different social actors in relationship to one another, are often linguistically constructed within social exchanges and interactions. It is arguable that both the research agenda and our understandings in this field have been unnecessarily restricted by the predominant use of a relatively small set of research methods.

\section{Conclusions}

This book has reviewed a large and diverse range of research literature on youth civic and political engagement. Across the course of the review, some key themes have emerged, and at this end point of the book, it will be useful to summarise a few of them here.

First, as we noted in Chapter 1, youth commitment to conventional forms of political participation is currently in decline in many Western democracies. The reasons for this trend are numerous. One salient reason is that young people often feel that they are not taken seriously by politicians; that politicians generally have little interest in their views, concerns or needs; and that most politicians make little or no attempt to communicate with them. Young people therefore feel that they cannot have any influence politically, with many regarding voting as one of the least effective ways of achieving change. In addition, 16- and 17-year-olds often perceive themselves as being excluded from political processes and institutions and feel disenchanted with conventional politics because they are denied the vote on the grounds of their age.

Consequently, many young people today view non-conventional political and civic forms of participation (e.g. demonstrations, protests, petitions, 
charitable activities and consumer activism) that are focused on single issues as being more effective for having an impact in the world than conventional politics. And indeed, young people are far from disengaged when it comes to global issues such as global warming, pollution, global poverty, the greed of multinational corporations and human rights, and local issues such as graffiti, litter, transport facilities, recycling facilities and youth amenities. In fact, their commitment to and enthusiasm over actions addressing these kinds of issues show that they are by no means alienated from or apathetic about the state of the world. Quite the contrary.

That said, voting does nevertheless remain the single most commonly used form of participation by young people, possibly because it is a very simple action that requires little effort - rather, the point about youth disengagement is that this extremely important form of action is now being used by youth less frequently than it was in the past. Furthermore, their growing disengagement from conventional politics is a serious problem, because it means that young people's views may not be represented effectively within the conventional political arena, and political decision-making and policymaking may therefore proceed without considering their needs or concerns. For this reason, it is important that young people living in democratic societies re-engage more comprehensively with conventional politics.

A further problem, however, is that young people also frequently feel that they do not know enough about political issues to be able to engage in effective action through conventional politics to influence change, and this lack of knowledge is sometimes experienced by them as a significant impediment to their own participation. They also commonly report that they have relatively little experience of political participation, and the experience that some of them have had is not always of high quality. This is another worrying pattern, insofar as the quality of participation experience is a significant predictor of future participation. These two issues mean that schools and youth organisations, in particular, could be important agents for re-engaging youth with the conventional political arena by equipping them with political knowledge and by providing them with the opportunity to acquire high-quality participation experience.

However, as we have seen over the course of Chapters 2, 3 and 4, trying to boost youth participation is a highly complex business. This is because youth civic and political participation is a product of factors operating at four levels: macro, demographic, social and psychological. Implementing interventions to boost youth engagement is further complicated by the fact that different forms of participation are related to different subsets of factors. In addition, any given form of participation may be linked to different subsets of factors depending on the specific demographic situation of the individual concerned. Indeed, both patterns of engagement, and the predictors of participation, are often specific to particular subgroups of individuals who occupy particular demographic niches as defined by the intersection of country, ethnicity, gender, age and locale. In other words, young people's civic and political concerns are invariably formed within 
highly specific demographic contexts situated within particular locations and at particular points in historical time, and their civic and political participation is therefore also often specific to those particular demographic contexts, locations and times.

Yet another complication is that, while studies have sometimes found fairly consistent associations between certain psychological factors and participation (e.g., between internal efficacy and all forms of participation), the causality in these relationships is not always clear. Furthermore, in a few cases, the causality has actually been discovered to run from participation to the psychological factor (e.g., with participation boosting the sense of internal efficacy), rather than the other way around. This means that interventions to boost young people's levels of conventional political participation need to incorporate high-quality participation experiences rather than just trying to boost psychological factors (such as internal efficacy) on their own. That said, the research does imply that the most consistent psychological predictors are political knowledge, political interest and internal efficacy. For this reason, interventions are most likely to succeed if they target these three psychological factors while simultaneously providing young people with high-quality participation experiences.

As we have seen in this current chapter, there are several social actors that are particularly well-positioned to promote youth civic and political engagement. Parents, schools, youth organisations and politicians and policymakers all have a significant role to play. Parents are, of course, ideally positioned to influence their offspring through their own political discourse and civic and political practices. Schools are also extremely important insofar as all young people spend a large proportion of their lives in school - for precisely this reason, schools can make a considerable impact through the curriculum and through the pedagogical and assessment practices that they adopt. Youth organisations are also extremely wellpositioned to provide young people with invaluable opportunities to acquire relevant and meaningful experiences of participation and to build their civic skills (but such organisations require public funding in order to be able to do so on a substantial scale). Finally, politicians and policymakers need to pay much closer attention to young people's views on civic and political matters and develop policies to address their concerns. One further specific action that could be taken in many countries is to lower the voting age from 18 to 16 years. This could not only have a significant impact on youth involvement with conventional politics, especially if it is accompanied by appropriate educational support for their political research, reasoning and critical evaluation of political positions and perspectives, but could also have the additional benefit of enabling 16- and 17-year-olds to seek political representation on crucial matters affecting their lives.

Given the many challenges that Western democracies currently face (e.g., increasing employment insecurity, growing inequality, social and political polarisation, rising support for anti-establishment populist parties and the arrival of a new era of 'post-truth' politics), we believe that it is vital that action is taken to empower youth so that they can respond in appropriate ways to these 
138 Theoretical integration and actions

numerous challenges. In the absence of such action, young people will inevitably continue to avoid engaging with the conventional political arena, with significant consequences for the perceived legitimacy of elected democratic governments, for the ways in which such governments seek to tackle these various challenges, and for youth themselves due to their lack of political representation on their most pressing needs and concerns. 


\section{REFERENCES}

Aarts, K. \& Semetko, H.A. (2003). The divided electorate: Media use and political involvement. Journal of Politics, 65(3), 759-784. DOI:10.1111/1468-2508.00211

Abramson, P.R. \& Aldrich, J.H. (1982). The decline of electoral participation in America. American Political Science Review, 76, 502-521.

Ajzen, I. (1985). From intentions to actions: A theory of planned behavior. In J. Kuhl \& J. Beckmann (Eds.), Action control: From cognition to behavior (pp. 11-39). New York: Springer Verlag.

Ajzen, I. (1991). The theory of planned behavior. Organizational Behavior and Human Decision Processes, 50(2), 179-211.

Ajzen, I. \& Fishbein, M. (1980). Understanding attitudes and predicting social behavior. Englewood Cliffs, NJ: Prentice-Hall.

Albanesi, C., Cicognani, E. \& Zani, B. (2007). Sense of community, civic engagement and social well-being in Italian adolescents. Journal of Community and Applied Social Psychology, 17, 387-406.

Amadeo, J., Torney-Purta, J., Lehmann, R., Husfeldt, V. \& Nikolova, R. (2002). Civic knowledge and engagement: An IEA study of upper secondary students in sixteen countries. Amsterdam: IEA.

Amnå, E. \& Ekman, J. (2014). Standby citizens: Faces of political passivity. European Political Science Review, 6, 261-281.

Amnå, E. \& Ekman, J. (2015). Standby citizens: Understanding non-participation in contemporary democracies. In M. Barrett \& B. Zani (Eds.), Political and civic engagement: Multidisciplinary perspectives (pp. 96-108). London: Routledge.

Andolina, M.W., Jenkins, K., Zukin, C. \& Keeter, S. (2003). Habits from home, lessons from school: Influences on youth civic engagement. Political Science and Politics, 36(2), 275-280.

Ansolabehere, S. \& Iyengar, S. (1995). Going negative. New York: Free Press.

Astin, A.W., Sax, L.J. \& Avalos, J. (1999). Long-term effects of volunteerism during the undergraduate years. The Review of Higher Education, 22, 187-202.

Atkins R. \& Hart, D. (2003). Neighborhoods, adults, and the development of civic identity in urban youth. Applied Developmental Science, 7(3), 156-164. DOI: 10.1207/ S1532480XADS0703_6 
Azevedo, C.N. \& Menezes, I. (2007). Learning politics beyond cognition - the role of experience and participation in political development. In Kryger, N. \& Ravn, B. (Eds.), Learning beyond cognition (pp. 95-114). Copenhagen: Danish University of Education Press.

Bajoghli, N. (2014). Digital technology as surveillance: The Green Movement in Iran. In L. Herrera \& R. Sakr (Eds.), Wired citizenship: Youth learning and activism in the Middle East (pp. 180-194). New York: Routledge.

Bakagiannis, S. \& Tarrant, M. (2006). Can music bring people together? Effects of shared musical preference on intergroup bias in adolescence. Scandinavian Journal of Psychology, 47, 129-136.

Bandura, A. (1986). Social foundations of thought and action. Englewood Cliffs, NJ: PrenticeHall.

Bandura, A. (1989a). Social cognitive theory. In R. Vasta (Ed.), Annals of child development, Volume 6 (pp. 1-60). Greenwich, CT: JAI Press.

Bandura, A. (1989b). Human agency in social cognitive theory. American Psychologist, 44(9), 1175-1184. DOI:10.1037/0003-066X.44.9.1175

Barlow, J.P. (1996). A declaration of the independence of cyberspace. Electronic Frontier Foundation. https://www.eff.org/cyberspace-independence, accessed 25 August 2017.

Barrett, M. (2007). Children's knowledge, beliefs and feelings about nations and national groups. Hove: Psychology Press.

Barrett, M. (2012). The PIDOP Project: An Overview. Guildford: School of Psychology, University of Surrey. http://epubs.surrey.ac.uk/775796/1/Barrett\%20(2012).pdf, accessed 15 July 2013.

Barrett, M. (2015). An integrative model of political and civic participation: Linking the macro, social and psychological levels of explanation. In M. Barrett \& B. Zani (Eds.), Political and civic engagement: Multidisciplinary perspectives (pp. 162-187). London: Routledge.

Barrett, M. (2016). Competences for democratic culture: Living together as equals in culturally diverse democratic societies. Strasbourg: Council of Europe Publishing.

Barrett, M., de Bivar Black, L., Byram, M., Faltýn, J., Gudmundson, L., van't Land, H., Lenz, C., Mompoint-Gaillard, P., Popović, M., Rus, C., Sala, S., Voskresenskaya, N. \& Zgaga, P. (2018a). Reference framework of competences for democratic culture, Volume 1: Context, concepts and model. Strasbourg: Council of Europe Publishing.

Barrett, M., de Bivar Black, L., Byram, M., Faltýn, J., Gudmundson, L., van't Land, H., Lenz, C., Mompoint-Gaillard, P., Popović, M., Rus, C., Sala, S., Voskresenskaya, N. \& Zgaga, P. (2018b). Reference framework of competences for democratic culture, Volume 2: Descriptors of competences for democratic culture. Strasbourg: Council of Europe Publishing.

Barrett, M., de Bivar Black, L., Byram, M., Faltýn, J., Gudmundson, L., van't Land, H., Lenz, C., Mompoint-Gaillard, P., Popović, M., Rus, C., Sala, S., Voskresenskaya, N. \& Zgaga, P. (2018c). Reference framework of competences for democratic culture, Volume 3: Guidance for implementation. Strasbourg: Council of Europe Publishing.

Barrett, M. \& Brunton-Smith, I. (2014). Political and civic engagement and participation: Towards an integrative perspective. Journal of Civil Society, 10(1), 5-28.

Barrett, M. \& Zani, B. (2015a). Political and civic engagement: Theoretical understandings, evidence and policies. In M. Barrett \& B. Zani (Eds.), Political and civic engagement: Multidisciplinary perspectives (pp. 3-25). London: Routledge.

Barrett, M. \& Zani, B. (Eds.) (2015b). Political and civic engagement: Multidisciplinary perspectives. London: Routledge.

Baumeister, R.F. \& Leary, M.R. (1995). The need to belong: Desire for interpersonal attachments as a fundamental human motivation. Psychological Bulletin, 117, 497-529. 
Beaton, A.E., Mullis, I.V.S., Martin, M.O., Gonzalez, E.J., Kelly, D.L. \& Smith, T.A. (1996). Mathematics achievement in the middle school years: IEA's Third International Mathematics and Science Study (TIMSS). Chestnut Hill, MA: TIMSS.

Bedolla, L.G. (2000). They and we: Identity, gender and politics among Latino youth in Los Angeles. Social Science Quarterly, 81, 106-122.

Bee, C. \& Guerrina, R. (Eds.) (2014). Framing civic engagement, political participation and active citizenship in Europe. London: Routledge.

Bennett, A. (2000). Popular music and youth culture: Music, identity and place. Basingstoke: Macmillan.

Bennett, L.L. \& Bennett, S.E. (1989). Enduring gender differences in political interest. American Politics Research, 17(1), 105-122. DOI: 10.1177/1532673X8901700106

Bennett, S.E. (1986). Apathy in America, 1960-1984: Causes and consequences of citizen political indifference. Dobbs Ferry, NY: Transnational Publishers.

Bennett, W.L. (2007). Civic learning in changing democracies: challenges for citizenship and civic education. In P. Dahlgren (Ed.), Young citizens and new media: Learning democratic engagement (pp. 59-77). New York: Routledge.

Bennett, W.L., Freelon, D. \& Wells, C. (2010). Changing citizen identity and the rise of a participatory media culture. In L.R. Sherrod, J. Torney-Purta \& C.A. Flanagan (Eds.), Handbook of research on civic engagement in youth (pp. 393-423). Hoboken, NJ: John Wiley \& Sons.

Bennett, W.L. \& Segerberg, S. (2012). The logic of connective action: Digital media and the personalization of contentious politics. Information, Communication \& Society, 15, $739-768$.

Bennie, L. \& Russell, A. (2012). Radical or compliant? Young party members in Britain. Paper presented at the Elections, Public Opinion and Parties (EPOP) Conference, University of Oxford, 7-9th September 2012.

Bernhagen, P. \& Marsh, M. (2007). Voting and protesting: Explaining citizen participation in old and new European democracies. Democratization, 14, 44-72.

Berzonsky, M.D. (2011). A social-cognitive perspective on identity construction. In S.J. Schwartz, K. Luyckx \& V.L. Vignoles (Eds.), Handbook of identity theory and research (pp. 55-76). New York: Springer.

Beutel, A.M. \& Johnson, M.K. (2004). Gender and prosocial values during adolescence: A research note. The Sociological Quarterly, 45(2), 379-393.

Beutel, A.M. \& Marini, M.M. (1995). Gender and values. American Sociological Review, $60,436-448$

Billig, S. (2000). Research on K-12 school-based service-learning: The evidence builds. School K-12. Paper 3. http://digitalcommons.unomaha.edu/slcek12/3.

Black, P. (1998). Testing: Friend or foe? The theory and practice of assessment and testing. London: Falmer Press.

Blais, A. (2010). Political participation. In L. LeDuc, R.G. Niemi \& P. Norris (Eds.), Comparing democracies 3: Elections and voting in the 21st century (pp. 164-183). Los Angeles, CA: Sage.

Blanch, D. (2005). Between the traditional and the postmodern: Political disaffection and youth participation in Galicia. In J. Forbrig (Ed.), Revisiting Youth Political Participation (pp. 61-69). Strasbourg: Council of Europe.

Bogard, K.L. \& Sherrod, L.R. (2008). Citizenship attitudes and allegiances in diverse youth. Cultural Diversity and Ethnic Minority Psychology, 14, 286-296.

Bowyer, B. \& Kahne, J. (2016). When young people get involved in online communities, it leads them towards politics. Monkey Cage, Washington Post, 21 October 2016. https://ypp.dmlcentral.net/publications/311, accessed 24 August 2017. 
Bozkurt, S., Çok, F. \& Şener, T. (2015). Government perspectives on civic and political participation of youth and women in Turkey. In M. Barrett \& B. Zani (Eds.), Political and civic engagement: Multidisciplinary perspectives (pp. 420-435). London: Routledge.

Brady, H.E., Verba, S. \& Schlozman, K.L. (1995). Beyond SES: A resource model of political participation. American Political Science Review, 89(2), 271-294.

Brewer, M.B. (1993). The role of distinctiveness in social identity and group behaviour. In M.A. Hogg \& D. Abrams (Eds.), Group motivation: Social psychological perspectives (pp. 1-16). New York: Harvester Wheatsheaf.

Bringle, R.G. (2015). "I'm so angry I could ... help!" The nature of empathic anger as a motive for volunteering. Paper presented at the Pathways to Achieving Civic Engagement Conference, Elon, NC.

Bringle, R.G. (2017). Social psychology and student civic outcomes. In J.A. Hatcher, R.G. Bringle \& T.W. Hahn (Eds.), Research on student civic outcomes in service learning: Conceptual framework and methods (pp. 69-89). Sterling, VA: Stylus Publishing.

Bronfenbrenner, U. (1979). The ecology of human development. Cambridge, MA: Harvard University Press.

Bronfenbrenner, U. (1989). Ecological systems theory. Annals of Child Development, 6, 187-249.

Bronfenbrenner, U. \& Ceci, S.J. (1994). Nature-nurture reconceptualised in developmental perspective: A bioecological model. Psychological Review, 101, 568-586.

Brown, J.D. \& Bobkowski, P.S. (2011). Older and newer media: Patterns of use and effects on adolescents' health and well-being. Journal of Research on Adolescence, 21, 95-113.

Brown, L.M. (1999). Raising their voices: The politics of girls' anger. Cambridge, MA: Harvard University Press.

Brunton-Smith, I. (2011). Modelling existing survey data: Full technical report of PIDOP Work Package 5. Department of Sociology, University of Surrey. http://epubs.surrey. ac.uk/739988/, accessed 29 June 2012.

Brunton-Smith, I. \& Barrett, M. (2014). Political and civic participation: Findings from the modelling of existing survey data sets. In M. Barrett \& B. Zani (Eds.), Political and civic engagement: Multidisciplinary perspectives (pp. 195-212). London: Routledge.

Bruter, M. \& Harrison, S. (2009). Tomorrow's leaders? Understanding the involvement of young party members in six European democracies. Comparative Political Studies, 42, 1259-1290.

Burns, N., Schlozman, K.L. \& Verba, S. (2001). The private roots of public action. Cambridge, MA: Harvard University Press.

Bynner, J. \& Ashford, S. (1994). Politics and participation: Some antecedents of young people's attitudes to the political system and political activity. European Journal of Social Psychology, 24(2), 223-236. DOI:10.1002/ejsp.2420240202

Campbell, A. (1980). The American voter. Chicago, IL: University of Chicago Press.

Capella, J. \& Jamieson, K. (1997). Spiral of cynicism. New York: Oxford University Press.

Capelos, T. (2013). Understanding anxiety and aversion: The origins and consequences of affectivity in political campaigns. In N. Demertzis (Ed.), Emotions in politics: The affect dimension in political tension (pp. 39-59). Basingstoke: Palgrave Macmillan.

Capelos, T. \& Exadaktylos, T. (2015). 'The good, the bad and the ugly': Stereotypes, prejudices and emotions on Greek media representation of the EU financial crisis. In G. Karyotis \& R. Gerodimos (Eds.), The politics of extreme austerity: Greece in the Eurozone crisis (pp. 46-68). Basingstoke: Palgrave Macmillan.

Capelos, T. \& Exadaktylos, T. (2017). Feeling the pulse of the Greek debt crisis: Affect on the web of blame. National Identities, 19(1), 73-90. DOI: 10.1080/ 14608944.2015.1113241 
Chan, T.W. \& Clayton, M. (2006). Should the voting age be lowered to sixteen? Normative and empirical considerations. Political Studies, 54, 533-558.

Chrona, S. \& Bee, C. (2017). Right to public space and right to democracy: The role of social media in Gezi Park. Research and Policy on Turkey, 2(1), 49-61.

Chryssochoou, X. \& Lyons, E. (2011). Perceptions of (in)compatibility between identities and participation of ethnic minorities to the national polity. In A. Azzi, X. Chryssochoou, B. Klandermans \& B. Simon (Eds.), Identity and participation in culturally diverse societies: A multidisciplinary perspective (pp. 69-88). Oxford: Wiley-Blackwell.

Cicognani, E. \& Zani, B. (2015). Social and psychological factors influencing political and civic participation, a psychological perspective. In M. Barrett \& B. Zani (Eds.), Political and civic engagement: Multidisciplinary perspectives. London: Routledge.

Cicognani, E., Zani, B., Fournier, B., Gavray, C. \& Born, M. (2012). Gender differences in youths' political engagement and participation: The role of parents and of adolescents' social and civic participation. Journal of Adolescence, 35(3), 561-576. DOI: 10.1016/j.adolescence.2011.10.002

Citrin, J. \& Muste, C. (1999). Trust in government. In J.P. Robinson, P. R. Shaver \& L.S. Wrightsman (Eds.), Measures of social psychological attitudes, Vol. 2. Measures of political attitudes (pp. 465-532). San Diego, CA: Academic Press.

Cnaan, R.A., Handy, F. \& Wadsworth, M. (1996). Defining who is a volunteer: Conceptual and empirical considerations. Nonprofit and Voluntary Sector Quarterly, 25, 364-383.

Cohen, A., Vigoda, E. \& Samorly, A. (2001). Analysis of the mediating effect of personal-psychological variables on the relationship between socioeconomic status and political participation: A structural equations framework. Political Psychology, 22(4), 727-757.

Cohen, C.J., Kahne, J., Bowyer, B., Middaugh, E. \& Rogowski, J. (2012). Participatory politics: New media and youth political action. Oakland, CA: Mills College School of Education. https://ypp.dmlcentral.net/sites/default/files/publications/Participatory_ Politics_Report.pdf, accessed 24 August 2017.

Conway, M.M. (1991). Political participation in the United States (2nd edition). Washington, DC: CQ Press.

Council of Europe (2006). A European Framework for Youth Policy. Strasbourg: Council of Europe Publishing.

Council of Europe (2015). The fight against violent extremism and radicalisation leading to terrorism - Action Plan. Committee of Ministers Documents, CM(2015)74, 19 May 2015. Strasbourg: Council of Europe. https://rm.coe.int/16805c3576, accessed 10 April 2018.

Council of Europe (2016a). Time for Europe to get migrant integration right. Strasbourg: Council of Europe.

Council of Europe (2016b). Action Plan on Building Inclusive Societies (2016-2019). Committee of Ministers Documents, CM(2016)25, 2 March 2016. Strasbourg: Council of Europe. https://rm.coe.int/16805c1a1f, accessed 10 April 2018.

Council of Europe (2016c). Securing democracy through education: The development of a reference framework of competences for democratic culture. Final declaration on the conference theme. Council of Europe Standing Conference of Ministers of Education, 25th session, Brussels, MED-25-3 Final, 12 April 2016. Strasbourg: Council of Europe. https://rm.coe.int/16806b9405, accessed 10 April 2018.

Craig, S.C., Niemi, R.G. \& Silver, G.E. (1990). Political efficacy and trust: A report on the NES pilot study items. Political Behavior, 12(3), 289-314.

Crocetti, E., Erentaite, R. \& Žukauskienè, R. (2014). Identity styles, positive youth development, and civic engagement in adolescence. Journal of Youth and Adolescence, 43(11), 1818-28. 
Crocetti, E., Garckija, R., Gabrialaviciute, I., Vosylis, R. \& Žukauskienė, R. (2014). Reciprocal associations between identity and civic engagement in adolescence: A two-wave longitudinal study. International Journal of Developmental Science, 8, $115-124$.

Crocetti, E., Jahromi, P. \& Meeus, W. (2012). Identity and civic engagement in adolescence. Journal of Adolescence, 35, 521-532.

Crocetti, E., Rubini, M. \& Meeus, W. (2008). Capturing the dynamics of identity formation in various ethnic groups: Development and validation of a threedimensional model. Journal of Adolescence, 31, 207-222.

Crocetti, E., Schwartz, S.J., Fermani, A., Klimstra, T. \& Meeus, W. (2012). A crossnational study of identity status in Dutch and Italian adolescents: Status distributions and correlates. European Psychologist, 17, 171-181.

Crystal, D.S. \& DeBell, M. (2002). Sources of civic orientation among American youth: Trust, religious valuation, and attributions of responsibility. Political Psychology, 23, 113-132.

Curran, J., Coen, S., Soroka, S., Aalberg, T., Hayashi, K., Hichy, Z., Iyengar, S., Jones, P. \& Mazzoleni, G. (2014). Reconsidering 'virtuous circle' and 'media malaise' theories of the media: An 11-nation study. Journalism, 15(7), 815-833. DOI: $10.1177 / 1464884913520198$

Dahlgren, P. \& Olsson, T. (2007). Young activists, political horizons and the Internet: Adapting the net to one's purposes. In B.D. Loader (Ed.), Young citizens in the digital age: Political engagement, young people and new media (pp. 68-81). London: Routledge.

Dalton, R. (2008). The good citizen: How a younger generation is reshaping American politics. Washington, DC: CQ Press.

Dassonneville, R., Quintelier, E., Hooghe, M. \& Claes, E. (2012). The relation between civic education and political attitudes and behavior: A two-year panel study among Belgian late adolescents. Applied Developmental Science, 16(3), 140-150. doi: 10.1080/10888691.2012.695265

De Vreese, C. \& Semetko, H. (2002). Cynical and engaged: Strategic campaign coverage, public opinion, and mobilization in a referendum. Communication Research, 29(6), 615-641.

Dean, J. (2015). Volunteering, the market, and neoliberalism. People, Place and Policy, 9(2), 139-148. DOI: 10.3351/ppp.0009.0002.0005

Deaux, K. (1992). Personalizing identity and socializing self. In G.M. Breakwell (Ed.), Social psychology of identity and the self concept (pp. 9-33). London: Academic Press.

Deaux, K. (1996). Social identification. In T.E. Higgins \& A.W. Kruglanski (Eds.), Social psychology: Handbook of basic principles (pp. 777-798). New York: Guilford Press.

Deaux, K. (2000). Models, meanings and motivations. In D. Capozza \& R.J. Brown (Eds.), Social identity processes: Trends in theory and research (pp. 1-14). London: Sage.

Delli Carpini, M.X. \& Keeter, S. (1996). What Americans know about politics and why it matters. New Haven, CT: Yale University Press.

Diekman, A.B. \& Eagly, A.H. (2000). Stereotypes as dynamic constructs: Women and men of the past, present, and future. Personality and Social Psychology Bulletin, 26(10), $1171-1188$.

Diemer, M.A. \& Li, C.H. (2011). Critical consciousness development and political participation among marginalised youth. Child Development, 82(6), 1815-1833.

Dion, K.K. \& Dion, K.L. (2001). Gender and cultural adaptation in immigrant families. Journal of Social Issues, 57(3), 511-521.

Djupe, P.A. \& Grant, J.T. (2001). Religious institutions and political participation in America. Journal for the Scientific Study of Religion, 40(2), 303-314. 
Drury, J. \& Reicher, S. (2009). Collective psychological empowerment as a model of social change: Researching crowds and power. Journal of Social Issues, 65, 707-725.

Durkin, K. (2005). Children's understanding of gender roles in society. In M. Barrett \& E. Buchanan-Barrow (Eds.), Children's understanding of society (pp. 135-167). Hove: Psychology Press.

Easton, D. \& Dennis, J. (1967). The child's acquisition of regime norms: Political efficacy. American Political Science Review, 61(01), 25-38.

Eisenberg, N., Spinrad, T.L. \& Knafo-Noam, A. (2015). Prosocial development. In M.E. Lamb (Ed.), Handbook of child psychology and developmental science (7th edition), Volume 3: Socioemotional processes (pp. 610-656). Hoboken, NJ: Wiley.

Ekman, J. \& Amnå, E. (2012). Political participation and civic engagement: Towards a new typology. Human Affairs, 22(3), 283-300.

Emler, N.P. (2011). What does it take to be a political actor in a multicultural society? In M. Barrett, C. Flood \& J. Eade (Eds.), Nationalism, ethnicity, citizenship: Multidisciplinary perspectives. Newcastle: Cambridge Scholars Publishing.

Emler, N. \& Frazer, E. (1999). Politics: The education effect. Oxford Review of Education, $25,251-274$.

Erikson, E. (1963). Childhood and society (2nd edition). New York: W.W. Norton and Co.

Erikson, E. (1968). Identity: Youth and crisis. New York: W.W. Norton and Co.

European Commission (2016). Women and men in decision-making: Gender statistics database. http://eige.europa.eu/gender-statistics/dgs/browse/wmidm, accessed 25 January 2018.

European Youth Forum (2016). Inspiring!Youth organisations' contribution to citizenship education. Brussels: European Youth Forum. http://www.youthforum.org/assets/2016/10/Youthorganisations-contribution-to-citizenship-education.pdf, accessed 17 August 2017.

Eurydice (2009). Integrating immigrant children into schools in Europe. Brussels: Eurydice, European Commission. http://eacea.ec.europa.eu/education/eurydice/documents/ thematic_reports/101EN.pdf, accessed 23 July 2013.

Eurydice (2017). Citizenship education at school in Europe - 2017. Luxembourg: Publications Office of the European Union. https://webgate.ec.europa.eu/fpfis/ mwikis/eurydice/images/6/68/215_EN_Citizenship_2017_N.pdf, accessed 10 November 2017.

Feldman, L., Pasek, J., Romer, D. \& Jamieson, K.H. (2007). Identifying best practices in civic education: Lessons from the student voices program. American Journal of Education, 114(1), 75-100.

Fernandes-Jesus, M., Malafaia, C., Ferreira, P., Cicognani, E. \& Menezes, I. (2012). The many faces of Hermes: The quality of participation experiences and political attitudes of migrant and non-migrant youth. Human Affairs, 22(3), 434-447.

Fernandes-Jesus, M., Malafaia, C., Ribeiro, N. \& Menezes, I. (2015). Participation among youth, women and migrants: findings from Portugal. In M. Barrett \& B. Zani (Eds.), Political and civic engagement: Multidisciplinary perspectives (pp. 311-333). London: Routledge.

Ferreira, P.D., Azevedo, C.N. \& Menezes, I. (2012). The developmental quality of participation experiences: Beyond the rhetoric that "participation is always good!" Journal of Adolescence, 35(3), 599-610.

Fife-Schaw, C. \& Breakwell, G.M. (1990). Predicting the intention not to vote in late teenage: A UK study of 17- and 18-year-olds. Political Psychology, 11(4), 739-755.

Flanagan, C.A., Bowes, J.M., Jonsson, B., Csapo, B. \& Sheblanova, E. (1998). Ties that bind: Correlates of adolescents' civic commitments in seven countries. Journal of Social Issues, 54, 457-475. 
Flanagan, C.A., Campbell, B., Botcheva, L., Bowes, J., Csapo, B., Macek, P. \& Sheblanova, E. (2003). Social class and adolescents' beliefs about justice in different social orders. Journal of Social Issues, 59(4), 711.

Flanagan, C.A., Cumsille, P., Gill, S. \& Gallay, L. (2007). School and community climates and civic commitments: Patterns for ethnic minority and majority students. Journal of Educational Psychology, 99, 421-431.

Flanagan, C.A., Gallay, L.S., Gill, S., Gallay, E. \& Nti, N. (2005). What does democracy mean? Correlates of adolescents' views. Journal of Adolescent Research, 20(2), 193-218.

Flanagan, C., Stoppa, T., Syvertsen, A.K. \& Stout, M. (2010). School and social trust. In L.R. Sherrod, J. Torney-Purta \& C.A. Flanagan (Eds.), Handbook of research on civic engagement in youth (pp. 307-329). Hoboken, NJ: Wiley \& Sons.

Forbrig, J. (Ed.) (2005). Revisiting youth political participation. Strasbourg: Council of Europe.

Fuks, M. \& Avila Casalecchi, G. (2012). Trust and political information: Attitudinal change in participants in the youth parliament in Brazil. Brazilian Political Science Review, 6(1), 70-89.

Galligan, Y. (2012). The contextual and individual determinants of women's civic engagement and political participation. Unpublished paper, The PIDOP Project.

Gavray, C., Born, M. \& Fournier, B. (2015). Participation among youth, women and migrants: Findings from the Wallonia-Brussels Federation of Belgium. In M. Barrett \& B. Zani (Eds.), Political and civic engagement: Multidisciplinary perspectives (pp. 292-310). London: Routledge.

Gerbaudo, P. (2012). Tweets and the streets: Social media and contemporary activism. London: Pluto Press.

Geys, B. (2006). Explaining voter turnout: A review of aggregate-level research. Electoral Studies, 25, 637-663.

Gladwell, M. (2010). Small change: Why the revolution will not be tweeted. The New Yorker (4 October 2010), 42-49.

Gniewosz, B., Noack, P. \& Buhl, M. (2009). Political alienation in adolescence: Associations with parental role models, parenting styles and classroom climate. International Journal of Behavioral Development, 3, 337-346.

Goel, L.M.-M. \& Milbrath, L. (1977). Political participation. How and why people get involved. Chicago, IL: Rand McNally \& Company.

Goodwin, J., Jasper, J.M. \& Polletta, F. (2004). Emotional dimensions of social movements. In D.A. Snow, S.A. Soule \& H. Kriesi (Eds.), The Blackwell companion to social movements (pp. 413-432). Oxford: Blackwell.

Gordon, H.R. \& Taft, J.K. (2011). Rethinking youth political socialization: Teenage activists talk back. Youth \& Society, 43(4), 1499-1527.

Green, D.P. \& Gerber, A.S. (2004). Get out the vote! How to increase voter turnout. Washington, DC: Brookings Institution Press.

Gueorguieva, V. (2008). Voters, MySpace, and YouTube: The impact of alternative communication channels on the 2006 election cycle and beyond. Social Science Computer Review, 26(3), 288-300.

Guerrina, R. \& Bee, C. (2012). Collation and analysis of current policies. Full technical report of PIDOP work package 2. Department of Politics, University of Surrey.

Hague, B. \& Loader, B. (Eds.) (1999). Digital democracy: Discourse and decision making in the information age. London: Routledge.

Hahn, C.L. (1998). Becoming political: Comparative perspectives on citizenship education. Albany, NY: State University of New York Press. 
Hart, D. \& Atkins, R. (2002). Fostering citizenship in urban youth. Applied Developmental Science, 6, 227-237.

Hart, D., Atkins, R. \& Ford, D. (1998). Urban America as a context for the development of moral identity in adolescence. Journal of Social Issues, 54, 513-530.

Hart, D. \& Gullan, R.L. (2010). The sources of adolescent activism: Historical and contemporary findings. Handbook of research on civic engagement in youth (pp. 67-90). Hoboken, NJ: John Wiley \& Sons.

Hart, D., Donnelly, T.M., Youniss, J. \& Atkins, R. (2007). High school community service as a predictor of adult voting and volunteering. American Educational Research Journal, 44(1), 197-219. DOI: 10.3102/0002831206298173

Haseeb, K.E-D. (2012). The Arab Spring revisited. Contemporary Arab Affairs, 5, 185-197.

Hashem-Wangler, A., Busse, B., Tholen, J. \& Wolnik, K. (2015). Youth sections of political, labour and state-sponsored organisations. Deliverable 7.2: Transnational cluster report, MYPLACE (Memory, Youth, Political Legacy and Civic Engagement) project. http://www.fp7-myplace.eu/documents/D7_2/D7.2\%20Transnational\%20 Report\%20Cluster\%205.pdf, accessed 23 August 2018.

Haski-Leventhal, D., Grönlund, H., Holmes, K., Meijs, L.C.P.M., Cnaan, R.A., Handy, F., Brudney, J.L., Hustinx, L., Kang, C., Kassam, M., Pessi, B.A., Ranade, B., Smith, K.A., Yamauchi, N. \& Zrinscak, S. (2010). Service-learning: Findings from a 14-nation study. Journal of Nonprofit and Public Sector Marketing, 22, 161-179.

Haste, H. \& Hogan, A. (2006). Beyond conventional civic participation, beyond the moral/political divide: Young people and contemporary debates about citizenship. Journal of Moral Education, 35(4), 473-493.

Hatcher, J.A. (2017). Philanthropic studies and student civic outcomes. In J.A. Hatcher, R.G. Bringle \& T.W. Hahn (Eds.), Research on student civic outcomes in service learning: Conceptual framework and methods (pp. 135-154). Sterling, VA: Stylus Publishing.

Hatcher, J.A., Bringle, R.G. \& Hahn, T.W. (Eds.) (2017). Research on student civic outcomes in service learning: Conceptual frameworks and methods. Sterling, VA: Stylus Publishing.

Henn, M., Weinstein, M. \& Forrest, S. (2005). Uninterested youth? Young people's attitudes towards party politics in Britain. Political Studies, 53, 556-578.

Herrera, L. \& Sakr, R. (Eds.) (2014). Wired citizenship: Youth learning and activism in the Middle East. New York: Routledge.

Hinton, P.R. (2016). The perception of people: Integrating cognition and culture. London: Routledge.

Hobbs, T. (2017). Shock general election result shows the importance of authenticity and youth targeting. Marketing Week, 9 June 2017. https://www.marketingweek. com/2017/06/09/general-election-aftermath-labour-conservatives-corbyn/, accessed 28 August 2017.

Hogg, M.A. \& Abrams, D. (Eds.) (1993). Group motivation: Social psychological perspectives. New York: Harvester Wheatsheaf.

Hooghe, M., Oser, J. \& Marien, S. (2016). A comparative analysis of 'good citizenship': A latent class analysis of adolescents' citizenship norms in 38 countries. International Political Science Review, 37(1), 115-129.

Hooghe, M. \& Stolle, D. (2004). Good girls go to the polling booth, bad boys go everywhere: Gender differences in anticipated political participation among American fourteen-year-olds. Women \& Politics, 26(3-4), 1-23.

Hooghe, M., Stolle, D. \& Stouthuysen, P. (2004). Head start in politics: The recruitment function of youth organizations of political parties in Belgium (Flanders). Party Politics, 10, 193-212. 
Howard, P.N., Agarwal, S.D. \& Hussain, M.M. (2011). When do states disconnect their digital networks? Regime responses to the political uses of social media. The Communication Review, 14(3), 216-232.

Huang, H.-P. \& Yore, L.D. (2005). A comparative study of Canadian and Taiwanese grade 5 children's environmental behaviors, attitudes, concerns, emotional dispositions, and knowledge. International Journal of Science and Mathematics Education, 1(4), 419-448.

Ichilov, O. (1991). Political socialization and schooling effects among Israeli adolescents. Comparative Education Review, 35, 430-447.

IES (Institute of Educational Sciences, National Center for Education Statistics) (2015). The condition of education 2015. Washington, DC: NCES.

Inglehart, R. (1971). The silent revolution in Europe: Intergenerational change in postindustrial societies. American Political Science Review, 65(4), 991-1017.

Inglehart, R. (1997). Modernization and postmodernization: Cultural, economic and political change in 43 societies. Princeton, NJ: Princeton University Press.

Inglehart, R.F. (2008). Changing values among western publics from 1970 to 2006. West European Politics, 31(1-2), 130-146.

Inglehart, R. \& Norris, P. (2003). Rising tide: Gender equality and cultural change around the world. New York: Cambridge University Press.

International IDEA (Institute for Democracy and Electoral Assistance) (2004). Voter Turnout in Western Europe since 1945: A Regional Report. Stockholm: International IDEA.

Inter-Parliamentary Union (2016). Youth participation in national parliaments 2016. Geneva, Switzerland: Inter-Parliamentary Union.

Ireland, P. (1994). The policy challenge of ethnic diversity. Cambridge, MA: Harvard University Press.

Jasper, J.M. (1998). The emotions of protest: Affective and reactive emotions in and around social movements. Sociological Forum, 13, 397-424.

Jennings, M.K. (1996). Political knowledge over time and across generations. Political Opinion Quarterly, 60, 228-252.

Jennings, M.K. (2002). Generation units and the student protest movement in the United States: An intra- and intergenerational analysis. Political Psychology, 23, 303-324.

Jennings, M.K. \& Niemi, R.G. (1968). The transmission of political values from parent to child. American Political Science Review, 62, 169-184.

Jensen, L.A. (2008). Immigrants' cultural identities as sources of civic engagement. Applied Developmental Science, 12(2), 74-83.

Jensen, L.A. (2010). Immigrant youth in the United States: Coming of age among diverse civic cultures. In L.R. Sherrod, J. Torney-Purta \& C.A. Flanagan (Eds.), Handbook of research in civic engagement in youth (pp. 425-443). Hoboken, NJ: Wiley \& Sons.

Jensen, L.A. \& Flanagan, C.A. (2008). Immigrant civic engagement: New translations. Applied Developmental Science, 12(2), 55-56.

Jones, C., Ramanau, R., Cross, S.J. \& Healing, G. (2010). Net generation or digital natives: Is there a distinct new generation entering university? Computers and Education, 54(3), 722-732.

Jost, J.T. \& Amodio, D.M. (2012). Political ideology as motivated social cognition: Behavioral and neuroscientific evidence. Motivation and Emotion, 36, 55-64.

Jugert, P., Greenaway, K.H., Barth, M., Büchner, R., Eisentraut, S. \& Fritsche, I. (2016). Collective efficacy increases pro-environmental intentions through increasing selfefficacy. Journal of Environmental Psychology, 48, 12-23.

Juris, J.S. (2012) Reflections on \#Occupy Everywhere: Social media, public space, and emerging logics of aggregation. American Ethnologist, 39(2), 259-279. 
Kahne, J., Middaugh, E. \& Allen, D. (2014). Youth, new media, and the rise of participatory politics. Oakland, CA: Youth and Participatory Politics Research Network. https:// dmlcentral.net/wp-content/uploads/files/ypp_workinpapers_paper01_1.pdf, accessed 25 August 2017.

Karp, J. A. \& Banducci, S. A. (2008). When politics is not just a man's game: Women's representation and political engagement. Electoral Studies, 27(1), 105-115.

Kassimir, R. \& Flanagan, C. (2010). Youth civic engagement in the developing world: challenges and opportunities. In L.R. Sherrod, J. Torney-Purta \& C.A. Flanagan (Eds.), Handbook of research on civic engagement in youth (pp. 91-113). Hoboken, NJ: Wiley \& Sons.

Keeter, S., Horowitz, J. \& Tyson, A. (2008). Young voters in the 2008 election. Pew Research Centre. http://www.pewresearch.org/2008/11/13/young-voters-in-the2008-election/, accessed 27 August 2017.

Kelly, D.C. (2009). Exploring civic participation and social trust among young minorities. Youth \& Society, 40(4), 526-540.

Kennedy, G., Judd, T. \& Dalgarno, B. (2010). Beyond natives and immigrants: Exploring types of net generation students. Journal of Computer Assisted Learning, 26(5), 332-343.

Kerestes, M., Youniss, J. \& Metz, E. (2004). Longitudinal patterns of religious perspective and civic integration. Applied Developmental Science, 8(1), 39-46.

Kiesa, A., Orlowski, A.P., Levine, P., Both, D., Kirby, E.H., Lopez, M.H. \& Marcelo, K.B. (2007). Millenials Talk Politics: A Study of College Student Political Engagement. College Park, MD: CIRCLE.

King, G., Pan, J. \& Roberts, M.E. (2013). How censorship in China allows government criticism but silences collective expression. American Political Science Review, 107(2), 326-343.

Klandermans, B. (1984). Mobilization and participation: Social-psychological expansions of resource mobilization theory. American Sociological Review, 49(5), 583-600.

Klandermans, B. (1997). The social psychology of protest. Oxford: Blackwell.

Klandermans, B. (2002). How group identification helps to overcome the dilemma of collective action. American Behavioral Scientist, 45(5), 887-900.

Klandermans, B. (2014). Identity politics and politicized identities: Identity processes and the dynamics of protest. Political Psychology, 35(1), 1-22. DOI: 10.1111/pops.12167

Klandermans, B. (2015). Collective action. In J.D. Wright (Ed.), Elsevier encyclopedia of social and behavioral sciences (2nd edition) (pp. 145-150). Oxford: Elsevier.

Kriesi, H., Koopmans, R., Duyvendak, J.W. \& Giugni, M.G. (1995). New social movements in Western Europe: A comparative analysis. London: UCL Press.

Kroger, J. (2004). Identity in adolescence: The balance between self and other. Hove: Routledge.

Kroger, J. (2007). Identity development: Adolescence through adulthood (2nd edition). Thousand Oaks, CA: Sage.

Kruikemeier, S. \& Shehata, A. (2017). News media use and political engagement among adolescents: An analysis of virtuous circles using panel data. Political Communication, 34(2), 221-242, DOI: 10.1080/10584609.2016.1174760

Kyranakis, K. \& Nurvala, J.-P. (2013). Bringing politics to the youth: How to generate interest in electoral politics. European View, 12, 263-269.

Lauglo, J. (2013). Do more knowledgeable adolescents have more rationally based civic attitudes? Analysis of 38 countries. Educational Psychology, 33(3), 262-282.

Leach, C.W., Iyer, A. \& Pedersen, A. (2006). Anger and guilt about ingroup advantage explain the willingness for political action. Personality and Social Psychology Bulletin, $32(9), 1232-1245$. 
Lenhart, A., Kahne, J., Middaugh, E., Macgill, A.R., Evans, C. \& Vitak, J. (2008). Teens, Video Games, and Civics. Washington, DC: Pew Internet and American Life Project. http://www.pewInternet.org/2008/09/16/teens-video-games-and-civics/, accessed 23 August 2017.

Lenzi, M., Vieno, A., Pastore, M. \& Santinello, M. (2013). Neighborhood social connectedness and adolescent civic engagement: An integrative model. Journal of Environmental Psychology, 34, 45-54. DOI: 10.1016/j.jenvp.2012.12.003

Lenzi, M., Vieno, A., Sharkey, J., Mayworm, A., Scacchi, L., Pastore, M. \& Santinello, M. (2014). How school can teach civic engagement besides civic education: The role of democratic school climate. American Journal of Community Psychology, 54, 251-261. DOI 10.1007/s10464-014-9669-8

Levesque-Bristol, C., Knapp, T.D. \& Fisher, B.J. (2010). The effectiveness of servicelearning: It's not always what you think. Journal of Experiental Education, 33, 208-224.

Levinson, M. (2010). The civic empowerment gap: Defining the problem and locating solutions. In L.R. Sherrod, J. Torney-Purta \& C.A. Flanagan (Eds.), Handbook of research on civic engagement in youth (pp. 331-361). Hoboken, NJ: John Wiley \& Sons.

Levinson, M. (2012). No citizen left behind. Cambridge, MA: Harvard University Press.

Linnenbrink, L. \& Anderman, E.L. (1995). Motivation and news-seeking behavior. Paper presented at the Annual Meeting of the American Educational Research Association, San Francisco, CA, April 18-22 1995. https://files.eric.ed.gov/fulltext/ED392709.pdf, accessed 15 May 2010.

Livingstone, S., Couldry, N. \& Markham, T. (2007). Youthful steps towards civic participation: Does the Internet help? In B.D. Loader (Ed.), Young citizens in the digital age: Political engagement, young people and new media (pp. 21-34). London: Routledge.

Loader, B.D. (Ed.) (1997). The governance of cyperspace: Politics, technology and global restructuring. London: Routledge.

Lopez, M.H. \& Marcelo, K.B. (2008). The civic engagement of immigrant youth: New evidence from the 2006 Civic and Political Health of the Nation Survey, Applied Developmental Science, 12, 66-73.

Luengo Kanacri, B.P., Rosa, V. \& Di Giunta, L. (2012). The mediational role of values in linking personality traits to civic engagement in Italian youth. Journal of Prevention E Intervention in the Community, 40(1), 8-21.

Luttig, M.D. \& Cohen, C.J. (2016). How social media helps young people - especially minorities and the poor - get politically engaged. Monkey Cage, Washington Post, 9 September 2016. https://www.washingtonpost.com/news/monkey-cage/wp/ 2016/09/09/how-social-media-helps-young-people-especially-minorities-and-thepoor-get-politically-engaged/?utm_term=.24f55ee31b9a, accessed 24 August 2017.

Lyons, E. (2008). Political trust and participation amongst young people from ethnic minorities in the NIS and EU countries: a social psychological investigation. Unpublished report, Department of Psychology, University of Surrey.

Lyons, E., Chrysanthaki, T., Verkuyten, M., Selivanov, M. \& Pavlenko, V. (2008). Predicting political participation of young people from different ethnic origins in Europe. Paper presented at the Annual meeting of International Society of Political Psychology, Paris, France.

Lyons, E. \& Menezes, I. (2012). Processes in the co-construction of citizenship in different life contexts. Full technical report of PIDOP Work Package 6. Department of Psychology, University of Surrey.

Macedo, S. (2005). Democracy at risk: How political choices undermine citizen participation, and what we can do about it. Washington, DC: Brookings Institution Press. 
Maira, S.M. (2002). Desis in the house: Indian American youth culture in New York City. Philadelphia, PA: Temple University Press.

Malafaia, C., Menezes, I. \& Neves, T. (2018). Living, doing, and learning from politics in a youth wing of a political party. The Qualitative Report, 23(1), 49-79.

Malin, H., Ballard, P.J. \& Damon, W. (2015). Civic purpose: An integrated construct for understanding civic development in adolescence. Human Development, 58(2), 103130. DOI: $10.1159 / 000381655$

Marcia, J.E. (1966). Development and validation of ego-identity status. Journal of Personality and Social Psychology, 3(5), 551.

Marcia, J.E., Waterman, A.S., Matteson, D.R., Archer, S.L. \& Orlofsky, J.L. (1993). Ego identity: A handbook for psychosocial research. New York: Springer.

Marsh, S., O'Toole, T. \& Jones, S. (2007). Young people and politics in the UK: Apathy or alienation? London: Palgrave.

Martínez, M.L., Peñaloza, P. \& Valenzuela, C. (2012). Civic commitment in young activists: Emergent processes in the development of personal and collective identity. Journal of Adolescence, 35(3), 474-484. DOI: 10.1016/j.adolescence.2011.11.006

Martiniello, M. (2005). Political participation, mobilisation and representation of immigrants and their offspring in Europe. Willy Brandt Series of Working Papers in International Migration and Ethnic Relations, 1/05. Malmö, Sweden: Malmö University.

McDevitt, M. \& Chaffee, S. (2002). From top-down to trickle-up influence: Revisiting assumptions about the family in political socialization. Political Communication, 19(3), 281-301. DOI: 10.1080/01957470290055501

McFarland, D.A. \& Thomas, R.J. (2006). Bowling young: How youth voluntary associations influence adult political participation. American Sociological Review, 71(3), 401-425.

McLeod, J., Shah, D., Hess, D. \& Lee, N-J. (2010). Communication and education: Creating competence for socialization into public life. In L.R. Sherrod, J. TorneyPurta \& C.A. Flanagan (Eds.), Handbook of research on civic engagement in youth (pp. 363-391). Hoboken, NJ: John Wiley \& Sons.

Meeus, W. (1996). Studies on identity development in adolescence: An overview of research and some new data. Journal of Youth and Adolescence, 25, 569-598.

Meeus, W., Iedema, J., Helsen, M. \& Vollebergh, W. (1999). Patterns of adolescent identity development: Review of literature and longitudinal analysis. Developmental Review, 19, 419-461.

Meeus, W., van de Schoot, R., Keijsers, L., Schwartz, S.J. \& Branje, S. (2010). On the progression and stability of adolescent identity formation. A five-wave longitudinal study in early-to-middle and middle-to-late adolescence. Child Development, 81, 1565-1581.

Mesch, G.S. \& Coleman, S. (2007). New media and new voters: Young people, the Internet and the 2005 UK election campaign. In B.D. Loader (Ed.), Young citizens in the digital age: Political engagement, young people and new media (pp. 35-47). London: Routledge.

Mesch, G.S. \& Talmud, I. (2010). Wired youth: The social world of adolescence in the information age. Hove: Routledge.

Miller, D., Cronin, T., Garcia, A. \& Branscombe, N. (2009). The relative impact of anger and efficacy on collective action is affected by feelings of fear. Group Processes $\mathcal{E}$ Intergroup Relations, 12(4), 445-462.

Miranda, D. (2013). The role of music in adolescent development: much more than the same old song. International Journal of Adolescence and Youth, 18(1), 5-22. DOI: 10.1080/02673843.2011.650182 
Morgan, W. \& Streb, M. (2001). Building citizenship: How student voice in servicelearning develops civic values. Social Science Quarterly, 82, 154-170.

Morozov, E. (2011). The net delusion: The dark side of Internet freedom. New York: Public Affairs.

Mycock, A. \& Tonge, J. (2012). The party politics of youth citizenship and democratic engagement. Parliamentary Affairs, 65, 138-161.

NESSE (2008). Education and migration: Strategies for integrating migrant children in European schools and societies. A synthesis of research findings for policy-makers. Bamberg, Germany: NESSE.

Neufeind, M., Jiranek, P. \& Wehner, T. (2014). Beyond skills and structure: Justice dispositions as antecedents of young citizens' volunteering and political participation. Journal of Community and Applied Social Psychology, 24(4), 278-295.

Newton, K. (1999). Mass media effects: Mobilization or media malaise? British Journal of Political Science, 29(4), 577-599.

Newton, K. (2001). Trust, social capital, civil society, and democracy. International Political Science Review, 22(2), 201-214.

Newton, K. (2013). Social and political trust. European Social Survey Education Net. http://essedunet.nsd.uib.no/cms/topics/2/, accessed 4 December 2014.

Nie, N.H., Junn, J. \& Stehlik-Barry, K. (1996). Education and democratic citizenship in America. Chicago, IL: University of Chicago Press.

Nie, N.H., Verba, S. \& Kim, J.-O. (1974). Political participation and the life cycle. Comparative Politics, 6(3), 319-340.

Niemi, R.G. \& Jennings, M.K. (1991). Issues and inheritance in the formation of party identification. American Journal of Political Science, 35, 970-988.

Niemi, R.G. \& Junn, J. (1998). Civic education: What makes students learn? New Haven, CT: Yale University Press.

Noack, P. \& Jugert, P. (2015). Participation and engagement of young people in Germany: Findings on adolescents and young adults of German and Turkish family background. In M. Barrett \& B. Zani (Eds.), Political and civic engagement: Multidisciplinary perspectives (pp. 232-247). London: Routledge.

Norris, P. (2000). A virtuous circle: Political communications in postindustrial societies. Cambridge: Cambridge University Press.

Norris, P. (2002). Democratic phoenix: Reinventing political activism. New York: Cambridge University Press.

Norris, P. (2003). Young people and political activism: From the politics of loyalties to the politics of choice? Report for the Council of Europe symposium on 'Young people and democratic institutions: From disillusionment to participation'. http://www.hks.harvard.edu/fs/ pnorris/Acrobat/COE\%20Young\%20People\%20and\%20Political\%20Activism.pdf, accessed 10 February 2015.

O’Toole, T. (2004). Explaining young people's non-participation: Towards a fuller understanding of the political. Paper presented at the European Consortium of Political Research, Uppsala, Sweden.

O’Toole, T., Lister, M., Marsh, D., Jones, S. \& McDonagh, A. (2003). Tuning out or left out? Participation and non-participation among young people. Contemporary Politics, 9, 45-61.

OECD (2012). Equity and quality in education: Supporting disadvantaged students and schools. Paris: OECD Publishing.

OECD (2014). Unpaid care work: The missing link in the analysis of gender gaps in labour outcomes. http://www.oecd.org/dev/development-gender/Unpaid_care_ work.pdf, accessed 25 January 2018. 
OECD (2015). Gender wage gap. http://www.oecd-ilibrary.org/employment/genderwage-gap/indicator/english_7cee77aa-en, accessed 25 January 2018.

OECD (2016). Labour force participation rate. http://www.oecd-ilibrary.org/ employment/labour-force-participation-rate/indicator/english_8a801325-en, accessed 25 January 2018.

OECD (2018). Social protection and well-being. http://stats.oecd.org/index. aspx?queryid $=54752$, accessed 25 January 2018.

Ofcom (2016). Children and parents: Media use and attitudes report. London: Ofcom.

Ogilvy PR and Georgetown University's Center for Social Impact Communication (2011). Dynamics of cause engagement. New York: Ogilvy Public Relations Worldwide.

Omoto, A. \& Snyder, M. (1995). Sustained helping without obligation: Motivation, longevity of service, and perceived attitude change among AIDS volunteers. Journal of Personality and Social Psychology, 68(4), 671-686.

Omoto, A.M. \& Snyder, M. (2002). Considerations of community: the context and process of volunteerism. American Behavioral Scientist, 45, 846-867.

Pachi, D. (2015). Le rôle de la discrimination et d'autres facteurs dans la participation politique des jeunes d'origine immigrée. Les Politiques sociales, 3-4, 11-22.

Pachi, D. (2018). Youth civic/political participation and popular culture: A qualitative analysis of international music lyrics. Paper presented at the International Congress of Applied Psychology, Montreal, Canada, 26-30 July 2018.

Pachi, D. \& Barrett, M. (2011a). Impediments to political and civic participation locally, nationally and at a European level for British Bangladeshi and Congolese youth living in London. Paper presented at the Annual Scientific Meeting of the International Society of Political Psychology, Istanbul, Turkey.

Pachi, D. \& Barrett, M. (2011b). Sources of influence on young British Bangladeshi, Congolese and English people living in London: WP6 Interview Report, PIDOP Project. Department of Psychology, University of Surrey.

Pachi, D. \& Barrett, M. (2012a). Perceived effectiveness of conventional, nonconventional and civic forms of participation among minority and majority youth. Human Affairs, 22(3), 345-359. DOI: 10.2478/s13374-012-0029-9

Pachi, D. \& Barrett, M. (2012b). Survey of young British Bangladeshi, Congolese and English people living in London: WP6 Survey Report, PIDOP Project. Department of Psychology, University of Surrey.

Pachi, D. \& Barrett, M. (2012c). Patterns of civic and political participation amongst young people in London: Differences between English, Bangladeshi and Congolese young people. Paper presented at the 2nd PIDOP Conference on Civic and Political Participation, University of Surrey, Guildford, UK, 16-17 April 2012.

Pachi, D. \& Barrett, M. (2014). Civic and political engagement among ethnic minority and immigrant youth. In R. Dimitrova, M. Bender \& F. van de Vijver (Eds.), Global perspectives on well-being in immigrant families (pp. 189-211). New York: Springer.

Pachi, D. \& Barrett, M. (2015). The expectations and understandings of influential others who can mobilise youth participation. In M. Barrett \& B. Zani (Eds.), Political and civic engagement: Multidisciplinary perspectives (pp. 292-310). London: Routledge.

Pachi, D., Chrysanthaki, T. \& Barrett, M. (2014). Political and civic participation amongst ethnic majority and minority youth. In H. Dekker, C. Kinnvall, T. Capelos \& P. Nesbitt-Larking (Eds.), The Palgrave handbook of global political psychology (pp. 297315). Basingstoke: Palgrave Macmillan.

Pachi, D., Garbin, D. \& Barrett, M. (2011). Focus groups with young British Bangladeshi, Congolese and English people living in London: WP6 Focus Group Report, PIDOP Project. Department of Psychology, University of Surrey. 
Palfrey, J. \& Gasser, U. (2008). Born digital: Understanding the first generation of digital natives. New York: Basic Books.

Pasek, J., Feldman, L., Romer, D. \& Jamieson, K.H. (2008). Schools as incubators of democratic participation: Building long-term political efficacy with civic education. Applied Development Science, 12(1), 26-37.

Passini, S. (2012). The Facebook and Twitter Revolutions: Active participation in the 21st century. Human Affairs, 22, 301-312.

Pattie, C., Seyd, P. \& Whiteley, P. (2003). Citizenship and civic engagement: attitudes and behaviour in Britain. Political Studies, 51, 443-468.

Penninx, R., Martiniello, M. \& Vertovec, S. (Eds.) (2004). Citizenship in European cities: Immigrants, local politics and integration policies. London: Ashgate.

Plowman, L. (2011) Research briefing one: Rethinking young children and technology. Glasgow: Scottish Universities Insight Institute, University of Strathclyde.

Portes, A. \& Rumbaut, R.G. (2001). Legacies: The story of the immigrant second generation. Berkeley, CA: University of California Press.

Portes, A. \& Rumbaut, R.G. (2006). Immigrant America: A portrait (3rd edition). Berkeley, CA: University of California Press.

Prensky, M. (2001). Digital natives, digital immigrants. On the Horizon, 9(5), 1-6.

Prosser, C., Fieldhouse, E.A., Green, J., Mellon, J. \& Evans, G. (2018). Tremors but no youthquake: Measuring changes in the age and turnout gradients at the 2015 and 2017 British general elections. https://papers.ssrn.com/sol3/papers.cfm?abstract_id=3111839, accessed 29 January 2018.

Putnam, R.D. (2000). Bowling alone: The collapse and revival of American community. New York: Simon \& Schuster.

Quintelier, E. (2008). Who is politically active: The athlete, the scout member or the environmental activist? Young people, voluntary engagement and political participation. Acta Sociologica, 51, 355-370.

Quintelier, E., Stolle, D. \& Harell, A. (2012). Politics in peer groups: Exploring the causal relationship between network diversity and political participation. Political Research Quarterly, 65(4), 868-881. DOI: 10.1177/1065912911411099

Quintelier, E. \& van Deth, J.W. (2014). Supporting democracy: Political participation and political attitudes. Exploring causality using panel data. Political Studies, 62, 153171. DOI:10.1111/1467-9248.12097

Rainsford, E. (2017). UK political parties' youth factions: A glance at the future of political parties. Parliamentary Affairs, gsx040, https://doi.org/10.1093/pa/gsx040.

Rauschert, P. \& Byram, M. (2017). Service learning and intercultural citizenship in foreign-language education. Cambridge Journal of Education, published online 5 July 2017. DOI: $10.1080 / 0305764 X .2017 .1337722$

Reicher, S. \& Drury, J. (2010). Collective identity, political participation and the making of the social self. In A.E. Azzi, X. Chryssochoou, B. Klandermans \& B. Simon (Eds.), Identity and participation in culturally diverse societies. Oxford: Wiley-Blackwell.

Rentfrow, P.J. \& Gosling, S.D. (2006). Message in a ballad: The role of music preferences in interpersonal perception. Psychological Science, 17, 236-242.

Rentfrow, P.J., McDonald, J.A. \& Oldmeadow, J.A. (2009). You are what you listen to: Young people's stereotypes about music fans. Group Processes E Intergroup Relations, 12, 329-344.

Roberts, D.F., Henriksen, L. \& Foehr, U.G. (2009). Adolescence, adolescents, and media. In R.M. Lerner \& L. Steinberg (Eds.), Handbook of adolescent psychology, Volume 2: Contextual influences on adolescent development (3rd edition) (pp. 314-344). Hoboken, NJ: Wiley. 
Roberts, H. (2016). The Turkish Government reportedly blocked WhatsApp and other social media sites. Business Insider. http://uk.businessinsider.com/social-media-andmessaging-sites-blocked-in-turkey-2016-11, accessed 15 March 2018.

Rosenstone, S.J. \& Hansen, J.M. (1993). Mobilization, participation, and democracy in America. New York: Macmillan.

Rossi, G., Lenzi, M., Sharkey, J.D., Vieno, A. \& Santinello, M. (2016). Factors associated with civic engagement in adolescence: The effects of neighbourhood, school, family, and peer contexts. Journal of Community Psychology, 44(8), 1040-1058. DOI: 10.1002/ jcop. 21826

Rumbaut, R.G. (2008). Reaping what you sew: Immigration, youth, and reactive ethnicity. Applied Developmental Science, 12, 108-111.

Russo, S. \& Stattin, H. (2017). Stability and change in youths' political interest. Social Indicators Research, 132(2), 643-658. DOI: 10.1007/s11205-016-1302-9

Sakr, R. (2014). In L. Herrera \& R. Sakr (Eds.), Wired citizenship: Youth learning and activism in the Middle East (pp. 180-194). New York: Routledge.

Schulz, W. (2005). Political efficacy and expected political participation among lower and upper secondary students; A comparative analysis with data from the IEA Civic Education Study. Paper presented at the ECPR General Conference, Budapest.

Schulz, W., Ainley, J., Fraillon, J., Kerr, D. \& Losito, B. (2010). ICCS 2009 International Report: Civic knowledge, attitudes, and engagement among lower secondary school students in 38 countries. Amsterdam: IEA.

Schulz, W., Ainley, J., Fraillon, J., Losito, B., Agrusti, G. \& Friedman, T. (2017). Becoming Citizens in a Changing World: IEA International Civic and Citizenship Education Study 2016 International Report. Amsterdam: IEA.

Schwartz, S.H. (1994). Are there universal aspects in the structure and contents of human values? Journal of Social Issues, 50(4), 19-45.

Schwartz, S.H. (2006). Les valeurs de base de la personne: théorie, mesures et applications. Revue française de sociologie, 42, 249-88.

Schwartz, S.H. (2013). Human values. European Social Survey Education Net. http:// essedunet.nsd.uib.no/cms/topics/1/, accessed 4 December 2014.

Schwartz, S.J, Luyckx, K. \& Vignoles, V.L. (2013). Handbook of identity theory and research. New York: Springer.

Seif, H. (2010). The civic life of Latina/o immigrant youth: Challenging boundaries and creating safe spaces. In L.R. Sherrod, J. Torney-Purta \& C.A. Flanagan (Eds.), Handbook of research on civic engagement in youth (445-470). Hoboken, NJ: John Wiley and Sons.

Semetko, H.A. \& Valkenburg, P.M. (1998). The impact of attentiveness on political efficacy: Evidence from a three-year German panel study. International Journal of Public Opinion Research, 10(3), 195-210.

Şener, T. (2015). Participation among Turkish, Roma, and Bulgarian resettler youth living in Turkey. In M. Barrett \& B. Zani (Eds.), Political and civic engagement: Multidisciplinary perspectives (pp. 334-351). London: Routledge.

Šerek, J., Machackova, H. \& Macek, P. (2017). The chicken or egg question of adolescents' political involvement: Longitudinal analysis of the relation between young people's political participation, political efficacy, and interest in politics. Zeitschrift für Psychologie, 225(4), 347-356. DOI: 10.1027/2151-2604/a000297

Šerek, J., Petrovičová, Z. \& Macek, P. (2015). Civic organizations and the Internet as the opportunities for minority youth civic participation: Findings from the Czech Republic. In M. Barrett \& B. Zani (Eds.), Political and civic engagement: Multidisciplinary perspectives (pp. 213-231). London: Routledge. 
Shephard, M. \& Patrikos, S. (2013). Making democracy work by early formal engagement? A comparative exploration of youth parliaments in the EU. Parliamentary Affairs, 66, 752-771.

Silva, L.D., Sanson, A., Smart, D. \& Toumbourou, J. (2004). Civic responsibility among Australian adolescents: Testing two competing models. Journal of Community Psychology, 32(3), 229-255. DOI: 10.1002/jcop.20004

Simon, B. (2011). Collective identity and political engagement. In A. Azzi, X. Chryssochoou, B. Klandermans \& B. Simon (Eds.), Identity and participation in culturally diverse societies (pp. 137-157). Oxford: Wiley-Blackwell.

Simon, B. \& Grabow, O. (2010). The politicization of migrants: Further evidence that politicized collective identity is a dual identity. Political Psychology, 31, 5, 717-738. DOI: $10.1111 / \mathrm{j} .1467-9221.2010 .00782 . x$

Simon, B. \& Klandermans, B. (2001). Politicized collective identity: A social psychological analysis. American Psychologist, 56, 319-331.

Simon, B., Loewy, M., Stürmer, S., Weber, U., Freytag, P., Habig, C., Kampmeier, C. \& Spahlinger, P. (1998). Collective identification and social movement participation. Journal of Personality and Social Psychology, 74, 646-658.

Sloam, J. (2016). Diversity and voice: The political participation of young people in the European Union. The British Journal of Politics and International Relations, 18(3), 521-537.

Slovic, P. (1999). Trust, emotion, sex, politics, and science: Surveying the risk-assessment battlefield. Risk Analysis, 19(4), 689-701.

Smith, A. \& Rainie, L. (2008). The Internet and the 2008 election. Washington, DC: Pew Internet and American Life Project.

Smith, E.S. (1999). The effects of investment in the social capital of youth on political and civic behavior in young adulthood: A longitudinal analysis. Political Psychology, 20, 553-580.

Smith, H.J., Cronin, T. \& Kessler, T. (2008). Anger, fear, or sadness: Faculty members' emotional reactions to collective pay disadvantage. Political Psychology, 29(2), 221-246.

Soss, J. (1999). Lessons of welfare: Policy design, political learning, and political action. American Political Science Review, 93(2), 363-380.

Sotiropoulos, G. (2017). Staging democracy: The Aganaktismenoi of Greece and the squares movement(s). Contention, 5(1), 84-107.

Spratt, M. (2005). Washback and the classroom: The implications for teaching and learning of studies of washback from exams. Language Teaching Research, 9(1), 5-29.

Stepick, A. \& Stepick, C.D. (2002). Becoming American, constructing ethnicity: Immigrant youth and civic engagement. Applied Developmental Science, 6, 246-257.

Stepick, A., Stepick, C.D. \& Labissiere, Y. (2008). South Florida's immigrant youth and civic engagement: Major engagement: Minor differences. Applied Developmental Science, 12, 57-65.

Stobart, G. (2008). Testing times: The uses and abuses of assessment. London: Routledge.

Stockard, J. \& Johnson, M.M. (1992). Sex and gender in society (2nd edition). Englewood Cliffs, NJ: Prentice Hall.

Street, J. (2003). 'Fight the power': The politics of music and the music of politics. Government and Opposition, 38(1), 113-130.

Street, J. (2012). Music and politics. Cambridge: Polity Press.

Street, J., Hague, S. \& Savigny, H. (2008). Playing to the crowd: The role of music and musicians in political participation. British Journal of Politics and International Relations, 10, 269-285. 
Stryker, S. (1980). Symbolic interactionism A social structural version. Menlo Park, CA: Benjamin/Cummings Publishing Company.

Taft, J.K. (2010). Rebel girls: Youth activism and social change across the Americas. New York: NYU Press.

Tajfel, H. (1978). Social categorization, social identity and social comparison. In H. Tajfel (Ed.), Differentiation between social groups: Studies in the social psychology of intergroup relations (pp. 61-76). London: Academic Press.

Tarkowski, A., Fathy, B. \& Melyantsou, D. (2011). From the network to the streets: Online tools and democratization in Egypt and Belarus. Policy Brief No. 5. Prague: Policy Association for an Open Society (PASOS).

Tarrant, M., North, A.C. \& Hargreaves, D.J. (2000). English and American adolescents' reasons for listening to music. Psychology of Music, 28, 166-173.

Therrien, A. (2017). General election 2017: What caused Labour's youth vote surge? BBC News Online, 16 June 2017. http://www.bbc.co.uk/news/uk-politics-40244905, accessed 28 August 2017.

Thomas, M. (2011). Deconstructing digital natives: Young people, technology and the new literacies. New York: Routledge.

Torney-Purta, J. (2002). The school's role in developing civic engagement: A study of adolescents in twenty-eight countries. Applied Developmental Science, 6(4), 203-212.

Torney-Purta, J. (2009). International psychological research that matters for policy and practice. American Psychologist, 64(8), 825-837.

Torney-Purta, J. \& Barber, C. (2011). Fostering young people's support for participatory human rights through their developmental niches. American Journal of Orthopsychiatry, 81(4), 473-481.

Torney-Purta, J., Barber, C.H. \& Richardson, W.K. (2004). Trust in governmentrelated institutions and political engagement among adolescents in six countries. Acta Politica, 39(4), 380-406.

Torney-Purta, J., Barber, C.H. \& Wilkenfeld, B. (2007). Latino adolescents' civic development in the United States: Research results from the IEA Civic Education Study. Journal of Youth and Adolescence, 36, 111-125.

Torney-Purta, J., Lehmann, R., Oswald, H. \& Schulz, W. (2001). Citizenship and education in twenty-eight countries: Civic knowledge and engagement at age fourteen. Amsterdam: IEA.

Turkie, A. (2010). More than crumbs from the table: A critique of youth parliaments as models of representation for marginalised young people. In B. Percy-Smith \& N. Thomas (Eds.), A handbook of children and young people's participation: Perspectives from theory and practice (pp. 262-269). London: Routledge.

United Nations (2014). Definition of youth. New York: United Nations.

van Bergen, D.D., Feddes, A.F., Doosje, B. \& Pels, T.V.M. (2015). Collective identity factors and the attitude toward violence in defense of ethnicity or religion among Muslim youth of Turkish and Moroccan Descent. International Journal of Intercultural Relations, 47, 89-100.

van Zomeren, M., Postmes, T. \& Spears, R. (2008). Toward an integrative social identity model of collective action: A quantitative research synthesis of three sociopsychological perspectives. Psychological Bulletin, 134(4), 504-535.

van Zomeren, M., Spears, R., Fischer, A. \& Leach, C.W. (2004). Put your money where your mouth is! Explaining collective action tendencies through group-based anger and group efficacy. Journal of Personality and Social Psychology, 87, 649-664.

Vecchione, M. \& Caprara, G.V. (2009). Personality determinants of political participation: The contribution of traits and self-efficacy beliefs. Personality and Individual Differences, 46(4), 487-492. 
Verba, S., Nie, N.H. \& Kim, J.O. (1978). Participation and political equality: A seven-nation comparison. Cambridge: Cambridge University Press.

Verba, S., Schlozman, K.L. \& Brady, H.E. (1995). Voice and equality: Civic voluntarism in American politics. Cambridge: Harvard University Press.

Villano, P. \& Bertocchi, A. (2014). On active citizenship: Discourses and language about youth and migrants in Italy. Journal of Civil Society, 10(1), 82-99.

Vráblíková, K. (2014). How context matters? Mobilization, political opportunity structures, and nonelectoral political participation in old and new democracies. Comparative Political Studies, 47(2), 203-229.

Vráblíková, K. \& Císař, O. (2015). Individual political participation and macro contextual determinants. In M. Barrett \& B. Zani (Eds.), Political and civic engagement: Multidisciplinary perspectives (pp. 33-53). London: Routledge.

Vromen, A. (2003). 'People try to put us down...'? Participatory citizenship of 'Generation X'. Australian Journal of Political Science, 38(1), 79-99.

Wagner, M., Johann, D. \& Kritzinger, S. (2012). Voting at 16: Turnout and the quality of vote choice. Electoral Studies, 31, 372-383.

Wall, J. \& Dar, A. (2011). Children's political representation: The right to make a difference. International Journal of Children's Rights, 19, 595-612.

Wattenberg, M.P. (2007). Is voting for young people? New York: Longman.

Weatherford, M.S. (1987). How does government performance influence political support? Political Behavior, 9, 5-28.

Weller, S. (2007). Teenagers' citizenship: Experiences and education. London: Routledge.

Wentzel, K.R. \& McNamara, C.C. (1999). Interpersonal relationships, emotional distress and prosocial behaviour in middle school. Journal of Early Adolescence, 19, 114-125.

Wilson, J. (2000). Volunteering. Annual Review of Sociology, 26, 215-240.

Wolak, J. \& McDevitt, M. (2011). The roots of the gender gap in political knowledge in adolescence. Political Behavior, 33(3), 505-533.

Wolfinger, R.E. \& Rosenstone, S.J. (1980). Who votes? New Haven, CT: Yale University Press.

Wray-Lake, L., Syvertsen, A.K. \& Flanagan, C.A. (2008). Contested citizenship and social exclusion: Adolescent Arab American immigrants' views of the social contract. Applied Developmental Science, 12, 84-92.

Wu, C.-L. (2003). Psycho-political correlates of political efficacy: The case of the 1994 New Orleans mayoral election. Journal of Black Studies, 33(6), 729-760.

Yates, M. \& Youniss, J. (1998). Community service and political identity development in adolescence. Journal of Social Issues, 54, 495-512.

YouGov (2017). How Britain voted at the 2017 general election. https://yougov.co.uk/ news/2017/06/13/how-britain-voted-2017-general-election/, accessed 28 August 2017.

Youniss, J., McClellan, J., Su, A. \& Yates, M. (1999). The role of community service in identity development: Normative, unconventional, and deviant orientations. Journal of Adolescent Research, 14, 248-261.

Youniss, J., McLellan, J.A. \& Yates, M. (1997). What we know about engendering civic identity? American Behavioral Scientist, 40, 620-631.

Zaff, J.F., Malanchuk, O. \& Eccles, J.S. (2008). Predicting positive citizenship from adolescence to young adulthood: The effects of a civic context. Applied Developmental Science, 12, 38-53. 
Zeglovits, E. \& Zandonella, M. (2013). Political interest of adolescents before and after lowering the voting age: The case of Austria. Journal of Youth Studies, 16(8), 1084-1104. DOI: 10.1080/13676261.2013.793785

Zukin, C., Keeter, S., Andolina, M., Jenkins, K. \& Delli Carpini, M.X. (2006). A new engagement? Political participation, civic life, and the changing American citizen. New York: Oxford University Press. 


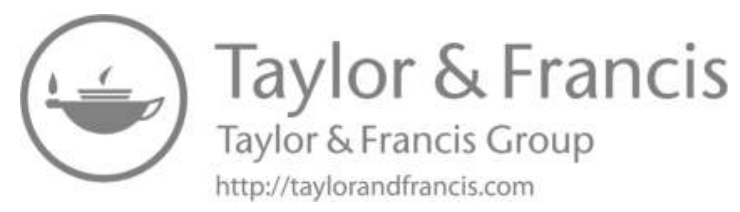




\section{AUTHOR INDEX}

Aalberg, T. 63

Aarts, K. 63

Abrams, D. 110

Abramson, P.R. 29

Agarwal, S.D. 97

Agrusti, G. 13, 20

Ainley, J. 13, 14, 20

Ajzen, I. 111

Albanesi, C. 13, 56

Aldrich, J.H. 29

Allen, D. 100

Amadeo, J. 30, 42

Amnå, E. 4, 10, 11, 12, 37

Amodio, D.M. 110

Anderman, E.L. 62

Andolina, M. 4, 46, 51

Ansolabehere, S. 63

Archer, S.L. 33

Ashford, S. 27, 28, 68

Astin, A.W. 54

Atkins, R. 13, 50, 54, 67, 70, 72

Avalos, J. 54

Avila Casalecchi, G. 90

Azevedo, C.N. 47, 52, 57

Bajoghli, N. 96

Bakagiannis, S. 65

Ballard, P.J. 39

Banducci, S.A. 68

Bandura, A. 110, 111

Barber, C. 37, 70, 112

Barlow, J.P. 95

Barrett, M. 2, 5, 12, 14, 15, 17, 18, 19, 20, $22,24,27,29,32,35,38,42,47,59$,
$65,70,71,72,73,74,78,80,101,110$, $112,114,115,117,123,125,126,127$, 128, 129, 130

Baumeister, R.F. 110

Beaton, A.E. 67

Bedolla, L.G. 72

Bee, C. 83, 96

Bennett, A. 64

Bennett, L.L. 13, 26, 28, 69

Bennett, S.E. 13, 26 27, 28, 69

Bennett, W.L. 25, 92, 96, 97, 101

Bennie, L. 60

Bernhagen, P. 79

Bertocchi, A. 85

Berzonsky, M.D. 34

Beutel, A.M. 70

Billig, S. 54

Black, P. 93

Blais, A. 29, 115

Blanch, D. 8

Bobkowski, P.S. 64

Bogard, K.L. 72

Born, M. 28, 51, 70

Bowes, J.M. 46

Bowyer, B. 98, 99

Bozkurt, S. 84

Brady, H.E. 3, 15, 27, 29, 31, 50, 58, 67, 80, 115, 116

Branscombe, N. 41

Breakwell, G.M. 22

Brewer, M.B. 110

Bringle, R.G. 41, 54

Bronfenbrenner, U. 113

Brown, J.D. 64 
Brown, L.M. 42

Brunton-Smith, I. 12, 14, 15, 18, 22, 27, 29, 30, 37, 68, 78, 80, 114, 115, 116

Bruter, M. 61

Buhl, M. 46

Burns, N. 68

Busse, B. 60

Bynner, J. 27, 28, 68

Byram, M. 54

Capella, J. 63

Capelos, T. 41

Caprara, G.V. 31, 69

Ceci, S.J. 113

Chaffee, S. 16, 48

Chan, T.W. 86

Chrona, S. 96

Chrysanthaki, T. 35

Chryssochoou, X. 35

Cicognani, E. 13, 28, 51, 56, 58

Císar̆, O. 78

Citrin, J. 36

Claes, E. 29

Clayton, M. 86

Cnaan, R.A. 54

Coen, S. 63

Cohen, A. 32

Cohen, C.J. 98, 99

Çok, F. 84

Coleman, S. 95, 96, 97, 98

Couldry, N. 95

Council of Europe 2, 82, 123, 124, 126, 132

Craig, S.C. 29

Crocetti, E. 33, 34, 36

Cronin, T. 41

Cross, S.J. 95

Crystal, D.S. 13, 58

Csapo, B. 13, 46

Cumsille, P. 52

Curran, J. 63

Dahlgren, P. 95

Dalgarno, B. 95

Dalton, R. 6, 40, 41, 92

Damon, W. 39

Dar, A. 91

Dassonneville, R. 29, 69

De Vreese, C. 63

Dean, J. (2015). 16

Deaux, K. 33, 110

DeBell, M. 13, 58

Delli Carpini, M.X. 4, 12, 23, 24, 28, 29, 50, 67
Dennis, J. 31

Di Giunta, L. 38

Diekman, A.B. 70

Diemer, M.A. 72

Dion, K.K. 70, 73

Dion, K.L. 70.73

Djupe, P.A. 58

Donnelly, T.M. 54

Doosje, B. 35

Drury, J. 15, 36

Durkin, K. 110

Duyvendak, J.W. 78

Eagly, A.H. 70

Easton, D. 31

Eccles, J.S. 48

Eisenberg, N. 77

Ekman, J. 4, 10, 11, 12, 37

Emler, N.P. 12, 27, 28, 50, 51

Erentaitè, R. 34

Erikson, E. 33

European Commission 69

European Youth Forum 88

Eurydice 82, 92, 93, 94

Evans, G. 102

Exadaktylos, T. 41

Fathy, B. 96

Feddes, A.F. 35

Feldman, L. 26, 52

Fermani, A. 34

Fernandes-Jesus, M. 26, 58, 60, 71

Ferreira, P. 57, 58, 60, 71

Fieldhouse, E.A. 102

Fife-Schaw, C. 22

Fishbein, M. 111

Fisher, B.J. 55

Flanagan, C.A. 13, 15, 31, 35, 36, 39, 46, 49, 52

Foehr, U.G. 64

Forbrig, J. 6

Ford, D. 13, 67

Forrest, S. 67

Fournier, B. 28, 51, 70

Fraillon, J. 13, 14, 20

Frazer, E. 12, 28, 50, 51

Freelon, D. 97

Friedman, T. 13, 20

Fuks, M. 90

Gabrialaviciute, I. 34

Gallay, E. 39

Gallay, L. 39, 52

Galligan, Y. 79 
Garbin, D. 17, 24, 29, 65

Garcia, A. 41

Garckija, R. 34

Gasser, U. 95

Gavray, C. 28, 51, 70, 72

Gerbaudo, P. 96

Gerber, A.S. 15, 101

Geys, B. 77, 86, 88

Gill, S. 39, 52

Giugni, M.G. 78

Gladwell, M. 99

Gniewosz, B. 46

Goel, L. M.-M. 31

Goodwin, J. 41

Gordon, H.R. 42

Gosling, S.D. 65

Grabow, O. 67

Grant, J.T. 58

Green, D.P. 15, 101

Green, J. 102

Gueorguieva, V. 97

Guerrina, R. 83

Gullan, R.L. 25, 67

Hague, B. 95

Hague, S. 65

Hahn, C.L. 12, 52, 62, 63

Hahn, T.W. 54

Handy, F. 54

Hansen, J.M. 101

Harell, A. 48

Hargreaves, D.J. 64

Harrison, S. 61

Hart, D. 13, 25, 50, 54, 67, 70, 72

Haseeb, K.E.-D. 16, 96

Hashem-Wangler, A. 60, 61, 62

Haski-Leventhal, D. 54

Haste, H. 29, 39, 69

Hatcher, J.A. 54

Hayashi, K. 63

Healing, G. 95

Helsen, M. 33

Henn, M. 67

Henriksen, L. 64

Herrera, L. 16, 96

Hess, D. 96

Hinton, P.R. 110

Hobbs, T. 102

Hogan, A. 29, 39, 69

Hogg, M.A. 110

Hooghe, M. 29, 40, 41, 60, 61, 69

Horowitz, J. 102

Howard, P.N. 97

Huang, H.-P. 41
Husfeldt, V. 30

Hussain, M.M. 97

Ichilov, O. 52

Iedema, J. 33

IES 15,80

Inglehart, R. 9, 79

International IDEA 6

Inter-Parliamentary Union 89, 90

Ireland, P. 81

Iyengar, S. 63

Iyer, A. 41

Jahromi, P. 34

Jamieson, K. 26, 52, 63

Jasper, J.M. 41

Jenkins, K. 4, 46

Jennings, M.K. 12, 45, 46

Jensen, L.A. 35

Jiranek, P. 38

Johann, D. 87

Johnson, M.M. 70, 73

Jones, C. 95

Jones, S. 6, 7

Jonsson, B. 13, 46

Jost, J.T. 110

Judd, T. 95

Jugert, P. 30, 47, 49, 53, 120

Junn, J. 12, 25, 51, 67, 69

Juris, J.S. 96

Kahne, J. 98, 99, 100

Karp, J.A. 68

Kassimir, R. 36

Keeter, S. 4, 12, 23, 24, 28, 29, 46, 50, 67, 102

Kelly, D.C. 37

Kennedy, G. 95

Kerestes, M. 59

Kerr, D. 14, 20

Kessler, T. 41

Kiesa, A. 7, 9, 27

Kim, J.O. 22, 68

King, G. 97

Klandermans, B. 29, 32, 33, 34, 36

Klimstra, T. 34

Knafo-Noam, A. 77

Knapp, T.D. 55

Koopmans, R. 78

Kriesi, H. 78

Kritzinger, S. 87

Kroger, J. 33

Kruikemeier, S. 63, 64

Kyranakis, K. 90 
Labissiere, Y. 13, 70

Lauglo, J. 36

Leach, C.W. 41

Leary, M.R. 110

Lee, N.-J. 96

Lehmann, R. 13, 30

Lenhart, A. 97

Lenzi, M. 13, 48, 50, 53

Levesque-Bristol, C. 55

Levinson, M. 25, 70, 72

Linnenbrink, L. 62

Livingstone, S. 95, 96

Loader, B. 95

Lopez, M.H. 13, 71

Losito, B. 13, 14, 20

Luengo Kanacri, B.P. 38

Luttig, M.D. 98

Luyckx, K. 110

Lyons, E. 31, 35, 69

Macedo, S. 6

Macek, P. 28, 47

Machackova, H. 28

Maira, S.M. 73

Malafaia, C. 26, 58, 61

Malanchuk, O. 48

Malin, H. 39

Marcelo, K.B. 13, 71

Marcia, J.E. 33

Marien, S. 40

Marini, M.M. 70

Markham, T. 95

Marsh, M. 79

Marsh, S. 6, 7, 9, 27

Martínez, M.L. 34

Martiniello, M. 81, 82

Matteson, D.R. 33

McClellan, J. 13, 58

McDevitt, M. 13, 16, 25, 48, 69

McDonald, J.A. 65

McFarland, D.A. 57, 60

McLeod, J. 96, 97, 98

McNamara, C.C. 13,48

Meeus, W. 33, 34

Mellon, J. 102

Melyantsou, D. 96

Menezes, I. 26, 31, 47, 52, 57, 58, 61, 69

Mesch, G.S. 95, 96, 97, 98

Metz, E. 59

Middaugh, E. 98, 100

Milbrath, L. 31

Miller, D. 41

Miranda, D. 64

Morgan, W. 55
Morozov, E. 99

Muste, C. 36

Mycock, A. 60

NESSE 82

Neufeind, M. 38

Neves, T. 61

Newton, K. 36, 63

Nie, N.H. 12, 15, 22, 26, 51, 67, 68

Niemi, R.G. 25, 29, 46, 51, 67, 69

Nikolova, R. 30

Noack, P. 46, 47, 49, 53

Norris, P. 9, 63, 79

North, A.C. 64

Nti, N. 39

Nurvala, J.-P. 90

O'Toole, T. 6, 7, 29

OECD 15, 69

Ofcom 95

Ogilvy PR and Georgetown University's Center for Social Impact Communication 99

Oldmeadow, J.A. 65

Olsson, T. 95

Omoto, A. 16, 41

Orlofsky, J.L. 22

Oser, J. 40

Oswald, H. 13

Pachi, D. 17, 24, 29, 32, 35, 42, 59, 64, 65, 70, 72, 73, 74, 110, 115, 117

Palfrey, J. 95

Pan, J. 97

Pasek, J. 26, 52

Passini, S. 100

Pastore, M. 50

Patrikos, S. 90

Pattie, C. 67

Pavlenko, V. 35

Pedersen, A. 41

Pels, T.V.M. 35

Peñaloza, P. 34

Penninx, R. 81

Petrovičová, Z. 47

Plowman, L. 95

Polletta, F. 41

Portes, A. 72

Postmes, T. 25, 29

Prensky, M. 95

Prosser, C. 102

Putnam, R.D. 6, 24, 63, 67, 79

Quintelier, E. 13, 29, 31, 48, 56, 57, 60, 115 
Rainie, L. 97

Rainsford, E. 61

Ramanau, R. 95

Rauschert, P. 54

Reicher, S. 15, 36

Rentfrow, P.J. 65

Ribeiro, N. 26

Richardson, W.K. 37

Roberts, D.F. 64

Roberts, H. 97

Roberts, M.E. 97

Rogowski, J. 98

Romer, D. 26, 52

Rosa, V. 38

Rosenstone, S.J. 15, 29, 101

Rossi, G. 13, 48

Rubini, M. 33

Rumbaut, R.G. 72

Russell, A. 60

Russo, S. 27

Sakr, R. 16, 96

Samorly, A. 22

Sanson, A. 13, 48

Santinello, M. 13, 48, 50

Savigny, H. 65

Sax, L.J. 54

Schlozman, K.L. 3, 15, 29, 50, 58, 68, 115

Schulz, W. 12, 13, 14, 15, 19, 20, 23, 24, $25,26,27,28,29,30,31,36,45,46$, $52,53,62,68,69,79,80,115,116,119$

Schwartz, S.H. 38

Schwartz, S.J. 33, 34, 110

Segerberg, S. 96

Seif, H. 71

Selivanov, M. 35

Semetko, H. 63

Şener, T. 71, 84

Š́erek, J. 28, 31, 47, 49, 115, 116, 119

Seyd, P. 67

Shah, D. 96

Sharkey, J. 13, 48

Sheblanova, E. 13, 46

Shehata, A. 63, 64

Shephard, M. 90

Sherrod, L.R. 72

Silva, L.D. 13, 48

Silver, G.E. 29

Simon, B. 32, 34, 67

Sloam, J. 10, 76, 79, 80

Smart, D. 13, 48

Smith, A. 97

Smith, E.S. 54

Smith, H.J. 41
Snyder, M. 16, 41

Soroka, S. 63

Soss, J. 29, 31, 68

Sotiropoulos, G. 96

Spears, R. 25, 29

Spinrad, T.L. 77

Spratt, M. 93

Stattin, H. 27

Stehlik-Barry, K. 12, 51

Stepick, A. 13, 59, 70, 71, 72

Stepick, C.D. 13, 59, 70, 71

Stobart, G. 93

Stockard, J. 70, 73

Stolle, D. 48, 60, 69

Stoppa, T. 35

Stout, M. 35

Stouthuysen, P. 60

Streb, M. 55

Street, J. 65, 74

Stryker, S. 33

$\mathrm{Su}$, A. 13,58

Syvertsen, A.K. 35

Taft, J.K. 42

Tajfel, H. 33

Talmud, I. 95

Tarkowski, A. 96, 100

Tarrant, M. 64, 65

Therrien, A. 102

Tholen, J. 60

Thomas, M. 95

Thomas, R.J. 57, 60

Tonge, J. 60

Torney-Purta, J. 9, 13, 14, 19, 20, 23, 24 , $25,30,36,37,42,49,52,53,62,68$, $70,79,80,112,115$

Toumbourou, J. 13, 48

Turkie, A. 15, 91

Tyson, A. 102

United Nations 2, 36, 80

Valenzuela, C. 34

van Bergen, D.D. 35

van Deth, J.W. 31, 115

van Zomeren, M. 25, 29, 30, 34, 38, 41

Vecchione, M. 31, 69

Verba, S. 3, 15, 22, 29, 50, 51, 58, 67, 68, 115

Verkuyten, M. 35

Vertovec, S. 81

Vieno, A. 13, 48, 50

Vignoles, V.L. 110

Vigoda, E. 22 
Villano, P. 85

Vollebergh, W. 33

Vosylis, R. 34

Vráblíková, K. 78

Vromen, A. 13, 69

Wadsworth, M. 54

Wagner, M. 87

Wall, J. 91

Waterman, A.S. 33

Wattenberg, M.P. 24

Weatherford, M.S. 36

Wehner, T. 38

Weinstein, M. 67

Weller, S. 8, 9, 89

Wells, C. 97

Wentzel, K.R. 13, 48

Whiteley, P. 67

Wilkenfeld, B. 70

Wilson, J. 42, 54
Wolak, J. 13, 25, 69

Wolfinger, R.E. 15

Wolnik, K. 60

Wray-Lake, L. 72

Wu, C.-L. 31, 68, 69

Yates, M. 13, 48, 58

Yore, L.D. 41

YouGov 102

Youniss, J. 13, 48, 54, 58, 59

Zaff, J.F. 48, 58

Zandonella, M. 87

Zani, B. 2, 5, 13, 17, 18, 19, 20, 22, 27, 28, 47, 51, 56, 70, 71, 101, 115,117

Zeglovits, E. 87

Žukauskienè, R. 34

Zukin, C. 4, 6, 12, 13, 15, 23, 26, 27, 46, 51, 58, 67, 70, 101 


\section{SUBJECT INDEX}

Bold typeface indicates main entries.

African Youth Charter 2

Amnesty International 9

analytical and critical thinking skills 126 ,

127, 132; see also critical thinking

anger $12,38,41,42,71$

Arab Spring 16, 96, 97

assessment (in citizenship education)

93, 94, 109, 121, 124, 128, 129, 130,

131,137

associational membership, see community

organisations, religious organisations,

youth organisations

autonomous learning skills 126

behavioural choices 111, 134

beliefs about 'good citizenship' 40-41, 43, 92, 108, 127

benevolence 38

causality 44, 74, 80-81, 107-110, 134, 137

citizen, defined 2

citizenship education 91-94, 123-133

CIVED 19, 20, 23, 25, 30, 31, 36, 37, 42, $49,52,53,62,66,67,79$

civic engagement, passim; defined 3

civic participation, passim; defined 4;

forms of 5

civic skills $6,12,50,51,55,59,72,80$,

91, 109, 118, 137

civic-mindedness 126, 127, 129

civil liberties 14, 40, 78, 79

clicktivism 99 collective action 30, 34, 36, 38, 41, 66

collective efficacy, 29, 30, 43, 52, 53, 108;

defined 29

collective identity 33, 34-35

community, defined 3

community organisations 56-60, 119

community service, see service learning, volunteering

competences for democratic culture, see

Reference Framework of Competences

for Democratic Culture (RFCDC)

compulsory voting 77

conflict-resolution skills 126, 127, 131

conspiracy theories 65

conventional political participation, passim; defined 3 ; forms of 5

conversation analysis 135

cooperation skills 126, 127, 131

Corbyn, Jeremy 101, 102-103

Council of Europe 2, 123-133

critical thinking 61,92 ; see also analytical and critical thinking skills

cross-curricular approach 92, 93, 130, 131

cultural macro factors $14,19,55,75,76$, 79,80

curriculum development 128, 130, 131

decentralisation 78

democracy $6,38,39,78,79,83,88,89$, $90,103,124-125,126,127$

democratic culture 123, 124, 132

democratic ethos in the classroom 52-53 
demographic factors $13,15,21,22,44$, 66-73, 75, 81, 103, 107, 108, 109

demonstrations, protests and marches 4, 5, $7,8,10,12,15,16,23,25,28,30,31$, $32,37,38,39,40,41,46,56,57,59,61$, 69, 70, 77, 78, 82, 84, 96, 97, 98, 100, 115, 116, 122, 135

descriptors (RFCDC) 125, 128-129, 130,131

digital technology, see Internet and social media

discourse analysis 135

disengagement 3, 4, 7, 66, 133, 136; see also political apathy, political alienation, standby citizen distrust, see trust and distrust duty-based values 40, 92

echo chambers (online) 100 ecological niche 112, 114 ecological systems theory 113-114 economic macro factors $14,15,75,76,77$, 78, 80, 103, 108

education policies 76, 91-94, 103, 108, 109, 121

education, see schools

emotions 12, 22, 35, 41-43, 85, 108, 117; see also anger, national feelings

empathy 41, 42, 126, 127, 131

engaged citizenship values 40

environmental activism and beliefs 4,7 , 8, 29, 30, 39, 40, 41, 42, 54, 82, 93, 126, 136

equality 9, 38, 39, 68, 73, 126, 127

ESS (European Social Survey) 18, 27, 30,37

ethnic identity 35

ethnicity 13-14, 16, 17, 18, 20, 25, 32, 43-44, 49, 70-73, 75, 109, 117, 133, 134,136

Eurydice 92-94

experiential learning 131

external efficacy, 18, 29-31, 32, 52, 68, 71, 108; defined 29

extra-curricular activities 39, 93, 94, 121,130

fake news 99, 132

family and parents 12, 13, 15, 16, 17, 24, 28, 31, 39, 43, 44, 45-48, 50, 64, 66, $67,68,71,72,73,74,81,93,99,104$, 108, 109, 112, 113, 117-118, 119-120, $123,133,137$

family climate 47, 118 family values 45,46

filter bubbles (online) 100

flexibility and adaptability 126

Friends of the Earth 9

gaming 97

gender 13, 14, 16, 17, 18, 20, 25, 28-29, 31, $32,33,42,43-44,45.47,68-70,72-73$, 75, 96, 98, 108, 117, 133, 134, 136

Gezi Park protests 84, 96

good citizenship, see beliefs about 'good citizenship'

government accountability 78, 79, 80, 103,108

grime 102

grounded theory 135

hate speech 132

hip-hop 65-66

historical macro factors $11,14,19,67,76$, 77, 78-79, 80, 103, 108, 112, 113, 137

human dignity 126, 129, 132

human rights $2,7,9,14,39,40,56,78$, $79,80,82,83,102,103,108,124,126$, 132,136

ICCS 2009 19, 20, 28, 36, 40, 45, 46, 52, $62,66,67,68,79,80,119$

ICCS 2016 19, 20, 23, 24, 25, 26, 27, 28, $29,30,36,37,43,52,53,62,66,67$, $68,79,80$

identity 9, 22, 33-36, 42, 43, 44, 57, 64, 108,133

illegal forms of participation, 4, 5, 17, 23, $32,42,44,57,70$

independent judiciary 78

Indignados protests 96

injustice, see justice

institutional trust 25, 31, 37, 51; defined 36

integrative multi-level ecological model 1, 107-114

intercultural competence 125-126, 130

intercultural dialogue $83,85, \mathbf{1 2 4 - 1 2 5}$

intergenerational connectedness 50

internal efficacy, 12, 15, 26, 29-31, 43, 44, 47, 52, 61, 68, 69, 88, 108, 111, 115, 116, 117, 118, 127, 137; defined 29

Internet and social media $2,5,7,8,9,10$, $25,26,27,35,36,37,43,62,64,69$, 76, 94-101, 102, 103, 104, 108, 122, 132,133

interpersonal trust, defined 36

intersectionality 16-18, 20, 32, 35, 44, $72,73,75,117,134,136-137$ 
interventions (to promote youth engagement) $16,18-19,27,52$, 114-133, 134, 136, 137

issue-based activism 9

justice and injustice 12, 25, 36, 38, 39, 41, $42,65,83,84,102,126,127$

Labour Party 102

language instruction (for migrants) 82,121

learning 54, 93, 110, 126, 129, 130, 131, learning outcomes 93, 128-129, 130, 131 legal institutions 14, 77, 78, 79 linguistic, communicative and plurilingual skills 126

macro factors $14,15,16,20,22,24,55$, 75, 76-105, 106, 107, 108, 109, 110, $111,112,113,114,133,134,136$

marches, see demonstrations, protests and marches

mass media 13, 62-64, 66, 74, 94, 108, 112, 133; see also newspapers, television media malaise 63-64, 74

migrant integration policies 81-83, 103, 104, 108, 109, 120, 121-122

misinformation 132

mixed-methods designs 134-135

motivational processes $35,38,74,99,100$, 110-111, 112, 133, 134

multiple identities 35, 44, 133; see also intersectionality

national feelings 39,42

neighbourhood 3, 33, 49-50, 66, 74, 108, 110,133

newspapers 10, 26-27, 31, 36, 37, 62-64, 74, 102,109

NGOs (non-governmental organisations) 85,94

Non-conventional political participation, passim; defined 3 ; forms of 5

Obama, Barack 101-102, 103

Occupy protests 96

online participation, see Internet and social media

open classroom climate $12, \mathbf{5 2}-\mathbf{5 3}, \mathbf{9 1}$, 108, 120, 130

openness 126,127

Oxfam 9

parents, see family and parents

participatory culture of adults 76-79, 108 pedagogy 92, 94, 109, 121, 124, 128, 130, 131,137

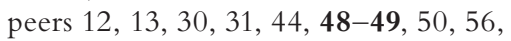
$65,66,74,93,98,108,112,113,133$

perceived effectiveness of participatory actions 32, 43, 108

perceived injustice, see justice and injustice

petitions $4,5,10,12,32,37,51,56,57$, $70,77,78,82,98,99,122,135$

PIDOP 17, 18, 19, 20, 24, 27, 30, 32, 42, $47,49,53,58,59,66,69,70,72,78$, $80,83,101,114,117$

policies, see education policies, migrant integration policies, youth policies

political alienation 46-47, 63, 84; see also disengagement, political apathy

political apathy 7, 8, 27; see also disengagement, political alienation political attentiveness 18, 19, 25-27, $28,37,43,46,51,53,55,108,116$, 117,127

political efficacy 29-31; see also collective efficacy, external efficacy, internal efficacy

political engagement, passim; defined 3 political interest $3,4,7,8,9,10,11,12$, 13, 15, 22, 27-29, 30-31, 43, 44, 45, $46,47,48,51,52,53,55,57,62,64$, $67,68,69,74,79,81,86,87,88,90$, 91. 108, 115, 116, 117, 118, 119, 127, 133,137

political knowledge, 3, 6, 10, 12, 13, 14, 15, 22-25, 26, 27, 28, 36, 37, 43, 45, 46, 47, $48,49,50,51,52,53,57,61,62,63,64$, $67,68,69,70,71,79,80,81,86,87,90$, 91, 104, 108, 113, 115, 116, 117, 118, $119,125,126,127,136,137$

political maturity $86-88$

political participation, passim; defined 3 political parties $5,7,8,9,11,22,23$, 25, 31, 36, 60-62, 66, 69, 74, 76, 78, 101-103, 108, 120, 122, 133, 137; see also youth sections of political parties political trust, 52, 53, 108; defined 36 politicians $4,6,7,8,9,29,32,36,52$, 61, 63, 85, 86, 87, 101-103, 108, 114, 120-121, 122-123, 135, 137

popular music 64-66, 74, 108, 133

power 39, 44, 46, 68, 90, 97, 101, 110, 133,135

propaganda 65,132

proportional representation 77

protests, see demonstrations, protests and marches 
psychological engagement, passim; defined 3; forms of 6

psychological factors $12,14,15,18$, 22-24, 68, 75, 85, 103, 106, 107, 108, 109, 110-111, 114-117, 127, $133,134,137$

quality of participation experiences 57-58, 59, 61, 71, 109, 116, 119, 120, $131,136,137$

radicalisation 130,132

Reference Framework of Competences for Democratic Culture (RFCDC) 123-133, 134

religious organisations $5,13,32,56,57$, 58-59, 66, 89, 108, 117, 119, 123 respect $52,56,83,103,118,122,126$, 127, 130, 131

responsibility $15,39,42,46,48,50,53$, $55,56,61,63,118,119,126,127$

rule of law 14, 22, 38, 44, 78, 79, 80, 103, $108,124,126,127$

schools 5, 12, 13, 15, 16, 24, 25, 30, 35-36, 43, 44, 49, 50-56, 72, 73, 80, 82, 85, 87, 89, 90, 91-94, 104, 108, 109, 113, 115, 117, 118-119, 120, 121, 123-133, 136, 137

school councils and parliaments 53, 56, 91, 93, 94, 108, 119, 120, 121; see also youth councils, youth parliaments self-efficacy 110, 126, 127; see also political efficacy

service learning 54-55, 56, 91, 94, 108, $119,121,130$

SES (socio-economic status) 13, 14, 15, 24-25, 28, 31, 43, 44, 66-68, 72, 73, 75, 108, 109, 133, 134

skills of listening and observing 126, 129, 131

slacktivism 99

social factors $12,13,15,18,22, \mathbf{4 5 - 6 6}$, 71, 73, 80, 81, 106, 107, 108, 109, 110, $111,112,113,114,117,120$

social media, see Internet and social media social trust 37-38, 50, 108; defined 36 standby citizen $\mathbf{1 0 - 1 1 , ~} 37$

summative assessment 93, 94, 121, 129, 131 sustainability 126 teacher education and training 92, 93-94, 121,130

teaching to the test 93

television $25,26,31,36,37,62,63,64$, 74, 101, 109

thematic analysis 135

tolerance of ambiguity 126, 127

trust and distrust 7, 8, 11, 12, 14, 25, 31, 36-38, 43, 50, 51, 52, 53, 63, 65, 71, 79, 85, 87, 91, 96, 101, 108, 117

\section{UNICEF 2}

United Nations 2

universalism 38

values $6,9,13,37, \mathbf{3 8 - 4 1 , 4 3 , ~ 4 5 , ~ 4 6 , ~ 6 5 , ~}$ 70, 72, 74, 81, 84, 108, 112, 113, 124, $125,126,127,132,133$

virtuous circle (theory of media usage) 63-64, 74

voluntary service, see volunteering volunteering $5,7,8,12,13,16,28,31$, 34, 37-38, 39, 40, 41, 42, 46, 48, 50, 52, 54-55, 59, 67, 70, 71, 93, 94, 97, 108, 115, 121, 122

voter registration $6,10,13,71,77$

voting 3, 4, 5, 6, 7, 8, 9-10, 13, 14, 18, $19,23,24,31,32,37,38,40,42,43$, 51, 52, 53, 54, 59, 67, 68, 71, 76, 77, 78, 79, 81, 85, 89, 99, 102, 103, 108, $115,120,135,136,137$; see also voting age

voting age $32,81, \mathbf{8 6}-\mathbf{8 8}, 89,103,108$, 120,137

whole-school approach 130, 131

youth councils 57, 84; see also school councils and parliaments

youth organisations 2, 16, 56-60, 73, 76, 83, 84, 88-89, 90, 91, 94, 103, 104, 108, 109, 119, 120, 121, 123, 136, 137; see also youth parliaments, youth sections of political parties youth parliaments 15, 76, 89-91, 103, 104, 108, 109, 122, 133

youth policies $\mathbf{8 3 - 8 5}, \mathbf{8 9}, \mathbf{1 0 4}, \mathbf{1 0 8 ,} 120$ youth sections of political parties 60-62, $66,74-75,108,122,133$

youth, passim; defined 2 